Jahrbuch der Deutschen Dostojewskij-Gesellschaft

\title{
Dostojevvskij intermedial
}

Herausgegeben von Gudrun Goes 
Jahrbuch der Deutschen Dostojewskij-Gesellschaft · 2011 


\title{
Jahrbuch der Deutschen Dostojewskij-Gesellschaft
}

\author{
Herausgegeben \\ im Auftrag der Deutschen Dostojewskij-Gesellschaft \\ und im Namen des wissenschaftlichen Beirats der Gesellschaft \\ von Gudrun Goes
}

\section{Jahrbuch 18}

\section{1}

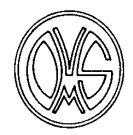

Verlag Otto Sagner

München - Berlin 


\title{
Dostojewskij intermedial
}

\author{
Herausgegeben von Gudrun Goes
}

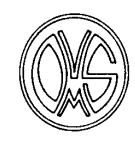

Verlag Otto Sagner • München - Berlin 


\section{Bibliografische Information der Deutschen Bibliothek}

Die Deutsche Bibliothek verzeichnet diese Publikation in der Deutschen Nationalbibliografie; detaillierte bibliografische Informationen sind im Internet über http://dnb.ddb.de abrufbar.

Online steht dieses Jahrbuch in Kürze als Volltextversion über den Katalog der Bayerischen Staatsbibliothek München (www.bsb-muenchen.de) zur Verfügung.

\section{BS: $\begin{aligned} & \text { Bayerische } \\ & \text { StaatsBibliothek }\end{aligned}$}

(C) 2012 bei Kubon \& Sagner GmbH

Heßstraße 39/41 Friedrichstraße 200

80798 München 10117 Berlin

Telefon +49 (0)8954 218-107

Telefax +49 (0)8954 218-226

verlag@kubon-sagner.de

«Verlag Otto Sagner» ist ein Imprint der Kubon \& Sagner GmbH

Umschlaggestaltung: Christopher Triplett, Marburg

Satz: robert jones, marburg

Lektorat: Sylvia Morhart

Druck und Bindung: Difo-Druck, Bamberg

Printed in Germany

Alle Rechte vorbehalten

ISSN 1437-5265

ISBN: 978-3-86688-193-8

ISBN (eBook): 978-3-86688-194-5 


\section{Inhaltsverzeichnis}

Gudrun Goes

Vorwort

Wolf Schmid

„Die Brüder Karamazov“ - Dostoevskijs Pro und Contra

Philip Maroldt

Aus der allereigensten Enge

Lutz Keßler

Verbrechen und Strafe in Göttingen

Thomas Bischoff

Spielfassung von Fjodor Dostojewskijs "Verbrechen und Strafe“

in der Übersetzung von Swetlana Geier für das Deutsche Theater in Göttingen

Anja Sackarendt

»Bin ich ein Mensch oder eine Laus?»

Zur Magdeburger Inszenierung von »Schuld und Sühne»

Isabelle Kock, Josefine Preiss

Eine vergleichende Analyse ausgewählter stofflich-thematischer Aspekte in Dostojewskijs "Schuld und Sühne“ und der gleichnamigen Inszenierung am Magdeburger Schauspielhaus

Dunja Brötz

Dostojewskijs „Schuld und Sühne“ (Prestuplenie i nakazanie, 1866)

als filmischer Albtraum bei Heithor Dhalia („Nina“ 2004) und

Brad Anderson („The Machinist“ 2004)

Thomas Blume

Wie viel Dostojewskij steckt in Tarkowskij? Eine Annäherung

Clemens Heithus

Dostojewskij-Bibliographie 2010

Rezensionen

Peter Krüger-Lenz

Horst-Jürgen Gerigk

Gisela Begrich

Autorenverzeichnis 
Gudrun Goes - 978-3-86688-194-5

Downloaded from PubFactory at 01/11/2019 02:24:17AM

via free access 


\section{Gudrun Goes}

\section{Vorwort}

Die Tagung der Deutschen Dostojewskij-Gesellschaft im September 2011 in Meißen war zum einen dem 20 jährigen Bestehen der Gesellschaft gewidmet, was in einer Laudatio für die Gründerin der Gesellschaft und langjährigen Vorsitzenden, Frau Ellen Lackner, und für ihre Nachfolgerin, Frau Dr. Maike Schult, zum Tragen kam und durch den Festvortrag des sehr bekannten Dostojewskij-Forschers, Herrn Prof. Dr. Wolf Schmid, ebenso gewürdigt wurde. Dieser Festvortrag stellte den Roman Die Brüder Karamasow in den Mittelpunkt und offenbarte Dostojewskijs Pro und Kontra. Mit ihm eröffnen wir unser Jahrbuch. Dem theoretisch anspruchsvollen literaturwissenschaftlichen Beitrag von Wolf Schmid lassen wir den Essay des jungen Schriftstellers Philip Maroldt folgen, der auf eine ganz andere Weise die Auseinandersetzung mit Fjodor Dostojewskij sucht. Diese Gegensätzlichkeit wird eine ästhetische Spannung erzeugen und inhaltliche Diskussionen auslösen.

Die anderen Beiträge des Jahrbuchs beschäftigen sich mit der künstlerischen Rezeption der Romane von Fjodor Dostojewskij in verschiedenen Medien.

Nicht nur Leser und Schriftsteller wurden in jeder Generation durch die Lektüre der Werke des russischen Schriftstellers auf vielfältige Weise angeregt. Eine breit gefächerte Wirkungsgeschichte seiner Romane gibt darüber überzeugende Auskunft. Man kann sogar behaupten, und darin folgen wir verschiedenen Literaturwissenschaftlern, dass die Geschichte des modernen Romans im 20. Jahrhundert ohne den Einfluss des literarischen Werkes von Fjodor Dostojewskij ganz anders verlaufen wäre. Aber auch andere Künstler sind der Faszination der vom russischen Schriftsteller gestalteten Themen erlegen; so können wir heute eine ebenso lange Rezeptionsgeschichte vor allem der Romane in den verschiedenen Medien konstatieren. Und dabei rückt in den Fokus der Beobachtungen, dass die Werke Dostojewskijs sehr nachhaltig die Theaterbühnen erobert haben und ebenfalls als Filmgeschichte präsent sind. Zweifellos steht Fjodor Dostojewskijs Roman Verbrechen und Strafe im Zentrum künstlerischer Adaptionen. Die Geschichte dieser Adaptionen weisen natürlich einen genetischen Zusammenhang auf, sind aber fast immer auch typologisch begründet, weil, wie bereits angedeutet, Dostojewskij jeder Generation zu jeder Zeit etwas erzählen konnte und kann. ${ }^{1}$

1 In den letzten Jahren haben wir sehr unterschiedliche Inszenierungen nach Werken von Fjodor Dostojewskij auf deutschen Bühnen erlebt, von denen nur ein kleiner Ein- und Überblick 


\section{Heinrich Böll kaufte sich 1935 den Roman Schuld und Sühne und seine Schreib-} versuche waren auch durch die Lektüre dieses Romans beeinflusst worden: „Mein

gegeben werden soll, der weder vollständig sein, noch alle theaterwissenschaftlichen Aspekte dabei tangieren kann.

Im Jahr 2008 inszenierte der lettische Regisseur Alvis Hermanis am Züricher Schauspielhaus die Kapitel 2-7 von Fjodor Dostoevskijs Roman Der Idiot. Das war eine interessante, aber auch gewagte Unternehmung. Dieser auf die Bühne gebrachte Ausschnitt bestand vor allem aus den Reiseberichten des Fürsten Myschkin. Der Regisseur ließ ein Bühnenbild bauen, das die Zuschauer in den Glauben versetzen sollte, einer Aufführung eben jenes Stückes am Moskauer Künstlertheater um 1869 beizuwohnen: „Außer auf Myschkin scheint Alvis Hermanis den Fokus vor allem auf den Prozess des Erzählens und Zuhörens zu legen: Wenn Myschkin seine langen Monologe hält, folgen ihm Mutter und Mädchen mit roten Backen und aufgerissenen Augen [...].“(Eva Behrendt: Monster sehen anders aus. In: Theater heute 4 (2008), S. 29.)

Im Mai 2011 hatte die adaptierte Fassung des Romans Der Idiot in der Regie des ukrainischen Regisseurs Andriy Zholdak in Oberhausen Premiere. Der Regisseur vertritt ein Theater der Hässlichkeit und der Deformation. Die Inszenierung beginnt mit einem Clown, der auf die Pauke schlägt, um Karussell und Hysterie in Gang zu setzen und im Heute anzukommen. Dabei blieben Fragen nach der Irrationalität oder Rationalität menschlichen Handelns unbeantwortet. Jens Dirksen meinte, dass der Regisseur auf ein Theater der Über-Stilisierung setze. (Vgl. Jens Dirksen: Dostojewski unter Strom. In: WAZ vom 23.5.2011.) Die Zuschauer werden mit den vielen Bildern am Ende allein gelassen.

Peter Stein hat 2010 den Roman die Dämonen (Die Besessenen) ins Italienische übersetzt und eine Spielfassung von 12 Stunden hergestellt. Als sein Projekt am Turiner Teatro Stabile aus Kostengründen scheiterte, spielte er sein Stück auf seinem italienischen Grundstück. Im Juni 2010 gastierte er mit den Dämonen im Wiener Museumsquartier. Wer das Regiekonzept von Peter Stein kennt, der weiß, dass er sich dem Stoff als Ganzem hingibt, um ihn ganz subtil zu erschließen und ebenso genau wiederzuerzählen und das gelingt ihm hochkonzentriert in dieser an sich ganz minimalistischen Form: „Er will, man mag das bemängeln, gar nichts Bestimmtes erzählen, sondern, um mit Beckett zu sprechen, nur alles‘. Es gibt da keine große Konzeption oder szenische Phantasie, nichts, woran Stein sich reiben würde. Es gibt nur den Roman, Kapitel für Kapitel [...].“ (Christine Dössel: Zwölf Stunden für die große Idee. In: Süddeutsche Zeitung vom 6.,7. 6.2010.)

Am Hamburger Thalia-Theater, Spielstätte Gauss, brachte der ungarische Regisseur Kornél Mundrczó ebenfalls diesen Roman unter dem Titel Die Zeit der Besessenen heraus. Der Regisseur will in seiner Adaption der Frage nachgehen, wie revolutionäre Gewalt entstehen und wie diese zum Äußersten führen kann. Die Aufführung erinnerte von ihrer Spielvorlage und dem Bühnenbild her stark an Andrei Tarkowskijs Film Stalker. In der Thalia Spielstätte Gauss treffen Nikolaj Stawrogin und Pjotr Werchowenskij auf einem ehemaligen Flugplatz in den USA zusammen, aber eigentlich kein wirklicher Ort, um ein Attentat vorzubereiten. Bizarr und künstlich wirkt die Welt, die man verändern will.

2007 inszenierte Nicolas Stemann eine Dramatisierung von Fjodor Dostojewskijs Roman Die Brüder Karamasow am Wiener Burgtheater. Seine theatralische Konzeption bezog sich auf das Wertesystem der 68er Generation, die der neuen Generation nicht mehr folgen kann. Der alte Karamasow kam als Altrocker daher, da „vergeht alle Leidenschaft, alles Pathos, die ganze Finsternis. [...] es werden immer wieder Sätze aus dem Roman projiziert. [...] Aber zu diesen Sätzen gibt es keine Figuren, alle sind nur Transportarbeiter des Diskurses. Stemann kommentiert nicht, ironisiert nicht und vor allem: er erzählt nicht." (Helmut Schödel: An der Wertewerkbank. In: Theater heute 2 (2008), S. 27f.) 
Vater betrieb damals eine Bildhauer- und Tischlerwerkstatt in einer klassischen Mietskaserne mit Hinterhaus aus dem 19. Jahrhundert - es war ein Haus, in dem die Marmeladows und Raskolnikow hätten wohnen können. ${ }^{\text {"2 }}$ Es sind besonders die Protagonisten der Dostojewskijschen Romane, die die Phantasie anderer Künstler befördern: Sie verkörpern eine Haltung, leben eine Idee und suchen die Grenzerfahrung. Die Theater, ob Stadt- oder Staatstheater, haben längst die theatralische Spannung und philosophische Wirkung der Romane von Fjodor Dostojewskij für den zeitgenössischen Zuschauer erkannt.

2005 inszenierte der schon durch mehrere Dostojewskij-Adaptionen bekannte Regisseur Frank Castorf (1999 Die Dämonen, 2001 Erniedrigte und Beleidigte, 2003 Der Idiot, 2011 Der Spieler) Schuld und Sühne an der Berliner Volksbühne. Der Regisseur lässt Raskolnikows Geschichte in einem Container-Dorf in einer 6 stündigen Fassung spielen. Die Protagonisten sind aus dem Russland des 19. Jahrhunderts in ein spätkapitalistisches heutiges Umfeld geraten, das sie mit Geschrei erfahren und erobern wollen. „Die Textfassung, schreibt Franz Wille, springt kopfüber zwischen die Ereignisse, rote Fäden werden systematisch gekappt, und wer den Roman nicht gerade frisch gelesen hat, dürfte bald ebenso ermüdet zwischen Kopfschmerzen und Wahnvorstellungen nach einem Ausweg suchen wie Raskolnikow nach seinen Morden. “3

Beeindruckend dagegen war die ebenfalls 6 stündige Aufführung von Verbrechen und Strafe in der Regie von Andrea Breth zu den Salzburger Festspielen 2008. Die Regisseurin hatte selbst die Textvorlage nach der Übersetzung von Svetlana Geier erarbeitet, die in unserem Jahrbuch von Horst-Jürgen Gerigk besprochen wird. Die ursprüngliche Fassung stammt von dem bulgarischen Schriftsteller Dimitré Dinev. Gerhard Stadelmaier hat in seiner Charakterisierung der Inszenierung hervorgehoben, dass man die Bühne im Roman nur freilegen und nicht für die Bühne bearbeiten musste. Er sah in der Aufführung ein großes Alptraumspiel, den Wahnsinn einer Grenzüberschreitung. Die Figur des Raskolnikow war auf der Kippe zwischen Manier und Manie angelegt. ${ }^{4}$ In der Diskussion um diese Inszenierung, in der selbstverständlich gegensätzliche Bewertungen aufeinanderstießen, wird Breths Mut hervorgehoben, den Stoff zu entrümpeln (Raffungen als Blackouts, blitzschnelle Szenenwechsel usw.5), um die Motivstränge deutlicher werden zu lassen und ihre Setzung auf die Subjektivität des Schmerzes, was aber wiederum zur Folge hat, dass sich diese Inszenierung über die Handlungslogik der philosophisch überhöhten Kriminalgeschichte hinwegsetzt. ${ }^{6}$ Der Theaterkritiker Christopher Schmidt meint,

2 Manes Sperber: Wir und Dostojewskij. Hamburg 1972, S. 61-62.

3 Franz Wille: Nur die Stärksten überleben. In: Theater heute 7 (2005), S. 7.

4 Vgl. Gerhard Stadelmaier: Der Erlös des Bösen. In: FAZ vom 30.7. 2008, S. 32.

5 Vgl. Peter Kümmel: Warum morden all die anderen nicht? In: Die Zeit vom 31.7. 2008.

6 Vgl. Christopher Schmidt: Russisch Brot, in Aspik eingelegt. In: Süddeutsche Zeitung vom 28.7.2008. 
dass Andrea Breth dem Erlösungspathos in diesem Roman ebenso misstraut habe wie seiner ideellen Konstruktion. ${ }^{7}$

In unserem Jahrbuch werden zwei Inszenierungen von Verbrechen und Strafe bzw. von Schuld und Sühne vorgestellt: Zum einen die Inszenierung von Jan Jochymski am Magdeburger Theater auf der Studiobühne aus dem Jahr 2009. Seine Inszenierung erfasst das Thema um Schuld und Sühne in 90 Minuten. Jan Jochymski hat eine eigene Fassung erstellt, die auf verschiedenen Übersetzungen gründet und das Material so aufbereitet, dass sie provokante Fragen an die Zuschauer stellt und diese Fragen in die Gegenwart holt. Der Roman diente dem Regisseur eher als Vorlage seiner Interpretation des Romans und erzeugte sehr starke Bilder, die ihren Rhythmus zusätzlich durch die Musik erhielten. Zwei Studentinnen haben in einem Seminar den Versuch unternommen, diese Aufführung auf der Grundlage des Romans zu analysieren und stellen diese Arbeit in dem Jahrbuch vor.

Die zweite Inszenierung stammt von dem Regisseur Thomas Bischoff, die 2010 am Deutschen Theater Göttingen Premiere hatte. Der Regisseur hat ebenfalls eine eigene 4 stündige Spielfassung erarbeitet. Aus dieser publizieren wir einen größeren Auszug, um sich einmal mit einer theatralischen Fassung auseinandersetzen zu können. Raskolnikow bildet in dieser Bearbeitung das Zentrum allen Handelns, er ist permanent auf der Bühne. Das Deutschlandradio Kultur nannte ihn das Prinzip des forschenden Täters. Die Fassung des Regisseurs verzichte allerdings auf alles, was außerhalb der Reichweite seines Antihelden liege. ${ }^{8}$ Den beiden Inszenierungen werden zwei regionale Theaterrezensionen zugeordnet.

Mit diesen Beispielen wären wir längst noch nicht am Ende, die Theatergeschichte von Dostojewskijs Werken auf deutschsprachigen Bühnen zu erzählen und zu diskutieren.

Unser Jahrbuch führt noch in das Medium Film ein. Dunja Brötz gilt als Spezialistin auf dem Gebiet und zeigt auf der Grundlage von sehr subtilen Filmanalysen den Einfluss der Romane des russischen Schriftstellers, der Ideen seiner Werke auf ganz unterschiedliche Filmschaffende. Abschließend soll eine erste Annäherung an den Filmregisseur Andrei Tarkowskij und dessen Beziehung zu Fjodor Dostojewskij erfolgen.

Die Heterogenität der Ansätze und Sichtweisen führt auch zu unterschiedlichen Formen der Darstellung, die als Lektüregewinn angesehen werden sollten. ${ }^{9}$

7 Vgl. ebenda.

8 Vgl. Sendung des Deutschlandradios Kultur vom 1.5.2010.

9 Als Problem erweist sich immer wieder die Schreibweise des Namens des russischen Schriftstellers, Auch wenn in wissenschaftlichen Arbeiten die transliterierte Form bevorzug wird, also Fëdor Dostevskij, so wird der Name im alltäglichen Umgang und in der medienwirksamen Öffentlichkeit als Fjodor Dostojewski transportiert. Die Herausgeberin kann in die Diversität der Darstellung und der damit verbundenen Schreibung des Namens nicht immer eingreifen und bittet deshalb um Verständnis, dass parallel verschiedene Namensschreibungen auftauchen, aber es ist immer derselbe Dichter gemeint. 


\section{„Die Brüder Karamazov“ - Dostoevskijs Pro und Contra}

Die Brüder Karamazov, 1878-1880 geschrieben, sind Dostoevskijs letzter Roman, der Höhepunkt seines gesamten Werks und der Abschluss des russischen Realismus. Der Roman bildet eine Art Summe von Dostoevskijs gesamtem Euvre, verbindet wesentliche Motive früherer Werke und setzt die in einzelnen Werken erprobten innovativen Erzählverfahren im Ensemble ein. Die Brüder Karamazov wurden zahllose Male dramatisiert und mindestens achtmal verfilmt. Im Deutschland der ersten Hälfte des 20. Jahrhunderts war Dostoevskijs Roman Bildungserlebnis der bürgerlichen Jugend, und er hat die europäische Literatur von Thomas Mann bis Albert Camus nachhaltig beeinflusst.

Worauf gründet die Popularität dieses Romans? Als Grund ist zunächst einmal der Synkretismus der Gattungen zu nennen. Dostoevskij verschmilzt in kühner Synthese heterogene Gattungen der europäischen Erzählkunst - vom Boulevardroman bis zur philosophischen Parabel. Er mischt die Gattungen und verletzt die Grenzen zwischen hoher und niederer Literatur, zwischen Unterhaltungsliteratur, philosophischer Reflexion und religiöser Botschaft.

Sehr unterschiedlich sind auch die Rezeptionshaltungen, die der Roman auszulösen sucht, und die Stimmungsqualitäten, die er vermittelt. Seine 1300 Seiten fordern einen aufmerksamen Leser mit gutem Gedächtnis, der weit auseinander liegende Motive aufeinander zu beziehen weiß, und dennoch ist der Roman auch überaus unterhaltend. Philosophische Reflexion und weltanschauliche Auseinandersetzung sind mit einer Handlung verknüpft, die außerordentliche Spannung erzeugt. Der Roman bietet Erhabenes und Triviales, Schauriges und Komisches, Erschütterndes und Idyllisches in dissonanter Einheit. Dissonant ist auch das Verhältnis des Erzählakts zum Erzählten. ${ }^{1}$ Der Erzähler changiert zwischen einem allwissenden Seelendarsteller und einem ungeschickten, etwas schwatzhaften Chronisten. Gerade an tiefernsten Stellen bringt letzterer durch seine narrativen Ungeschicklichkeiten unfreiwillige Komik ins Spiel. Der düstere Epileptiker, als der Dostoevskij vor allem in Deutschland figuriert, dieser "Gekreuzigte“ war unter anderm, wie Thomas Mann

1 Vgl. Wolf Schmid: „Единство разнонаправленных впечатлений восприятия. Рассказывание и рассказываемое в ,Братьях Карамазовых““. In: Dostoevsky Studies. Bd. 2 (1981), S. 51-59; engl. „Narration and Narrative Content in ,The Brothers Karamazov““. In: B. J. Amsenga et al. (Hg.): Miscellanea Slavica. To Honour the Memory of Jan M. Meijer. Amsterdam 1983, S. 389402. 
feststellte, „ein ganz großer Humorist“. ${ }^{2}$ Und gerade auf Thomas Mann hat die Vermittlung des Erschütternden durch einen den Untiefen nicht ganz gewachsenen Erzähler tiefen Eindruck gemacht. Die deutlichsten Spuren finden wir im Doktor Faustus, dem Roman, den der biedere Humanist Serenus Zeitblom vom Teufelspakt des Tonsetzers Adrian Leverkühn erzählt.

Im Mittelpunkt von Dostoevskijs Roman stehen die drei oder vier Brüder Karamazov und ihr Verhältnis zum gemeinsamen Vater Fedor Pavlovič, einem moralisch heruntergekommenen sentimentalen Lüstling und närrischen Zyniker. Dmitrij, der älteste Sohn, ein sinnlicher und leidenschaftlicher Mensch, gerät in Streit mit dem Vater, der ihm, wie er meint, Geld schuldet und der als sein Rivale bei der verführerischen Grušen'ka auftritt. Ivan, der zweite Sohn, verkörpert den von den geistigen Strömungen der Zeit geprägten fortschrittlichen Intellektuellen. Aleša, der jüngste, ist Klosterzögling. Ein vierter Bruder ist möglicherweise - so wird angedeutet - Smerdjakov, Koch bei Fedor Pavlovič und Sohn der halbidiotischen Närrin in Christo Lizaveta, genannt Smerdjaščaja, die Stinkende, die der alte Karamazov in perverser Lust missbraucht hat. Die zwei älteren Söhne teilen mit dem Vater, jeder auf seine Weise, das Karamazovsche Wesen und bringen dennoch oder vielleicht gerade deswegen ihrem Erzeuger Verachtung und Hass entgegen. Beide wünschen seinen Tod. Damit ist die Konstellation eines spannungsreichen Familienromans gegeben.

Das Genre des Kriminalromans kommt ins Spiel, als der alte Karamazov ermordet wird. Der Verdacht fällt sofort auf den impulsiven Dmitrij, der ein doppeltes Motiv hat, das Geld und die Leidenschaft für Grušen'ka. Überdies hat er schon Morddrohungen ausgestoßen. Sämtliche Indizien sprechen gegen ihn, und er wird zu Zwangsarbeit in Sibirien verurteilt.

Im zwölften und letzten Buch mit dem Titel „Ein Justizirrtum“ werden die Brüder Karamazov zu einem Gerichtsroman. Die dargestellte Gerichtsverhandlung wird nach dem 1864 eingeführten Strafprozessrecht vollzogen, das für den vorliegenden Tatbestand ein Geschworenengericht vorsieht. Dostoevskij, der ein Kritiker des neuen Prozessrechts war, zeigt nicht nur die Fehlbarkeit jedes irdischen Gerichts, sondern auch die Schwächen der neuen Strafprozessordnung auf.

In den Plädoyers von Ankläger und Verteidiger klingen aktuelle Ideen aus den ideologischen Diskursen der Zeit an. So bemüht sich der Verteidiger, den vermeintlichen Mörder Dmitrij, an dessen Schuld er glaubt, mit dem Verweis auf seine erbärmliche Kindheit und die Verkommenheit des Vaters zu entlasten. Das Kernargument lautet: Dmitrij wollte nicht töten, er handelte im Affekt. „Ein solcher Mord ist kein Mord“. Und noch mehr: „Ein solcher Mord ist kein Vatermord“ (XV, 176) ${ }^{3}$. Weil dieser Vater kein Vater war. So werden die Brüder Karamazov zu einem

2 „Dostojewski - mit Maßen“ (1946). In: Thomas Mann: Gesammelte Werke in 13 Bänden. Bd. IX. Frankfurt a.M. 1990, S. 656-674, hier: S. 668.

3 Hier und im Weiteren wird mit eigener Übersetzung zitiert nach: F. M. Dostoevskij: Polnoe sobranie sočinenij v 30 tomach. Leningrad 1972-1990. Angegeben sind Band in römischen und Seite in arabischen Ziffern. 
Zeit- und Feuilletonroman, in dem der Autor mit progressiven Ideen der 1860er und 70er Jahre polemisiert.

Der wahre Mörder ist, wie der Leser erst im elften von zwölf Büchern erfährt, Smerdjakov. Er hat einen epileptischen Anfall vorgetäuscht, den Vater ermordet und die Spur zu Dmitrij gelegt. Der Vatermörder offenbart seine Täterschaft und die geradezu diabolisch raffiniert ausgeführte Tat seinem Halbbruder Ivan, den er als seinen Mentor ansieht. Die drei Gespräche Smerdjakovs und Ivans sind ein Meisterstück der Bewusstseinskunst und geben dem Werk den Charakter eines psychologischen Romans. Dem geistig unterentwickelten, aber mit krimineller Intelligenz ausgestatteten Mörder gelingt es, sein verblüfftes Gegenüber davon zu überzeugen, dass er, Ivan, unterschwellig den Auftrag zum Vatermord gegeben hat, dass er der Hauptmörder gewesen ist und Smerdjakov nur sein treuer Erfüllungsgehilfe. Zwanzig Jahre vor der Entwicklung der Psychoanalyse gibt Dostoevskij ein Beispiel dafür, wie die seelische Ebene, die Sigmund Freud das „Unbewusste“ nennen wird, das Handeln der Menschen leiten und dabei dem bewussten Ich verborgen bleiben kann.

Wenn der Mörder Smerdjakov schließlich Selbstmord begeht, so ist das nicht ein Akt der Reue und auch nicht Folge der Verzweiflung, wie oft interpretiert wird, sondern äußerste Verfeinerung des Bösen. Denn mit sich nimmt Smerdjakov die Wahrheit über den Mord aus der Welt. Niemand kann mehr die Wahrheit bezeugen. Der einzige Mitwisser, Ivan, ist nach dem im Albtraum geführten Gespräch mit dem Teufel in seinem Bewusstsein getrübt, und die Selbstbezichtigung des Seelenverwirrten wird vom Gericht nicht als glaubwürdig betrachtet. Das aber hat ihm der weitsichtige Smerdjakov schon vorausgesagt.

Mit dem Teufel als Ivans Albtraum scheint der realistische Roman in die Gattung der phantastischen Literatur überzugehen. Aber wie schon im Frühwerk, z. B. im Doppelgänger, relativiert Dostoevskij das scheinbar Phantastische als Erscheinung einer gespaltenen Psyche. Der angespannte Dialog mit dem Teufel erweist sich als die Wechselrede zwischen zwei Instanzen eines Bewusstseins.

Der Roman enthält noch eine weitere Dimension, die in der westeuropäischen Rezeption der ersten Hälfte des 20. Jahrhunderts die intensivste Wahrnehmung erfahren hat. Das ist die philosophische und theologische Problematik. Sie hat das besondere Interesse deutscher Theologen gefunden, katholischer wie protestantischer. Erwähnt seien nur die Namen Romano Guardini ${ }^{4}$ und Walter Nigg 5 .

Das theologische Thema gipfelt in der Auseinandersetzung um die Existenz und die Güte Gottes. Dem Pro und Contra, wie das gotteskritische fünfte Buch mit Ivans Auflehnung gegen Gott und seiner Legende vom Großinquisitor betitelt ist, gilt die vorliegende Abhandlung.

Dostoevskij hat seine Brüder Karamazov als einen christlichen Bekenntnisroman konzipiert. Eine der zentralen Fragen, um die sein Denken in quälerischem Zweifel

4 Vgl. etwa R. Guardini: Religiöse Gestalten in Dostojewskijs Werk. München 1947.

5 Vgl. W. Nigg: Religiöse Denker. Kierkegaard, Dostojewskij, Nietzsche, Van Gogh. Bern 1942. 
kreiste, war das Problem, das seit Leibnizens berühmter Abhandlung ${ }^{6}$ als „Theodizee" bekannt ist: die Rechtfertigung der Existenz und der Güte Gottes angesichts des in der Welt vorkommenden Bösen. Kann Gott das Übel nicht verhindern oder will er es nicht? Leibniz antwortet: er hätte gekonnt, hat aber nicht gewollt, um der plénitude, der Fülle der Phänomene willen. Die beste aller möglichen Welten ist die Welt mit der größten Vielfalt der Vollkommenheitsgrade der Wesenheiten. Leibniz postuliert, dass Gott, in seiner Güte die beste Welt schaffend, das Übel und das Leiden nicht eigentlich will, sondern nur zulässt, um die gewünschte Vielfalt zu verwirklichen, das höchste Gut eines Demiurgen.

Mit Leibnizens Idee der vom allmächtigen, allwissenden und allgütigen Gott geschaffenen Welt als der besten aller möglichen Welten hat Voltaire in seinem Roman Candide ou l'optimisme (1759) polemisiert. Nach einer Aufzeichnung von 1877 „Für das ganze Leben (XV, 409) plante Dostoevskij einen „russischen Candide“, d. h. aber einen Anti-Candide, zu schreiben, und diesen Plan hat er in den Brüdern Karamazov, seinem Vermächtnisroman, realisiert.

In diesem Roman sollte das progressive Denken seiner Zeit, das im Zweifel an der Existenz eines allmächtigen und gütigen Gottes kulminierte und - wie Dostoevskij bekundete - zu nichts anderem als Zerstörung und Anarchismus führte, triumphal überwunden werden.

Nach dem Willen des Autors soll der Roman Katechese betreiben, intuitiven Glauben und Demut des Geistes propagieren, die intuitio gegen die ratio, das Gewissen gegen den Verstand ausspielen und damit Sozialismus und Anarchismus bekämpfen, jene Strömungen der siebziger Jahre, die der Publizist Dostoevskij als Ausgeburt des humanistischen Atheismus betrachtete.

Der Autorintention entsprechend hat man aus dem Roman immer wieder eine eindeutige Botschaft herausgelesen. Diese lautet etwa so: Der Sinn der Welt ist nicht mit der rationalen "natürlichen Vernunft“, sondern nur mit der intuitiven ,gläubigen Vernunft“ zu erfassen. Verlässt sich der Mensch auf seinen Verstand, sein „euklidisches Denken“, so entfremdet er sich Gott, den Menschen und letztlich sich selbst. Die beiden Typen der Vernunft, die natürliche und die gläubige, verkörpern im Roman der intellektuelle, europäisch gesinnte, aber menschlich kalte Ivan und der sinnliche, aber nicht sehr scharfsinnige Dmitrij. Die Sympathie des Autors scheint ganz auf der Seite des Raufbolds und Saufbruders Dmitrij zu liegen, der Verkörperung des „unmittelbaren Russland“. Während Dmitrij den Weg zum Schuldbekenntnis in christlicher Demut findet, demonstriert Ivans geistige Zerrüttung, wie weit man kommt, wenn man sich auf seinen aufgeklärten Verstand verlässt.

Die Brüder Karamazov waren ein heftiger Angriff auf den mainstream des Denkens im Russland der 1870er Jahre. Der Autor erwartete deshalb die schroffe Ablehnung seines Romans durch die Mehrheit seiner Zeitgenossen und war davon überrascht, wie viele Leser ihm schon nach Erscheinen der ersten Kapitel in ihren

6 G. W. Leibniz: Essai de Théodicée (1710). 
Briefen begeistert applaudierten. In der offiziellen Kulturpolitik des kommunistischen Russland waren Dostoevskij und sein größter Roman naturgemäß nicht besonders gut gelitten. In der Perestrojka-Zeit setzte dagegen eine heftige Rehabilitierung unter national-christlichem Vorzeichen ein. In der heutigen russischen DostoevskijRezeption richtet man sich besonders auf die slavophilen, national-orthodoxen Aspekte in Dostoevskijs Denken. Der einflussreiche Kritiker Igor' Vinogradov, Herausgeber der russischen Ausgabe der Zeitschrift Kontinent, beschließt beispielsweise eine umfangreiche Polemik gegen einen Aufsatz von $\mathrm{mir}^{7}$, in dem ich die Zwiespältigkeit der Autorposition konstatiert habe ${ }^{8}$, mit der Feststellung, dass die Brüder Karamazov vielleicht der einzige wirklich große christliche Roman der Weltliteratur sei.

Die eindeutig christliche Sinngebung, die sich auf zahlreiche Äußerungen des Autors berufen kann, bringt das geniale Werk in die Nähe eines Thesenromans. Den Brüdern Karamazov ist Gott sei Dank jedoch ein Gegensinn eingeschrieben, der die christliche Lektüre erheblich relativiert.

In welcher Weise ist dieser Gegensinn präsent? Nicht als intendierte Botschaft des Autors. Eingeschrieben ist der Gegensinn im Modus des zu relativierenden nadryv.

Nadryv (von den Wörterbüchern erläutert als die ,Verhebung', die ,Überanstrengung', die ,Überspanntheit') ist eine psycho-ethische Grundsituation in der Welt Dostoevskijs, eine überspannte sittliche Haltung, die einer eigentlichen Neigung widerspricht, eine Form pseudo-idealistischer Selbstverleugnung. An den meisten Stellen ist nadryv am besten mit Selbstvergewaltigung wiederzugeben. In den Brüdern Karamazov wird diese Selbstvergewaltigung paradigmatisch. Das vierte Buch, das dieses Wort als Überschrift trägt, zeigt eine ganze Serie von nadryvy, weltliche und geistliche, „im Salon“, „in der Hütte“ „und an der frischen Luft", wie die drei letzten Kapitel des Buches heißen.

Nun kommt eine psychologische Spekulation ins Spiel, die sich einer Methode des Romans selbst bedient: Sollte dem Autor, der mit äußerstem psychologischen Feinsinn hinter allerlei Idealismen Selbstvergewaltigung aufspürt und mit großer Plausibilität ihre Mechanismen bloßlegt, diese Haltung selbst fremd sein? Können wir nadryv nicht auch als die Formel verstehen, der sich der ganze Roman als Theodizee verdankt? Kann man in der konsequent katechetischen Logik der erzählten Geschichte nicht eine Selbstvergewaltigung ihres Autors sehen, der, in Wahrheit Ivan nahestehend, seinen eigenen Zweifel und seine eigene Gottesanklage unterdrückt, die Kraft der Vernunft leugnet und mit aller Gewalt einen intuitiven Glauben

7 I. Vinogradov: «Osanna» ili ,Gornilo somnenij‘? Po povodu stat'i Vol'fa Šmida, in: Kontinent Nr. 90 (1996), S. 294-342.

8 V. Šmid: „Brat’ja Karamazovy - nadryv avtora, ili roman o dvuch koncach“. In: V. M. Markovič/V. Šmid (Hg.): Avtor i tekst. Sbornik statej. Sankt-Peterburg 1996, S. 268-287. Frühere deutsche Version: „Die ,Brüder Karamazov“ als religiöser ,nadryv' ihres Autors“. In: R. Fieguth (Hg.): Orthodoxien und Häresien in den slavischen Literaturen. Wien 1996 (= WSA. Sonderband 41), S. 25-50. 
propagiert, zu dem er vielleicht selbst nicht fähig war? Hat nicht Dostoevskijs metaphysischer Glaube selbst jenes Gewollte, Gewalttätige, das der Autor der Auflehnung Ivans unterschiebt, und ist er nicht unendlich weit entfernt von jener utopischheiteren Glaubensgewissheit, die den franziskanischen Pantheismus des Mönches Zosima kennzeichnet?

Meine - zugegeben spekulative - These lautet jedenfalls: Die von Dostoevskij geradezu obsessiv verfolgte Haltung der Selbstvergewaltigung ist jene psychologische Struktur, der sich der Roman selbst verdankt. Gegen den Willen des konkreten Autors ist jegliche Affirmation des metaphysischen Glaubens von seiner geheimen Negation begleitet. Diese Negation tritt meistens als überzogene Affirmation auf.

Des nadryv, also der Selbstvergewaltigung, verdächtig ist ja auch die oft zitierte Stelle aus einem Brief des jungen Dostoevskij: „Wenn mir jemand bewiese, dass Christus außerhalb der Wahrheit ist, und wenn es wirklich so wäre, dass die Wahrheit außerhalb Christus ist, so würde ich lieber mit Christus bleiben als mit der Wahrheit“ (XXVIII/1, 176). In dem Brief hat sich Dostoevskij zuvor als „Kind des Jahrhunderts, als Kind des Unglaubens und des Zweifels“ bezeichnet und bekannt, der „Durst nach dem Glauben“ koste ihn schreckliche Qualen, aber er sei in seiner Seele um so stärker, je mehr Gegenargumente er habe.

Man darf solche Aussagen nicht als generelles Plädoyer für die Irrationalität verstehen. Dostoevskij vertraute im Allgemeinen zu sehr der Vernunft, um bereitwillig ihr Urteil zu suspendieren. Das erhellt aus der Polemik gegen den Spiritismus, die er 1876 im Tagebuch eines Schriftstellers führte. Bei mystischen Ideen, so wird dort resignierend konstatiert, bedeuteten die "mathematischsten“ Beweise überhaupt nichts. Wer unbedingt glauben wolle, den könne man nicht aufhalten (XXII, 100 f.).

Der nadryv des Autors bedeutet seine Spaltung in eine affirmierende und eine negierende Instanz, in Dostoevskij I, der den wahren Glauben predigt und durch den ganzen Roman Ivan Karamazov verfolgt, und Dostoevskij II, den Zweifler, zu dessen Sprachrohr derselbe Ivan Karamazov wird. Wir haben hier den Fall, dass sich die Intention eines Autors in seinem Werk nicht ungebrochen durchsetzt. Während der reale Autor in seinen Lebenszeugnissen eine klare und eindeutige Position vertritt, spaltet sich der werkimmanente abstrakte Autor in zwei Instanzen auf, die gegensätzliche Positionen einnehmen, Dostoevskij I und Dostoevskij II.

Der dem Werk eingezeichnete Gegensinn, die Stimme von Dostoevskij II, artikuliert sich am deutlichsten in Ivans „Auflehnung“ und in seiner Legende vom Großinquisitor, in jenen Kapiteln also, deren Atheismus, wie sich der Autor rühmte, an Stärke alles in Westeuropa Ausgedrückte übersteigt.

Vorweg sei die geläufige Rezeption von Ivans „Auflehnung“ in drei Punkten korrigiert:

1. Ivan ist nicht einfach Atheist, er leugnet nicht Gottes Existenz, sondern zweifelt an ihr. Wenn er aber die Existenz Gottes annimmt, stellt er Gottes Gerechtigkeit und Barmherzigkeit in Frage und die Vollkommenheit seiner Schöpfung. Das war für Dostoevskij letztlich eine Verschärfung der Gottesgegnerschaft. 
2. Zwischen Pro und Contra schwankend, nimmt Ivan in jeder Lebensphase eine andere Position ein. Die unterschiedlichen Positionen sind in seinen Texten dokumentiert, unter denen die Legende vom Großinquisitor nur einer ist. In seinen Texten spielt Ivan Denkmodelle durch, ohne sich mit einem von ihnen zu identifizieren. Das Schwanken seines Denkens unterscheidet Ivan von allen seinen Anhängern, die jeweils eines seiner theoretischen Modelle existentialisieren und fixieren.

3. Keineswegs postuliert Ivan das berüchtigte Alles ist erlaubt. Dieses Diktum, auf das sich alle berufen, viele Interpreten eingeschlossen, ist bei Ivan Teil eines Konditionalsatzes: Wenn es keine Unsterblichkeit der Seele gibt, dann ist alles erlaubt. ${ }^{9}$ Das aber ist genau die Position des realen Autors, der in seinem Tagebuch eines Schriftstellers die Idee der Unsterblichkeit der menschlichen Seele als die höchste Idee auf Erden bezeichnet, der alle andern hohen Ideen entspringen.

Ivans Argument im Kapitel Die Auflehnung ist nun, dass die Leiden der Welt, vor allem die Leiden der unschuldigen Kinder, ein zu hoher Preis für die am Weltenende eintretende göttliche Harmonie seien. Er akzeptiert diese Harmonie nicht, für die das Leiden der Kinder als „Dünger", als „Stallmist" dienen soll, und erlaubt sich, dem Schöpfer seine Eintrittskarte in die finale Weltharmonie zurückzugeben. Aus Liebe zur Menschheit lehnt er die mit dem Leiden der unschuldigen Kinder erkaufte finale Harmonie ab.

Liebe zur Menschheit ist auch das Argument des Großinquisitors, des Helden der von Ivan ausgedachten Geschichte. Gott hat den Menschen zu schwach geschaffen, als dass er mit gutem Recht eine freie, nicht durch Wunder, Geheimnis und Autorität erleichterte Entscheidung für sich fordern dürfte. Aus Liebe zu den schwachen Menschen organisieren die wenigen Starken das Glück der Masse, indem sie ihnen die ungebührlich schwere Last der freien Entscheidung abnehmen. Den Fluch der Erkenntnis von Gut und Böse auf sich nehmend, opfern die Wenigen ihr ewiges Glück dem irdischen Glück der vielen, für die das Jenseits, wenn es ein solches gibt, ohnehin nicht vorgesehen ist.

Wenn wir nun Ivans Auflehnung mit der Klagerede des Großinquisitors zusammennehmen und sie über den expliziten Wortlaut fortschreiben, dann ergibt sich etwa folgende Gotteskritik: Gott hat den Menschen die Freiheit der Entscheidung gegeben, sie mit dieser Freiheit aber überfordert, weil er die Menschen mit dem euklidischen Verstand zu schwach ausgestattet hat; wenn Gott gleichwohl ein Bekenntnis zu sich verlangt, so geschieht das aus unchristlichen Motiven, aus bloßer Eigenliebe, aus Eitelkeit.

9 Die Konditionalität des Alles ist erlaubt geht eindeutig aus Miusovs Wiedergabe von Ivans Ideen (XIV, 64 f.) hervor und wird von ihrem Urheber bekräftigt, vgl. Ivans lakonische Formel: „Es gibt keine Tugend, wenn es keine Unsterblichkeit gibt" (XIV, 65). Sogar Smerdjakov bestätigt die Konditionalität von Ivans Ausspruch: nach dem Mord hält er Ivan vor, er, Ivan, habe ihn gelehrt, wenn es keinen unendlichen Gott gebe, gebe es auch keine Tugend, ja man brauche sie dann überhaupt nicht (XV, 67). 
Man hat in den beiden Kapiteln Die Auflehnung und Der Großinquisitor ein Plädoyer für die unbedingte Freiheit der Glaubensentscheidung gesehen. Die Glaubensentscheidung wird durch keinerlei euklidisches Argument erleichtert. Im Gegenteil: Der Wert der Freiheit fordert, dass die Entscheidung für Gott durch das für den euklidischen Verstand Widersinnige erschwert werde. Von allen Widersinnigkeiten wählt Dostoevskij in Ivans Gottesanklage die für ihn selbst am schwersten erträgliche, das Leiden der unschuldigen Kinder. Für Ivans „schöne Kollektion“ gequälter Kinder hat Dostoevskij bezeichnenderweise seine eigene Sammlung von Zeitungsausschnitten ausgewertet.

Aus Dostoevskijs Briefen wissen wir, dass er das fünfte Buch (Pro und contra) durch das sechste Buch (Ein russischer Mönch) auszugleichen, Ivans „Gotteslästerung" durch die Vita und die Lehren des sterbenden Mönchs Zosima "triumphal zu widerlegen" suchte. ${ }^{10}$ Er wusste aber, dass die Gotteskritik auf rationale Weise nicht $\mathrm{zu}$ widerlegen, dass Ivan nicht mit seinen Waffen zu schlagen war. Die Antwort konnte, wie er in einem Brief schrieb, keine „direkte“ sein, nicht auf die vorgetragenen Thesen „nach Punkten“ eingehen, sondern musste ,indirekt“ sein, in einem „künstlerischen Bild“ bestehen (XXX/1, 122). Deshalb wechselte er die Argumentationsebene, rekurrierte auf Ästhetik und Pragmatik.

Um Ivans Gottesanklage zu widerlegen, benutzt Dostoevskij I zwei Argumente. Das erste ist die Schönheit und Wohlgeordnetheit der Welt. Damit greift Dostoevskij zum probaten Verfahren der Theodizee, dem Lobpreis der Schöpfung, der Kosmodizee. In Zosimas Vita gibt es Hinweise auf einen prominenten Prätext für die Kosmodizee als Theodizee. Das ist das Buch Hiob, das für Dostoevskij - wie seine Frau berichtet - von großer Bedeutung war. In seinen „Unterweisungen“ gibt auch Zosima dem Buch Hiob Priorität unter den Büchern des Alten und Neuen Testaments. Und wir können ahnen, warum Dostoevskij an Zosimas Präferenz gelegen war. Die Nacherzählung des Buches Hiob ist eine der Keimzellen des Romans. Im Buch Hiob wird die zentrale Frage der Theodizee gestellt: Wie kann der allmächtige und allgütige Gott das Böse und das Leiden zulassen? Dostoevskij, der Philosoph des Leidens, war natürlich an der in dem alttestamentlichen Buch gegebenen Antwort auf die Frage nach dem Sinn des Leidens höchst interessiert.

In seiner Paraphrase des Buches Hiob antwortet Zosima auf die brennenden Fragen mit der finalen Zufriedenheit des Demiurgen: „Wie der Schöpfer in den ersten Tagen der Schöpfung jeden Tag mit dem Lob beschloss, Gut ist das, was ich geschaffen habe', so schaut er auf Hiob und rühmt sich von neuem seiner Schöpfung" (XIV, 265).

10 Vgl. die in diesem Punkt ähnlich lautenden Briefe an N. A. Ljubimov vom 10.5.1879 (XXX/1, 63-65) und an K. N. Pobedonoscev vom 19.5.1879 (XXX/1, 66 f.). In beiden Briefen wird das Buch, das in der damaligen Konzeption neben Ivans Auflehnung sowohl den Großinquisitor als auch den Russischen Mönch enthalten und tatsächlich Pro und contra durchspielen sollte, als „Kulminationspunkt des Romans“ bezeichnet. 
Betrachten wir Gottes Part im Buch Hiob näher. Der Klage des geschlagenen Menschen begegnet die Gottesrede aus dem Sturmwind. Diese Rede gibt aber im Grunde keine Antwort auf Hiobs Klage. Das Leiden wird nicht erklärt und nicht begründet. Die Gottesreden zeigen weder den Grund noch den Zweck, noch die Notwendigkeit von Hiobs Leiden auf. ${ }^{11}$ Stattessen rühmt sich der Weltenschöpfer seiner demiurgischen Kompetenz und preist die Vollkommenheit seiner Schöpfung, die er mit der Wohlorganisiertheit von Rotwild, Wildesel, Vogel Strauß, Nilpferd und Krokodil anschaulich vor Augen führt.

Dass Gottes Rede aus dem Sturmwind auf die Fragen, Zweifel und Klagen des geschlagenen Menschen im Grunde keine Antwort gibt, ist oft als genetisch bedingte Inkonsistenz des Buches Hiob betrachtet worden. Dostoevskij hat das jedoch nicht als Webfehler, sondern als intendierte Struktur gesehen. Der Klage des uneinsichtigen Helden wird mit dem Hinweis auf die Wohlgeordnetheit der Welt, die Überlegenheit des Schöpfers und die Inkompetenz des Menschen begegnet.

Im Buch Hiob nimmt die Theodizee also die Form der Kosmodizee an. Dieser Preis der Schöpfung hat in Dostoevskijs Roman ein Äquivalent. Von der Schönheit der Welt angerührt, bricht der junge Zosima in ein Lob der von Gott geschaffenen Teleologie aus. Jedes Gräschen, jedes Käferchen, die Ameise, das goldene Bienchen, sie alle kennen erstaunlich gut ihren Weg, obwohl sie doch keinen Verstand haben, und sie zeugen von Gottes Geheimnis: „Schau [...] auf das Pferd, das große Tier, das dem Menschen nahesteht, oder auf den Ochsen, den düsteren und nachdenklichen, der ihn ernährt und für ihn arbeitet. [...] Die ganze Schöpfung und jede Kreatur, jedes Blättchen strebt nach dem Wort, singt Gottes Ruhm, weint zu Christus, und vollführt das alles unbewusst, durch das Geheimnis seines sündlosen Lebens" (XIV, 267 f.).

Den Roman durchzieht eine Kette von Konversionen. Sie geht aus von Markel, dem gottlosen älteren Bruder Zosimas, und erreicht über Zosima schließlich Aleša, Grušen'ka und Dmitrij. Sogar Ivan wird noch von der Kettenreaktion erreicht, wenn seine Konversion auch auf der Kippe steht. Allen Konversionen gemeinsam ist, dass sie sich ereignen angesichts der Schönheit der Welt. ${ }^{12}$ Die Konvertiten werden jeweils inspiriert durch ein ergreifendes Erleben der Natur und ihrer Ordnung. An Zosima werden die Bedingungen und Phasen der Konversion deutlich: das Erwachen des Gewissens, der Blick auf die Natur, die Wahrnehmung der Schönheit der Welt, das Lauschen auf das Singen der Vögelchen, die mit ihrem Gesang „Gott loben“ - der "Gottesvögelchen“, wie sie Markel franziskanisch apostrophiert hat -, und schließlich die Erkenntnis, dass ,jeder vor allen für alle schuldig ist“. Die Liebe zur Natur beobachten wir in der Schwundstufe sogar an Ivan, der, obwohl Ratio-

11 Vgl. Jürgen Ebach: „Hiob/Hiobbuch“. In: Theologische Realenzyklopädie. Bd. XV. Berlin/New York 1986, S. 370.

12 Vgl. W. Schmid: „Die Schönheit der Welt in Dostoevskijs ästhetischem Gottesbeweis“, in: Wiener Slawistischer Almanach 66 (2010), S. 59-72. 
nalist, Aleša gesteht, dass er die „klebrigen im Frühling aus Knospen aufbrechenden Blättchen" liebe (XIV, 210). Es handelt sich freilich bei den klebrigen Blättchen um ein literarisches Zitat aus Puškins Gedicht Noch wehen die kalten Winde (1828). Ivans Naturliebe wird - abgesehen von der Partialität seines Fokus auf die Natur also auch durch ihre Literarizität ein wenig relativiert. Diese Einschränkung entspricht der Unabgeschlossenheit seiner Konversion.

Die Kettenreaktion der Konversionen geht von der geistigen Wiedergeburt des sterbenden Markel aus. Am Rande des Todes ist der junge Atheist zur Überraschung aller bereit, sich auf das Abendmahl vorzubereiten, um, wie er sagt, die Mutter „zu erfreuen und zu beruhigen“. Der Sterbende macht in der Folge eine Reihe von Aussagen, die wir als Kernbotschaften des Romans interpretieren müssen. Eine dieser Aussagen drückt die emphatische Annahme des Diesseits aus: „Das Leben ist ein Paradies, und alle sind wir im Paradies und wollen das doch nicht wahrhaben, wenn wir es aber erkennen wollten, wäre morgen schon auf der ganzen Welt das Paradies“" (XIV, 262).

Die Auffassung vom Diesseits als einem potentiellen Paradies wird dann Zosimas durchaus heterodoxes Credo. Durch die Reihe der Konvertiten werden Markels zentrale Aussagen weitergegeben: die Anerkenntnis der Schuld eines jeden vor allen und an allem und das Bekenntnis, er, Markel, trage größere Schuld als alle andern vor allen und an allem. Allen Konvertiten gemeinsam ist der Lobpreis von Gottes herrlicher Welt.

Hier zeichnet sich das ideelle Design des Romans ab: die Liebe zu den Menschen ist untrennbar mit der Annahme von Gottes Welt verbunden, mit der ästhetischen Freude an der wohlgeordneten Natur und mit dem Bekenntnis zur eigenen Schuld. Es ist freilich nicht zu verkennen, dass der Glaube, den Dostoevskij I hier propagiert, weniger auf die Transzendenz als - ganz franziskanisch, ja pantheistisch - auf die Immanenz gerichtet ist. Das hat auch die russische Orthodoxie verstanden und entsprechend gerügt. Im Glauben des sterbenden Markel figuriert Gott nicht so sehr als transzendentes Wesen, sondern verschmilzt mit der Liebe, der Schönheit und der Freude, in denen er sich manifestiert.

Wie sehr sich Dostoevskij auch um eine realistisch-prosaische Ausgestaltung der Details im frommen sechsten Buch, das Ivans Gottesanklage widerlegen sollte, gesorgt haben mag, werden Zosimas Leben und Lehren nur den überzeugen, der schon überzeugt ist. Wie schon viele Zeitgenossen konstatiert haben und spätere Leser durch raffendes Lesen immer aufs Neue bestätigen, ist Zosima als Gegengewicht zu Ivan weder ethisch noch ästhetisch vollständig gelungen. Im Grunde genommen hat sich der Autor auf die argumentative Kraft des frommen Buchs auch nicht verlassen, sondern die Widerlegung auf anderem Wege und weit über das sechste Buch hinaus, letztlich mit dem ganzen Roman und der Entwicklung seiner Helden betrieben.

Dostoevskij sucht Ivans Gottesanklage mit dem argumentum ad personam zu widerlegen, und er folgt dabei dem biblischen Motto für das Erkennen falscher Propheten: „An ihren Früchten sollt ihr sie erkennen“ (Mt. 7, 16). Ein Beweis für die 
Existenz eines guten Gottes ist das Handeln der positiven Figuren. Ethisches Handeln ist nach Dostoevskijs Überzeugung nur im Glauben an Christus möglich. Sittliche Ideen entstehen im Gefühl. Das religiöse Gefühl ist die Schnittstelle für den Kontakt mit der Transzendenz. Verstandesgründe und weltimmanent-ethische Motive für das Handeln lässt Dostoevskij I nicht gelten. Für eine ethische Begründung der Sittlichkeit fehlt dem Menschen die Kraft zur Brüderlichkeit. (Dieses Argument benutzt Dostoevskij in seinen publizistischen Schriften. In der Fiktion wird es von Ivan vertreten, und es kehrt in den Worten des Großinquisitors wieder.) Die Möglichkeit einer Ethik ohne Glauben an die Unsterblichkeit der Seele propagiert lediglich der gewissenlose Priesterzögling Rakitin, eine der negativsten Figuren des Romans.

Die Gotteskritik wird unter anderm mit der Kompromittierung des Kritikers entkräftet. Dostoevskij I bringt gegen Ivan ein ganzes System von Diskreditierungen in Anschlag, von denen hier nur die wichtigsten erwähnt seien:

1. Ivan wird durch sein rationalistisches Denken diskreditiert. In der Konzeption von Dostoevskij I ist das Leiden der Kinder ein Vorwand. Ivan geht es gar nicht um die Kinder und ihr Leiden. Er ist am Menschen und am Menschlichen im Grunde nicht interessiert. Den leidenden Kindern, von Ivan als Argument missbraucht, sind im Roman andere Kindermotive entgegengesetzt, die mustergültige christliche Haltungen im Angesicht des Leidens demonstrieren. Grigorij, der Diener, hadert nach dem Tod seines einzigen Kindes nicht mit dem Herrgott, sondern widmet sich der Lektüre religiöser Texte und findet besondere Erbauung im Buch Hiob. Dmitrij wird vom weinenden „Kindchen“, das er im Traum sieht, allererst zur christlichen Erleuchtung geführt. Anstatt, wie Ivan, nach dem Sinn des Leidens der Kinder zu fragen, empfindet Dmitrij das Bedürfnis, etwas zu tun, damit die Kinder nicht mehr weinen. Der rationalistischen Theorie Ivans wird als richtige Reaktion auf das Leiden also das aus dem Mitgefühl erwachsende Handeln entgegengesetzt.

2. Ivan wird von Dostoevskij I durch seine Adepten und Doppelgänger diskreditiert, von denen zumindest vier existieren: Rakitin, der karrieresüchtige Student der Theologie, Materialist und Positivist, glaubt an eine freie, gleiche und brüderliche Menschheit ohne Gott und erweist sich auf Schritt und Tritt als ausgemachter Schuft. Smerdjakov, ein weiterer Adept Ivans, ist der einzige unrettbare Sünder des Romans, die Inkarnation des Bösen. Für den menschlichen Geist ist es nicht gerade schmeichelhaft, dass der Vatermörder mit besonderen Verstandeskräften ausgestattet ist. Nicht gebildet oder klug, ist Smerdjakov gleichwohl hochintelligent oder teuflisch raffiniert. Sein Mordplan ist mit bewundernswerter Weitsicht konzipiert, und er durchschaut wie kein anderer die Menschen, ihre geheimen Triebfedern und ihre Schwächen. Schon als Kind vermochte er Fragen zu stellen, die alle in Verlegenheit brachten, wie z. B. Voltaires Frage, woher am ersten Tag der Erschaffung der Welt das Licht gekommen sei, wenn Gott Sonne, Mond und Sterne erst am vierten Tag geschaffen habe. Auf diese Art Sophisterei wird der euklidische Verstand durch Dostoevskij I reduziert. 
Der spießige Teufel in Ivans Alptraum, der so gerne mit den jubelnden Himmelsscharen Hosianna rufen möchte und nur aus Pflichtbewusstsein und mit Rücksicht auf seine soziale Stellung das Böse bewirkt, entlarvt die Träume einer diesseitigen, von einer weltimmanenten Ethik gesteuerten Ordnung ohne Gott, ja den gesamten atheistischen Humanismus als bloße Skrupellosigkeit. Auch dass der Teufel in spießbürgerlicher Gestalt auftritt, ist ein Schachzug von Dostoevskij I: so soll die wahre Natur der intellektuellen Rebellion demonstriert werden. Der Cauchemar ist ja nichts anderes als die Ausgeburt des kranken Ivan. Der Teufel sagt nichts, was Ivan nicht schon gedacht hätte. Hier tritt lediglich nach außen, was in der Seele des Aufrührers bereits angelegt war.

Die Ivan am meisten kompromittierende Gestalt ist der Großinquisitor, die Figur seines Gedankenexperiments, die eine von Ivans Theorien in der historischen Wirklichkeit erprobt und bis zum Äußersten durchspielt. Der ungläubige Kirchenfürst, der den schwachen Menschen um ihres Glückes willen die Freiheit nimmt, zeigt als die wahre Triebfeder der für die Menschen angeblich „Leidenden“ den unbändigen Willen zu Herrschaft und Macht.

3. Ivan wird durch seinen Charakter, sein Ethos, seine Rede, ja sogar durch seine körperlichen Eigenschaften diskreditiert. Er hat eine steife Körperhaltung, seine Bewegungen sind hölzern. Seine Rede begleitet ein spöttisches Lachen, das Attribut des Teufels. Auch Ivans Vermischung von Ernsthaftigkeit und Spott, sein sarkastisches Scherzen mit dem Ernsten, ja Heiligen sind diabolischen Ursprungs. Ivan ist stolz, von ihm geht menschliche Kälte aus, er liebt angeblich die Menschheit, kann aber wie er gesteht - seinen Nächsten nicht lieben. Der Menschenliebe des barmherzigen Johannes unterstellt er nadryv, Selbstvergewaltigung. Ivans Rede zeichnet sich durch leere Rhetorik, Unoriginalität des Wortes aus: alles ist fremde Rede, entlehnt und geborgt. Und nachdem Ivan seine Großinquisitorlegende erzählt hat, geht er „irgendwie schaukelnd“, mit herabhängender rechter Schulter, den ersten Körpermerkmalen des Pferdefüßigen, von dannen.

4. Am gravierendsten wird Ivan durch sein Handeln diskreditiert: Er hat ja unterschwellig Smerdjakov zum Vatermord angestiftet, zumindest hat er dem Versucher unbewusst sein Einverständnis mit dem andeutungsweise umschriebenen Mordplan bedeutet. Der Mord am leiblichen Vater ist für Dostoevskij I die direkte Folge des Mords am himmlischen Vater.

Wie kommen nun Dostoevskij II und der von ihm subliminal angelegte Gegensinn zur Erscheinung? Paradoxerweise durch die Aufdringlichkeit von Dostoevskij I, der uns mit der Kettenreaktion der Konversionen ziemlich viel zumutet. Dieser Dostoevskij I hätte sich gegen die Unterstellung eines seinem Werk eingeschriebenen Gegensinns entrüstet verwahrt. Hat er nicht an Ivans Person und Schicksal deutlich genug gezeigt, wohin man mit europäisch-rationalistischem Herumklügeln kommt? Ja, er hat das überdeutlich gezeigt und damit nur seine eigenen Zweifel bloßgelegt. Ist er, wenn er durch den ganzen Roman Ivan unerbittlich verfolgt und ihm nicht die geringste menschliche Schwäche nachsieht, nicht ein wenig auch sich selbst auf 
der Spur? Die Menge, die Systematik und die Konsequenz der Diskreditierungen sind der unterschwelligen Gegenintention verdächtig. Diese Struktur wird wie andere Züge des Autorverhaltens in der dargestellten Welt bloßgelegt. Der Teufel hält Ivan, der seine Autonomie bezweifelt, lachend entgegen: „Der Eifer, mit dem du mich ablehnst [...], überzeugt mich, dass du trotzdem an mich glaubst" (XV, 79).

Eifer ist auch spürbar in der Diskreditierung Ivans durch Dostoevskij I. Aber gegen alle Widerlegungsversuche und gerade weil sie vom Autor so hartnäckig bekämpft wird, bleibt Ivans euklidische Argumentation im Roman wirksam und für viele Leser überzeugend. Nicht von ungefähr ist sofort nach Erscheinen des Romans Ivan als alter ego des Autors bezeichnet worden. So schreibt ein Kritiker 1881, dass der Skeptiker Dostoevskij zusammen mit seinem Helden seinen eigenen Glauben in Frage stelle: „Dostoevskij glaubt und predigt die ,Demut ' [...], und selbst zweifelt er, und selbst sündigt er als erster gegen das Gebot der ,Demut des Geistes' [...] Er straft Ivan, und damit straft er sich selbst, die Zweifel und Regungen seines stolzen Verstands [...] Dostoevskij hätte die Ideen Ivan Karamazovs nicht so einfühlsam, so authentisch und vor allem mit so viel feuriger Beredsamkeit aussprechen können, wenn er sie nicht selbst geteilt hätte, wenn diese Zweifel nicht seine eigenen gewesen wären. [...] Er predigte die Demut und praktizierte sie auch, aber der mit Füßen getretene Verstand erhob sich und sprach lauter, stärker, sprach mit feurigem Wort!"13

Man könnte nun einwenden, und es ist dies oft getan worden: Ivans Argumentation musste deshalb so stark gemacht werden, damit ihre Widerlegung voll überzeuge. Die christliche Position sollte nicht schon auf Grund mangelnder Kraft ihrer Gegner obsiegen. (Damit schafft man eine Analogie zwischen Gott, der die freie, durch das Leiden erschwerte Entscheidung für sich fordert, und dem Autor, der die freie, durch verführerische Gegenpositionen erschwerte Entscheidung für den richtigen Sinn fordert.) Man wird aber zugestehen, dass Ivans Auflehnung ihre Widerlegung überlebt und nicht nur als „Dünger“ für die finale Romanharmonie fungiert.

Diese Widerlegung ist im Übrigen, um ein Bild aus dem Roman aufzugreifen, ein Stock mit zwei Enden, eine zweischneidige Angelegenheit. Ivan, der Gottesankläger, der - wie sein Gespräch mit dem Teufel zeigt - nach dem Glauben an ein gerechtes Jenseits dürstet, ist letztlich viel mehr Metaphysiker, denkt viel transzendenter als der weltfromme Mönch. Der franziskanisch-pantheistische Glaube Zosimas an die Schöpfung, seine ästhetisierte Religion, sein mystischer Vitalismus, seine Verehrung der Mutter Erde, die Überzeugung, dass durch den rechten Glauben und durch gottgefälliges Verhalten der Mensch schon auf der Erde das Paradies erlangen könne, sind ja eher auf das Diesseits als auf das Jenseits gerichtet. Und während Ivan die Gerechtigkeit in der finalen Weltharmonie einklagt, entwirft Zosima die säkulare Utopie einer Welt, in der sich die Verbrechen auf ein "unwahrscheinliches Maß“

13 Russkoe bogatstvo, 1881, № 11, S. 35 f., zit. nach Kommentar in PSS XV, 510. 
verringern. Jedenfalls macht die Gottesanklage des Theoretikers auf viele Leser mehr Eindruck als die auf das Diesseits gerichtete Frömmigkeit des Mönchs.

Die dem Roman gegen die Intention von Dostoevskij I eingeschriebene Gotteskritik wird in ihrer ganzen Reichweite erst recht vor dem Hintergrund des Buches Hiob deutlich. Im Horizont des christlichen Sinnes, den Dostoevskij I intendiert haben mag, erinnert Hiobs Geschichte daran, dass der Mensch viel zu schwach ist, um die Weisheit und Allmacht Gottes begreifen zu können, und dass er folglich frevelt, wenn er in seinem Leiden an Gottes Gerechtigkeit zweifelt. Aber das Buch Hiob exponiert in dem Roman noch einen ganz andern Sinn, den Zosima durch seine Paraphrase unfreiwillig herauskehrt: die Rivalität zwischen Gott und Teufel, einen Kampf zwischen zwei antinomischen Mächten, die Hiobs Treue zum Gegenstand einer Wette machen. In seiner Nacherzählung des Buches Hiob betont Zosima mehrfach, dass „sich Gott vor dem Teufel gerühmt habe, auf seinen Knecht, den großen Heiligen, verweisend“ (XIV, 265). Das ist nicht ganz korrekt: Gott rühmt vor Satan nicht sich selbst, sondern die Gottesfurcht seines Knechtes Hiob. Dieses Lob ist nicht reflexiv.

Mit seiner Abweichung führt Zosima - und mit ihm Dostoevskij - in den alttestamentlichen Text das dort noch gar nicht existierende Motiv der Rivalität zwischen Gott und Satan ein. Dem entspricht, dass Zosima den Gegenspieler Teufel nennt. Aber das ist ein Anachronismus. Im Alten Testament bezeichnete Satan nicht den Feind Gottes, sondern den Staatsanwalt an Gottes Hof. Die Einführung des neutestamentlichen Teufels in die alttestamentliche Hiobsgeschichte bringt den dort noch gar nicht vorhandenen agonalen Dualismus allererst hervor.

Der im Roman subliminale Gedanke des Wettkampfs zwischen Gott und seinem Widersacher wird durch die Spötter und Lästerer expliziert, deren stolze Worte Zosima hört: „Wie konnte der Herr den Liebsten seiner Heiligen dem Teufel zur Belustigung überlassen, ihm seine Kinder nehmen, ihn selbst mit Krankheit und Schwären schlagen [...] und wozu? Nur um sich vor Satan zu rühmen: ,Siehst du, was mein Heiliger um meinetwillen zu ertragen vermag?"“ (XIV, 265).

Die von den Spöttern und Lästerern herausgekehrte Selbstbezüglichkeit und die Instrumentalisierung des menschlichen Leidens für Gottes Ruhm finden im biblischen Text keine Stütze. Solche Veränderungen und Akzentverschiebungen, die Zosima an dem heiligen Text vornimmt, bilden Ansatzpunkte für eine Gotteskritik, hinter der wir Dostoevskij II erkennen.

Auch das Räsonnement des Teufels in Ivans Alptraum legt den Schluss nahe: Gott lässt das Böse zu, nur um die Entscheidung für sich künstlich zu erschweren. Die Erschwernis durch die Freiheit dient aber nichts anderem als der größeren Glorie des eitlen Demiurgen.

Die These von der Selbstvergewaltigung des Autors bedeutet, dass Dostoevskij II insgeheim auf der Seite des von Dostoevskij I kompromittierten Gotteskritikers Ivan steht oder zumindest mit seiner Argumentation sympathisiert. Dafür gibt es unübersehbare Anzeichen. Ich erwähne hier nur zwei kleine Symptome. 
1. Von Dostoevskij wissen wir, wie sehr er die Instrumentalisierung des Leidens Unschuldiger verachtete. In seiner berühmten Puškin-Rede demonstriert er an Tat'janas Verhalten in Puškins Versroman Evgenij Onegin, dass es kein Glück geben kann, wenn es auf dem Leiden Unschuldiger aufgebaut ist. In genau denselben Worten erläutert im Roman Ivan dem Bruder Aleša seine Gründe für die Rückgabe des Eintrittsbillets in die ewige Harmonie.

2. In seinen Äquivalenzen, den Nischen und Winkeln, die Dostoevskij I nicht voll unter Kontrolle hat, entwickelt der Text Strukturen, die auch die heiligsten Dinge als Stöcke mit zwei Enden erscheinen lassen. Ein Beispiel dafür ist die überraschende Äquivalenz zwischen Hiob und dem halbverrückten, mit allem denkbaren Unglück geschlagenen Stabshauptmann Snegirev. In seiner Erzählung davon, wie Hiobs gestorbene Kinder durch neugeborene ersetzt werden, fingiert Zosima die Frage der „Spötter und Lästerer" - eine nicht-biblische Frage -, wie sich der wieder ins Glück gesetzte Hiob der neu geborenen Kinder freuen konnte, nachdem er die früheren eingebüßt hatte. Konnte er im Gedenken an die genommenen mit den neuen vollkommen glücklich werden? Auf solche Fragen, die dem Autor, der gerade seinen dreijährigen Sohn Aleša verloren hatte, sehr am Herzen gelegen haben müssen, hat der fromme Zosima die Antwort sofort parat: „Ja, ja, er konnte es, denn der alte Kummer geht nach einem großen Geheimnis des menschlichen Lebens allmählich in stille, gerührte Freude über" (XIV, 265). Der Ersatz für verstorbene Kinder taucht als Motiv im Roman noch einmal, mehr als 240 Druckseiten später, auf. Der sterbende Iljuša Snegirev weist seinen Vater an, nach seinem Tode einen andern, einen guten Jungen zu nehmen, ihn Iljuša zu nennen und ihn an seiner Statt zu lieben. Aber Snegirev will keinen andern Jungen, wie er mit zum Himmel erhobenen Händen und mit knirschenden Zähnen flüstert. Indem er dabei Worte aus dem Psalm 136 zitiert, „Wenn ich dich vergesse, Jerusalem, klebe mir klebe mir die Zunge am Gaumen“, beschwört er ein alttestamentliches Muster der Treue. Die Treue dieses unglücklichen Vaters wirft natürlich einen Schatten auf Hiobs finale Zufriedenheit. Und mit der Mustergültigkeit Hiobs wird auch die Theodizee seiner Geschichte zweifelhaft.

Es sollte gezeigt werden, dass Die Brüder Karamazov in ihrer russisch-christlichen, antieuropäischen, antieuklidischen Agitation eine geheime Sinnalternative bereithalten, die uns Dostoevskij als großen Zweifler und Gotteskritiker zeigt. Diese Alternative ist vom Autor nicht bewusst angelegt, nicht intendiert. Sie ist aber gleichwohl hinter dem Rücken des eifernden Autors in den Roman eingegangen. Weder Ergebnis willkürlicher Lektüre noch bloßer Sinnwunsch des Lesers, bildet die Alternative ein im Werk selbst vorhandenes Sinnpotential.

Dostoevskij II trägt freilich nicht einfach den Sieg über Dostoevskij I davon. Der Roman ist sowenig eindeutig Gotteskritik, wie er Theodizee ist. Seine Botschaft schwankt vielmehr unsistierbar zwischen Pro und Contra, welche Formel dem „Kulminationspunkt" des Romans ja auch den Namen gegeben hat. Nicht eine eindeutige Botschaft kennzeichnet die Sinnfaktur des Romans, sondern das unsistierbare 
Schwanken zwischen zwei einander ausschließenden Positionen, das nicht zur Ruhe kommende Oszillieren zwischen Dostoevskij I und Dostoevskij II, zwischen dem intendierenden und das Werk kontrollierenden Werksubjekt und seinem subliminalen, subversiven Antagonisten, jenen beiden Manifestationen, in denen der abstrakte Autor hier zur Erscheinung kommt.

Die Oszillation ist kein bewusster und zugelassener Akt, sondern eine Bewegung, die dem Autor, der sich mit Gewalt, im nadryv, in der Selbstvergewaltigung, über eine Seite seines bipolaren Denkens hinwegsetzt, gegen seine Intention gleichsam unterläuft. Diese nicht-intendierte Oszillation zwischen Glaube und Zweifel sichert dem Roman eine Anregungskraft, die einer der Gründe für seine die Zeiten überdauernde Aktualität ist.

So sind die Brüder Karamazov zwar eine nicht ganz eindeutig gelungene Theodizee, ein Stock mit zwei Enden, eine Medaille mit zwei Seiten, eine zweischneidiges Schwert, um einige der zahlreichen binaristischen Formeln des Textes aufzugreifen, aber ein herrlicher Roman, in dem der Autor, ohne es zu wollen, den großen Konflikt seiner Existenz zu einem Sujet gemacht hat. 


\section{Philip Maroldt}

\section{Aus der allereigensten Enge}

Vor zwei Jahren, im Sommer 2009, unterhielt ich mich nach einer Lesung mit einer ehrgeizigen, noch jungen Literaturwissenschaftlerin über Dostojewskij. Sie könne mit ihm nichts anfangen, sagte sie: lauter dauerhysterische Figuren, permanenter emotionaler Ausnahmezustand, eine zwanghafte Fixierung auf völlig abstrakte, philosophisch sinnlose (Sinn-)Fragen und, als sei das nicht genug, auch noch dieser Wahn, im christlich-orthodoxen Glauben die Erlösung zu sehen - künstlich, nervtötend, unerträglich sei das.

Es gehört zu den beglückenden Kleinigkeiten, den Feinheiten im Verhältnis von Literatur und Leben, dass Dostojewskij so wunderbar als Indikator dafür taugt, mit wem es sich zu reden lohnt.

Denn das gilt bei weitem nicht für jeden Weltliteraten.

Mit unserem trauten Geheimrat Goethe funktioniert ein solcher Test beispielsweise kaum - verhandelt er die sogenannten letzten Fragen doch allzu jambischwohlgenährt. Sein Teufel liebt die klassisch-effektvollen Auftritte, kommt reichlich pompös daher und wäre niemals als abgehalfterter Gutsbesitzer vorstellbar, der eher, als sympathy for - den leidenden Weltmann - devil auszulösen, mit seinem schmuddeligen Aufzug und seiner Neigung zum Schwatzen den Ärger des von einer derart stillosen Heimsuchung in seinem Stolz verletzten Iwan Karamasow auf sich zieht.

Kurzum: Angesichts der edlen Vielheit und klangvollen Größe, made in Germany, lässt sich schlecht streiten. Wenn selbst Thoas einsieht, dass er aus moralischen Gründen seine Hohepriesterin mit ihrem sich von Ohnmacht zu Ohnmacht schleppenden Bruderherz abreisen lassen muss, wird einem vor lauter Ausgewogenheit und Humanität mitunter ganz schwindlig - so viel Synthese können wohl auch nur die (Wilhelm) Meister dieser Welt richtig verarbeiten, uns chronisch unvervollkommneten Normalsterblichen vergeht mit fortschreitender Lektüre jeder klare Gedanke.

Doch auch so mancher ,Radikale eignet sich nicht als Lackmustest für die Seelenzustände wirklicher Menschen. Nehmen wir - im Gedenkjahr - Kleist als Beispiel. Er ist einfach nicht recht diskursfähig. Über Kleist zu sprechen, heißt ihn verleugnen, es sei denn, man gäbe - in einer Art rousseauschen Ursprache vielleicht fortwährend Laute des Erstaunens von sich, was doch eher debil anmuten, als uns Erkenntnissehnsüchtige auf ewiger Expedition um die Welt einen Schritt weiter in Richtung Hintertür des Paradieses bringen würde.

Wenn es eine vollkommene Realisation der schon etwas überstrapazierten Performanztheorie in der Literatur gibt, dann sind es die Texte Kleists - sie sprechen nicht, 
sie sind auch nicht zu besprechen, sondern sie finden statt. Eine buchstäblich liebeshungrige Penthesilea zu analysieren, hat etwas schockierend Unangemessenes; es erinnert mich an manche Trauerreden, die ich gezwungen war anzuhören.

Kleist stößt einen vor den Kopf, schlägt einem ins Gesicht - es streitet sich nicht gut über Kleist. Dostojewskij aber fordert die Debatte. Indem wir über ihn sprechen, sind wir Teil seiner Romane, und die Romane Teil unserer unmittelbaren Wirklichkeit, da sie selbst wesenhaft existentielles Gespräch - oft genug auch in Gestalt von Geplauder, Gefasel, Geschwätz - sind, in das wir uns einklinken, das wir fortschreiben. Sie haben dabei nichts Jambisch-fünffüßiges an sich, hier ist nicht die Kunst am Werk, „über die sich gut sprechen lässt“, jene Kunst also, der sich Celan mit seinem Meridian, die nicht richtig hinhörende Lucile aus Dantons Tod zitierend, entgegenstellt. Dostojewskijs Menschen sprechen um ihr Leben und damit auch um unser Leben, sie versuchen sich mit jedem Wort zu einer Wahrheit durchzukämpfen, die, indem sie angestrebt wird, zugleich auch schon immer in Frage steht, während ihnen ihre Wirklichkeit jederzeit zu entgleiten droht. Wenn nötig, muss selbst mit dem Teufel ausführlich diskutiert werden, um sie nicht ganz zu verlieren das heißt: wird wirklich diskutiert? Es ist wohl eher das (Selbst-)Gespräch zweier Hanswürste oder eines „Nervenfieber"-bedingten Hanswursts, der es jedoch versteht, auch in und aus der Unwürdigkeit Konversation zu machen: „,Der Teufel hat Rheumatismus?' ,Warum denn nicht, wenn ich mich schon gelegentlich inkarniere. Ich inkarniere mich, also habe ich mit gewissen Folgen zu rechnen. ${ }^{\text {'“ }}$ So ergeht es auch den Romanfiguren Dostojewkijs, auch sie haben mit "gewissen Folgen“ zu rechnen, sind sie doch keine Kunstfiguren, sondern allesamt inkarnierte Geister, die nach Welt lechzen.

Iwans Gespräch mit seiner Halluzination bzw. dem Teufel dreht sich eben dort, wo es von den hosiannaresistenten Lebensprinzipien handelt, auch und gerade um jene Voraussetzungen, welche die ungeheure Vitalität dieser Prosa überhaupt erst ermöglichen. Die poetologische Lesart liegt nahe, denn über Gott und die Welt wird grundsätzlich unter ästhetischen Vorzeichen gesprochen, oft genug geradezu kalauernd, als Suche nach dem in geselliger Runde wirksamen Bonmot, ein Tick, der uns als besonderes Merkmal von Stepan Trofimowitsch Werchowenski auch als Leitmotiv in den Bösen Geistern begegnet; Iwan Karamasow erfährt ihn jedoch als absichtliche Boshaftigkeit: „Ich hatte mir nämlich vorgenommen, dich durch eine literarische Einlage zu gewinnen: Dieses ,Hosianna' im Himmel ist mir, das musst du zugeben, doch ganz gut gelungen? Und unmittelbar darauf dieser sarkastische Ton à la Heine, stimmt doch, nicht wahr? "2 Der Sinn oder Unsinn des Lebens abgehandelt als mäßig originelles Geplänkel des Kunstverständigen und als un(frei)williger $\mathrm{Zu}$ hörer ein aufgeklärter Intellektueller, dessen Schmerz durchaus an Büchners/Celans Lucile erinnert - nur, dass es hier die klappernde Kunstmaschine ist, die dem armen

1 Fjedor M. Dostojewskij: Die Brüder Karamasow. Frankfurt am Main 2006, S. 1018.

2 Ebd., S. 1033. 
Iwan immer wieder dazwischen kommt, als Teufelswerk eingesetzt gegen seine Glaubenssehnsucht - man könnte auch sagen: Wirklichkeitssucht, denn eigentlich versucht er ja, aus den eigenen Rationalismen, den sogenannten Vernunftwahrheiten, aus einem vom nächtlichen, diabolischen Besucher bewusst solipsistisch (miss-) verstandenen Cartesianismus, einer schalen, einsamen Diesseitigkeit auszubrechen und sich endlich auf die Suche nach der Welt zu begeben. Gefunden werden könnte der Zugang zu einer Art inkarniertem Paradies, das also weder blutleer wäre noch im mit dem Leben unvereinbaren „Hosianna“ erstarrte, sondern als lebendiger, schöner Widerspruch dem Denken, dem Bewusstsein überhaupt eine Heimstatt werden, es aus der scheinbar als Naturgesetz festgeschriebenen Selbstzerfleischung - dem uns aus den Aufzeichnungen aus dem Kellerloch wohlbekannten Krankheitsstatus befreien könnte. Ein kontaminiertes Paradies also - und zugleich ein Paradies der Kontamination. ${ }^{3}$

Eine Zweckfreiheit, verstanden als l'art pour l'art, ist für Dostojewkij nicht vorstellbar, und gerade deshalb taugen seine Romane noch heute hervorragend als Argument gegen einen „Zweckneurotischen“ Materialismus, stehen dem vulgärnaturwissenschaftlichen Weltbild, das den Diskurs unserer Kommunikationsgesellschaft auf breiter Linie beherrscht, weiter als überzeugende Unerhörtheit gegenüber: Sie verabschieden sich nicht aus den Wirklichkeitszusammenhängen, sondern schreiben sich ihnen ein, gestalten sie, ringen um einen Sinn und ermöglichen so überhaupt erst die wohltuende Gefährlichkeit des luziden Unsinns, mit dem uns ein mehr oder weniger halluzinierter Teufel oder der Kellerlochmensch überschütten.

„Diskurse im Sinne der an die Arbeiten Foucaults anschließenden Theorien sind [...] dadurch bestimmt, dass sie sich auf spezielle Wissensausschnitte [...] beziehen, deren Grenzen durch die Regulierung dessen, was sagbar ist, was gesagt werden muss und was nicht gesagt werden kann, gebildet sind “" .

Die Diskurstheorie betont - laut „Metzler Lexikon Literatur- und Kulturtheorie“5 - im Hinblick auf die Literatur wiederum besonders zwei Aspekte: ihre re-integrativen Fähigkeiten, d.h. also ihre Potenz, verschiedene Einzeldiskurse zusammenzuführen, zum Teil vielleicht auch: zu synthetisieren (mehr alchimistisch als dialektisch verstanden). Zugleich sei sie jedoch selbst „Spezialdiskurs mit eigenen Formationsregeln". 6

Hinzufügen müsste man, dass literarische Texte auch metadiskursiv äquivalent zur Diskurstheorie sein können, sie - so sie gelungen sind, also funktionieren - vielleicht immer schon sind. Das gilt insbesondere für die großen Gesellschaftsromane

3 Vgl. auch Harold Bloom: Genius. Die hundert bedeutendsten Autoren der Weltliteratur. München 2006, S. 1012: „Man könnte Dostojewskij einen Genius für die Kontamination nennen.“

4 Metzler Lexikon Literatur- und Kulturtheorie. Herausgegeben von Ansgar Nünning, Stuttgart: Metzler 2001, S.115.

5 Das Metzler-Lexikon ist immerhin so verbreitet, daß es hier exemplarisch für einen Rezeptionsmainstream stehen soll.

6 Ebd. S. 116. 
des 19. Jahrhunderts, die einen Höhepunkt des literarischen Vollzugs von Gespräch darstellen. Vielleicht findet sich hier sogar die bessere Diskurstheorie. Man könnte sagen: sie ist immer einen Schritt voraus. Ursächlich hierfür ist eine grundsätzliche Stärke der Literatur: Sie kann (sich selbst) reflektieren und (von sich selbst) abstrahieren, ohne dadurch theoretisch zu werden. Auch so wirkt sie integrativ. Diese Stärke zeigt sich aber besonders im Diskurs jener Themenfelder, wo in der Sprache unserer Wissenschaftskultur ein besonders hoher Grad an Abstraktheit auf einen besonders unklaren Gegenstand trifft, wie es z.B. in der Kulturtheorie der Fall ist.

Diskurstheoretische Modelle der oben beschriebenen Art lassen sich nicht ohne Foucaults im Kern relativistischen Macht- bzw. Wahrheitsbegriff verstehen: Diskurse dienen immer der Erzeugung von Wahrheiten und damit dem Aufbau von Machtzentren. Die Ironie dabei ist, dass die poststrukturalistische Terminologie selbst schon ein überaus leistungsstarkes Dispositiv darstellt, gewissermaßen als die autoritärste aller antiautoritären Keulen verwendet werden kann. Als hochexklusiver Diskurs ist sie wesenhaft aristokratisch - in einem heiklen, mehrdeutigen, vielleicht nietzscheanischen Sinn. Nun ist das ,Funktionsprinzip' von Kunstwerken nicht gerade Demokratie- bzw. Egalité-verdächtig, aber Kunst wird erst dort interessant, wo ihre Künstlichkeit implodiert bzw. nicht Selbstzweck ist, sondern ein grenzüberschreitender Weg - hin zu einer orbitalen Aussichtsplattform auf das Leben möglicherweise. Imre Kertész schreibt in seinem als Selbstinterview verfassten Buch Dossier K.: „Ob es uns gefällt oder nicht gefällt, die Kunst betrachtet das Leben immer als Feier.“ Als sein ,Interviewer' nachfragt: „Als Karneval oder als Trauerfeier?“, lautet seine lapidare Antwort: „Als Feier." Vermutlich ist sie grundsätzlich beides. Vielleicht ist sie jedoch auch tatsächlich zuweilen eine reine Feier, ohne auch nur einen zugesetzten Buchstaben, kompositumfrei; der Name dafür wäre dann wohl: Transzendenz.

Wer von Transzendenz spricht, befindet sich - ob er will oder nicht - in der Reichweite Gottes, zumindest aber operiert er mit einem für jede Metaphysik konstitutiven Begriff. Und genau hier liegt die demokratische Sprengkraft bzw. die tiefe ethische Verwurzelung einer Literatur, die dieser Tatsache eingedenk bleibt; sie findet in der Sprache statt ohne sich mit Sprachimmanenz zu begügen. Sie ist mit denen, die das nicht sagen, was gesagt werden muss, die sich abmühen, das auszusprechen, was nicht gesagt werden kann, und die es als persönliche Beleidigung ansehen, zu akzeptieren, was sagbar ist - und was nicht. Sie ist mit den Kellerlochmenschen, die (un-)verdrossen gegen die Mauer rennen, ebenso wie mit den Erniedrigten und Beleidigten.

„Dostojewskij lernte eifrig von Shakespeare. Man könnte ihn den Shakespeare der Romanciers nennen, da seine grandiosen Figuren geradezu vibrieren von der Bewußtseinsenergie, die wir als shakespearesch erkennen. ${ }^{\text {"8 }}$ Es wäre ein Fehler, Harold

7 Imre Kertész: Dossier K.. Reinbek bei Hamburg 2008, S. 118.

8 Bloom (2006), S. 1013. 
Blooms Vergleich auf einen Ritterschlag zu reduzieren (den offenbar nicht zuletzt er selbst, der eigenen Bedeutsamkeit gewiss, darin sieht). Es bestehen viele Gemeinsamkeiten, die durchaus konkreter zu benennen sind als mit bloßer „Bewusstseinsenergie“: Die augenfälligste ist zweifellos, dass sich kaum ein dritter Schriftsteller finden lässt, der eine solche Vielfalt von fundamentalen Untiefen [sic!] der menschlichen Seele auslotet und ähnlich radikale, dabei zugleich aber sorgfältig gewählte und entwickelte Kunstmittel einsetzt. Keine noch so extreme Handlung, keine Bodenlosigkeit ist den Figuren dieser beiden Autoren fremd.

Wenn bei Shakespeare Gespenster und Hexen auftreten, so nicht als zerstörerische dei ex machina, sondern als sozusagen vorzeichenverkehrte Inkarnationen der zutiefst menschlichen, diesseitigen Abgründe. Die „three witches“ aus Macbeth scheinen als jenseitige Macht das Schicksal zu bestimmen, aber angesichts der unglaublichen Sprachgewalt des Tyrannen, die jeden dramaturgischen Kniff und phantastischen Effekt in den Hintergrund rückt, muss man wohl eher sagen: sie zeigen das Schicksal an. Und zwar nicht einmal wie ein Augur. Sondern eher wie ein Monitor. Sie sind die einzig adäquate Form, ein Grauen auf die Bühne zu bringen, das sehr wohl von dieser Welt ist. Dostojewskijs phantastische Gestalten wiederum, deren Existenz wir uns nie sicher sein können, die als potentielle Hirngespinste also weit weniger in der Lage scheinen, eine aus den Fugen geratene Welt anzuzeigen, als der Geist von Hamlets Vater oder der blutige Banquo am Banketttisch, sind jenen shakespeareschen Gespenstern doch näher, als man auf den ersten Blick meint. Das positivistische 19. Jahrhundert hat ihnen nicht die Kraft genommen, sie nicht entzaubert, sondern nur heimtückischer gemacht. Sie haben sich angepasst, haben verstanden, sich den Umstand zunutze zu machen, dass sie nun nur noch als psychische Extremzustände, als Einbildungen im Fieberwahn, als Visionen vor epileptischen Anfällen auftreten können. Ob nun bei Dostojewskij in mutmaßlich natürlichen Vorgängen das Übernatürliche lauert - oft aber auch als Versprechen leuchtet oder bei Shakespeare das Übernatürliche mit wuchtiger Selbstverständlichkeit über ,weltliche' Figuren hereinbricht, die noch im Zustand der völligen Verzweiflung die hintersten Winkel ihrer Seele in kristallklaren Versen erfassen können, in beiden Fällen haben wir es mit echten Grenzgängern zu tun, mit Medien der Transzendenz, die hermetisch sind, wenn man dem Wort jene Etymologie zuschreibt, die es, auf die Literatur angewandt, eigentlich unbedingt nötig und verdient hätte: nämlich die Zuordnung zum Götterboten.

„Nichts so Natur als Shakespeares Menschen!“ Der berühmte Ausruf des noch stürmenden und drängenden Goethe gilt ebenso für die Menschen Dostojewskijs wenn man die Natur als eine kulturkontaminierte versteht und vice versa. Doch sie sind keine sprachgewaltigen Gegenmächte zu den sie heimsuchenden Geistern, sondern ihnen ausgeliefert. Sie reden sich immer wieder um Kopf und Kragen und brauchen dafür nicht einmal einen besonderen Anlass. Sie verhaspeln sich, pöbeln und lallen besoffen vor sich hin, kalauern, zitieren Schiller, machen im nächsten Moment einen faulen Witz oder sagen einfach das Richtige am falschen Ort und das 
Falsche am richtigen - sie sind notorisch unangemessen in ihrem Sprechen, sie schämen sich fortwährend, was die Sache nicht besser macht, wie Starez Sosima weiß. Sie suhlen sich in Selbstmitleid, und wenn sie von aufrichtiger Liebe erfüllt sind, ist der Auftritt als Elefant im Porzellanladen schon vorprogrammiert. Sie tun alles, vernichten sich zur Not sogar selbst, um in die heiligen Hallen ihrer Ideen zu gelangen, aber veranstalten dabei einen Jahrmarkt der Eitelkeiten. So manches Mal sind sie dümmer als ihre Worte, oft genug ist es aber auch umgekehrt. Wenn es hart auf hart kommt, sagen sie hin und wieder gar nichts mehr; stattdessen stottern und grimassieren sie, laufen weg, fallen in Ohnmacht, werden todkrank - verhalten sich mithin denkbar undiskursiv. Auf argumentative Spitzfindigkeiten ihrer Gesprächspartner reagieren sie meist keineswegs mit rhetorischer Brillanz, sondern mit mal ernst, mal weniger ernst gemeinten Schimpftiraden (Rasumichin ${ }^{9}$ ), unstrukturierten Wortschwällen (Fürst Myschkin) oder keuscher Zurückhaltung (Aljoscha). Die gebildeten, weltgewandten unter ihnen sind von der eigenen Eloquenz wiederum so angewidert, glauben den eigenen Worten so wenig, dass sie sich absichtlich danebenbenehmen. Man kann sagen, es gehört zur Grundaustattung der Geschöpfe Dostojewskijs, sich nicht richtig ausdrücken zu können - oder aber es nicht zu wollen. Gekoppelt ist dieser scheinbare Mangel jedoch an einen omnipräsenten und starken Drang zur Einsicht, zur Selbstbeobachtung und Selbstbespiegelung. In eben jener paradoxen Verbindung liegt wohl die Energiequelle für das, was Dostojewskij den Ruf des erschreckend genauen Psychologen eingebracht hat: Bei ihm sind logos und ratio nicht nur nicht deckungsgleich (wie sie es - vereinfachend gesagt - in der modernen Sprachphilosophie sind), sondern sie können sich so weit voneinander entfernen, dass im Moment der katastrophalsten Logorrhoe die höchste Gedankenklarheit erreicht wird. Und genau hier entsteht auch jene unerhörte, ungeheuerliche Diskursivität. Dostojewskijs ÄsthEthik zielt auf Wahrheitsgewinn durch explizite Innerlichkeitsschau gerade dort, wo Sprache nicht hinreicht. Er kennt noch nicht die bequeme Verantwortungsgarderobe namens Unterbewusstsein oder Über-Ich und hätte sich wohl auch, ganz im Sinne seines Bewunderers Nietzsche, solchen Systematisierungen verweigert bzw. sie als westliche Dekadenz verworfen. Dennoch ist sein Unternehmen nicht weniger als eine Phänomenologie des Geistes - das heißt: eine Phänomenologie der Geister. Denn hier ist der Geist etwas zutiefst Individuelles, nicht zu denken ohne die ganz konkret zu verstehenden Phänomene, die Albernheiten, Schrulligkeiten, Unzulänglichkeiten der beschriebenen Menschen ebenso wie die Momente der Größe, zu der sie so plötzlich wie unerwartet fähig sind. Der Geist ist dabei unauflösbar an eine Weltlichkeit gebunden, so dass die Einzelbeobachtungen fast immer ihre Unabhängigkeit gegenüber Systematisierungsversuchen bewahren - wenn nötig sogar gegenüber der Kausalität.

9 Für Dostojewskij, dem Harold Bloom „Obskurantismus“ (vgl. Bloom 2006) vorwirft, wohl kaum im Widerspruch zum sprechenden Namen. 
Es führte jedoch ebenso in die Irre, Dostojewskijs Darstellungsprinzip als Charakterkasuistik verstehen zu wollen, denn eben die beständigen Widersprüche zwischen dem, was sich zeigt, und den Interpretationsschemata, die von der Erzählung selbst nahegelegt werden, sowie den Wahrnehmungsrastern der Romanfiguren, ihres Autors wie auch denen der Leser, sind ja die Reaktanden, durch die eine Lektüre von mehr als tausend Seiten dieser Prosa ein exothermes Vergnügen wird.

Als Politiker ist Dostojewskij nicht gerade salonfähig.

Der eingangs erwähnte zwanghafte Wunsch nach dem wahren Christentum, verstanden als verkörpert und nur zu verwirklichen im und durch das auserwählte russische Volk, gepaart mit einem Hass auf alles Westliche im Allgemeinen und Deutsche im Besonderen sowie der obligatorischen imperialistischen Boshaftigkeit gegen die Polen und einem schwer zu bewertenden Antisemitismus ${ }^{10}$, sind für uns, deren Wahrnehmung stark von den Kriegen, Diktaturen und Massenmorden des zwanzigsten Jahrhunderts geprägt ist, schwer zu verdauen - Harold Bloom schafft es, sich auf zehn Buchseiten mindestens dreimal darüber zu echauffieren. ${ }^{11}$ Hierzulande sind gleich mehrere Buchpublikationen zu Dostojewskijs Aufenthalten im deutschsprachigen Raum erschienen; ich habe sie mit Interesse, gleichwohl nur bedingt mit Vergnügen gelesen. Insbesondere die Lektüre der Selbstzeugnisse löst geradezu Depressionen aus, begegnet man doch einem ignoranten, zornigen Mann, der es nicht einmal fertig bringt, originell zu schimpfen, sondern die immergleichen pejorativen Formeln wiederholt, litaneiartig jammernd seine Umwelt kaum $\mathrm{zu}$ registrieren scheint. Das Wetter, die Hotels, die Städte können es ihm nicht recht machen (daran kann auch die Sixtinische Madonna nichts ändern), und als Deutscher hat man sowieso verloren. Sicher, Dostojewskij war lange Zeit nicht freiwillig im Ausland, trug große Sorgen mit sich herum, hatte Gewissensbisse, die ihm den Aufenthalt verleiden mussten. Aber das allein erklärt keine derart beständige, wahrnehmungstrübende Aggression, die irgendwann nur noch ermüdet. Man kann diese Seite Dostojewskijs mit dem Klischee der Widersprüchlichkeit des Genies versehen und in TrotzdemSätzen über die Größe des Schöpfers der Brüder Karamasow sprechen. Ich glaube jedoch, dass genau jene vorgeblich oder tatsächlich unangenehmsten Eigenschaften Dostojewskijs einschließlich seines religiösen „Obskurantismus“ Ursprung jener „vibrierenden Bewusstseinsenergie“ (Bloom) sind, durch die seine Texte bis heute

10 Dostojewskijs Haltung ist durchaus nicht so homogen, wie es beispielsweise Harold Bloom in Genius darstellt; auch hier steht mehrfach die konkrete Wahrnehmung dem ideologischen Muster entgegen (vgl. unter anderem die Aufzeichnung aus einem Totenhaus). Vor allem aber ist der Antisemitismus etwas, das eher wie ein Fremdkörper in diesem zutiefst ethisch motivierten Gesamtwerk wirkt, als dass er einen integralen Bestandteil desselben bildete - ganz im Gegensatz z.B. zu Richard Wagner, bei dem die deutschtümelnden Stoffe seiner Opern ebenso wie der Emotionstotalitarismus, etwa in Gestalt einer süffigen Todesverherrlichung im Tristan, eine bestimmt nicht unbedenkliche Verbindung mit seinen antisemitischen Propagandaschriften (von Dostojewskij gibt es dergleichen nicht!) eingehen.

11 Vgl. Bloom (2006): Genius. 
nichts an Brisanz verloren haben. Aus dem zornigen Mann spricht die nicht literarisierte Version des Kellerlochmenschen in ihrer ganzen abstoßenden Erbärmlichkeit. Aber diese Erbärmlichkeit ist letztlich ein unersetzlicher Baustein im Literarisierungsprozess, dessen erstes Produkt der Kellerlochmensch ist - ein weitaus störrischerer Revolutionär, als es alle Märtyrer des Kommunismus je sein konnten, die sehr reibungslos ihren Platz im Walhalla bzw. Pandämonium der Unterhaltungskultur gefunden haben. Nicht einmal so sehr, weil er nicht zum Helden taugt. Sondern weil sein Hass immer Selbsthass ist und mit diesem Selbsthass Ernst gemacht wird. Das zieht an. So wird es unmöglich, eine klare emotionale Position zu ihm einzunehmen, da man den Charakter des charmelosen Schambolzens, der sich da vor einem windet, nicht wirklich fassen, nicht klar bewerten kann, so abscheulich man einzelne Handlungen finden mag.

Aus solchen Ambivalenzen schöpfen auch die großen Romane Dostojewskijs ihre Kraft, und deshalb ist es unsinnig, den (angeblichen!) slawophilen Fanatiker vom genialen Psychologen trennen zu wollen. Seine bizarren Idiosynkrasien schärfen ihm den Blick, und die infantilen Aggressionsausbrüche können der Nährboden für bahnbrechende Gedanken sein.

Man sollte nicht vergessen, dass eine Menge der Prophezeiungen Dostojewskijs tatsächlich eingetroffen sind. Die Selbstherrlichkeit, mit der die Anhänger einer angeblich fortschrittlichen Ideologie die Menschen nicht nur knechten, sondern auch massenweise umbringen, haben wir im zwanzigsten Jahrhundert zur Genüge erlebt. Doch auch wir „Westler“ leben ja nicht im „Kristallpalast“ oder im Garten Eden der Aufklärung, sondern in einer Leistungsgesellschaft, die - bei allem Luxus, den sie bietet - in weiten Teilen nach sozialdarwinistischen Prinzipien funktioniert. Insbesondere die unselige Verbindung aus kulturalistischem Kreidefressen - was sowohl einige zweifelhafte Dogmen in den geisteswissenschaftichen Disziplinen als auch die politische Korrektheit genannten Auswüchse der für den öffentlichen Raum verbindlichen Redeweise hervorgebracht hat - und quasi-religiösem Glauben an ein undifferenziertes naturwissenschaftliches Weltbild, der sich vom Men's-Health-Artikel, über Feuilletondebatten bis zu den Maßstäben für die Verteilung von Forschungsgeldern zieht, ist durchaus geeignet, einen tiefen Ekel gegenüber der westlichen Welt auszulösen. Überdies braucht man sich nur einmal im Fernsehen einen Werbeblock anzuschauen, um von einem dümmlichen, affirmativen Hedonismus regelrecht erschlagen zu werden. Tagtäglich wird er uns als Norm von einer Wirtschaft eingeprügelt, die einen Großteil ihrer Ressourcen darauf verwendet, belanglose Spielereien als revolutionäre Neuerungen zu verkaufen. Unsere Telefone werden immer smarter, ganz im Gegensatz zu uns. Vielleicht, weil wir uns nicht mehr viel zu sagen haben. Die allgegenwärtige Unverbindlichkeit entzieht den Wörtern jedes Gewicht. Es entsteht dabei jedoch keine federleichte Sprache, sondern alle unsere Aussagen werden porös, die Gedanken zerfallen uns, wenn wir sie in den Mund nehmen - und Stück für Stück zersetzt sich so auch unsere Aufmerksamkeit. Die Sinnesorgane funktionieren reibungslos, aber unsere Wahrnehmung erblindet, weil wir nicht mehr in der 
Lage sind, Sinn zu stiften. Das Ergebnis ist eine Gesellschaft, die in ihren Kernbereichen zunehmend pornographisch ${ }^{12}$ wird. Sie wird es, indem sie einen Kultus der Immanenz pflegt. Der sture Marxist und notorische Christ Terry Eagleton schreibt: „Im Konflikt zwischen dem westlichen Kapitalismus und dem radikalen Islam entspricht der Glaubensmangel auf der einen Seite dem Übermaß an Glauben auf der anderen. Der Westen sieht sich einem metaphysischen Großangriff ausgesetzt, und das zu einer Zeit, da er selbst sozusagen philosophisch abgerüstet hat."13 Es ist jener Mangel an Metaphysik, gegen den Dostojewskij sich mit aller Kraft wehrt - aus einem tiefsitzenden Unbehagen heraus. Dass er sich seinerzeit eine chauvinistische Ideologie als Krücke zurechtzimmert, ist eine Sache. Sie sollte aber ebenso wenig wie das schlechte Beispiel bombenwerfender Taliban dazu verleiten, Metaphysik und Fanatismus bzw. Metaphysik und Irrationalismus gleichzusetzen. Auch der Artikel Eins des Grundgesetzes ist nur, wenn man ihn transzendent betrachtet, also als unhintergehbaren Wert, wirklich so belastbar, dass wir eine Gesellschaft darauf aufbauen können. Die schalen Vokabeln „inakzeptabel“ und „alternativlos“ gehören inzwischen zum Standardvokabular der Politik und demonstrieren deren Kraftlosigkeit. Wir verwalten unsere Freiheit, aber begehren sie nicht mehr, kämpfen nicht mehr um sie. Ein beunruhigender Zustand, der zeigt, wie weit die Romane eines russischen Schriftstellers des 19. Jahrhunderts in unsere unmittelbare Gegenwart hineinreichen. Der Impetus Dostojewskijs ist also keineswegs ein reaktionärer, er ist vielmehr unhintergehbar ambivalent, da er auf eine emphatisch und absolut verstandene Wahrheit zielt, die aber in der unvollkommenen Wirklichkeit entdeckt und verankert werden soll: eine Don Quijoterie vielleicht - in jedem Fall eine unendliche Aufgabe. Für ihn wäre die Würde des Menschen anzutasten, abzutasten, abzuklopfen. Auf Herz und Nieren müsste sie überprüft werden, immer neu. Eben weil sie jederzeit hohl klingen könnte. Immer ist sie gefährdet, brüchig. Nur durch präzise, aber nicht zimperliche Probebohrungen ist ihre Statik, ihre Integrität immer wieder aufs Neue zu sichern. Dostojewskijs mit starkem politischen Sendungsbewusstsein verfassten Romane sind ja keine tausendseitigen Indoktrinationsschriften, sie verlangen zu keinem Zeitpunkt einen bedingungslosen Glauben an irgendetwas. Das Gegenteil, der immer schon präsente Zweifel, ist ihre epistemologische Voraussetzung. Aber sie gehen davon aus, dass es nicht nur lohnt, sondern eine moralische Verpflichtung ist, um den Glauben zu ringen, da er integraler Bestandteil unseres Menschseins, unseres Erkenntnisvermögens ist. Tatsächlich utopistisch sind sie nie. Trotz der etwas sentimentalen Kinderszene am Ende der Brüder Karamasow wird wohl kein Leser auf die Idee kommen, jetzt sei alles in Ordnung und die Zeit der Erlösung durch das christlich-orthodoxe bzw. altgläubige Russland nahe. „[N]ach

12 Ich will hier nicht die Debatte um Wert oder Unwert der Pornographie führen. Mich interessiert allgemeiner der entsubjektivierende, vielleicht auch „verdinglichende“ pornographische Modus, der zum Moloch (Fritz Langs, Allen Ginsbergs) wird, wenn er in den Mittelpunkt eines gesellschaftlich akzeptierten Weltbildes rückt.

13 Terry Eagleton: Der Sinn des Lebens. Berlin 2010, S. 31. 
Ansicht mancher religiöser Menschen macht die Gegenwart Gottes die Welt sogar noch mysteriöser. Wenn er ihr einen Sinn gegeben hat, dann einen ziemlich unverständlichen. Gott ist nicht die Lösung für ein Problem. Durch ihn werden die Dinge eher rätselhafter als klarer. ${ }^{\text {14 }}$

Wer bei dem Gedanken an Gott Unbehagen verspürt, kann einen Schritt weiter gehen, (vorerst) auf das Wort Gott verzichten und stattdessen Transzendenz sagen.

Imre Kertész, der anders als jene deutschen Wegschauer mit ihren sogenannten Naturgedichten, für die diese Bezeichnung als Euphemismus geprägt wurde, tatsächlich Jahrzehnte in der inneren Emigration gelebt hat, betont die fundamentale Bedeutung der Transzendenz für jedes künstlerische Schaffen oder vielmehr Sprechen durch Kunst hindurch; er weiß nur zu gut, dass man weder für sich selbst noch für ein Publikum schreibt, sondern immer in dem - nicht Glauben, nicht Bewusstsein, sondern ... in dem mal sehr unbestimmten, mal sternenhimmelklaren Empfinden schreibt, dass es eine Wahrheit gibt und eine - wenn auch noch so hypothetische Instanz, die sie erkennen kann, für die man dokumentiert, Zeugnis ablegt, so gut es eben mit unseren menschlichen Erkenntnismitteln geht (und es wäre eine unzulässige Selbstbeschneidung, würde man auf das vielleicht stärkste dieser Mittel: die ästhetische Wahrnehmung, verzichten).

Um die Empfindung haben zu können, man müsse Zeugnis ablegen, braucht es jedoch nicht nur das Gericht als anhörende, zuhörende Instanz, sondern es ist auch notwendig, überhaupt an ein wahrnehmendes, denkendes Ich zu glauben, das irgendetwas bezeugen kann: „Geh mit der Kunst in deine allereigenste Enge. Und setze dich frei! “"15 Diese Enge ist immer ein prekärer Ort. Ein inneres Exil. Ein Gefängnis. Eine Bodenlosigkeit. Der Ort des Kellerlochmenschen. Celans für die Dichtung formulierte Forderung kann, muss vielleicht ebenso für die Prosa gelten.

„Auch wer das Unglück hat, in einem Land mit großer Literatur geboren zu sein, muss in seiner Sprache schreiben wie ein tschechischer Jude im Deutschen oder ein Usbeke im Russischen: schreiben wie ein Hund sein Loch buddelt, wie eine Maus ihren Bau gräbt. Dazu ist erst einmal der Ort der eigenen Unterentwicklung zu finden, das eigene Kauderwelsch, die eigene Dritte Welt, die eigene Wüste. "16

Es ist ein verbreiteter Irrtum, ein Romanautor würde seine Phantasie nutzen, um weite Welten zu erschaffen und so das Epische hervorzubringen. Für die wirklich großen Romane gilt das nicht. Sie entstehen aus der Enge, aus der neurotischen Selbsterforschung und unfreiwilligen Selbsterfahrung, aus der Konfrontation mit dem allereigensten, leuchtenden und schmutzigen Detail und gewinnen ihre epische Breite, indem sie von dieser Keimzelle aus die Wahrnehmung, getriggert von mal gezähmter, mal unbändiger Sprachlust, wuchern lassen. Jenes kauzige Buch der ewigen Abschweifung, Laurence Sternes Tristram Shandy, offenbart erst in seinem atem-

14 Ebd., S. 68.

15 Paul Celan: Gesammelte Werke. Bd. 3. Frankfurt am Main 2000, S. 200.

16 Gilles Deleuze, Félix Guattari: Kafka. Für eine kleine Literatur. Frankfurt am Main 1976, S. 27. 
losen Ende rückhaltlos, dass es keineswegs von Witzfiguren handelt, sondern ein geradezu scheherazadeskes Anerzählen gegen den Tod ist. Melvilles Moby Dick ist bestimmt von der Enge, nämlich der unendlichen Verlorenheit des Propheten Jonas im Bauch des Wals. Im sorgfältig geordneten Fatalismus Kafkas muss man die „eigene Wüste" nicht lange suchen. Geradezu die Monumentalversion der Fixierung auf das Allereigenste ist Prousts Recherche, deren berühmter Eingangssatz bereits den Weg ins Innere weist: Was in dem Schlaf für Träume kommen mögen? Und schließlich gilt es auch für Dostojewskij: bezeichnenderweise werden die Aufzeichnungen aus dem Kellerloch als der Wendepunkt zu seinen großen Romanen angesehen. „Die großen Entdeckungen der Literaturgeschichte werden wie das, was wir persönlichen Stil nennen, meist nicht durch berechnende Entwürfe gemacht. Wie in den ,Aufzeichnungen' entstehen diese verblüffenden, befreienden Entdeckungen durch die äußerste Anstrengung eines schöpferischen Autors, der versucht, sich aus einer widersprüchlichen, unerträglichen Lage zu befreien. ${ }^{17}$ Sinnsucht und Spielsucht - denn auch Spieler sind sie im Grunde alle, die Dostojewskijgestalten: Immer wieder erfasst sie der quälende Verdacht, in der Versuchung könnte etwas Wahres liegen -, verdichtet auf engstem Raum, sind der Ursprung seines Schreibens, sie sind der rote Faden, den es in dieser "unsteten“ (Bloom, Genius) Prosa sehr wohl gibt, der jedoch nicht absichtsvoll eingewebt wird, sondern wie ganz von selbst all jene wahnwitzigen Figuren verbindet: eben weil sich ihre radikal unterschiedlichen Ideologien und Gedankengebäude doch aus demselben glühenden Kern entwickeln. Und so, wie das Denken, Fühlen, Handeln der Menschen aus einem metaphysischen Urknall entsteht, aus der plötzlichen Ausdehnung des noch unfassbaren Gefühls- und Gedankenknäuels, der „unerträglichen Lage“ also, gibt es auch in der Dramaturgie häufig eine solche Explosion: In den Bösen Geistern ist es eine Ohrfeige, für die sage und schreibe 260 Seiten Verdichtungsarbeit geleistet werden müssen.

Oft ist in Bezug auf Böse Geister oder Die Brüder Karamasow von Vielstimmigkeit, von Polyphonie gesprochen worden - eine zwar intuitiv nachvollziehbare Beschreibung, die jedoch zentrale Aspekte der Erzähltechnik Dostojewskijs ausblendet.

Ingo Schulzes in den neunziger Jahren erschienenes Buch Simple Stories, vielleicht der erste Wenderoman, erzählt, meine ich, in Stimmen: Die Romanfiguren berichten von sich, ganz wie es der Titel suggeriert, in einem Ton, der stets realistisch bleibt in dem Sinn, dass er plausibel, also der jeweiligen Figur angemessen und niemals elaborierter oder flapsiger ist, als man es vom Sprecher erwarten würde. Eine übergeordnete Instanz gibt es nicht, selbst dort nicht, wo in der dritten Person erzählt wird, es sei denn, man bezeichnete sie als totale Neutralität (die aber nicht übergeordnet sein kann). Ähnlich verhält es sich beim unlängst erschienenen Debüt von Judith Zander, interessanterweise auch eine Geschichte aus der ostdeutschen Provinz.

17 Orhan Pamuk: Wie man Erniedrigung genießt. In: Carl Hegemann (Hg.): Erniedrigung genießen. Kapitalismus und Depression III. Berlin 2001, S. 46. 
Haben vierzig Jahre DDR vielleicht zur Folge, dass das Individuum nur noch als relativer Partikel sprechen kann?

Diese peinlich genaue Vermeidung jeder Konstruktion, die auch nur entfernt an einen auktorialen Gestus erinnern könnte, ist einem Dostojewskij, der wohlgemerkt keinen seiner Romane wirklich auktorial erzählt ${ }^{18}$, jedenfalls völlig fremd; charakteristisch für den „unsteten“ Dostojewskij ist das Mäandern der Perspektive von einer an der Szene beteiligten Person bis hin zur Beinahe-Autonomie der einzelnen Stimmen. Es bleibt jedoch beim Beinahe, denn der emotional teilnehmende Erzähler ist zumindest potentiell immer in der Nähe; wenn er schweigt, dann haben wir ihn noch in Erinnerung oder wittern schon seine Rückkehr auf der nächsten Seite. Das Außergewöhnliche an dieser zentralen Stimme ist, dass sie sich "gelegentlich inkarniert" und dann wieder zur reinen, sinnlichen und affektiven Wahrnehmung wird, die jeden Ort besuchen, den Menschen überallhin folgen kann, aber dabei dicht bei ihnen bleibt, nie abhebt und sich in ein allsehendes Auge verwandelt. $\mathrm{Ob}$ nun aber verkörpert oder vergeistigt, immer ist sie empathisch über die erwartbare Teilnahme eines wohlwollenden Beobachters hinaus. Es ist, als würde stets etwas von den ureigensten Erfahrungen all der Menschen, die sich um sie herum unablässig in Extremzuständen befinden, in ihr nachhallen - und damit ist in ihr auch das Echo der zerrissen-starken Ich-Erzähler Dostojewskijs vernehmbar: des Kellerlochmenschen natürlich, aber auch des Grünen Jungen.

Ich glaube, man kann jene mäandernde Stimme einen transzendenten Erzähler nennen, denn sie ist das Bindeglied zwischen allereigenster Enge und epischer Breite ebenso wie zwischen unmittelbarer, unvermittelter, oftmals überwältigender IchErfahrung und hochsensibler, nach außen gerichteter Wahrnehmung. Sie schenkt uns für Momente die Empfindung, dass Subjekt und Objekt in eins fallen. Sie ist Einladung zur Feier und zugleich feierlicher Ort.

Eine solche Stimme wäre auch unserem Jahrhundert zu wünschen. Was für eine Welt könnte sie uns aus ihrem Kellerloch erschaffen!

18 Was ein auktorialer Erzähler im 19. Jahrhundert tatsächlich sein und leisten kann, aber auch, inwiefern dieser ,Seherblick' für uns wohl heute nicht mehr so recht taugt, zeigt Victor Hugos großer Roman Les Misérables. 
Lutz Keßler

\section{Verbrechen und Strafe in Göttingen}

Notizen zu Thomas Bischoffs Inszenierung in der Spielzeit 2009/2010 am Deutschen Theater in Göttingen

Nicht nur der hochbegabte Jura-Student Rodion Raskolnikow muss „730“ Schritte zurücklegen, um schließlich zu jenem Ort zu gelangen, der ihm Aufschluss darüber geben soll, ob er zu den genialischen Menschen gehört, denen es zum Wohl der Menschheit erlaubt ist, sich über alle Grenzen der Moral und des Rechts hinwegzusetzen. Auch für eine Übertragung dieses großen Romans von Fjodor Dostojewski auf die Bühne sind fast 730 Schritte, bzw. Seiten zu bewältigen. Fast schon programmatisch für das Unterfangen beginnt da Thomas Bischoffs Fassung, die er mit der persönlichen Genehmigung von Swetlana Geier erstellte, wenn er mit dem ersten von Raskolnikow im Roman geäußerten Satz beginnt:

„Auf welches Wagnis will ich mich einlassen und vor welchen Lappalien fürchte ich mich!“

Thomas Bischoff, der am Deutschen Theater in Göttingen zuvor Goethes „Faust“ und Kleists „Familie Schroffenstein“ inszenierte, hat dieses Wagnis in der Spielzeit 2009/2010 akribisch vorbereitet und seine Fassung im Hinblick auf die zum Einsatz kommenden Schauspieler abgestimmt, ihnen die Rollen gewissermaßen auf den Leib geschrieben. Obwohl die Textvorlage mit ihren 46 A4-Seiten im Vergleich zum Roman unverhältnismäßig dünn daherkommt, ist es Bischoff trotzdem gelungen, darin die epische Dimension des Romans, den Weg Raskolnikows von seinen anfänglichen Zweifeln über den Mord bis zum letzten Schritt seiner Verhaftung in knapp vier Stunden nachzuzeichnen. Dabei dient ihm Dostojewskis Antiheld gewissermaßen als "Fackel", als "Leuchtspur" auf dem Weg durch den Roman. Lediglich die Stationen und Figuren werden somit auf der Bühne erhellt, die unmittelbar mit Raskolnikow in Berührung kommen.

Die Fassung besteht zudem ausschließlich aus den den Großteil des Romans bestimmenden wörtlichen Reden, die einer Bühnenadaption sehr entgegen kommen. Hier sieht Bischoff auch einen Schlüssel für seine Aneignung, denn das unaufhörliche Reden, das ewige Schwadronieren und Räsonieren der Figuren ist es ja, was einer Tat, wie sie Raskolnikow beabsichtigt, im Wege steht, bzw. eine ganze Gesellschaft im Würgegriff des Stillstands hält. Aus diesem versucht sich Raskolnikow mit dem Beil einen Fluchtweg zu schlagen und - scheitert. Auch er wird nicht von der Stelle kommen. Isabelle Krötsch hat dafür einen genialen Raum geschaffen, der sich 
blitzschnell, dank dreier mysteriöser „Herren “ in Zylindern, durch den Einsatz leichtbeweglicher Schiebewände verwandeln kann. Raskolnikows Stube, das Büro des Staatsanwalts, die Wohnung der Pfandleiherin oder die offenen Plätze St. Petersburgs, buchstäblich im Handumdrehen und beinahe magisch verwandelt sich der Raum in die jeweils nötigen Schauplätze. Durch diese Organizität vermittelt sich der Eindruck, dass nicht nur die Figuren, sondern auch die Räume immer zu Raskolnikow kommen, während dieser somit auch räumlich bis zum Schluss nicht aus seinem (Denk)Gefängnis herausfinden wird. So steht nicht nur der Protagonist in Dostojewskis Roman unter dem enormen psychischen Druck seiner Tat, sondern auch der Schauspieler Alois Reinhardt, der ihn verkörpert, lässt ihm doch diese Raumstruktur keine Möglichkeit eines - erholenden - Abgangs für die Dauer der Aufführung. Reinhardt gelingt es jedoch mit bewundernswerter Ausdauer und großer psychischer Intensität, die Zuschauer mitzunehmen auf die Reise durch das alptraumhafte Martyrium Raskolnikows. Bischoff verstärkt den Eindruck dieser surrealen Szenerie zusätzlich durch das Hinzufügen einer rätselhaften Figur, die er entsprechend „Die Fremde“ nennt. Paula Hans spielt diesen Engel des Todes, der Raskolnikow als treuer Kompagnon durch den Abend begleitet und ihm immer wieder das Kinderlied vom Soldaten, der in den Krieg zieht und nicht mehr zurückkommt, singt.

„Malborough s'en va-t-en guerre / Ne sait quand reviendra..."

Es ist eines der Lieder, das der kleine Kolja im Auftrag seiner - dem Wahnsinn nahen - Mutter, Katerina Iwanowna singen soll, um Geld zu erbetteln.

Doch nicht nur hier spielt die Musik eine große Rolle. Bischoff hat sich zur Unterstützung seinen langjährigen Bühnenmusiker, FM Einheit, dazugeholt. Der ehemalige Schlagwerker der Einstürzenden Neubauten hat für diese Inszenierung eine durchgängige oft nur beiläufig wahrzunehmende Tonspur von großer suggestiver Sogwirkung geschaffen. Nicht selten entsteht so der Eindruck, man befinde sich unmittelbar im Kopf von Raskolnikow, man könne das Blut in dessen Adern pulsieren, die Herzschläge galoppieren oder seine Gehirnströme hören.

FM Einheit schlägt damit eine musikalisch-klangliche Brücke zwischen der unter der Last seiner Tat oszillierenden und zusammenbrechenden Psyche des Protagonisten und der Wahrnehmung durch den Zuschauer. Alle Bühnenmittel zielen bei Bischoff unmittelbar auf das emotionale Zentrum der Zuschauer. Unterstützt wird diese wirkungsästhetische Absicht zudem über schemenhafte Bildprojektionen auf den halbtransparenten Wänden, die mit assoziativen Bildern die surreale Atmosphäre der verschiedenen ineinander "fließenden“ Räume noch verstärken.

Lässt man sich darauf ein, entfaltet Bischoffs Inszenierung eine einzigartige Sogkraft von geradezu hypnotischer, fieberhafter Qualität, die den Zuschauer mitnimmt auf einen emotionalen auf die Perspektive Raskolnikows fokussierten Trip durch den Roman. Erst am Ende holt Bischoff die Zuschauer wieder auf den Boden der Realität zurück, indem er sich eine winzige Abweichung vom Roman erlaubt, jedoch mit gravierenden Folgen. Dunja, die den Gutsbesitzer Swidrigailow gegen Ende des Romans mit einer Pistole bedroht, darf bei Bischoff noch einen zweiten 
Schuss abfeuern, der tödlich ist. Und damit endet der Abend wie er begonnen hat, mit einem Mord. Und während wir sehen, wie sich Raskolnikow freiwillig der Justiz überstellt, macht sich die „Fremde“ auf den Weg zu Dunja und singt ihr ihr trauriges Lied. Ein Einzelner, so die offensichtliche Botschaft, lässt sich vielleicht retten, aber das Verbrechen lässt sich nicht ausrotten, solange die Verhältnisse sind wie sie sind. 
Auszug aus Thomas Bischoffs Spielfassung als Grundlage seiner Inszenierung von

\section{FJODOR DOSTOJEWSKIJ}

\section{VERBRECHEN UND STRAFE}

In der Übersetzung von Swetlana Geier

Deutsches Theater Göttingen

03/04.2010 


\section{Namen/Rollen}

[1] Rodion Romanowitsch Raskolnikow (Rodja, Rod'ka, Romanytsch)

\section{ALOIS REINHARDT}

[2] Pulcherija Alexandrowna Raskolnikowa, seine Mutter / Aljona Iwanowna

(Beamtenwitwe, Pfandleiherin) / Amalija Fjodorowna Lippenwechsel (Wirtin)

\section{INGRID DOMANN 1. Doppelrolle}

[3] Awdotja Romanowna Raskolnikowa, seine Schwester (Dunja, Dunetschka)

\section{MARIE-ISABEL WALKE}

[4] Dmitrij Prokofjitsch Rasumichin, Student

\section{PHILIP HAGMANN}

[5] Sossimow, Arzt / Andrej Semjonowitsch Lebesjatnikow, Ministerialbeamter

\section{DANIEL SELLIER 2. Doppelrolle}

[6] Porfirij Petrowitsch (Familienname nicht angegeben), Ermittelnder Staatsanwalt / Ilja Petrowitsch, Polizeileutnant

\section{PAUL WENNING 3. Doppelrolle}

[7] Arkadij Iwanowitsch Swidrigailow, Gutsbesitzer / Nikodim Fomitsch, Polizeiinspektor / Koch, ein Kunde von Aljona Iwanowna / Kaufmannsgehilfe

\section{BENJAMIN BERGER 4. Doppelrolle}

[8] Pjotr Petrowitsch Luschin, Hofrat

\section{FLORIAN EPPINGER}

[9] Semjon Sacharytsch Marmeladow, Titularrat a. D. / Seltsamer Mann

\section{MEINOLF STEINER 5. Doppelrolle}

[10] Katerina Iwanowna Marmeladowa, seine zweite Frau

\section{JULIA HANSEN}

[11] Sofja Semjonowna Marmeladowa, seine Tochter aus erster Ehe (Sonja, Sonetschka)

\section{SYBILLE WEISER}

[12] Nikolaj Dementjew, Anstreicher (Mikolka) / Hausdiener / Schreiber / Pestrjakow (Student)

\section{GERD ZINK 6. Doppelrolle}

Leierkastenmann

Tochter des Leierkastenmannes PAULA HANS

3 Gäste (Statisterie) 


\section{Szene 1}

VIDEO/Mord: Von Raskolnikow werden Aljona und Lisaweta Iwanowna mit dem Beil erschlagen; beraubt sie. Rodin Romanowitsch Raskolnikow allein; Straße (offener Raum).

\section{Raskolnikow}

Auf welches Wagnis will ich mich einlassen und vor welchen Lappalien fürchte ich mich! Alles hat der Mensch in der Hand, und alles läßt er sich vor der Nase wegschnappen, aus purer Feigheit ... Das ist ein Axiom ... Wovor fürchten sich die Menschen am meisten? Vor einem neuen Schritt, vor einem neuen eigenen Wort, davor fürchten sie sich am meisten ... Übrigens rede ich viel zu viel. Deshalb handle ich auch nicht, weil ich rede. Allerdings kann es auch sein: Ich rede weil ich nicht handle. Also wozu gehe ich jetzt dorthin? Kann ich das etwa tun? Ist es mir damit etwa ernst? Es ist mir damit keineswegs ernst. Einfach so, Phantasie, ich mache mir selbst etwas vor; Spielerei! Ja, es wird wohl Spielerei sein! Spielerei!

\section{Szene 1/1}

Ein Seltsamer Mann, Marmeladow, geht vorbei. Er ruft im vorbeigehen:

\section{Marmeladow}

(Lachend:) Hast ja 'n deutschen Hut auf! Hast ja 'n deutschen Hut auf!

\section{Szene $1 / 2$}

\section{Raskolnikow}

Ich wußte es ja, ich habe es mir ja gedacht! Das ist das allerschlimmste! Eine solche Dummheit, eine ganz banale Kleinigkeit kann den ganzen Plan zunichte machen. Kleinigkeiten verderben immer alles! Ja, der Hut ist auffällig. Kein Mensch trägt einen solchen Hut, man erkennt ihn auf eine $\mathrm{Werst}^{1}$, und man erinnert sich an ihn ... das ist die Hauptsache, man erinnert sich später an ihn, und schon hat man ein Indiz ... ein Indiz!

Raskolnikow zählt die Schritte. Umbau (Zimmer von Aljona Iwanowna); er steht vor einer Tür. Klopf. Zögert und zögert. Klopft. Die Tür wird geöffnet von Aljona Iwanowna (Pfandleiherin). Raskolnikow tritt ein, nimmt den Hut ab.

\section{Szene 2}

\section{Raskolnikow}

Raskolnikow, Student. Vor einem Monat war ich schon einmal bei Ihnen.

\section{Aljona Iwanowna}

Ich weiß, mein Guter, ich weiß sehr wohl, daß Sie bei mir waren.

1 Russ. Längenmaß, 1,067 km 


\section{Raskolnikow}

Also, und jetzt wieder mit dem gleichen Anliegen. (Überreicht ihr eine silberne Uhr/ Taschenuhr.) Hier, ich möchte etwas versetzen!

\section{Aljona Iwanowna}

Aber auch das alte Pfand ist bereits fällig, seit vorgestern ist der Monat um.

\section{Raskolnikow}

Ich werde die Zinsen für einen weiteren Monat zahlen: gedulden Sie sich.

\section{Aljona Iwanowna}

Das liegt ganz bei mir, mein Guter, ob ich mich gedulde oder Ihr Pfand sogleich verkaufe.

\section{Raskolnikow}

Wieviel geben Sie für die Uhr, Aljona Iwanowna?

\section{Aljona Iwanowna}

Sie ist nichts wert.

\section{Raskolnikow}

Geben Sie vier Rubel, ich werde sie wieder auslösen, die Uhr ist von meinem Vater. Ich werde bald zu Geld kommen.

\section{Aljona Iwanowna}

Anderthalb Rubel und die Zinsen im voraus, wenn sie wünschen.

\section{Raskolnikow}

(Leise, wütend.) Geben Sie her! (Aljona Iwanowna zieht ein Schlüsselbund aus der Tasche und geht das Geld holen; Raskolnikow zieht aus der Manteltasche Bleistift und Papier, er macht sich hastig Notizen. Aljona Iwanowna kehrt zurück.)

\section{Aljona Iwanowna}

Also, mein Guter: Zehn Kopeken pro Rubel und Monat macht für anderthalb Rubel fünfzehn Kopeken - für einen Monat im voraus. Für die zwei ersten Rubel stehen nach derselben Berechnung weitere zwanzig Kopeken aus. Insgesamt also fünfunddreißig. Sie haben demnach für Ihre Uhr einen Rubel, fünfzehn Kopeken zu erhalten.

\section{Raskolnikow}

(Er nimmt das Geld ohne Widerspruch.) Ich werde Ihnen vielleicht in den nächsten Tagen noch etwas bringen ... Silber ... ein Zigarettenetui ... Und Sie sind immer allein zu Hause, Ihre Schwester ist wohl nie da?

\section{Aljona Iwanowna}

Was wünschen Sie von Ihr?

\section{Raskolnikow}

Nichts Besonderes. Ich frage nur so. Aber Sie denken gleich ... Leben Sie wohl, Aljona Iwanowna! Ich werde Ihnen vielleicht in den nächsten Tagen noch etwas bringen...

Raskolnikow zählt die Schritte/Umbau (offener Raum); Marmeladow im Hintergrund, geht auf ihn $z u$. 


\section{Szene 3}

\section{Raskolnikow}

O mein Gott! Wie widerlich ist das alles! Ist es möglich, auf so etwas Entsetzliches zu verfallen? Wessen ist mein Herz nicht alles fähig! Vor allem: schmutzig, ekelhaft, widerwärtig, widerwärtig! Pfui Teufel, was für eine Erbärmlichkeit!

\section{Marmeladow}

(Scheinbar betrunken; trägt eine Flasche Wodka in der Hand.) Ist es erlaubt, mein Herr, Sie mit allem gebührenden Anstand anzusprechen? Denn obwohl Ihr Aufzug nichts von Ihrer Bedeutung verrät, so erkennt mein erfahrener Blick in Ihnen einen Menschen von Bildung. Habe selbst immer höchste Verehrung für Bildung empfunden und stehe überdies im Range eines Titularrats. Ist die Frage erlaubt: Waren der Herr Beamter?

\section{Raskolnikow}

Nein, ich studiere.

\section{Marmeladow}

Das dachte ich mir gleich! Sie waren Student, Sie hatten sich also den Wissenschaften ... Doch erlauben Sie mir ... Mein Herr ... Armut ist keine ... Aber bettelarm, mein Herr, bettelarm sein, das ist eine Sünde. Sind Sie arm - gehen Sie der Würde der Ihnen angeborenen Gefühle nicht verlustig. Sind Sie aber bettelarm - immer und in jedem Fall! Bin ich erst bettelarm, bin ich als erster bereit, mich selbst zu beleidigen ... Meine Tochter geht mit dem

[Marmeladow] Gelben Billet ${ }^{2}$... Und daher das Trinken! [Mein Herr, es ist einen Monat her daß meine Gattin von Herrn Lebesjatnikow tätlich angegriffen wurde ... Mein Herr, befanden Sie sich schon in der Lage, auf der Newa, auf den Heukähnnen zun nächtigen?

\section{Raskolnikow}

Nein. Wieso?

Marmeladow

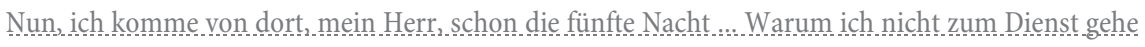
... Als Herr Lebesjatnikow meine Gemahlin eigenhändig prügelte und ich betrunken dalag .... Nun wohl, ich mag ein Schwein sein, sie aber ist eine Dame! Ich habe das Bild des Tieres angenommen, Katerina Iwanowna dagegen meine Gemahlin, ist eine gebildete Person und wurde als Tochter eines Stabsoffiziers geboren. Sie ist auf Grund ihrer Erziehung von edelsten Gefühlen erfüllt ... Indessen ... Und obwohl ich ja selbst einsehe, daß sie, wenn sie mich an den Haaren reißt ... Wissen Sie, Verehrtester daß ich sogar ihre Strümpfe versoffen habe? Nicht ihre Schuhe, denn das wäre wenigstens irgendwie zu erklären, aber die Strümpfe ausgerechnet ... Ihr Umlegetuch aus Ziegenhaar habe ich versoffen, ihr Eigentum, nicht meines ... sie hat sich erkältet und hustet inzwischen Blut ... Wir haben .....(Faßt ihn an.) Und ich fühle das alles mit! Und je mehr ich trinke, desto tiefer fühle ich mit. Deshalb trinke ich ja weil ich im Trinken Mitleid und Gefühl suche .:: Weil ich noch einmal so tief leiden will! (Läßt von ihm ab; wie verwandelt.).] In Ihrem Gesicht

2 polizeilicher Ausweis der Prostituierten

$3 \underline{\text { xxxxxxx}}]$ Kürzungen 
lese ich etwas wie Gram! Sie sollen wissen, daß meine Gemahlin in einem Pensionat für junge Damen aus Adelsfamilien erzogen wurde und sie scheuert eigenhändig die Dielen und lebt nur von trocken Brot, [aber Mißachtung duldet sie nicht. Darum wollte sie auch gegen die Grobheiten des Herrn $]^{4}$... Sie war schon Witwe, als ich sie heiratete, mit drei Kindern ... Das läßt erkennen, wie groß ihre Not gewesen sein muß! Ein ganzes Jahr lang erfüllte ich treu und heilig meine Pflicht und rührte die Flasche nicht an. Aber auch damit konnte ich vor ihren Augen keine Gnade finden; da verlor ich auch noch meine Stelle, ebenfalls nicht durch eigene Schuld ... Und hier bekam ich eine Stelle ... Ich bekam sie, um sie sofort wieder zu verlieren. Diesmal verlor ich sie durch eigenes Verschulden ... (Verweist auf die Flasche.) Wir logieren jetzt in einer Zimmerecke, bei Amalija Fjodorowna Lippenwechsel, unserer Wirtin. Aber wovon wir leben und wovon wir die Miete bezahlen, das weiß ich nicht ... Ja ... Unterdessen war mein Töchterchen, Sonja, sie ist so still ... hellblond, das Gesichtchen immer bleich und mager ... aus erster Ehe, mein Herr, herangewachsen ... Und hier die hungrigen Kinder ... Und hier ringt Katerina Iwanowna die Hände ... Ich lag damals betrunken da und hörte, wie meine Sonja sagt: >Wie, soll ich das denn wirklich tun?< Denn Darja Franzowna, ein übeltätiges und der Polizei sattsam bekanntes Frauenzimmer, hatte schon dreimal durch unsere Wirtin fragen lassen. >Warum denn nicht? < antwortete Katerina Iwanowna. Ich sah, wie Sonetschka aus dem Haus ging und nach acht wieder zurückkam und schweigend dreißig Rubel auf den Tisch legte. Sie sprach kein Wort, die schmalen Schultern, ja, der ganze Körper zitterte. Darauf war meine Tochter gezwungen, das Gelbe Billet $\mathrm{zu}$ nehmen und konnte infolgedessen nicht länger bei uns bleiben. Und nun besucht uns Sonetschka in der Dämmerung, hilft Katerina Iwanowna und versorgt sie nach Kräften mit Geld ... Sie wohnt bei dem Schneider Kapernaumow, sie hat dort ein Zimmer gemietet ... (Kichert und tanzt.) Semjon Sacharytsch ist wieder im Dienst und bezieht Gehalt, er sprach bei seiner Exzellenz persönlich vor, und seine Exellenz kamen persönlich heraus, geboten allen zu warten, nahmen Semjon Sacharytsch Marmeladow bei der Hand und führten ihn an allen anderen vorbei in ihr Kabinett! Und als ich Katerina Iwanowna, es sind sechs Tage her, mein erstes Gehalt brachte, da nannte sie mich Goldkäferchen ... > $>$ Goldkäferchen! $<$, sagte sie ... Und im Verlauf jenes [Marmeladow] paradiesischen Tages gab ich mich flüchtigen Träumen hin: wie ich die Kinderchen kleiden und ihr den Frieden geben und meine Tochter aus der Schande in den Schoß der Familie zurückführen würde ... Das ist erlaubt, mein Herr. Und nun, mein Herr, schon am folgenden Tag nach diesen Träumen entwendete ich den Schlüssel zu ihrer Truhe, nahm alles, was von dem heimgebrachten Gehalt übrig war ... Seit fünf Tagen war ich nicht mehr zu Hause ... Und alles ist aus! ... Sag, mein Guter, hast du Erbarmen mit mir oder nicht? He-he-he-he! ... (Erschöpft.) Bringen Sie mich nach Hause ... Haus Kosel, im Hinterhof. Es wird Zeit ... Herr, Dein Reich komme!

$4[\underline{\operatorname{xxxxxxx}}]$ Kürzungen 
Katerina Iwanowna und Sonja sind aufgetreten. Marmeladow kniet nieder als er sie entdeckt; jammernd, murmelnd, sich schützend. Raskolnikow kann den Blick von Sonja nicht nehmen.

\section{Szene 3/1}

\section{Katerina Iwanowna}

(Schreiend, hustend.) Da bist du! Zuchthäusler, Unmensch ... Wo ist das Geld? Was hast du in der Tasche, zeig her! Wo ist das Geld! Sprich! ... Wo ist das Geld? ... O Gott, hat er denn alles vertrunken! Es waren noch zwölf Silberrubel in der Truhe! ... Versoffen! Alles, alles versoffen! Und die Kinder sind hungrig! ... Hungrig! ... Hast du mit ihm gesoffen? Du hast es getan! Du hast es getan! (Katerina Iwanowna zerrt Marmeladow mit sich; Raskolnikow gibt Sonja verschämt sein letztes Geld.)

\section{Marmeladow}

Es wird Zeit ... Es wird Zeit ...

Raskolnikow zählt die Schritte/Umbau (Zimmer von Raskolnikows); allein. Er findet den Brief seiner Mutter (Pulcherija Raskolnikowa); er öffnet ihn, zig Blätter fallen auf den Boden. Er liest.

\section{Szene 4}

\section{Simultan}

\section{Pulcherija Raskolnikowa}

Mein Rodja! ... Du weißt, wie sehr ich Dich liebe, Du bist unser (mein und Dunjas) ein und alles, unsere Hoffnung, unsere Zuversicht. Wie war mir, als ich erfuhr, daß $\mathrm{Du}$ bereits vor Monaten die Universität verlassen mußtest, weil du Deinen Lebensunterhalt nicht mehr bestreiten konntest ... (Stille.) Die fünfzehn Rubel, die ich Dir vor vier Monaten schickte, hatte ich, wie Du weißt, auf meine nämliche Pension geborgt ... Aber nachdem ich das Recht, meine Pension in Empfang zu nehmen, abgetreten hatte, mußte ich warten, bis meine Schuld getilgt war, was soeben geschehen ist, so daß ich Dir die ganze Zeit nichts mehr schicken konnte ... (Stille.) Kannst Du Dir vorstellen, lieber Rodja, daß Deine Schwester seit nunmehr seit anderthalb Monaten bei mir ist und daß wir uns auch künftig nicht mehr trennen werden? Dem Herrn sei gedankt, daß ihr Martyrium ein Ende genommen hat ... Was wir bis jetzt vor Dir verheimlich haben: Die Hauptschwierigkeit bestand darin, daß Dunetschka, als sie im vorigen Jahr die Stelle einer Gouvernante im Hause Swidrigajlow antrat, ganze hundert Rubel als Vorschuß erhielt und sie die Stelle unmöglich aufgeben konnte, bevor diese Schuld nicht bezahlt war. Die Summe aber hatte sie sich vor allem deshalb vorstrecken lassen, um Dir jene sechzig Rubel $\mathrm{zu}$ schicken, die Du damals so dringend brauchtest ... Stell Dir vor, Herr Swidrigajlow, dieser sonderbare Mensch war schon seit langem in Leidenschaft für Dunetschka entbrannt, was er aber unter der Maske von Grobheit und Geringschätzung zu verstecken trachtete! Vielleicht schämte er sich ... (Stille.) Schließlich vermochte er sich doch nicht mehr zu beherrschen und erlaubte sich, Dunja einen eindeutigen und niedrigen Antrag zu machen ... Marfa Petrowna belauschte ihren 
Gatten zufällig, als er Deine Schwester im [Pulcherija Raskolnikowa] Garten bestürmte, legte alles falsch aus ... sie hat Dunja sogar geschlagen ... (Stille.) Ich wagte nicht, Dir zu schreiben, Dunetschka hat es mir verboten ... Man klatschte in der ganzen Stadt über die Geschichte. All unsere Bekannten zogen sich von uns zurück ... Das alles war das Werk Marfa Petrownas, der es inzwischen gelungen war, Dunja in allen Häusern zu beschuldigen und zu beschimpfen ... Doch Herr Swidrigajlow kam zur Besinnung und legte Beweise für Dunetschkas völlige Unschuld vor. Nämlich den Brief, welchen Dunja zu schreiben und ihm zu überreichen sich genötigt sah ... In diesem Brief tadelte sie ihn mit größter, glühendster Entrüstung ... Marfa Petrowna war auf das tiefste und $>$ von neuem tödlich getroffen $<$, wie sie uns beteuerte ... Noch an demselben Morgen, fuhr sie, ohne zu säumen, von uns aus in der ganzen Stadt von Haus zu Haus, stellte überall in den schmeichelhaftesten Ausdrücke, weinend, Dunetschkas Ehre wieder her ... (Stille.) Du mußt wissen, mein lieber Rodja, daß Dunja um ihre Hand gebeten worden ist und daß sie bereits ihr Jawort gegeben hat ... Er ist bereits Hofrat, Pjotr Petrowitsch Luschin, ein entfernter Verwandter Marfa Petrownas ... Er ist ein tüchtiger und vielbeschäftigter Mann und eilt jetzt nach Petersburg ... Ich möchte Dich im voraus bitten, wenn Du mit ihm zusammentriffst, was in Kürze geschehen wird, nicht vorschnell und hitzig über ihn urteilst ... (Stille.) Zum Beispiel äußerte er, daß er sich vorgenommen habe, nur ein ehrbares Mädchen ohne Mitgift, welches die Not kennengelernt hätte, zu ehelichen, denn der Mann, so erklärte er uns, solle seiner Frau durch nichts verpflichtet sein, und es sei weit besser, wenn die Frau ihren Mann als ihren Wohltäter betrachte ... (Stille.) Er beabsichtigt, in Petersburg eine Anwaltskanzlei zu eröffnen. Also kann er auch Dir sehr nützlich sein, sogar in allem, und Dunja und ich meinen, daß Du sogar schon jetzt Deine künftige Karriere als begonnen und Deine Zukunft als gesichert ansehen kannst ... (Stille.) Dunja träumt von nichts anderem ... Sozius Pjotr Petrowitschs, um so mehr, als Du selbst ja an der juristischen Fakutät studierst ... (Stille.) Dunja ist fest überzeugt, daß sie durch ihren guten Einfluß auf ihren zukünftigen Gatten alles erreichen wird ... (Stille.) Du sollst wissen, mein liebes Kind, daß wir alle uns nach fast dreijähriger Trennung vielleicht sehr bald wiedersehen. Es ist bereits beschlossene Sache, daß ich und Dunja nach Petersburg reisen werden ... Wir werden seelenruhig in der dritten Klasse voyagieren. Also wird es mir gelingen, dir nicht fünfundzwanzig, sondern (ziemlich sicher) ganze dreißig Rubel zukommen zu lassen ...

Sie geht.

\section{Raskolnikow}

(Außer sich vor Zorn.) Nein, Mama, wäre Herr Luschin von Kopf bis Fuß gediegenes Gold oder reiner Diamant, das hätte sie nicht bewegt, die legitime Konkubine dieses Herrn zu werden! Aber für den Bruder, für die Mutter ist sie bereit, sich zu verkaufen! Alles zu verkaufen! ... Nein Dunja, es soll euch nicht gelingen, mich zu 
hintergehen! Diese Heirat kommt nicht zustande! Wie sollte man um dieses Erstgeborenen willen nicht sogar die Tochter opfern, Mutter! Ich will euer Opfer nicht, Dunetschka! Ich nehme euer Opfer nicht an, Mutter!

Verliert sich in seiner Vision.

Szene 4/1

\section{Traum/Vision}

\section{Raskolnikow}

(Im Wahn, aggressiv.) Steigt auf! Alle mitfahren! Aber sie ist doch bestimmt zehn Jahre nicht mal mehr Trab gelaufen! Aber jetzt! Aber jetzt! Hüh! Hüh! Papa, was tun sie? Sie schlagen das Pferdchen! Wir wollen gehen! Sie sind betrunken, sie machen Unfug. Papa, das arme [Raskolnikow] Pferdchen! Sie gehört mir! Ich kann machen, was ich will! Ich will, daß sie galoppiert! Hüh! Aufs Maul! Peitscht sie auf die Augen, auf die Augen! Papa, er schlägt sie tot! Ach Papa! Wofür haben sie das arme Pferdchen erschlagen! Bauern! Bauern! Sie sind betrunken!

Seltsamer Mann (Marmeladow), der in sein Zimmer eintritt und Raskolnikow anspricht, als kenne er ihn, als hätten sie ein Gespräch unterbrochen, das der Mann jetzt weiterführt.

\section{Szene $4 / 2$}

\section{Seltsamer Mann}

Lisaweta, sie ist etwas Besonders. Ihr Lächeln ist sogar schön. Diese verdammte Alte könnte ich ermorden und ausrauben, und zwar ohne die leisesten Gewissensbisse, das schwör' ich dir! Also ... Auf der einen Seite ein dummes, unnützes, nichtswürdiges, böses und krankes altes Weib, das kein Mensch braucht und das, im Gegenteil, alle schädigt und das morgen sowieso sterben wird. Auf der anderen Seite junge, frische Kräfte, die einfach zugrunde gehen, weil es für sie keine Hilfe gibt, und zwar zu Tausenden, und überall! Dutzende von Familien, die vor Verfall, Zersetzung, Untergang, Laster, die vor Geschlechtskrankheiten und Siechenhäusern mit dem Geld der Alten, das einem Kloster zufallen wird, gerettet werden könnten. Wird ein allerwinzigstes Verbrechen durch tausende von guten Taten wettgemacht? Ein Tod gegen hundert Leben - das ist doch Arithmetik! (Er geht wie er gekommen ist.)

Raskolnikow, der wieder zu sich selbst findet, packt hastig das Pfand ein: Schachtel in Schachtel. Er sucht und findet das Beil - er probiert, wie er es unter seinem Mantel verstecken kann. Ein Glockenturm schlägt 5 Uhr. 
Szene 4/3

\section{Raskolnikow}

(Murmelnd, dann schreiend, dann wieder murmelnd.) Bald sieben! Bald sieben! Mein Gott! Also meinetwegen, ich gehe eben mal hin und probiere es, man kann doch nicht ewig träumen! (Er nimmt seinen Hut, betrachtet ihn.) Mein Gott! Ich hab' ihn nicht durch eine Mütze ersetzt! Ich hab’ ihn nicht durch eine Mütze ersetzt! ...

Raskolnikow zählt die Schritte/Umbau (Zimmer von Aljona Iwanowna); er steht vor einer Tür. Klopf. Zögert und zögert. Klopft. Die Tür wird geöffnet von Aljona Iwanowna (Pfandleiherin). Raskolnikow tritt ein, nimmt den Hut ab. VIDEO/Mord. Es klopft an der Tür; Koch und der Studenten Pestrjakow. Raskolnikow erstarrt.

\section{Szene 4/4}

\section{Koch}

(Läutet, klopft an die Tür.) Was soll denn das? Pennen die oder hat sie jemand abgemurkst? Verdammte Weiber! ... He, Aljona Iwanowna, alte Hexe! Lisaweta Iwanowna, schönste aller Frauen! Schlafen die etwa, die verdammten Weiber?

\section{Pestrjakow}

(Hinzukommend.) Ist wirklich keiner zu Hause? ... Guten Tag! Ich komme geschäftlich.

\section{Koch}

Ich auch, mein Lieber, ich auch!

\section{Pestrjakow}

Ich hatte gehofft, Geld aufzutreiben ... Hier, sehen Sie mal: Die Tür bewegt sich ja, wenn man rüttelt!

Koch

Ja und?

\section{Pestrjakow}

Das heißt, daß sie nicht abgeschlossen ist, sondern verriegelt, vielmehr, der Haken ist vorgelegt. Hören Sie, wie der Haken rappelt?

\section{Koch}

\section{Und?}

\section{Pestrjakow}

Begreifen Sie denn nicht? Dann muß doch eine von ihnen zu Hause sein. Um den Haken von innen vorzulegen, muß man doch zu Hause sein, begreifen Sie? Die sitzen da drin und machen nicht auf!

\section{Koch}

Wahrhaftig! Was fällt denen denn ein?

\section{Pestrjakow}

Irgendwas stimmt hier nicht ... Warten Sie! Bleiben Sie lieber hier, ich laufe allein runter und hole den Hausknecht. 


\section{Koch}

Warum soll ich denn hierbleiben!

\section{Pestrjakow}

Wer weiß? ... Die beiden sind entweder ohnmächtig oder ...

\section{Koch}

Oder was?

\section{Pestrjakow}

Ich will ermittelnder Staatsanwalt werden! Das ist klar, ganz klar, hier stimmt etwas nicht! Geht ab. (Koch wartet. Er wird ungeduldig.)

\section{Koch}

Wo bleibt er nur, hol ihn der Teufel!

Geht ab. Raskolnikow flieht; betrachtet die Beute - versteckt sie; zählt die Schritte (versetzter Umbau zu Raskolnikows Zimmer).

\section{Szene 5}

\section{Simultan/Umbau}

\section{Seltsamer Mann}

Steigt auf! Alle mitfahren! Hüh! Hüh! Sie gehört mir! Ich kann machen, was ich will! Ich will, daß sie galoppiert! Hüh! Aufs Mau!! Peitscht sie auf die Augen, auf die Augen!

\section{Szene 6}

\section{Raskolnikow}

(Versteckt die Beute; untersucht seine Kleidung.) Flecken! Tatsächlich - Flecken! Wohin? ... Ich werfe alles weg. Ja, am besten werfe ich alles weg! ... (Zeit; er ist wie gelähmt.) Und zwar sofort! ... Augenblicklich, unverzüglich! ...

Der Hausdiener klopft.

\section{Szene 6/1}

\section{Hausdiener}

Mach auf! ... Den lieben langen Tag döst er vor sich hin, wie 'n Köter! Ein richtiger Köter! Mach endlich auf!

\section{Raskolnikow}

(Öffnet.) Was wollen Sie?

\section{Hausdiener}

Eine Vorladung, aus dem Bureau.

\section{Raskolnikow}

Aus welchem Bureau?

\section{Hausdiener}

Von der Polizei, Sie werden also vorgeladen, aufs Bureau. Ist doch klar, was für ein Bureau. 


\section{Raskolnikow}

Wieso?

\section{Hausdiener}

Woher soll ich das wissen. Wenn sie einen vorladen, muß man hin. Im Abgehen, flüsternd: Peitscht sie auf die Augen, auf die Augen!... Auf die Augen ... die Augen!

\section{Raskolnikow}

(Allein.) Ich gehe hin: ich gehe sofort hin! ... Die Flecken sind da, aber sie fallen kaum auf; alles ist schmutzig, verwischt und bereits verblaßt ... verblaßt ... Wenn man es nicht schon weiß, wird man nichts erkennen ... Alles Konvention, alles relativ und alles bloß Formsache. Formsache! ... Das ist eine Falle! Sie wollen mich in eine Falle locken und plötzlich überführen! Wenn sie mich fragen, werde ich es ihnen vielleicht sagen ... Ich werde eintreten, ich werde mich auf die Knie werfen und alles erzählen ... erzählen! ... Hüh! Hüh! Hüh! Hüh! Aufs Maul! Peitscht sie auf die Augen, auf die Augen!

Raskolnikow zählt die Schritte/Umbau (Polizei-Bureau). Im Bureau befinden sich Nikodim Fomitsch (Vorsteher), Ilja Petrowitsch (Stellvertreter), Schreiber, Koch, Pestrjakow (Tische; Stühle).

\section{Szene 7}

\section{Nikodim Fomitsch}

(Im Gespräch mit Ilja Petrowitsch - ̈̈ber Raskolnikow hinweg; er hört zu.) ... Ausgeschlossen, sie werden beide wieder auf freien Fuß gesetzt. Erstens, lauter Widersprüche: Wozu rufen sie den Hausknecht, wenn sie die Täter sind? Etwa, um sich selbst zu überführen? Und zweitens haben beide Hausknechte und eine Frau den Studenten Pestrjakow in der Toreinfahrt gesehen, genau in dem Augenblick, als er hereinkam: Er war in Gesellschaft von drei Freunden, verabschiedete sich von ihnen unmittelbar vor der Toreinfahrt und fragte bei den Hausknechten nach der Wohnung, alles noch in Gegenwart seiner Bekannten. Hätte er nach der Wohnung gefragt, wenn er mit solcher Absicht gekommen wäre? Und auch Koch saß, bevor er die Alte aufsuchen wollte, eine halbe Stunde lang unten beim Silberschmied und ist erst dann, genau viertel vor acht, zu der Alten hinauf. Und nun überlegen Sie ...

\section{Ilja Petrowitsch}

Aber erlauben Sie, da liegt ein Widerspruch vor: Die beiden behaupten doch, daß sie geklopft hätten und daß die Tür zugesperrt gewesen sei, aber drei Minuten später, als sie mit dem Hausknecht zurückkamen, stellte sich heraus, daß die Tür nicht zugesperrt war?

\section{Nikodim Fomitsch}

Der Mörder war zweifellos in der Wohnung und hatte den Haken vorgelegt; und zweifellos hätten sie ihn dort erwischt, wenn Koch nicht die Dummheit begangen hätte, selbst herunterzugehen, um den Hausknecht zu holen. Und in der Zwischenzeit gelang es ihm, die Treppe hinunterzulaufen und auf irgendeine Weise an ihnen vorbeizuschlüpfen ... 


\section{Ilja Petrowitsch}

Und den Mörder hat niemand gesehen?

Nikodim Fomitsch

Wie sollte ihn jemand gesehen haben? Dieses Haus ist eine Arche Noah ... (Raskolnikow verliert im >Fieber< fast die Besinnung.) Was haben Sie, sind Sie krank?

\section{Raskolnikow}

Seit gestern ...

\section{Ilja Petrowitsch}

(Als wüßßte er alles.) Sind Sie gestern ausgegangen?

\section{Raskolnikow}

Ich bin ausgegangen.

\section{Ilja Petrowitsch}

Obwohl Sie krank waren?

\section{Raskolnikow}

Obwohl ich krank war.

\section{Ilja Petrowitsch}

Um wie viel Uhr?

\section{Raskolnikow}

Zwischen sieben und acht Uhr abends.

\section{Ilja Petrowitsch}

Und wohin, wenn man fragen darf?

\section{Raskolnikow}

Auf die Straße.

\section{Nikodim Fomitsch}

Er kann sich ja kaum auf den Beinen halten ...

\section{Ilja Petrowitsch}

Das hat nichts zu sagen; das hat nichts zu sagen ... Wir möchten Sie nicht länger aufhalten ...

Raskolnikow zählt die Schritte/Umbau (offener Raum); allein. Rasumichin tritt wie >aus dem Nichts< hinzu (Irreal); später Ilja Petrowitsch und Nikodim Fomitsch.

\section{Szene 8}

\section{Raskolnikow}

Diese Räuber! Sie ahnen etwas! ... Doch, wenn du die ganze Sache tatsächlich mit vollem Bewußtsein ausgeführt hast und nicht bloß idiotisch, wenn du tatsächlich ein bestimmtes und festes Ziel im Auge hattest, ... > Dutzende von Familien, die vor Verfall, Zersetzung, Untergang, Laster, die vor Geschlechtskrankheiten und Siechenhäusern mit dem Geld der Alten, das einem Kloster zufallen wird, gerettet werden könnten. Wird ein allerwinzigstes Verbrechen durch tausende von guten Taten wettgemacht? Ein Tod gegen hundert Leben - das ist doch Arithmetik!< 


\section{Rasumichin}

(Mustert ihn.) Geht es dir wirklich so schlecht? ... du bist müde ... Du bist ja ernstlich krank, weißt du das?

\section{Raskolnikow}

(Verwirrt.) Ich habe keinen einzigen Schüler mehr. Ich wollte ... Übrigens, ich brauche gar keine Schüler ...

\section{Rasumichin}

Du phantasierst ja!

\section{Raskolnikow}

Nein, ich phantasiere nicht ... Leb wohl ...

\section{Rasumichin}

Bist du verrückt geworden? Das ist eine Beleidigung!

\section{Raskolnikow}

Ich kenne außer dir keinen Menschen, der mir helfen könnte ... anzufangen ... Weil du gut bist, besser als alle anderen, ich meine klüger als alle anderen, und beurteilen kannst, ob ... Aber jetzt sehe ich, daß ich nichts brauche, hörst du, überhaupt gar nichts ... Keine Hilfe und [Raskolnikow] keine Anteilnahme ... Ich werde selbst ... Allein ... Und nun ist es genug! Laßt mich alle in Ruhe!

\section{Rasumichin}

(Lacht.) Jemand hat Cherwimow ... er verlegt alles mögliche ... Mehr als zwei Bogen deutscher Text; meiner Meinung nach aus der Feder eines Dummkopfs und Scharlatans: Es geht um die Frage, kurz gesagt, ob die Frau ein Mensch ist oder nicht. Und selbstverständlich wird mit allem Pomp bewiesen, daß sie ein Mensch ist. Cheruwimow bringt das als Beitrag zur Frauenfrage. Möchtest du den zweiten Bogen von „Ist die Frau ein Mensch?“ übersetzen? ... Drei Rubel: Da ich mir den Vorschuß ...

\section{Raskolnikow}

Ich brauche ... keine Übersetzungen ...

\section{Rasumichin}

(Brüllend.) Was soll dieses Theater, du Satan! Bist du im Delirium?

\section{Nikodim Fomitsch}

(Hinzutretend) Er kann sich ja kaum auf den Beinen halten ...

\section{Ilja Petrowitsch}

(Hinzutretend; flüsternd:) Lisaweta, sie ist etwas Besonders. Ihr Lächeln ist sogar schön. Diese verdammte Alte könnte ich ermorden und ausrauben, und zwar ohne die leisesten Gewissensbisse, das schwör' ich dir! (Zu Nikodim Fomitsch:) Das hat nichts zu sagen; das hat nichts zu sagen ... Wir möchten Sie nicht länger aufhalten ...

Raskolnikow verliert die Besinnung; die Männer heben ihn auf und tragen ihn fort. Umbau (Raskolnikows Zimmer mit Bett); Kaufmannsgehilfe, Rasumichin, Raskolnikow. 


\section{Szene 9}

\section{Gehilfe}

Der Herr sind zu sich gekommen!

\section{Raskolnikow}

Wer sind Sie?

\section{Gehilfe}

Ich bin Kaufmannsgehilfe beim Kaufmann Schelopajew ...

\section{Rasumichin}

Das hast du gut gemacht, daß du jetzt zu dir gekommen bist. Den vierten Tag schon hast du kaum gegessen und getrunken ... Zweimal habe ich Sossimow geholt. Erinnerst du dich an Sossimow? Er wird langsam ein guter Arzt. Er hat gesagt, irgend etwas rumort in deinem Kopf. Die Nerven sagt er, zu wenig Bier und Meerrettich, das sind die Ursachen deiner Krankheit. Sossimow ist großartig! ... (Sich an den Gehilfen wendend.) Hätten Sie die Güte, uns Ihr Anliegen vorzutragen?

\section{Gehilfe}

Von Afanassij Iwanowitsch Wachruschin ist auf Wunsch Ihrer Frau Mutter an unser Kontor eine Überweisung auf Ihren Namen eingegangen. Wachruschin, Afanassij Iwanowitsch, haben auch diesmal die Bitte Ihrer Frau Mama, die durch ihre Vermittlung Ihnen auf gleiche Weise schon einmal eine Zuwendung haben zukommen lassen, nicht abgeschlagen und Semjon Semjonowitsch dieser Tage aus ihrem Wohnort angewiesen, Ihnen fünfunddreißig Rubel einzuhändigen ... Es geht um die rechtskräftige Unterschrift. Das Quittungsheft, mit Verlaub. (Raskolnikow unterschreibt; der Gehilfe zahlt das Geld aus und geht.)

\section{Raskolnikow}

(Zurückhaltend.) Warst $d u$ das, den ich nicht erkannte, als ich im Fieber lag?

\section{Rasumichin}

Ja, das war ich.

\section{Raskolnikow}

Habe ich phantasiert?

\section{Rasumichin}

Und ob!

\section{Raskolnikow}

Wovon habe ich phantasiert?

\section{Rasumichin}

Wovon du phantasiert hast? Ist doch klar, wovon man phantasiert ...

\section{Raskolnikow}

(Sehr aggressiv.) Wovon habe ich phantasiert!

\section{Rasumichin}

Von Ohrringen ... von Ketten und von Nikodim Fomitsch und von Ilja Petrowitsch, dem Stellvertreter der Inspektors ... [Also, ans Werk! Hier liegen fünfunddreißig Rubel; ich nehme zehn Rubel mit und werde dir in ungefähr zwei Stunden über selbige Rechenschaft ablegen. In dieser Zeit will ich auch Sossimow verständigen, obwohl er längst hier sein müßtê. (Er geht in 
Eile.) ZEIT (Kehrt zurück mit Bündel/Tasche.) Aha, du bist wach, und ich bin wieder da! Jetzt wird abgerechnnet $\ldots . .$.

Raskolnikow

Wie spät ist es?

Rasumimichin

Du hast tüchtig geschlafen: bereits Abend vielleicht gegen sechs. Du hast also länger als sechs Stunden geschlafen ....

Raskolnikow

Mein Gott, wie konnte ich nur!

\section{Rasumichin}

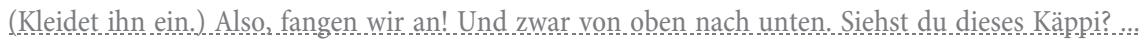
Paßt! Wie nach Maß! Die Kopfbedeckung mein Lieber ist das wichtigste Kapitel der Kleidung eine Art Visitenkarte .... Achtzig Kopeken! Und nur deshalb, weil sie schon getragen ist. Allerdings mit

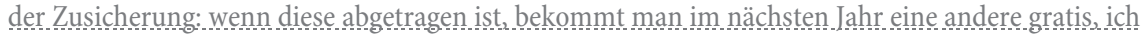
schwör's! .... Auf diese Beinkleider bin ich stolz! Keine Flecken, keine Löcher tadellos erhalten .... Also, rat mal! Was glaubst du, wieviel? Zwei Rubel und fünfundzwanzig Kopeken! Dabei, das mußt

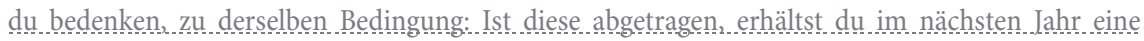
gratis! In Fedjajews Laden handelt man nach diesem Prinzip: einmal bezahlt, fürs ganze Leben bezahlt, denn ein zweites Mal geht man sowieso nicht mehr hin. .... Also, wenden wir uns jetzt den Stiefeln zu - wie findest du sie? Ein englischer Botschaftsssekretär hat sie vorige Woche auf dem Flohmarkt versilbert ganze sechs Tage hat er sie getragen, aber dann brauchte er plötzlich dringend Geld. Preis: ein Rubel fünfzig. Gut, was? ... Und über die Unterwäsche bin ich mit deiner Wirtin handelseinig geworden ... Insgesamt neun Rubel fünfundzwanzig Kopeken. Bitte fünfundvierzig Kopeken Wechselgeld in Kupfer in Empfang nehmen zu wollen ... Die Frage der Strümpfe et cetera überlasse ich dir ... (Raskolnikow sieht so aus, wie er zuvor aussah: > unverändert<.) ]

\section{Sossimow betritt das Zimmer.}

\section{Szene 9/1}

\section{Rasumichin}

Sossimow! Endlich!

Sossimow

Wie fühlen wir uns denn?

\section{Raskolnikow}

Ich bin gesund, vollkommen gesund!

\section{Sossimow}

(An Rasumichin:) Man kann ihm alles geben ... Suppe, Tee ... nur keine Pilze und keine Gurken, versteht sich ...

[Rasumichin

Morgen abend werde ich mit ihm spazierengehen! In den Jussupow-Garten, und dann kehren wir im $>$ Palais de cristal $<$ ein. 
Sossimow

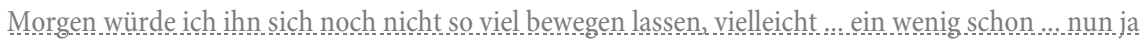
‥

Rasumichin

Iammerschade....

Sossimow

Nun ja.... wir werden sehen.]

\section{Rasumichin}

(Abwesend, nachdenklich, auf die Uhr blickend; die Unruhe Raskolnikows bleibt unbemerkt.) Da ist ja immer noch der Maler ... Dementjew, Mikolaj ... diesen kenne ich von Kind an ... Wir werden ihn schon frei bekommen ...

\section{Sossimow}

Von diesem Mord an der alten Pfandleiherin, der Beamtenwitwe, habe ich bereits gehört und interessiere mich sogar für diesen Fall ... zum Teil ... aus einem besonderen Grund ... Lisaweta haben sie auch umgebracht ... Also, was ist mit dem Anstreicher ...

\section{Rasumichin}

Der soll auch der Mörder sein!

\section{Sossimow}

Liegen etwa Indizien vor?

\section{Rasumichin}

Indizien? Zum Teufel mit den Indizien! Natürlich liegt da ein Indiz vor, aber dieses Indiz ist kein Indiz, und das ist es, was bewiesen werden muß! ... Sie irren sich, freilich, aber das ist es nicht. Ein Irrtum ist immer verzeihlich; ein Irrtum ist eine schöne Sache, denn der Irrtum führt zur Wahrheit. Nein, es ärgert einen, daß sie sich irren und die eigenen Fehler anbeten! ... Begreifst du, worüber ich mich aufrege? Ihre senile, gemeine, sklerotische Routine regt mich auf ... Und hier, mit diesem einen Fall, könnte man einen ganz neuen Weg einschlagen. Man könnte beweisen ... daß ... daß die ... rein psychologischen Faktoren genügen, um auf die richtige Spur zu kommen ...

Pjotr Petrowitsch Luschin betritt den Raum.

Szene $9 / 2$

\section{Luschin}

(Sich an die Anwesenden richtend:) Rodin Romanytsch Raskolnikow, Herr Studiosus oder ehemaliger Studiosus?

\section{Sossimow}

Das ist Raskolnikow.

\section{Luschin}

(Wendet sich an Raskolnikow.) Pjotr Petrowitsch Luschin. Ich darf mir mit der Hoffnung schmeicheln, daß mein Name Ihnen nicht ganz unbekannt ist. (Schweigen.) 
Wie? Sollten Sie in der Tat noch keinerlei Nachricht erhalten haben? ... Ich habe vorausgesetzt und damit [Luschin] gerechnet, daß ein Brief, der vor über zehn Tagen, ja sogar vor fast vierzehn Tagen expediert wurde ...

\section{Rasumichin}

Rodja ist schon seit fünf Tagen krank, drei Tage hat er phantasiert, jetzt ist er zu sich gekommen ... (Auf Sossimow weisend.) Hier sitzt sein Arzt ...

\section{Luschin}

(Übergeht den Einwurf.) Ihre Frau Mutter hatte noch während meines Verweilens in ihrer Nähe einen Brief an Sie zu schreiben begonnen. Hier eingetroffen, ließ ich mit Bedacht einige Tage verstreichen ...

\section{Raskolnikow}

Sie also sind das? der Bräutigam? Ich weiß schon! ... Genug davon! Genug! (Betrachtet ihn ungeniert.)

\section{Luschin}

(Selbstsicher.) Ihre Lieben, das heißt Ihre Frau Mutter und Ihr Fräulein Schwester, erwarte ich stündlich. Den Damen habe ich für die erste Zeit eine Unterkunft ...

\section{Raskolnikow}

Wo?

\section{Luschin}

Ganz in der Nähe, Hotel garni ... Haus Bakalejew ...

\section{Rasumichin}

Ich kenne es, ungemein scheußlich: Schmutz, Gestank und nicht von bestem Ruf ... Allerdings wohnt man dort billig!

\section{Luschin}

Zwei saubere und hübsche Zimmer; unsere künftige Wohnung wird renoviert: in der Zwischenzeit behelfe auch ich mich mit einem möblierten Zimmer ... Ich bin, sehen Sie, bereits ein Dezennium Petersburg ferngeblieben. Alle unsere Neuerungen, Reformen, Ideen, dies alles hat auch uns in der Provinz berührt; aber um alles klarer und im ganzen zu sehen, dazu muß man in Petersburg persönlich anwesend sein ... Es will mir scheinen, als fände ich hier einen klaren Blick, mehr Kritik sozusagen, größere Tüchtigkeit ...

\section{[Rasumichin}

Schwindel! .... Schwindel! Von Tüchtigkeit kann überhaupt keine rede sein. Tüchtigkeit wird langsam erworben, sie fällt einem nicht in den Schoß. Wir aber sind seit beinahe zweihundert Jahren von jeglicher Arbeit entwöhnt ... Mag sein daß es von Ideen gärt, und es gibt ein Streben nach dem Guten wenn auch ein kindliches, und sogar Ehrlichkeit obwohl bei uns die Gauner unzählbar wie die Pilze aus dem Boden schießen, aber Tüchtigkeit, die gibt es immer noch nicht! Bis wir tüchtig sind, werden wir noch viele Schuhsolen ablaufen!

\section{Luschin}

Ich kann mich mit Ihnen nicht einverstanden erklären ..: Es ist einiges getan worden: Verbreitung neuer nützlicher Ideen . Verbreitung bestimmter neuer nützlicher Bücher statt der früheren träumerischen und romantischen 
Spott preisgegeben ist manches schädliche Vorurteil ... Kurz, wir haben uns unwiderruflich von unsserer Vergangenheit losgessagt, und das ist. ist::

Raskolnikow

Das hat er auswendig gelernt! ... Auswendig! .... Um sich einzuführen!

Sosssimow

Alles sehr zutreffend! ... Sehr zutreffend!

Luschin

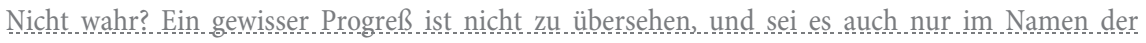
Wissenschaft und der ökonomischen Wahrheit!

Rasumichin

Eine Platitüide!

Luschin

Keineswegs! Wenn man mir bis jetzt zum Beispiel gesagt hat: >Liebe deinen Nächsten $<$ und ich

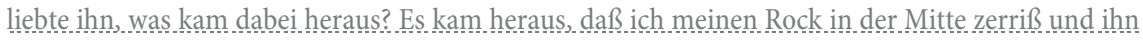
mit meinem Nächsten teilte. Auf diese Weise liefen wir beide halbnackt herum, nach dem russischen Sprichwort: > Jagst du viele Hasen zugleich, fängst du keinen. < Die Wissenschaft aber sagt: Liebe zuallererst dich selbst, denn alles in der Welt ist auf das Eigeninteresse gegründent. Wirst du dich selbst lieben, so wirst du alle deine Angelegenheiten in Ordnung halten und dein Rock wird ganz bleiben. Und die ökonomische Wahrheit ergänzt: Je zahlreicher die wohlgeordneten Privat-

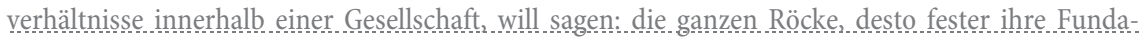
mente und desto glücklicher das Los der Allgemeinheit .... Nur Raskolnikow hört ihm scheinbar zu.) Also ... sorge ich für mein eigenes Wohl, sorge ich damit für die Gesamtheit der Menschen ... ]

\section{Sossimow}

(Zu Rasumichin in Mißachtung Luschins:) Ja! ... Ja! Einer ihrer Kunden hat sie umgebracht! ... Zweifellos!

\section{Rasumichin}

Es muß zweifellos ein Pfandschuldner gewesen sein! Ein Anfänger! ... Er war ungeschickt, denn geht man davon aus, daß er unerfahren ist, dann sieht man, daß nur der pure Zufall ihn gerettet hat! ... Überhaupt, wie geht er vor? Er greift nach Sachen im Wert von zehn oder zwanzig Rubeln, stopft sich damit die Taschen voll, wühlt in der Truhe, in den Lumpen, während in der Kommode, im obersten Schubfach, in einer Schatulle, anderthalbtausend in bar liegen ... Er hat nicht einmal verstanden, sie auszurauben, er konnte sie nur totschlagen! ... Nur totschlagen! ... Er ist ein Anfänger! Er hat den Kopf verloren!

\section{Luschin}

(Versucht sich einzubringen.) Mir scheint, Sie sprechen von dem Mord ...

\section{Sossimow}

Stimmt! Sie haben davon gehört?

\section{Luschin}

Selbstverständlich ...

\section{Rasumichin}

Kennen Sie die Einzelheiten? 


\section{Luschin}

Das möchte ich nicht behaupten; mich interessiert daran ein besonderer Umstand, sozusagen ein Problem für sich ... denn in den höheren Schichten steigt die Zahl der Verbrechen ebenso, ja, sozusagen parallel ... In Moskau, zum Beispiel, deckt man eine ganze Organisation auf, die die Obligationen der letzten Staatsanleihe fälschte und einer der Hauptschuldigen ist ein Lektor der Universalgeschichte ... Und was hat der Lektor geantwortet, als er gefragt wurde ... [I Ich erinnere mich nicht mehr an den genauen Wortlaut, aber der Sinn seiner Rede war daß er auf fremde Rechnung möglichst rasch und ohne etwas zu leisten reich werden wollte! .... Wenn die alte Pfandleiherin nun von einem Täter aus der besseren Gesellschaft ermordet wurde ...... das einfache Volk versetzt ja keinen Gold-

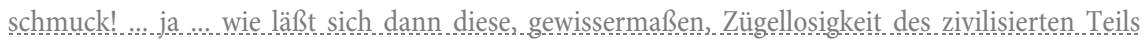
unserer Gesellschaft erklären?

Raskolnikow

(Wütend erhitzt; ohne Ankündigung.) Was wollen Sie eigentlich? Das entspricht doch Ihren eigenen Theorie! Ziehen Sie die letzte Konsequenz, so ergibt sich, daß es erlaubt ist Menschen abzuschlachten ...

Luschin

Aber ich bitte Sie! Alles hat seine Grenze. Eine ökonomische Idee ist noch lange Aufforderung zum Totschlag....]

\section{Raskolnikow}

(Zu Luschin:) Ist es wahr! ... ist es wahr, daß Sie Ihrer Braut ... in derselben Stunde, da Sie ihr Jawort erhielten, gesagt haben, Sie freuen sich vor allem darüber ... daß sie bettelarm ist ... weil es am vorteilhaftesten sei, eine Frau aus ärmlichen Verhältnissen $\mathrm{zu}$ ehelichen, um später zu dominieren ... und ihr die von Ihnen erwiesenen Wohltaten vorzuhalten?

\section{Luschin}

(Lacht.) Ich ahne, wer ... dieser Giftpfeil ... kurz ... Ihre Frau Mama ... sie schien mir ohnedem von einer gewissermaßen exaltierten und romantischen Gemütsart zu sein ... Trotzdem war ich weit entfernt von der Vermutung, daß sie einen Sachverhalt in einer Version wiedergeben könnte, die durch ihre Phantasie bis zur Unkenntlichkeit entstellt ist ...

\section{Raskolnikow}

(Ernstzunehmend aufgebracht.) Wenn Sie noch ein einziges Mal ... ein einziges Mal sich unterstehen, meine Mutter ... auch nur mit einem halben Wort zu erwähnen ... (Er muß aufgehalten werden, Luschin nicht anzugreifen. Dieser verläßt wortlos das Zimmer.) Laßt mich alle in Ruhe! ... Ihr Peiniger! ... Ich fürchte euch nicht! Jetzt fürchte ich keinen Menschen mehr! Keinen Menschen! Ich will allein sein, allein, allein, allein! Rasumichin

(Über ihn hinwegsprechend, als wäre er nicht vorhanden.) Was hat er bloß? 


\section{Sossimow}

Er braucht einen positiven Impuls, das wäre das Richtige! ... Weißt du was, er hat irgend etwas im Kopf! Eine belastende idée fixe ... Das macht mir große Sorgen; so ist es, unbedingt!

\section{Rasumichin}

Stimmt! Er interessiert sich nur für den Mord! ... Sie haben ihn ausgerechnet an dem Tag, an dem er krank wurde, erschreckt, im Bureau des Inspektors ...

\section{Sossimow}

Das mußt du mir ausführlicher erzählen ... (Im Fortgehen auf Raskolnikow weisend.) Er interessiert mich, außerordentlich!

Raskolnikow verläßt sein Zimmer, zählt die Schritte/Umbau (offener Raum); ein Leierkastenmann, der Zeitungen verliert, geht mit einem jungen Mädchen vorüber; das Mädchen ist wie eine $>$ Dame< gekleidet, mit Krinoline, Mantille, Handschuhen und einem Strohhütchen, an dem Federn stecken; sie singt:

„Hau mich nicht, du Wachmann mein, Will dir zu gefallen sein!"

\section{Szene 10}

\section{Raskolnikow}

(Hebt eine Zeitung auf; sucht.) Issler-Issler-Azteken-Bartola-Massimo-Azteken ... Sturz von der Leiter - Feuer auf der Peterburgskaja - Kleinbürger an Alkoholvergiftung gestorben - in Peski - noch einmal Feuer auf der Peterburgskaja - schon wieder Feuer auf der Peterburgskaja - Issler-Issler-Massimo - hier! ... Hier! ... Gestehen Sie ... gestehen Sie, Sie möchten wissen, was ich gelesen habe? ... Ich ... ich gestehe ... nein, ich sage aus! Das ist es! Ich sage aus, daß ich gelesen, mich interessiert ... gesucht ... geforscht habe, nach allem, was mit der Ermordung der alten Beamtenwitwe zusammenhängt ... Dieselbe Frau, von der im Polizeibureau gesprochen wurde, und ich wurde dabei ohnmächtig. Verstehen Sie jetzt?

Rasumichin tritt auf, entdeckt Raskolnikow.

\section{Szene 10/1}

\section{Rasumichin}

(Brüllend.) Hier steckst du also! Aus dem Bett ist er ausgerissen! Und ich suche ihn sogar unter dem Sofa! Auf dem Dachboden sind wir gewesen! Was bedeutet das? Sag mir die Wahrheit! Gesteh! Hörst du?

\section{Raskolnikow}

Ich will allein sein!

\section{Rasumichin}

Allein? wenn du dich kaum auf den Beinen halten kannst, wenn deine Visage totenbleich ist und du kaum Luft bekommst? Idiot! 


\section{Raskolnikow}

Laß mich!

\section{Rasumichin}

Laß mich?! Du unterstehst dich zu sagen: >laß mich? < Weißt du eigentlich, was ich jetzt mit dir mache? Ich nehme dich und mach' einen Knoten, trag' dich unterm Arm nach Hause und sperr dich ein!

\section{Raskolnikow}

(Kalt, gelassen.) Kannst du nicht begreifen, daß ich deine Wohltaten nicht wünsche? Wozu hast du mich beim Ausbruch meiner Krankheit aufgestöbert, vielleicht wäre ich froh gewesen, wenn ich gestorben wäre? Hab' ich dir heute etwa nicht deutlich genug zu verstehen gegeben, daß du mich quälst, daß ich ... dich leid bin! Was liegt dir eigentlich daran, andere zu quälen?

Wie, sag doch selber, wie soll ich dich anflehen, damit du mich in Ruhe läßt? ... Laß mich! Laß mich! (Will gehen.)

\section{Rasumichin}

Halt! Hör mich an. Ich erkläre hiermit, daß ihr alle, einer wie der andere, Schwätzer und Aufschneider seid! Ihr legt euch ein hübsches kleines Leiden zu und gackert darüber wie die Henne überm frischgelegten Ei. Sogar dabei klaut ihr bei einem fremden Autor! Nicht die leiseste Spur eines eigenständigen Lebens ist in euch zu finden! Ihr seid alle aus Spermazet gemacht und habt statt Blut Molke in den Adern! Ich nehme keinem von euch auch nur ein einziges Wort ab. ihr macht euch zur Hauptaufgabe, in jeder Situation nur ja nicht einem Menschen zu gleichen! ... Du sollst mich zu Ende hören! Du weißt, wir wollen heute bei mir feiern ... Kommst du?

\section{Raskolnikow}

Nein!

\section{Rasumichin}

Blödsinn! Wetten, daß du kommst! ... Wetten!

Rasumichin bleibt. Marmeladow tritt auf, betrunken; er stürzt - das Mädchen vom Leierkastenmann führt einen „Reifen am Stock" und >überfährt< Marmeladow. VIDEO/Tod: Pferdekutsche; Speichenräder, die etwas überrollen. Gaffer, Schutzmänner, Sossimow, Geschrei und Rufen. Das Geschehen bewegt sich auf Raskolnikow zu. Katerina Iwanowna und Sonja im Hintergrund (Sonja ist wie eine Prostituierte gekleidet); sie folgen dem $>$ Zug<.

\section{Szene 10/2}

\section{Raskolnikow}

(Schreit.) Ich kenne ihn, ich kenne ihn! ... Er ist Beamter, verabschiedeter Beamter, Titularrat Marmeladow! Er wohnt hier ganz in der Nähe, im Haus Kosel ... Holen Sie einen Arzt! Ich zahle, ich zahle!

\section{Katerina Iwanowna}

Was ist das? Mein Gott! Dieses dreimal verfluchte Leben! Er ist unter die Pferde geraten! Betrunken! ... Betrunken! 


\section{Raskolnikow}

Beruhigen Sie sich, um Gottes willen, Sie brauchen nicht zu erschrecken! Er wollte die Straße überqueren und wurde von einer Kutsche angefahren, machen Sie sich keine Sorgen, er wird zu sich kommen ...

\section{Katerina Iwanowna}

Jetzt hat er's erreicht!

\section{Raskolnikow}

Er ist verletzt, aber nicht tot, glauben Sie mir ...

\section{Katerina Iwanowna}

[(Zu Sonja:) Auf dem letzten Ball, bei dem Adelsmarschall ... als mich damals Fürstin Bessemelnaja sah h.: ist das nicht jenes reizende junge Mädchen, das beim Schlußball mit einer Stola getanzt hat? .... (Zu den Umstehenden; ausfallend:) Laßt ihn doch wenigstens ruhig sterben! Hier ist doch kein Theater ... vielleicht noch mit dem Hut auf dem Kopf ... Ist es etwa ungehörig, zu sterben? [.... (Zu Sonja:) Damals war aus Petersburg gerade der Kammeriunker Fürst Schtschegolskoj angereist, er tanzte mit mir die Mazurka und wollte gleich am anderen Tag bei meinem Vater um meine Hand anhalten ....]

\section{Sonja}

Mein Gott! Die ganze Brust ist zerquetscht! So viel Blut! So viel Blut!

\section{Katerina Iwanowna}

Und jetzt stirbt er, gottlob! Eine Sorge weniger! (Marmeladow versucht zu sprechen.) Schweig! Nicht nötig! ... Ich weiß, was du sagen willst ... (Marmeladow versucht sich $z u$ bewegen; sie schreit ihn an:) Bleib liegen! Bleib liegen! (Marmeladow stirbt; Sonja schreit.) Jetzt hat er's erreicht! ... Was soll ich jetzt tun? Von welchem Geld soll ich ihn beerdigen?

\section{Raskolnikow}

(Gehetzt.) Katerina Iwanowna, vorige Woche hat Ihr verstorbener Gatte mir sein ganzes Leben und alle seine Verhältnisse anvertraut ... Seien Sie versichert, er sprach von Ihnen mit einer geradezu schwärmerischen Hochachtung. An diesem Abend, an dem ich erfuhr, wie sehr er seiner ganzen Familie ergeben war und wie er Sie, Katerina Iwanowna, ganz besonders verehrte und liebte, ungeachtet seiner verhängnisvollen Schwäche, an diesem Abend wurden wir Freunde .... Erlauben Sie mir also jetzt ... etwas beizutragen ... wenn meinem Freund die letzten Ehren erwiesen werden. Hier sind ... Gibt ihr Geld. ... Ich werde wiederkommen ... Vielleicht komme ich schon morgen ... Leben Sie wohl!

Raskolnikow will gehen; Sonja folgt ihm ... Sossimow und Rasumichin.

\section{Szene 10/3}

\section{Raskolnikow}

Der Arzt war da, der Priester war da, alles in Ordnung .... Ich bin voll Blut .... ich bin voll Blut! .... Ja, ich habe mich mit Blut beschmiert .... (Zu Sonja:) Ich heiße Rodion; bitte, beten Sie für mich: > und Rodion, den Knecht Gottes< - weiter nichts. 


\section{Sonja}

(Sonja umarmt Raskolnikow; küßt ihn.) Mein ganzes Leben werde ich für Sie beten! .... mein ganzes Leben!

\section{Raskolnikow}

Ja, es gibt Leben! Mein Leben! ... Jetzt wollen wir unsere Kräfte messen! .... Kraft braucht man, Kraft!

Sonja sieht Sossimow und Rasumichin, die betrunken wirken; sie läßt von Raskolnikow ab und geht; Sossimow flüstert mit Rasumichin.

\section{Szene 10/4}

\section{Sossimow}

(Betrachtet Raskolnikow mit großem Interesse.) Sofort ins Bett und schlafen! Und für die Nacht noch eine Kleinigkeit einnehmen. Werden Sie das tun?

\section{Raskolnikow}

Meinetwegen ....

\section{Sossimow}

Sehr gut! .... Sehr gut! (Übergibt Raskolnikow ein Medikament, das dieser sofort nimmt; Sossimow beobachtet Raskolnikow aus der Distance.)

\section{Rasumichin}

Ich begleite dich nach Hause! .... Dir ist elend! .... Weißt du, was mir Sossimow eben ins Ohr geflüstert hat? Sossimow bat mich, dich zum Sprechen zu bringen und ihm dann alles zu berichten, denn er hat die Idee, daß du verrückt bist oder wenigstens nah dran. Stell dir das vor! .... Dieser gelernte Chirurg hat sich auf Gemütskrankheiten kapriziert! .... Weißt du, Rodja, ich habe jetzt einen kleinen Schwips .... Aber das macht nichts .... Es geht darum, daß diese Idee .... keiner wagt sie laut auszusprechen .... Vor allem dieser .... Für ihn war damals der springende Punkt deine Ohnmacht in der Kanzleit .... Aber nachdem sie den Anstreicher gefaßt haben, da ist alles geplatzt wie eine Seifenblase ....

\section{Raskolnikow}

Hör, Rasumichin .... Ich komme gerade von einem Toten .... Ich habe ihnen mein ganzes Geld gegeben .... Und außerdem hat mich ein Wesen geküßt, das mich, auch wenn ich jemanden ermordet hätte .... Ich weiß nicht, was ich rede; ich bin schwach

Ein Leierkastenmann geht mit dem Mädchen vorüber; sie singt:

„Hau mich nicht, du Wachmann mein,

Will dir zu gefallen sein!“

Pulcherija Alexandrowna Raskolnikowa (die Mutter) und Dunja (Awdotja Romanowna, die Schwester) sind angekommen (mit Gepäck) und sehen, wie Raskolnikow die Besinnung verliert. Entsetzen. 


\section{Szene 10/5}

Rasumichin (Zu allen:) Nur eine Ohnmacht, ganz belanglos! Vorhin erst sagte der Arzt, daß es ihm wesentlich besser geht, daß er vollkommen gesund ist! Da, er kommt schon zu sich, da, er ist wieder aufgewacht!

Sie bringen ihn fort. Sossimow beobachtet den Vorgang aus dem Hintergrund. Er macht sich Notizen. Umbau (Zimmer von Raskolnikow). VIDEO/Mord.

\section{Szene 11}

\section{Raskolnikow}

Geht nach Hause .... Geht .... geht! Geht nach Hause!

\section{Pulcherija Alexandrowna}

Der Zug hat sich schrecklich verspätet. Aber dich, Rodja, werde ich um keinen Preis allein lassen! Ich übernachte hier! .... hier!, neben dir!

\section{Raskolnikow}

Quält mich nicht! Genug, geht .... ich kann nicht!

\section{Rasumichin}

Ich werde bei ihm bleiben! Ich werde ihn keinen Augenblick allein lassen!

\section{Pulcherija Alexandrowna}

Wie, wie kann ich Ihnen nur danken?

\section{Dunja}

Wir wollen gehen, Mama, wir wollen wenigstens für einen Augenblick aus dem Zimmer gehen .... wir bringen ihn ja um, das sieht man doch!

\section{Pulcherija Alexandrowna}

(Den Einwand mißhörend.) Wir haben gehört, Rodja, daß Pjotr Petrowitsch so freundlich war, dich heute zu besuchen ....

\section{Raskolnikow}

Ja .... Er war so freundlich! (Sich an die Schwester wendend.) Dunja, ich habe Luschin zum Teufel gejagt! .... Ich wünsche diese Heirat nicht, und deshalb mußt du morgen schon, als erstes, die Verlobung auflösen ....

\section{Pulcherija Alexandrowna}

Aber Rodja!

\section{Dunja}

Vielleicht bist du jetzt nicht in der richtigen Verfassung, du bist müde ....

\section{Raskolnikow}

Vielleicht im Delirium? Nein .... nein! Du heiratest Luschin um meinetwillen. Ich nehme das Opfer nicht an! Morgen ist Schluß! .... Schluß!

\section{Dunja}

Mama, wir wollen gehen .... Leb wohl, Rodja! 


\section{Raskolnikow}

Schwester, diese Ehe ist eine Niedertracht. Ich mag niederträchtig sein, du aber sollst es nicht sein .... einer von uns, das reicht. Entweder ich oder Luschin! Geh jetzt .... Geht! Geh!

\section{Rasumichin}

(Brüllt.) Du bist ja verrückt! .... verrückt! Du bist ein Despot! (An Mutter und Schwester sich wendend:) Dieser Pjotr Petrowitsch ist ein Lump, wenn er Ihnen kein besseres Quartier .... Übrigens, dieses Hotel garni .... Wie konnte er sich nur unterstehen, Sie in einem solchen Haus unterzubringen! Ein Skandal! (Zu Dunja:) Sie sind doch seine Braut! seine Braut, nicht wahr? Dann sage ich Ihnen, daß Ihr Bräutigam ein Schuft ist! .... ein Schuft! .... Nicht, weil er stehenden Fußes vom Friseur kam, mit onduliertem Haar, und nicht, weil er es so eilig hatte, seine Ansichten zur Schau zu stellen, sondern weil er ein Voyeur und Spekulant ist, ein Jud und ein Gaukler, und das sieht man .... (Zur Mutter:) Ich bin leicht betrunken .... leicht .... Sie sind zwar seine Mutter, aber wenn Sie hierbleiben, bringen Sie ihn zur Raserei, und weiß der Teufel, wohin das führt! Es wäre besser gewesen, wenn Sie morgen gekommen wären. (Zu Dunja:) Ich bin betrunken wie ein Esel; aber es ist nicht der Wein. Sie sind - ein Engel! In dem Augenblick, als ich Sie sah, ist es mir zu Kopf gestiegen .... Ich übertreibe; ich bin Ihrer nicht würdig .... Ich bin Ihrer absolut nicht würdig! .... Warum habe ich so viel gesoffen? .... [Ich übertreibe ...: Aber mir gefälltt es, wenn phantasiert wird! Du phantasierst - und kommst schließlich zur Wahrheit! Ich phantasiere, also bin ich ein Mensch. Wir haben uns noch nie zu einer Wahrheit durchgerungen, ohne vorher mindestens vierzehnmal zu phantasieren, vielleicht sogar hundertvierzehnmal. Aber unser Grips reicht nicht, um originell zu phantasieren. (Hysterischi fanatisch, brüllend.) Wir sind auf den Geschmaack gekommen, auf Kosten fremder Köpfe zu leben! Stimmt das? Stimmt das, was ich sage?

Pulcherija Alexandrowna

Mein Gott, ich weiß nicht

Dunja

Ja $a_{2}$ es stimmt .... Obwohl ich nicht in allem mit Ihnen einverstanden bin.

Rasumichin

(Ergreift ihre Hand.) Ja? Sie sagen ja? nun, dann sind Sie .... Dann sind Sie die Verkörperung von Güte, Reinheit, Vernunft und Vollkommenheit! .... Ich muß Ihre Hand küssen, hier, jetzt, auf den Knien!

Duñụa

Stehen Sie doch auf!

Rasumichin

Sie anzubeten ist Pflicht eines jeden, sofern er nicht ein völliges Rindvieh ist!

Pulcherija Alexandrowna

Hören Sie auf, ich bitte Sie!

Dunja

(Gelassen.) Stehen Sie auf.] 


\section{Rasumichin}

(Steht auf.) Ich bin ein unseliger Tölpel .... ich schäme mich .... Sie zu lieben bin ich nicht würdig. (Lacht.) Ich übertreibe .... Ich übertreibe .... (Weist auf Raskolnikow, der $z u$ schlafen scheint.) Er schläft den Schlaf des Gerechten, ausgezeichnet, ruhig, und gebe Gott, daß er zehn Stunden weiterschläft .... Dieser Sossimow, der Arzt .... der hat neulich befürchtet, Rodja könnte überschnappen .... Es handelt sich sozusagen um das Produkt mehrerer komplexer psychischer und materieller Ursachen, Sorgen, Befürchtungen, Erregungen, gewisser Ideen .... und so weiter. Und das ist es, warum man ihn nicht reißen darf .... Egal! Egal! Gehen wir .... Es wäre besser gewesen, wenn Sie morgen gekommen wären.

Sie setzen sich. ZEIT. Warten. STILLE. Das Mädchen des Leierkastenmannes singt:

„Hau mich nicht, du Wachmann mein,

Will dir zu gefallen sein!"

Szene 11/1

\section{Pulcherija Alexandrowna}

Sagen Sie mir doch, was denken Sie über ... ach, entschuldigen Sie, ich weiß ja immer noch nicht, wie Sie heißen?

\section{Rasumichin}

Dmitrij Prokofjitsch.

\section{Pulcherija Alexandrowna}

Also, Dmitrij Prokofjitsch, ich möchte sehr, sehr gern wissen ... wie soll ich es ausdrücken ... was liebt er, was liebt er nicht? Ist er immer so gereizt? Welche Wünsche hat er? Welche Träume sozusagen?

\section{Dunja}

Mama, wie soll man das alles auf einmal beantworten ...

\section{Pulcherija Alexandrowna}

Ach, mein Gott, ich hatte doch nie erwartet ...

\section{Rasumichin}

Was kann ich Ihnen auch sagen? Ich kenne Rodion seit anderthalb Jahren: Er ist mürrisch, unfreundlich, verdrossen, hochmütig und stolz ... argwöhnisch und hypochondrisch. Großmütig und gutherzig. Vermeidet es, seine Gefühle zu zeigen, und ist eher bereit, eine Grausamkeit zu begehen, als sein Herz auszuschütten. Zuweilen entsetzlich wortkarg! Nie hat er Zeit, immer wird er von allen gestört, dabei liegt er nur da und tut nichts ... Hört nie zu, wenn jemand spricht, hat von sich selbst eine überaus hohe Meinung, und nicht ohne Grund, wie es scheint ...

\section{Dunja}

(Unterbricht ihn auf das freundlichste.) Sie haben viel Interessantes über den Charakter meines Bruders gesagt und ... Sie haben es ohne Befangenheit ausgesprochen. Das ist gut ... Eine Frau ... eine Frau sollte an seiner Seite sein ... Eine Frau! 
Wie in einem Traum betritt Sonja den Raum und legt sich zu Raskolnikow; er hat sie erwartet - er spricht mit ihr, sie mit ihm; flüsternd; sie küßt ihn; er versucht sie zu küssen - Sonja weicht dem aus, zärtlich - nur sie, die ihn küßt; sie gebietet ihm, sie nicht zu berühren, nur sie ist es, die ihn berührt $\cdots$

Szene 11/2

\section{Rasumichin}

(Die Erregung verbergend.) Er liebt doch niemand; und vielleicht wird er nie jemand lieben ...

\section{Dunja}

(Jähzornig.) Soll das heißen, daß er unfähig ist, zu lieben?

\section{Rasumichin}

Wissen Sie, Awdotja Romanowna, Sie ähneln Ihrem Bruder ja unglaublich, sogar in allem!

\section{Pulcherija Alexandrowna}

(Unterbricht ihn.) Sie können sich nicht vorstellen, Dmitrij Prokofjitsch, wie phantasievoll er ist, und, wie soll ich mich ausdrücken, wie launisch! Ich konnte mich nie auf seinen Charakter verlassen .... Dmitrij Prokofjitsch .... ich darf mit Dmitrij Prokofjitsch doch ganz offen sprechen, nicht wahr, Dunetschka?

\section{Dunja}

Selbstverständlich, Mama ....

\section{Pulcherija Alexandrowna}

Es geht um folgendes .... Heute, in aller Frühe, erhielten wir von Pjotr Petrowitsch ein Billet, als Antwort auf die gestrige Nachricht von unserem Eintreffen .... Am besten lesen Sie es selbst; es enthält einen Punkt, der mich sehr beunruhigt .... Sie kennen Rodjas Charakter besser als alle anderen und sind eher als alle anderen berufen, uns zu raten .... (Übergibt den Brief.)

\section{Rasumichin}

(Liest.)

\section{Luschin tritt auf.}

\section{Szene 11/3}

\section{Simultan}

\section{Luschin}

$>$ Ich werde mir erlauben, Sie am morgigen Tage in Ihrem Logis aufzusuchen und meine Aufwartung zu machen, Punkt acht Uhr abends, wobei ich mir gestatte, ergebenst, aber, wie ich hinzusetzen möchte, ausdrücklichst die Bitte anzufügen, bei unserm gemeinsamen Wiedersehen möge Rodion Romanowitsch unter keinen Umständen zugegen sein, denn er hat mir gestern, als ich ihm meinen Krankenbesuch abstattete, eine beispiellose und schnöde Kränkung zugefügt .... < Ergeht ab. 


\section{Szene 11/4}

\section{Pulcherija Alexandrowna}

(Jammernd und ihn unterbrechend.) Was soll ich jetzt tun, Dmitrij Prokofjitsch? Wie kann ich Rodja zumuten, nicht zu uns zu kommen? Gestern bestand er so hartnäckig darauf, daß wir Pjotr Petrowitsch abweisen, und heute wird von uns verlangt, ihn selbst nicht zu empfangen ... Und sie sagt (Weist auf Dunja.) .... es sei am besten, das heißt, nicht eigentlich am besten, aber in einer bestimmten Hinsicht notwendig, daß Rodja ebenfalls, erst recht, heute um acht, in das, wie Sie sagen, Hotel garni kommt und daß die beiden sich dort unbedingt treffen .... Ich dagegen wollte ihm diesen Brief nicht einmal zeigen .... Er ist doch so reizbar .... Ich habe Angst, Dmitrij Prokofjitsch .... Angst!

\section{Dunja}

Sie brauchen keine Angst zu haben, Mama. Sie sollten lieber an ihn glauben. Ich glaube.

Sossimow betritt den Raum; Sonja verläßt Raskolnikow, er ist erwacht.

\section{Szene 11/5}

\section{Sossimow}

(Begeistert, nach dem er den Kranken in Augenschein genommen hat.) Gesund! Gesund!

\section{Raskolnikow}

Ja, ich sehe selbst -

\section{Sossimow}

(Unterbricht ihn.) Noch drei oder vier Tage und er ist ganz der Alte, das heißt, wie er vor einem Monat oder auch vor zwei .... oder vielleicht auch vor drei? Das hat ja schon vor geraumer Zeit angefangen .... Geben Sie zu, daß Sie vielleicht nicht ganz schuldlos sind!

\section{Raskolnikow}

Sehr gut möglich.

\section{Sossimow}

Ich sage es nur deshalb, weil Ihre endgültige Genesung ausschließlich von Ihnen selbst abhängt. Ich möchte Ihnen dringend empfehlen, die primären, ich möchte sagen, prinzipiellen Ursachen zu beheben, die zu Ihren krankhaften Zuständen geführt haben .... Diese primären Ursachen sind mir nicht bekannt, Ihnen aber müssen sie bekannt sein. [İch glaube, der Beginn Ihrer Krankheit fälltt ungefähr mit Ihrer Exmatrikulation zusammen. Sie düren nicht ohne Beschäftigung bleiben und ich glaube, daß Arbeit und ein fest ins Auge gefaßte Ziel eine große Hilfe für Sie bedeuten würde.

\section{Raskolnikow}

Ich werde mein Studium wieder aufnehmen .... (Spottend an Sossimow gewandt:) Abgesehen vom

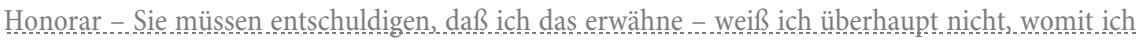
Thre so ganz besondere Aufmerksamkeit verdiene. Ich verstehe es einfach nicht .... und es fällt mir gar nicht so leicht, Sie zu ertragen, weil ich Sie nicht verstehe. 


\section{Sossimow}

Nehmen Sie an Sie sind mein erster Patient .... (Raskolnikow, der Sossimow nicht zuhört reicht Dunja die Hand die sie mit Freude nimmt.) .... Und unsereins, der gerade zu praktizieren anfängt, liebt seine Patienten wie die eigenen Kinder, und manchmal vernarrt er sich sogar in sie .....

Raskolnikow

(Fällt Sossimow ins Wort; zu Dunja:) Gestern, ja .... ich wollte zu euch gehen aber wegen meiner Kleider wurde ich aufgehalten; ich habe vergessen, dieses Blut auszuwaschen .... Es kommt daher, daß ich gestern immer noch etwas geistessabwesend, durch die Straßen streifte und auf einen

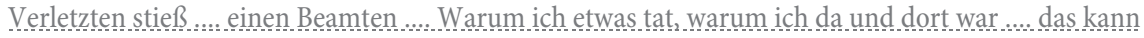
ich nicht richtig erklären .....

\section{Sossimow}

(Fällt Raskolnikow ins Wort.) Ein durchaus bekanntes Phänomen. Die Ausführung einer Handlung ist zuweilen meisterhaft, raffiniert, aber Steuerung und Antrieb sind gestört .....]

\section{Raskolnikow}

(Fällt Sossimow ins Wort; zu Dunja:) Möglicherweise ist es günstig, daß er mich für beinahe geisteskrank hält!

\section{Dunja}

Aber den Gesunden geht es eigentlich auch nicht anders.

\section{Sossimow}

Eine weitgehend zutreffende Bemerkung ....

\section{Simultan:}

\section{Sossimow}

In diesem Sinne sind wir tatsächlich alle, und zwar recht häufig, beinahe geisteskrank, mit dem kleinen Unterschied, daß die $>$ Kranken $<$ um ein geringes verrückter sind als wir, weshalb es hier gilt, eine strenge Grenze zu ziehen. Den harmonischen Menschen, das stimmt, gibt es kaum; unter Tausenden, vielleicht sogar unter vielen Hunderttausenden, begegnet man nur vereinzelten und noch dazu recht schwachen Exemplaren.... (Später:)

Für mich wird es Zeit. Ich werde wohl Noch einmal vorbeischauen .... (Niemand reagiert; er geht; Rasumichin sieht ihm nach.)

\section{Rasumichin}

(Zu Raskolnikow.) Was war eigentlich mit diesem Verletzten? Ich habe ....

\section{Raskolnikow}

(Zur Mutter:) Mama, ich habe gestern etwas Unverzeihliches getan; ich habe gestern das ganze Geld, das Sie mir geschickt haben, weggegeben .... an eine Frau, für die Beerdigung. Eine Witwe, schwindsüchtig, eine erbarmungswürdige Frau .... und dann eine Tochter .... Ich hatte dazu selbstverständlich nicht das geringste Recht, zumal ich wußte, unter welchen Opfern Sie dieses Geld aufgebracht haben. Um zu helfen, muß man zuerst einmal das Recht dazu haben, sonst - >Crevez, chiens, si vous n' êtes pas contens $!<-$ So ist es doch, Dunja?

\section{Dunja}

Nein, so ist es nicht! 


\section{Raskolnikow}

Nun, um so besser für dich .... und solltest du je eine Grenze erreichen, die du nicht $\mathrm{zu}$ überschreiten vermagst, dann wirst du unglücklich sein, aber wenn du sie überschreitest, vielleicht noch unglücklicher ....

\section{Pulcherija Alexandrowna}

Schon gut, Rodja, ich bin überzeugt, daß alles, was du tust, vollkommen richtig ist.

\section{Raskolnikow}

(Kalt, lächelnd.) Seien Sie lieber nicht so überzeugt! (Sieht, wie Rasumichin Dunja betrachtet; zu Dunja:) Gefällt er dir, Dunja?

\section{Dunja}

Sehr.

\section{Rasumichin}

(Zu Raskolnikow:) Schäm dich, was bist du für ein .... Trampel!

\section{Raskolnikow}

Folgendes, Dunja, ich halte es für meine Pflicht, dich noch einmal darauf hinzuweisen, daß ich in der Hauptsache nicht nachgebe. Entweder ich oder Luschin. Heiratest du Luschin, dann bist du von Stund an meine Schwester nicht mehr.

\section{Simultan}

\section{Dunja}

Bruder, bei der ganzen Sache liegt ein Irrtum deinerseits vor. Alles kommt daher, daß du, glaube ich, von der Voraussetzung ausgehst, ich brächte jemandem um jemandes willen ein Opfer. das ist durchaus nicht der Fall. Ich heirate einfach um meiner selbst Willen, weil mir dieses Leben schwerfällt; Mit einem Wort, ich werde Pjotr Petrowitsch heiraten, weil ich von zwei Übeln das kleinere wähle ....

\begin{abstract}
Raskolnikow
(Zu Pulcherija Alexandrowna:) Erinnern Sie sich, Mama, wie ich verliebt war und heiraten wollte? Sie war ein schwerkrankes Mädchen; todkrank; sie beschenkte gern Bettler und träumte immer vom Kloster; .... ja .... besonders hübsch war sie nicht. Wirklich, ich weiß nicht, weshalb ich mich zu ihr hingezogen fühlte .... Einfach so, ein Frühlingsrausch .... (Hält sein Ignorieren nicht durch; aufgebracht, aggressiv.) Du lügst, Schwester! Du lügst bewußt, einzig und allein aus weiblichem Eigensinn, nur um deinen Willen mir gegenüber zu behaupten. Du kannst Luschin nicht achten: Ich habe ihn gesehen und mit ihm gesprochen. Also verkaufst du dich für Geld und handelst folglich auf jeden Fall unwürdig ....
\end{abstract}




\section{Dunja}

(Nicht weniger aufgebracht.) Das ist nicht wahr! Ich würde ihn nicht heiraten, wenn ich nicht sicher wäre, daß er mich schätzt und ich ihm viel bedeute; ich würde ihn nicht heiraten, wenn ich nicht fest überzeugt wäre, daß auch ich ihn achten kann. Und selbst wenn du recht hättest und wenn ich mich tatsächlich zu einer Abscheulichkeit entschlossen hätte - ist es nicht grausam, so mit mir zu sprechen? Wieso verlangst du von mir einen Heroismus, zu dem du selbst vielleicht nicht bereit bist? das ist Tyrannei, das ist Gewalt! Und wenn ich jemand dabei zugrunde richte, dann mich selbst .... Ich habe noch niemand umgebracht! .... Warum starrst du mich so an? .... Mama, zeigen Sie Rodja Pjotr Petrowitschs Brief! (Pulcherija Alexandrowna übergibt den Brief; Raskolnikow liest - er gibt Dunja den Brief zurück; STILLE.)

\section{Raskolnikow}

Er schreibt einen schlechten Stil.

\section{Rasumichin}

(Empört über die lakonische Bemerkung Raskolnikows.) Aber die schreiben doch alle so!

\section{Raskolnikow}

Hast du ihn .... etwa .... gelesen?

\section{Rasumichin}

Ja .... ja, ja!

\section{Pulcherija Alexandrowna}

Wir haben ihm den Brief gezeigt, Rodja, wir wollten seine Meinung hören ....

\section{Raskolnikow}

Ein Geschäftsschreiben .... (Kalt, sachlich - zu Dunja:) Er drückt sich in der Behördensprache aus, das heißt zielbewußt, eindeutig und mit einer an Naivität grenzenden Direktheit. Ich kann mir nicht denken, daß er dich wirklich achtet ....

\section{Pulcherija Alexandrowna}

(Ihn unterbrechend:) Also, wie möchtest du dich entscheiden, Rodja? Hast du nun vor .... zu kommen?

\section{Raskolnikow}

(Ohne Interesse, abwesend.) Ich werde das tun, was Sie für das Beste halten.

\section{Pulcherija Alexandrowna}

Dunetschka hat sich bereits entschieden und ich ....

\section{Dunja}

(Ihr über den Mund fahrend.) Ich bitte dich ausdrücklich, bei unserer Begegnung anwesend zu sein. Wirst du kommen?

\section{Raskolnikow}

Ich werde kommen.

\section{Dunja}

(An Rasumichin:) Auch Sie bitte ich, um acht Uhr bei uns zu sein. 
Sofja Semjonowna Marmeladowa betritt, vor Angst fast zitternd, den Raum, ärmlich (nicht anzüglich, ihr $>$ Gewerbe $<$ definierend) gekleidet; Raskolnikow ist erstaunt, erfreut - begeistert, dann reserviert und äußerst zurückhaltend (Scham).

\section{Szene 11/6}

\section{Raskolnikow}

Ach .... Sie sind es? .... Ich habe Sie keineswegs erwartet .... Bitte, nehmen Sie doch Platz. Sie kommen gewiß im Auftrag von Katerina Iwanowna ....

\section{Sonja}

Ich komme nur für einen Augenblick, entschuldigen Sie, daß ich Sie störe .... Katerina Iwanowna läßt Sie sehr bitten, morgen bei der Aussegnung dabeizusein, vormittags .... nach dem Gottesdienst .... auf dem Mitrofanjewskij-Friedhof, und dann zu uns .... zu ihr ... zum Totenmahl .... die Ehre erweisen ....

\section{Raskolnikow}

Ich werde versuchen, unbedingt .... unbedingt

\section{Sonja}

Ohne Sie .... ohne Sie wüßten wir gar nicht, wovon wir ihn beerdigen sollten .... (Blickt sich in seinem Zimmer um; entsetzt von der Ärmlichkeit; fast flüsternd:) Sie haben uns gestern alles gegeben ....

\section{Raskolnikow}

Mama .... Mama, das ist Sofja Semjonowna Marmeladowa, die Tochter jenes unglücklichen Herrn Marmeladow, der gestern vor meinen Augen unter die Pferde gekommen ist ....

\section{Pulcherija Alexandrowna}

(Freundlich, Sonja zunickend; dann zu Dunja:) Dunetschka, wir wollen gehen .... Und Rodja, wir werden selbstverständlich zusammen zu Mittag speisen. (Sich an Rasumichin wendend:) Dmitrij Prokofjitsch, möchten sie wohl mit uns zu Mittag speisen?

\section{Dunja}

Bitte kommen Sie .... (Mutter und Tochter gehen; Raskolnikow wendet sich sofort an Rasumichin, welcher versonnen den beiden nachsieht.)

\section{Szene 11/6}

\section{Raskolnikow}

Ich möchte dich noch etwas fragen ....

\section{Sonja}

Dann werde ich Katerina Iwanowna ausrichten, daß Sie kommen ....

\section{Raskolnikow}

Einen Augenblick .... Sie stören nicht .... (An Rasumichin:) Du kennst doch diesen Porfirij Petrowitsch? Er bearbeitet doch diese Mordsache?

\section{Rasumichin}

Ja! .... Ein Verwandter .... Und ob! Warum? 


\section{Raskolnikow}

Er hat doch die Pfandschuldner verhört, und es ist auch von mir etwas dort .... Der Ring meiner Schwester, den sie mir zum Abschied geschenkt hat, und die silberne Uhr meines Vaters .... Meine Mutter könnte danach fragen .... Es ist das einzige Stück, das uns nach Vaters Tod geblieben ist. Sie wird krank werden, wenn die Uhr verlorengeht .... Ich weiß, daß ich es eigentlich auf dem Polizeibureau melden sollte. Aber wäre es nicht besser ....

\section{Rasumichin}

(Erregt und ihm das Wort abschneidend:) Auf keinem Fall zum Polizeibureau, du mußt zu Porfirij! Nein, wie ich mich freue! Gehen wir doch gleich, es sind ja nur ein paar Schritte .... Er wird sich sehr, sehr freuen, deine Bekanntschaft zu machen. Ich habe ihm viel von dir erzählt .... Du hast also die Alte gekannt? Darum also! .... Gehen wir! Raskolnikow

(Hält ihn auf; wendet sich an Sonja:) Sofja Semjonowna, das ist mein Freund Rasumichin .... Ich werde Sie heute noch aufsuchen .... Heute noch .... Bitte .... Mein Freund ist ein guter Mensch .... Gehen wir .... gehen wir!

Umbau (offener Raum); Luschin steht abseits und beobachtet die Szene; dann folgt er Sonja. 
Anja Sackarendt

»Bin ich ein Mensch oder eine Laus?»

Zur Magdeburger Inszenierung von »Schuld und Sühne»

Am 17. Oktober 2009 fand die Premiere von Fjodor M. Dostojewskijs "Schuld und Sühne", in der Regie von Schauspieldirektor Jan Jochymski auf der Studiobühne im Schauspielhaus Magdeburg statt. Da die Spieldauer einer Theaterinszenierung selten zwei Stunden überschreitet, erfordert jede Bühnenadaption von Dostojewskijs Roman notwendigerweise Kürzungen und die Konzentration auf bestimmte Figuren, Themen und Handlungsstränge. Im Folgenden werde ich nach einigen Anmerkungen zur Arbeitsweise und zur Bühne versuchen, das Erkenntnisinteresse von Ensemble und Inszenierungsteam ${ }^{1}$ an Dostojewskijs "Schuld und Sühne « deutlich zu machen und in einer Beschreibung der Figuren den besonderen Charakter der Magdeburger Inszenierung vorzustellen.

\section{Arbeitsweise}

$\mathrm{Zu}$ Probenbeginn hatte Regisseur Jan Jochymski nur die Auswahl und die Folge der Szenen von »Schuld und Sühne « festgelegt. Der Text dieser ersten Spielfassung ${ }^{2}$ hat sich im Verlauf der Proben stark verändert. Knapp die Hälfte der Szenen war ohne Dialoge, nur grob in ihrer Bedeutung für die gesamte Handlung angelegt. In Improvisationen entwickelten die Schauspieler und der Regisseur während der Proben die Szenen. Die Dialoge, die die Schauspieler in den Improvisationen anboten, wurden mitgeschrieben, verdichtet und mit Auszügen aus Dostojewskijs Roman angereichert. Auch Artikel über das heutige Russland, zu den Themen Alkoholmissbrauch, Schönheit und geistige Bewegungen, beeinflussten den Stücktext. Im Probenprozess arbeitete das Ensemble weiter an diesen Texten und Szenen. So entwickelte sich zum Beispiel die »Traumszene ${ }^{3}$, in der Raskolnikow allein durch die Straßen zieht und ihn Gestalten, halb Tier und halb Mensch, streifen, zu einer Choreographie, in der die Texte nur fragmentarisch erhalten blieben. Erst zur Premiere wurde die letzte Spielfassung festgehalten. Eine andere, visuelle Quelle für den Theatertext fand sich im Film: Beim Einlass des Publikums wurden Zitate aus dem Zeichentrickfilm

1 »Inszenierungsteam « meint den Regisseur Jan Jochymski, den Bühnen- und Kostümbildner Thilo Reuther und mich als Stück begleitende Dramaturgin.

2 Die Spielfassung basiert auf der Übersetzung von Hermann Röhl (Dostojewskij: Schuld und Sühne, Berlin 1956, abrufbar unter: http://gutenberg.spiegel.de), die stark bearbeitet wurde.

3 Auf diese Szene gehe ich im Abschnitt »Erkenntnisinteresse« näher ein. 
"Animal Farm« (nach George Orwell von John Halas und Joy Batchelor) und aus Martin Scorseses Film »Taxi Driver« auf das Bühnenbild projiziert.

\section{Bühne}

Bühnen- und Kostümbildner Thilo Reuther verbindet in seinem Theaterraum für »Schuld und Sühne« Elemente natürlicher Materialität und städtischer Sozialisation. Die unbehandelten Holzbohlen an den Bühnenseiten, die Raskolnikow in verschiedenen Szenen zerschlägt oder mit seinem Beil zerhackt, ${ }^{4}$ stehen in Kontrast zu dem großflächigen Fotoaufdruck einer heutigen Großstadt in Russland und der Werbeplane »PRADA« an der Rückwand.

\section{Erkenntnisinteresse}

Mit den Filmzitaten der Parabel "Animal Farm $"^{5}$ wird zu Beginn der Inszenierung die Grundfrage nach dem Menschen und seinem Handeln aufgeworfen. Die Tiere der "Animal Farm " verhalten sich wie Menschen. Was bedeutet es, menschlich oder unmenschlich $\mathrm{zu}$ handeln? Wie viel Tier oder wie viel Unmenschliches trägt der Mensch in sich? »Bin ich ein Mensch oder ein Laus? «, ${ }^{6}$ lautet zugespitzt Raskolnikows Konflikt. Durch den Mord an der alten Pfandleiherin, dieser grenzüberschreitenden Tat, versucht Raskolnikow sich zu beweisen, dass er ein Mensch ist - besser gesagt: der Ausnahmemensch, für den er sich hält. Das Ungeheuerliche dieses größenwahnsinnigen Gedankens und die Sinnlosigkeit der Tat, überführt Raskolnikow (Jonas Hien) vor dem Publikum der Magdeburger Inszenierung in eine Pseudolegitimation: Raskolnikow behauptet, mit dem Geld der erschlagenen Pfandleiherin die Welt verbessern zu wollen. ${ }^{7}$ Die Ausschnitte aus dem Film »Taxi Driver « nehmen dieses Motiv des Einzelgängers, der mit Waffengewalt für Ordnung sorgen will, auf.

4 Raskolnikows Name leitet sich vom russischen "raskolot» ab und bedeutet »zerhacken« oder »spalten«.

5 Die Tiere der "Animal Farm" haben die Menschen vom Hof gejagt und die Herrschaft übernommen, nun spielen sich die Schweine als die neuen Herren auf und unterwerfen alle anderen Tiere. Orwells Roman gilt als Parabel auf die Geschichte der Sowjetunion, auf die Pervertierung des Sozialismus zum Stalinismus.

6 Vgl. Fjodor Dostojewskij: Verbrechen und Strafe. Frankfurt/Main 1996, S. 567.

7 Vgl. Dostojewskij, 1996, S. 90f.. Hier verfolgt Raskolnikow in einem Gasthaus am Nachbartisch die Rede eines Studenten über die Pfandleiherin: »Ich könnte diese verdammte Alte ermorden und ausrauben, und zwar ohne die leisesten Gewissensbisse .... Hunderte, Tausende von guten Werken und Plänen könnte man in Angriff nehmen und in die Tat umsetzen mit dem Geld der Alten, das dem Kloster zufallen wird! ... Raskolnikows Zweifel an dem Mord und sein Unglaube ihn tatsächlich zu verüben (Vgl. Dostojewskij, 1996, S. 8, S. 74, S.83) werden durch den Zufall einer Information, dass die Pfandleiherin am nächsten Tag allein in ihrer Wohnung sei, zur Gewissheit: »Er überlegte nicht mehr und war auch völlig außerstande nachzudenken, aber mit seinem ganzen Wesen fühlte er plötzlich, dass er nicht mehr länger über die Freiheit des Verstandes noch über die des Willens verfüge und alles plötzlich entschieden sei.« (Ebd., S. 86). 
Die Fragen nach dem menschlichen Handeln, die Dostojewskij in seinem dramatischen Kriminalroman radikal stellt, sowie Raskolnikows Sehnsucht und Wahn die Grenzen eines gewöhnlichen Menschenlebens zu überschreiten, beschäftigte uns während der Proben lange. Sind alle Menschen vor dem Gesetz gleich? Was könnte in jemandem vorgehen, der sich als Ausnahmemensch bezeichnet und meint, das Gesetz übertreten und die gewöhnlichen Menschen unterdrücken oder gar töten zu dürfen? In der Regie von Jan Jochymski setzten sich die sechs Schauspieler auf der Bühne mit dem menschlichen Handeln und seinen Grenzen auseinander, mit Mitleid und Absolutismus, Grenzüberscheitung, der Berührung von Mensch und Tier, Leben und Tod. Sie treiben Raskolnikows Theorie, die Dostojewskij in seinem Roman verwirft, in eine letzte Konsequenz: Leben heißt sterben - oder töten.

\section{Raskolnikow}

In der Magdeburger Inszenierung spielt Jonas Hien Rodion Raskolnikow, der das Stück mit seinem Traum von einer nie da gewesene Seuche eröffnet: "Jeder glaubte sich im Alleinbesitz der Wahrheit, die Menschen töteten einander in einer Art unsinnigem Wahn «. ${ }^{8}$ In Dostojewskijs Roman erinnert sich Raskolnikow erst am Ende an diesen Fiebertraum - da ist der Mörder bereits umgekehrt und hat seine Schuld gesühnt. Jochymski schickt den Protagonisten jedoch in eine ewige Schlacht, die gleichsam sinnlos und beschlossen wie sein erster Mord erscheint. Raskolnikow bereut und sühnt seine Tat nicht, er wählt letztlich das Leben in einer Welt, in der es keinen Gott und keine Erlösung für Mörder, sondern nur die Wiederholung gibt.

In der oben erwähnten »Traumszene«, am Anfang des Stückes, irrt Raskolnikow allein durch die Straßen, Schweine und Menschenaffen streifen ihn: Mensch und Tier, Realität und Traum vermischen sich. Der Passant Raskolnikow gerät in verschiedene Großstadtszenarien, die er, ganz menschlich, zum Guten wenden will. Ein Kutschpferd wird zu Tode geschunden, ${ }^{9}$ die Prostituierte Sonja (Katharina Brankatschk) schreit, ${ }^{10}$ der betrunkene Marmeladow (Silvio Hildebrandt) bittet um Mitleid. Raskolnikow schüttelt diese ihn berührenden Eindrücke und sein Mitgefühl ab, er empfindet Abscheu und will sich auf seinen Plan konzentrieren, der ihm als Lösung und Ausweg aus der verwirrenden Umwelt erscheint. Trotz seiner rational berechnenden Erklärung: »Hunderte, Tausende von guten Taten könnte man in Angriff nehmen und verwirklichen mit dem Geld der Alten!«, ${ }^{11}$ wird Raskolnikow bei dem Gedanken an den Mord schwindelig, dreimal fällt er an diesem Theaterabend in Ohnmacht.

8 Fjodor Dostojewskij/Jan Jochymski: Schuld und Sühne. Fassung Theater Magdeburg. Magdeburg, 2009, S.2.; vgl. Dostojewskij, 1996, S. $739 f$.

9 Vgl. Dostojewskij, 1996, S. $76 \mathrm{ff}$.

10 Vgl. ebd., S. 65ff.

11 Ebd., S. 90; Dostojewskij/Jochymski, 2009, S. 10. 


\section{Rasumichin}

Bevor er den Mord begeht, redet Raskolnikow viel von seinem Willen zur Tat. Hitzig fordert er auch seinen Kommilitonen Rasumichin (Bastian Reiber) auf zu handeln: "Ausnahmemenschen übertreten das Gesetz und zerstören das Bestehende, im Namen eines Besseren. Sie bewegen die Welt und führen sie ihrem Ziel entgegen! « ${ }^{12}$ Rasumichin versucht, seinen geliebten Freund zu mäßigen und ihn von seiner radikalen Theorie abzubringen. Beherzt pragmatisch lenkt er Raskolnikows Blick auf den Alltag und bietet ihm konkrete Hilfe an, sein Leben in Ordnung zu bringen. Doch Raskolnikow schlägt das Jobangebot aus, er will sich auch kein Geld leihen und bringt dem Gefährten und dessen praktischer Lebensführung nur Verachtung entgegen. Rasumichin erträgt Raskolnikows Angriffe und Demütigungen nur bis zu einem gewissen Punkt, an dem er sich emanzipiert und von seinem Freund abwendet.

\section{Raskolnikowa}

Raskolnikows Mutter schreibt ihrem Sohn einen Brief, ${ }^{13}$ eine Botschaft aus seiner Vergangenheit auf dem ländlichen Gut, "wo wir damals alle glücklich waren «. ${ }^{14}$ Bei der Lektüre dieses Briefes betritt die Raskolnikowa (Michaela Winterstein) die Bühne und erscheint ihrem Sohn. Sie konfrontiert den Protagonisten, wie es später auch Sonja tun wird, mit den Idealen des christlichen Glaubens und fordert von ihm ein rechtschaffenes Leben. Raskolnikow, dem sowohl der Inhalt ihrer Worte als auch die mütterliche Liebe erdrückend erscheinen, gerät ins Zweifeln: »Ach Mama, werde ich denn wirklich, wirklich ein Beil nehmen, sie auf den Kopf schlagen, ihr den Schädel zerschmettern ... werde ich in das glitschige, warme Blut treten, das Schloss erbrechen, stehlen und zittern, mich verstecken, mit Blut befleckt ... bewaffnet nur mit einem Beil.«15

Nach einer zweiten Ohnmacht begeht Raskolnikow schließlich den Mord: Er zählt die Schritte zum Tatort und erschlägt die Pfandleiherin und deren Halbschwester Lisaweta, beide ebenfalls gespielt von Michaela Winterstein. Durch die Mehrfachbesetzung wird ersichtlich, dass der Mord auch seine Mutter meint. Raskolnikow löst sich aus dem Familienbund und von seinem mütterlichen Erbe, dem christlichen Glauben.

\section{Sonja}

Unmittelbar nach dem Mord trifft Raskolnikow die Prostituierte Sonja, der er bereits in der »Traumszene« begegnete, wieder. Sonjas Eltern, der Alkoholiker Marmeladow und seine Frau Ivanowna (Michaela Winterstein), haben das Mädchen auf den Strich geschickt, wo sie sich für das Überleben der Familie verdingt. Sonja hat ihre

12 Dostojewskij/Jochymski, 2009, S. 6; vgl. Dostojewskij, 1996, S. 352.

13 Dostojewskij, 1996, S. $43 \mathrm{ff}$.

14 Dostojewskij/Jochymski, 2009, S. 17.

15 Ebd., S. 17. 
Not sich zu prostituieren, in ein Bewusstsein von der eigenen Überlegenheit verkehrt. Indem sie die Männer erniedrigt, entwickelt sie ein starkes Machtgefühl. Sie betäubt sich, tötet sich selbst ab und übt an ihren Kunden kleine »Morde«.

Sonja findet Halt im Glauben. Sie erzählt dem verwirrten Mörder Raskolnikow von der göttlichen Gnade. Als ihr Hohn und Verachtung entgegenschlagen, wendet sie sich wie Rasumichin von Raskolnikow ab. Erst am Ende der Inszenierung, als der Staatsanwalt sie zu dem Mord an der Pfandleiherin verhört, wird sie sich ihrer Zuneigung zu Raskolnikow bewusst. Sie will ihn retten und zu diesem Zweck ist sie wie Raskolnikow bereit, Grenzen des menschlichen Handelns zu überschreiten, ihren Glauben zu verwerfen und zu töten.

\section{Marmeladow}

Sonjas Vater, der Trinker Marmeladow, fordert Gnade, Erbarmen und Mitleid für jeden Menschen und die tierische Kreatur, für die er sich hält. »Deshalb trinke ich ja, weil ich im Trinken Mitleid und Gefühl suche. ${ }^{16}$ In unserer Inszenierung will er dem Alkohol abschwören und hat sich einen Chip implantieren lassen, der bei Alkoholkonsum eine tödliche Reaktion auslöst. Da jeder Tropfen sein Leben verkürzt, verleiht diese Erfindung den Szenen des erbärmlichen Alkoholikers eine besondere Dringlichkeit und Spannung. Am Anfang der Proben spielte Silvio Hildebrandt die Figur Marmeladow, als einen, der sich auf Ivanownas Idee, die Tochter Sonja auf den Strich zu schicken, einlässt und seine Frau darin unterstützt. Im Probenprozess entwickelte er jedoch einen hilflosen und stummen Widerstand seiner Figur, die trotz aller Sachzwänge auf Menschlichkeit und Mitleid, Begehren und Liebe, aber auch auf Alkohol besteht und daran sterben muss.

\section{Ivanowna}

Marmeladows Frau Ivanowna ist bitter enttäuscht. Sie wirft ihrem Mann vor, ihr elendiges Leben in Armut verschuldet zu haben. Marmeladow liebt sie noch immer, sein Begehren widert Ivanowna an und sie tötet ihn mit Alkohol, als wolle sie sich für ihre zerschlagenen Lebensträume rächen. Ivanowna ist eine weitere Täterin.

\section{Porfirij}

Der Staatsanwalt Porfirij (Axel Strothmann), der in Raskolnikows Mordsache ermittelt, fordert ein Geständnis von Raskolnikow und dass dieser Leid und Reue auf sich nehme. Scharfsinnig, unberechenbar und perfide verhört Porfirij nicht nur den Täter, sondern lädt auch Marmeladow und seine Tochter Sonja ins Präsidium. Zunächst sieht es so aus, als könnte die Prostituierte Sonja, die sich zu einer kühlen Geschäftsfrau entwickelt hat, den Staatsanwalt, der sich seiner selbst, aber auch der Täterschaft Raskolnikows gewiss ist, emotional destabilisieren. Doch die Szene zwischen Porfirij und Sonja entwickelt sich anders: Sonja wird sich im Verhör ihrer

16 Ebd. S. 10, vgl. Dostojewskij, 1996, S. 23. 
Zuneigung und Sorge um Raskolnikow bewusst, flieht vor dem zudringlichen Staatsanwalt, und will Raskolnikow warnen.

\section{Ende}

Raskolnikow gesteht Sonja die Mordtat und bittet sie, ihn zu töten, um ihn zu erlösen. Sonja fügt sich widerstrebend, sie bricht mit ihrem Glauben und ist bereit seine Bitte zu erfüllen. Da erkennt Raskolnikow seinen Lebenswillen und bricht den Tötungsversuch ab. Sonja und Raskolnikow erkennen einander: Beide sind sie fähig, Grenzen zu überschreiten. Auf diese Weise vereint, beginnen sie gemeinsam ein neues Leben.

Am Ende der Vorstellung steht das Paar auf einer weißen Stoffbahn, unter der sich das gesamte Bühnenbild verbirgt. Videosequenzen einer sibirischen Landschaft werden auf diese helle Fläche projiziert. Die Projektion geht auf den frühen Entwurf eines möglichen Endes zurück, in dem Raskolnikow ähnlich »Vissarion $«{ }^{17}$ der in der Taiga eine spirituelle und ökologische Gemeinschaft leitet, als Anführer einer neuen geistigen Bewegung auftritt.

In der Magdeburger Inszenierung folgen Raskolnikow und Sonja am Ende keiner neuen ideellen Lebensauffassung, sondern handeln in einer Unbedingtheit, die wie Raskolnikows Mord unbegreiflich bleibt. Die Grenzüberschreitung, in letzter Konsequenz von Leben zu Tod, braucht für die beiden selbst ernannten Ausnahmemenschen keine vernünftige, nachvollziehbare Erklärung. In der Natur finden sie ihr Vorbild und eine Rechtfertigung: »Der Hai existiert bereits seit 300 Millionen Jahren, länger als jede andere Tierart. Das Besondere am Hai ist, dass sich die bereits im Mutterleib geschlüpften Jungtiere schon dort gegenseitig auffressen, so dass überhaupt nur eines, und zwar das Stärkste, zur Welt kommt. Damit ist der Hai das erfolgreichste Konzept der Natur. Wir müssen einsehen, eine Gleichheit der Menschen ist sozialer Schwachsinn und unsere verweichlichte Lebensweise wird unweigerlich zum Stillstand und schließlich zum Untergang unserer Art führen. Leben heißt töten! « ${ }^{18}$

17 Vissarion versteht sich als Religionsgründer und Messias. Drei Reisen (1998, 2000, 2002) führten ihn nach Deutschland, wo er für seine ökologisch-spirituelle Gemeinschaft Ökopolis im Süden Sibiriens warb. Seine russisch-orthodox geprägten Geisteslehren sind im Internet veröffentlicht: http://www.vissarion.info.

18 Dostojewskij/Jochymski, 2009, S. 44; vgl. http://www.haiwelt.de/haie/verhalten/paarung/paar ung.php 


\section{Inszenierungsfotos von Falk Wenzel/Theater Magdeburg.}

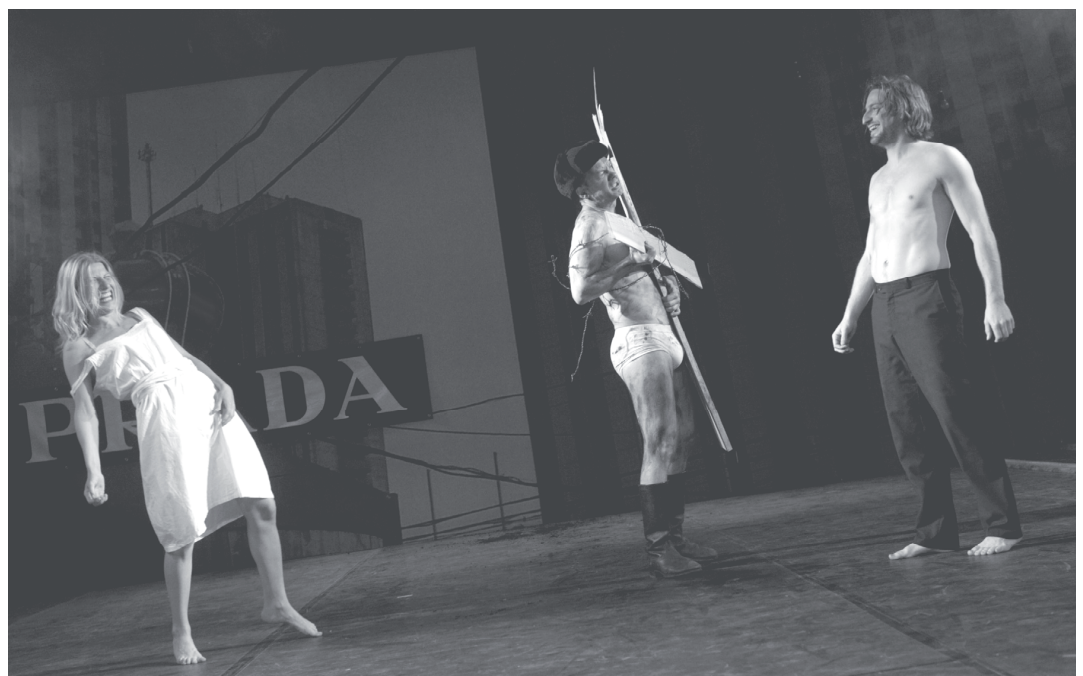

Raskolnikows Traum von einer nie dagewesenen Seuche

Sonja (Katharina Brankatschk), Porfirij (Axel Strothmann) und Raskolnikow (Jonas Hien)

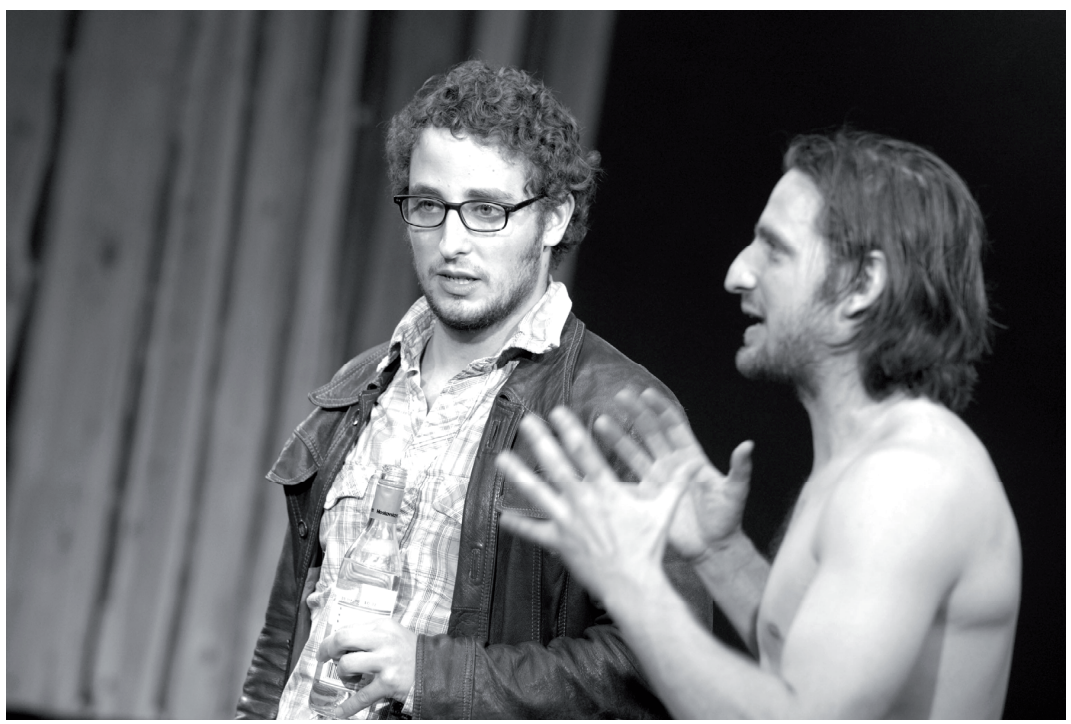

»Es gibt zwei Sorten: die gewöhnlichen Menschen und die eigentlichen, die Ausnahmemenschen."

Rasumichin (Bastian Reiber) und Raskolnikow (Jonas Hien) 


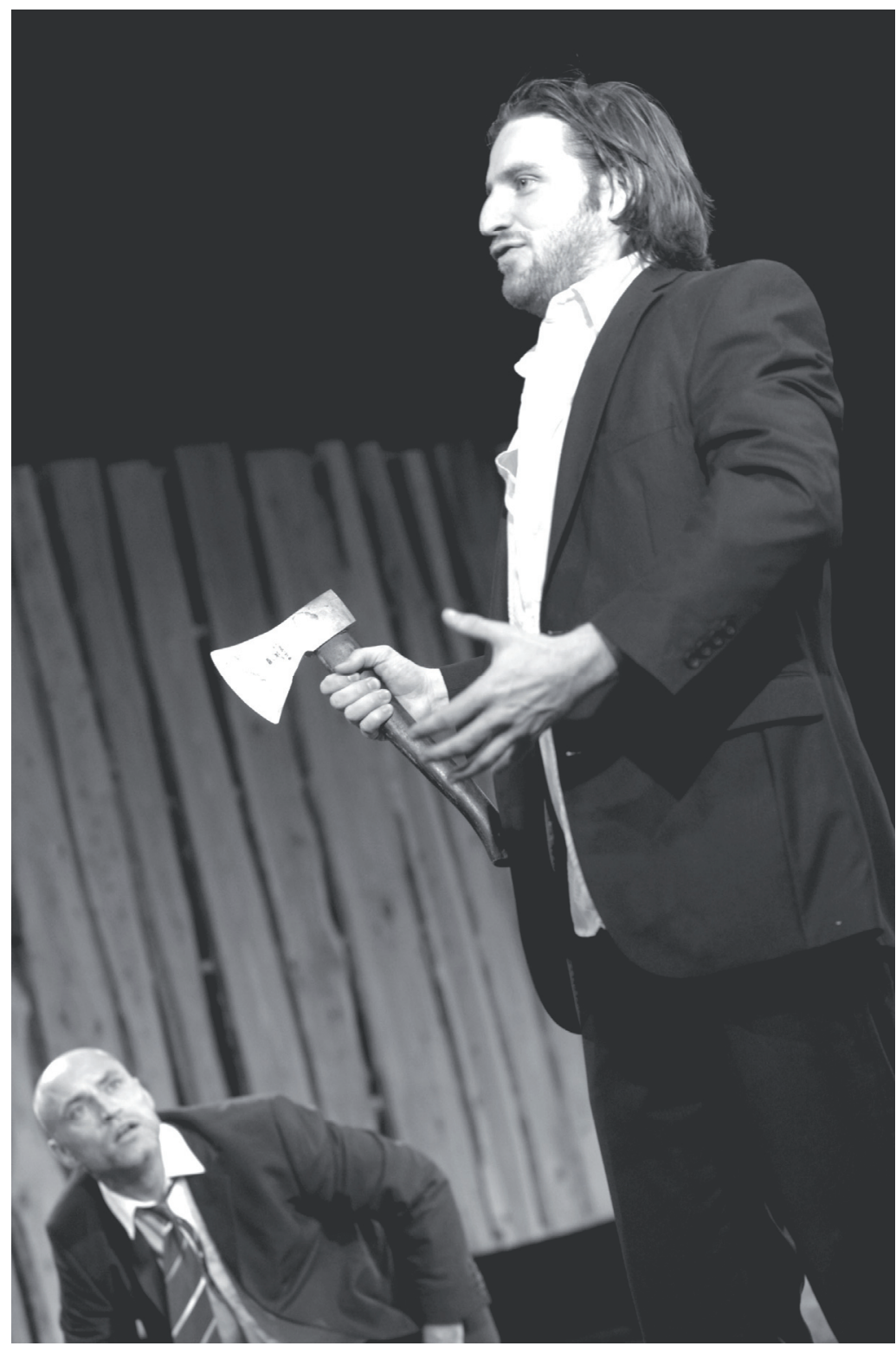

»Es müsste doch in der Welt so eingerichtet sein, dass jeder Mensch wenigstens eine Stelle hätte, wo jemand Mitleid mit ihm hat!«

Marmeladow (Silvio Hildebrandt) und Raskolnikow (Jonas Hien) 


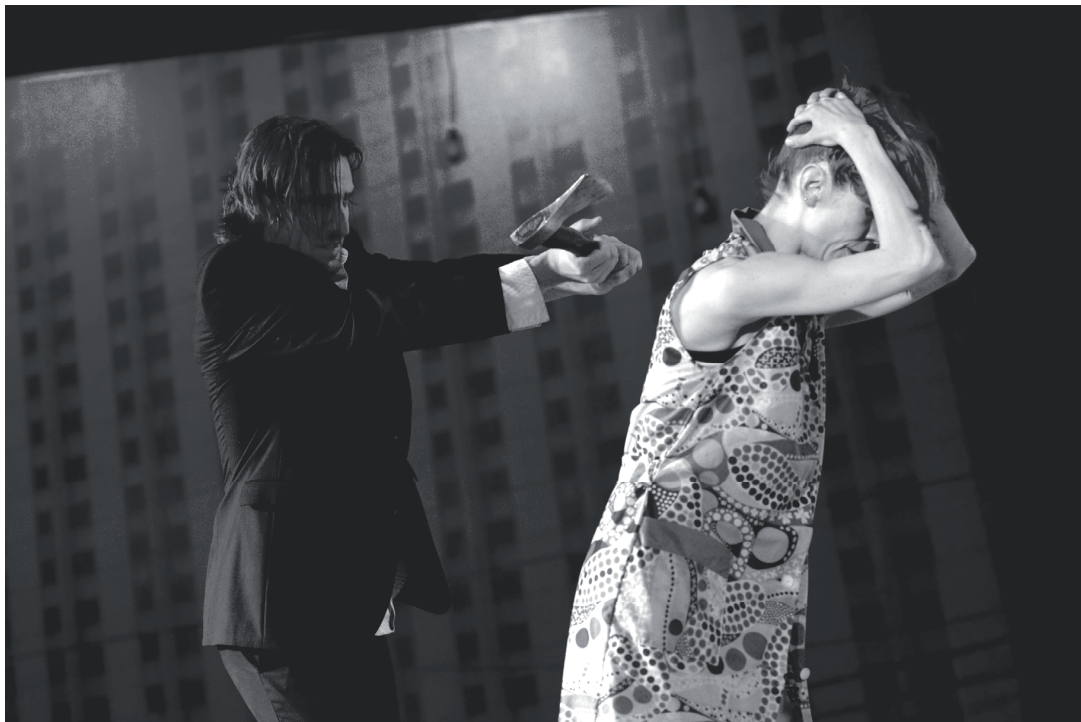

Raskolnikow (Jonas Hien) und die Pfandleiherin Aljona (Michaela Winterstein)

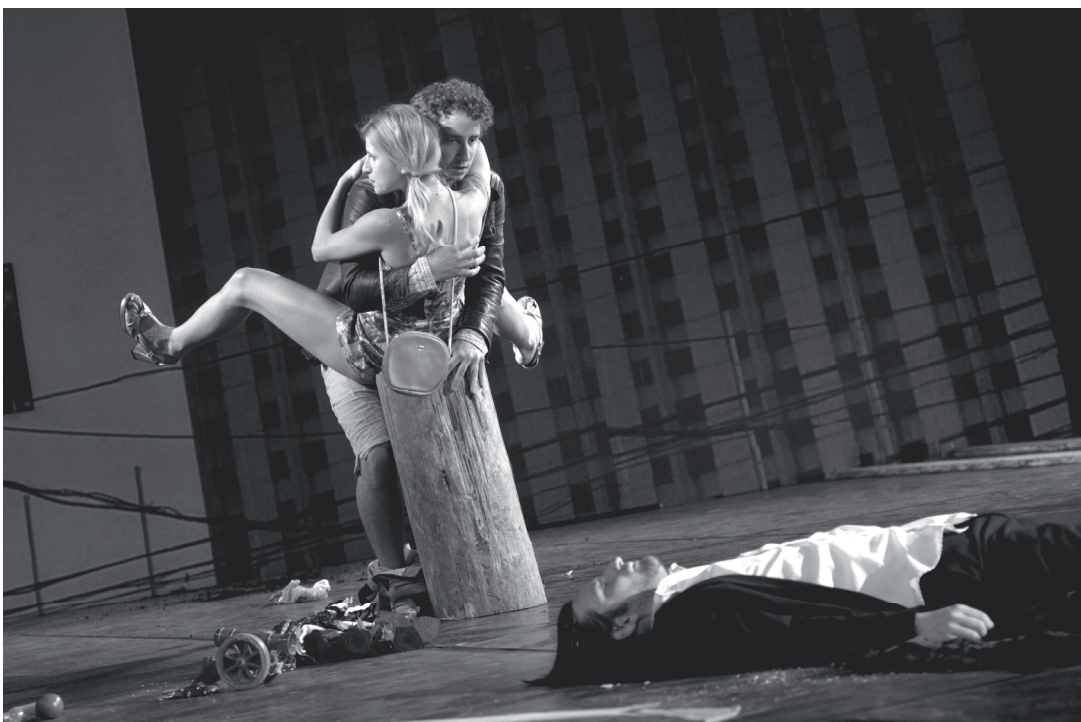

Sonja (Katharina Brankatschk), Rasumichin (Bastian Reiber) und Raskolnikow (Jonas Hien) 


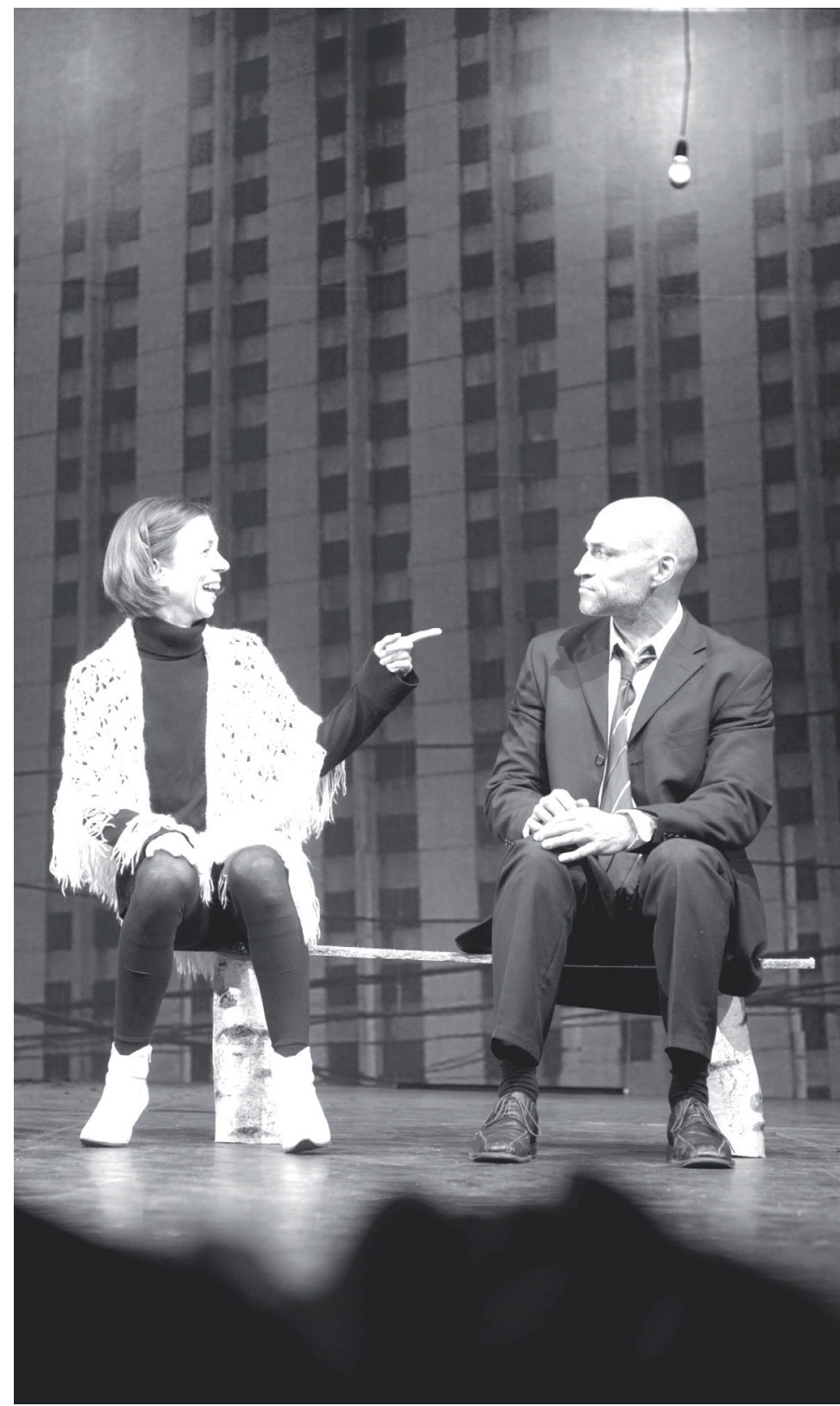

Ivanowna (Michaela Winterstein) und Marmeladow (Silvio Hildebrandt)

Gudrun Goes - 978-3-86688-194-5 


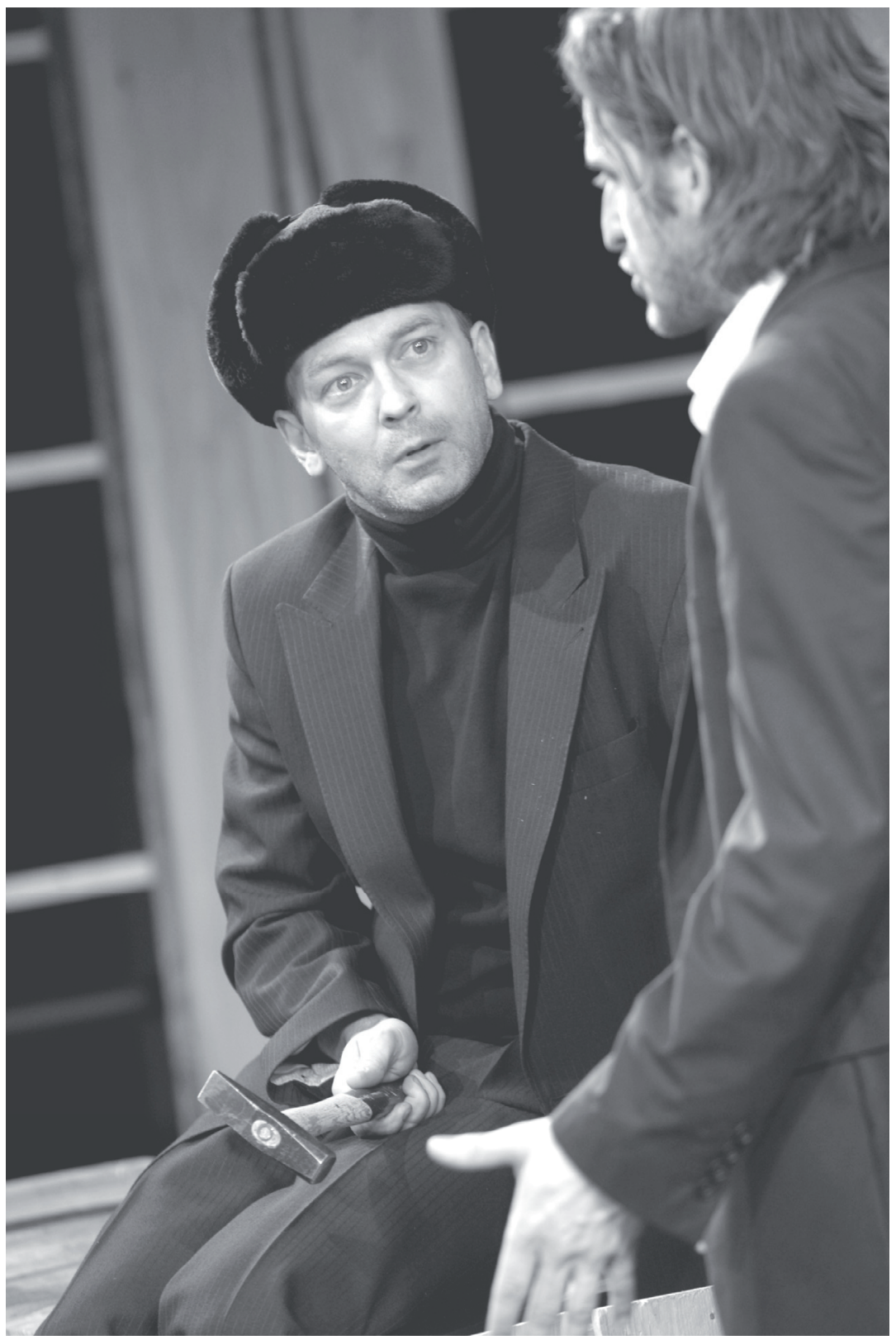

Porfirij (Axel Strothmann) und Raskolnikow (Jonas Hien) 


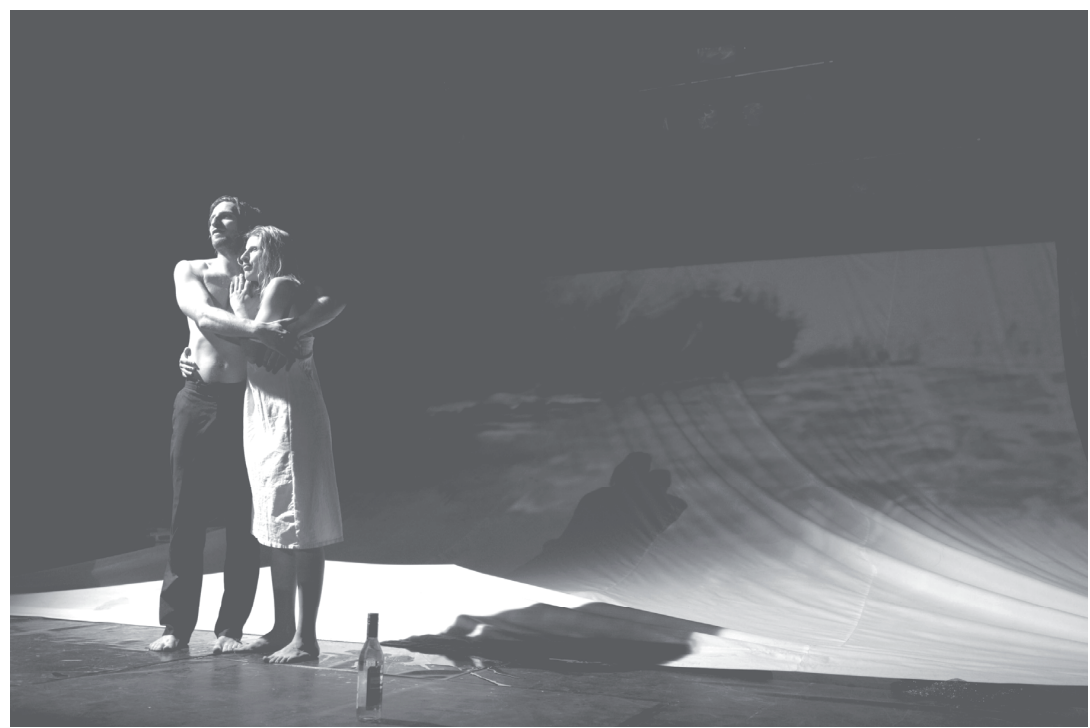

»Leben heißt töten.« Raskolnikow (Jonas Hien) und Sonja (Katharina Brankatschk) 


\section{Eine vergleichende Analyse ausgewählter stofflich-thematischer Aspekte in Dostojewskijs "Schuld und Sühne“ und der gleich- namigen Inszenierung am Magdeburger Schauspielhaus}

\section{Vorbemerkung}

„Jochymski und sein Team nutzen den Plot des Romans in totaler Freiheit als Material, um das Publikum mit provokanten Fragen zum heutigen Lebensinn [sic!] zu konfrontieren". ${ }^{1}$

Wie die Volksstimme Magdeburg hier bereits andeutet, veränderte der Regisseur Jan Jochymski den Roman "Schuld und Sühne“ von Fjodor Dostojewskij sehr, um die Handlung und die dahinterstehende Idee auf die heutige Zeit und die aktuellen Verhältnisse zu beziehen. Am 17. Oktober 2009 feierte das Stück am Magdeburger Schauspielhaus Premiere.

In der folgenden Arbeit soll verglichen werden, wie ausgewählte zentrale Aspekte des Romans in der Jochymski-Inszenierung umgesetzt, verändert oder gegebenenfalls erweitert werden. Zuerst wird der Aspekt der Prostitution (Kapitel zwei) untersucht, der in enger Verbindung zum Aspekt der Religion steht (Kapitel drei). Es folgt eine Untersuchung des Aspekts des außergewöhnlichen Menschen (Kapitel vier) und abschließend des Todes (Kapitel fünf).

Die Analyse erfolgt auf der Grundlage der Textfassung des Theaters Magdeburg vom 15.10.2009 und der „Verbrechen und Strafe“-Übersetzung von Swetlana Geier. Ein Vergleich zwischen einem Roman und einer entsprechenden Theaterinszenierung gestaltet sich schon aufgrund der beschränkten Spielzeit schwer, dennoch ist es möglich, gerade die von uns ausgewählten Aspekte vergleichend zu analysieren.

\section{Der Aspekt der Prostitution}

Das Phänomen der Prostitution, der käuflichen Liebe und Erotik ist zwar eine konstante Erscheinung in der Menschheitsgeschichte, jedoch erlebt es gerade in der Literatur des 19. Jahrhunderts einen Höhepunkt. Nicht nur in der zeitgenössischen französischen Kunst findet das Thema Anklang (erinnert sei hier nur an Alexandre Dumas' „Kameliendame“ oder an Honoré de Balzacs „Glanz und Elend der Kurti-

1 Volksstimme vom 18.10.2009 zitiert nach: Magdeburg Schauspielhaus (Hg.): Schuld und Sühne. Fjodor M. Dostojewskij. Auf: http://www.theater-magdeburg.de/front_content.php?idart=3837 (letzter Zugriff: 24.02.2010). 
sanen"), auch Dostojewskij verstand es, das allzu menschliche Faktum der Prostitution geschickt in seine Werke einzubinden, indem er Figuren schaffte, die dem scheinbar ehrlosen Gewerbe nachgehen.

Besonders interessant ist die Figur der Sonja in „Schuld und Sühne“ bzw. „Verbrechen und Strafe": Dostojewskij nutzt ihre Prostitution als Motiv und als Symbol, um auf etwas Höheres hinzuarbeiten.

"Sonja wurde zur Prostituierten, um ihre notleidende Familie zu unterstützen“.2 Sie ist die Tochter des Alkoholikers Marmeladow und stammt aus dessen erster Ehe. Katerina Iwanowna, ihre Stiefmutter, schickt sie auf die Straße, um Geld für die drei kleinen Stiefgeschwister und die Eltern zu verdienen. „Du wohnst bei uns, du Schmarotzerin, du ißt und trinkst und hast es schön warm!“, ${ }^{3}$ wirft Katerina ihr vor. Sonja fragt: „Wie, Katerina Iwanowna, soll ich das denn wirklich tun?" ${ }^{4}$ Die Antwort lautet: „Warum denn nicht? Was gibt es denn da zu hüten? Etwa einen Schatz?" ${ }^{\text {5 }}$

Somit ist Sonjas Schicksal besiegelt: „Um ihre Familie vor dem Hungertod zu bewahren, geht sie als Prostituierte auf die Straße. Sie nimmt die Selbsterniedrigung für ihre Angehörigen auf sich und opfert sich im Namen der Liebe und des Glaubens an den Menschen ". ${ }^{6}$ Sonja Marmeladowa erträgt ihr Leid und entsagt einem persönlichen Glück, indem sie ergeben ihr Schicksal annimmt und sich für den gelben Schein ${ }^{7}$ entscheidet, „um ihre Bereitschaft zum Dienen zu bekunden“.

Ihr Vater Marmeladow hindert sie nicht am Verkauf ihres Körpers; auch er erträgt das Schicksal. Im Zwiespalt zwischen Vatergefühlen und Geldnot (welche er verursachte), sieht er dem furchtbaren Geschehen aber nur wie gelähmt zu. Er erzählt von Sonjas erstem Gang auf die Straße:

„Sie kam herein, ging sogleich auf Katerina Iwanowna zu und legte schweigend dreißig Rubel ${ }^{9}$ vor sie auf den Tisch. Sie sprach kein Wort, sie hob nicht einmal die Augen, sie nahm nur unser großes grünes Tuch [...], verhüllte damit Gesicht und Kopf und legte sich auf das Bett [...], der ganze Körper zitterte ... Und ich lag noch immer da, wie vorher, im selben Zustand ... Und dann sah ich

2 Horst-Jürgen Gerigk: Die Sache der Dichtung: dargestellt an Shakespeares „Hamlet“, Hölderlins „Abendphantasie“ und Dostojewskijs „Schuld und Sühne“. Hürtgenwald 1991, S. 184.

3 Fjodor Dostojewskij: Verbrechen und Strafe. In der Neuübersetzung von Swetlana Geier. Frankfurt am Main 1997, S. 27 (1, II). Damit die Zitate in den verschiedenen Übersetzungen leichter auffindbar sind, werden in den Klammern der jeweilige Teil und als römische Zahl das jeweilige Kapitel des Romans angegeben.

4 Ebd.

5 Ebd.

6 Wolf Düwel (Hg.): Geschichte der russischen Literatur von den Anfängen bis 1917. Von der Mitte des 19. Jahrhunderts bis 1917. 2. Band. Berlin, Weimar 1986, S. 186.

7 Der gelbe Schein ist eine Art Ausweis, welcher in Russland von Polizisten an Prostituierte ausgegeben wurde.

8 Christel Roth-Müller: Die Verfemte in der Literatur. Zur Darstellung der Dirne in der Erzählkunst des 19. und 20. Jahrhunderts. Frankfurt am Main u. a. 1993, S. 134.

9 Auf den symbolischen Gehalt der „dreißig Rubel“ soll im nächsten Kapitel eingegangen werden. 
[...], wie Katerina Iwanowna, ebenfalls ohne ein Wort $\mathrm{zu}$ sprechen, an Sonetschkas Bettchen trat und den ganzen Abend am Fußende auf den Knien lag und ihr die Füße küßte $[. .$.$] ... Und ich ... ich lag da und war betrunken “. { }^{10}$

Seine Schilderung zeigt gleichzeitig, dass die Entscheidung für die Prostitution Sonjas für keines der Familienmitglieder leicht war. Dennoch wird das scheinbar unausweichliche Schicksal von allen angenommen. Marmeladow lebt nicht nur mit der Schande seiner Tochter, sondern sogar von ihr. Mag er auch als „heruntergekommenes Subjekt geringschätzig belächelt werden, den Scharfblick für die mannigfachen Spielarten der menschlichen Natur hat er sich bewahrt. Mut zu einer realistischen Bestandsaufnahme ist ihm nicht abzusprechen ". ${ }^{11}$ Er verspürt keine Wut gegenüber der Frau, die sein leibliches Kind auf die Straße schickt; er versteht vielmehr die Notwendigkeit von Sonjas Herabsteigen auf der sozialen Stufenleiter. Dennoch sieht er ihre Außergewöhnlichkeit. Sonja ertrinkt nicht im Selbstmitleid oder sucht nach einem Schuldigen, denn ein Blick auf die unschuldigen kleinen Kinder genügt ihr, um demütig und stumm das geächtete Gewerbe aufzunehmen. ${ }^{12}$ Ihr Vater zählt sie „zur Kategorie der Empfindsamen, da sie sich emotional der Wirklichkeit zuwendet“. ${ }^{13}$ Seine eigene Unzulänglichkeit lässt ihn das Leid seiner Tochter als unausweichlich annehmen.

Rodion Raskolnikow, Protagonist des Romans, sträubt sich gegen eine solche Abhängigkeit vom Leid seiner Nächsten, denn er befindet sich in einer ähnlichen Situation wie Marmeladow. In einem Brief seiner Mutter erfährt er von den Plänen seiner Schwester Dunja. Sie ist im Begriff, den „charakterlosen Karrieristen Luschin zu heiraten, nur um die finanzielle Lage des Bruders zu verbessern ", ${ }^{14}$ was Raskolnikow schwer trifft. Im Selbstgespräch äußert er: „Sind Sie, Dunetschka, sich im klaren darüber, daß Sonetschkas Los keineswegs schlimmer ist als Ihr Los an Herrn Luschins Seite?"15 Dunja will den gleichen Schritt wie Sonja gehen, nur auf einer von den bürgerlichen Konventionen sanktionierten Ebene. ${ }^{16}$ Zwar geht sie nicht als Dirne auf die Straße, doch sie gibt sich selbst auf, ,verkauft' ihr eigenes Glück für das ihres Bruders. „Das bereits vorliegende Schicksal Sonja Marmeladowas und das mögliche Schicksal seiner Schwester Dunja an der Seite Lushins fließen für Raskolnikow zu einem einzigen Anlaß der Empörung zusammen “. ${ }^{17}$ Beide Mädchen befinden sich im

10 Dostojewskij (1997), S. 27f. (1, II).

11 Roth-Müller (1993), S. 136.

12 Vgl. ebd.

13 Ebd.

14 Dietrich Wörn: F.M. Dostojewskis Roman „Schuld und Sühne“ oder „Verbrechen und Strafe“ eine Einführung. In: Heinz Setzer u. a. (Hg.): F.M. Dostojewski. Dichter, Denker, Visionär. Tübingen 1998, S. 48.

15 Dostojewskij (1997), S. 62 (1, IV).

16 Vgl. Wörn (1998), S. 48.

17 Gerigk (1991), S. 186. 
Würgegriff finanzieller Ohnmacht und im Gegensatz zu Marmeladow will Raskolnikow die Lösung, die seine Schwester vorschlägt, nicht annehmen. Marmeladow sieht Sonjas Selbstaufopferung zu; Raskolnikow stellt sich gegen Dunjas.

Dostojewskij wird eine enge Verbindung zur russischen Frauenbewegung nachgesagt $^{18}$ und er wollte hier zwei scheinbar unterschiedliche Frauenschicksale aufzeigen, die im Endeffekt doch einen gemeinsamen Auslöser haben: Unterdrückung durch das männliche Geschlecht. Die Bildung des Mannes und sein Wohlergehen standen über der Frau, doch der Autor begrüßte die neue Selbstständigkeit der Frau. „Durch Sonjas Funktion, den hochmütigen Mörder mit dem Menschlichen zu versöhnen, tritt in der Dialektik der Geschlechterbeziehungen eine Kehrtwende ein ". ${ }^{19}$ Unter anderem deshalb band Dostojewskij das Thema der Prostitution in seinen Roman ein. Um es von verschiedenen Seiten zu beleuchten, stattet er auch Dunja mit den Attributen der Demut und Opferbereitschaft aus. „Sie hat die Funktion, das Thema Unterordnung und Hingabe aus der Optik eines von sich selbst überzeugten Mädchens zu variieren. Der Kontrast zu Sonja liegt im Niveau der Bildung [...] “. ${ }^{20}$ Die Bildung Sonjas beschränkt sich auf die Lehre ihres Vaters über Geografie und ein wenig Geschichte. Das einzige Buch, welches sie vollkommen gelesen hat, ist die Bibel. Hierbei verbinden sich Dostojewskijs Motive der Prostitution und der Religion, denn bei aller Not und Schande ist es die Bibel, die Sonja den nötigen Halt verleiht. ${ }^{21}$

Nachdem die Zusammenhänge Sonja - Dunja bzw. Raskolnikow - Marmeladow betrachtet wurden, soll nun noch eine Beziehung zwischen Sonja und dem Protagonisten hergestellt werden, denn man wird die „Persönlichkeit Raskolnikows nicht anders verstehen können, als indem man in gewissem Sinne alle Personen des Romans als Teile seiner eigenen Psyche liest".22 Das Verbrechen des jungen Studenten steht in eindeutiger Analogie zur Prostitution Sonjas. Beide haben sich schuldig gemacht und eine Sünde begangen. Eine Grenze wurde überschritten: Raskolnikow tötete zwei Menschen; Sonja verkauft sich. Dieser Umstand führt beide in die gleiche Situation: „Das Ausgestoßensein aus dem Kreis der Geachteten“. ${ }^{23}$ Sie stehen außerhalb der Gesellschaft und außerhalb der Kirche. ${ }^{24}$ Doch während Raskolnikow nach einer Rechtfertigung sucht, seine Schuld nicht annimmt und an seiner Tat fast zerbricht, ist es Sonja, die Stärke ausstrahlt. In Demut erleidet sie ihre Sünde und findet

18 Vgl. Roth-Müller (1993), S. 132.

19 Ebd.

20 Ebd., S. 141.

21 Vgl. Eugen Drewermann: Daß auch der Allerniedrigste mein Bruder sei: Dostojewski - Dichter der Menschlichkeit. Fünf Betrachtungen. Zürich, Düsseldorf 1998, S. 148.

22 Ebd., S. 149.

23 Romano Guardini: Der Mensch und der Glaube. Versuche über die religiöse Existenz in Dostojewskijs großen Romanen. Leipzig 1932, S. 61.

24 Vgl. Birgit Harreß: Mensch und Welt in Dostoevskijs Werk: ein Beitrag zur poetischen Anthropologie. Köln u. a. 1993, S. 289. 
trotzdem die Kraft, nicht in ihr unterzugehen. Sie ist eine „Unschuld in der Maske des Lasters ${ }^{\text {“25 }}$ und trotz ihrer äußerlichen Schande innerlich rein geblieben. Den Rückhalt, der dazu nötig ist, findet sie im Vertrauen auf Gott, welches ihrem Dasein und dem Leben überhaupt einen Sinn verleiht. Raskolnikow erkennt nur langsam die Wahrheit, die in diesem Glauben steckt. Er selbst vergleicht sein Verbrechen mit Sonjas Prostitution:

„Hast du denn nicht dasselbe getan? Du hast auch ... überschritten ... Du hast es fertiggebracht, zu überschreiten. Du hast Hand an dich gelegt, du hast ein Leben vernichtet ... dein Leben (das macht keinen Unterschied!). [...] wir gehören also zusammen und haben denselben Weg". ${ }^{26}$

Erst im Epilog, als sich die beiden Protagonisten in Sibirien befinden, spürt man die Einsicht und das Verständnis Raskolnikows, als er vor Sonja auf die Knie fällt. Die Liebe spendet hier die ersehnte Erlösung von der Schuld; die Sühne wird geduldet. Nun können sich beide, sogar gemeinsam, Gott und dem Leben zuwenden und Raskolnikows vorherige Abwendung überwinden.

In der „Schuld und Sühne“-Inszenierung des Schauspielhauses Magdeburg wird der Aspekt der Prostitution ebenfalls verarbeitet. Im Roman haben wir Sonja Marmeladowa als ein Mädchen zwischen dichotomisierenden Extremen kennengelernt: Sie verkauft sich, sündigt dadurch, ist aber wegen ihres unerschütterlichen und festen Glaubens an Gott innerlich unschuldig und rein geblieben. Bei der Zeichnung seiner Figur lag für Dostojewskij der Fokus zweifelsfrei auf dem religiösen Aspekt. In der Theaterinszenierung wird diese Hierarchie nun umgekehrt.

Schon als Sonja zum ersten Mal auftritt (Szene vier: „Haare reißen“) und wir Zeuge werden, wie Katerina Iwanowna ihre Stieftochter auf die Straße schickt, um die Geldsorgen der Familie zu mindern, keimt in Sonja ein Gedanke, der gewissermaßen auf die Theodizee anspielt: „Was ist der Sinn von all der Trübseligkeit, von all dieser Langeweile mit sich selbst? Wenn Gott gewollt hat, dass wir erst im Himmel unser Glück finden, wenn wir erst im Himmel zu uns finden, warum dann die-

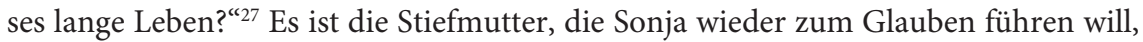
wenn auch aus niederen Motiven: „Heul nicht! Gott hat dich lieb! Schau dich an, wie schön du bist. Dich wärmt Gottes Gnade“.$^{28}$ Die Protagonistin wird nicht als gläubiges Gotteskind charakterisiert, sondern vielmehr als Zweiflerin. Dies verändert die Darstellung und Deutung ihrer Prostitution grundlegend. In Szene sechs („Nuttenschule") erleben wir Sonja mit ihrem ersten Freier, Rasumichin. Sie merkt, wie leicht es ihr fällt, einen Menschen zu erniedrigen, ${ }^{29}$ und ist stolz auf ihr erstes verdientes Geld. Die Überzeichnung und heftige Darstellung ihrer Käuflichkeit setzt sich auch

25 Roth-Müller (1993), S. 134.

26 Dostojewskij (1997), S. 444 (4, IV).

27 Theater Magdeburg (Hg.): Schuld und Sühne. Dostojewskij. Stand 15.10.2009, S. 13 (Szene 4).

28 Ebd.

29 Vgl. ebd., S. 18 (Szene 6). 
im Verlauf des Stückes fort. Beim Verhör des Untersuchungsrichters Porfirij (Szene elf: „Verhör 2“) gibt sich Sonja betont professionell und selbstbewusst. Auf die Frage, ob ihr der Job Spaß mache, antwortet sie: „Bei einem Vorschuss von 200 ja!" ${ }^{30}$ Zwar hat Sonja auch im Theaterstück die ehrlose Arbeit aufgenommen, um ihre notleidende Familie zu versorgen, doch schnell stellt sich heraus, dass sie, trotz des Fehlens eines festen christlichen Glaubens, ihr Schicksal annimmt und sich teilweise darüber sogar definieren und zu sich selbst finden kann. Sie lernt sich kennen, als Hure und als Mensch. Da der Ausgang der Geschichte in der Inszenierung vollkommen verändert wurde, fügt sich diese Darstellung Sonjas und die Betonung ihrer ,sündigen' Seite sehr gut in das Gesamtkonzept des Stücks. Sie ist nicht die Erlöserin, die Raskolnikow wieder zum Glauben und zum Leben führt, sie wird seine Verbündete in der Rebellion. Die Sühne bleibt aus. Somit ist Sonjas Aufgabe, Raskolnikows Auferstehung als geläuterten Menschen zu vollbringen, nicht existent und deshalb auch die Betonung ihrer religiösen Seite hinfällig. Wenden sich die beiden im Roman letztlich dem Leben wieder zu, endet das Stück mit den Worten: „Leben heißt töten!“31

Zusammenfassend kann hier festgehalten werden, dass die Inszenierung den Aspekt der Prostitution aus dem Roman übernimmt, ihn aber vollkommen anders attribuiert, charakterisiert und vor allem instrumentalisiert. Kann die Prostitution bei Dostojewskij, in Analogie zum Verbrechen Raskolnikows, als Mittel gesehen werden, dem Protagonisten den Weg zur Auferstehung zu zeigen, ${ }^{32}$ so stellt sie im Stück einzig und allein eine Gemeinsamkeit, nämlich die Grenzüberschreitung, zwischen Sonja und Raskolnikow her.

\section{Der Aspekt der Religion}

„Ich bin die Auferstehung und das Leben. Wer an mich glaubt, der wird leben, ob er gleich stürbe. Und wer da lebet und glaubet an mich, der wird nimmermehr sterben", heißt es im elften Kapitel des Johannes-Evangeliums. ${ }^{33}$

Der religiöse Gehalt in Dostojewskijs "Schuld und Sühne“ wird durch die Auferstehung des Lazarus im Neuen Testament symbolisiert. In ihr manifestiert sich die Einstellung des Autors zum christlichen Glauben.

30 Ebd., S. 34 (Szene 11).

31 Ebd., S. 44 (Szene 15).

32 Raskolnikow sieht bei Sonja, welche sich selbst durch die Prostitution schuldig macht, wie man doch ein reines Dasein führen kann: durch Demut, Opferbereitschaft und Hingabe bzw. Fügung. Ihm wird damit der Weg zu seiner eigenen Wiedergeburt vorgeführt.

33 Nach dem Johannesevangelium sind Lazarus und seine Schwestern Martha und Maria besondere Freunde von Jesus. Nachdem dieser in Abwesenheit von der Krankheit des Lazarus erfährt, reist er erst nach zwei Tagen nach Bethanien. Lazarus ist in der Zwischenzeit gestorben und bei der Ankunft Jesu bereits seit vier Tagen in einer Höhle beigesetzt. Jesus lässt den Stein vom Grab wegwälzen. Auf den Zuruf „Lazarus, komm heraus!“verlässt dieser - noch mit den Grabtüchern umwickelt - lebendig das Grab. 
Der Protagonist Raskolnikow bittet nach einem aufwühlenden polizeilichen Verhör die Prostituierte Sonja Marmeladowa, ihm die besagte Bibelstelle vorzulesen. Zögernd beginnt sie, ihre Hände zittern, ihre Stimme versagt und zweimal muss sie ansetzen ${ }^{34}$ doch dann trägt sie, beinahe auswendig, die Auferstehung des Lazarus vor. Warum lässt Dostojewskij seinen Helden gerade um diese Stelle bitten? Abgesehen davon, dass der Untersuchungsrichter Porfirij im Verhör bei Raskolnikow erfragte, ob er an Gott und die Geschichte des Lazarus wortwörtlich glaube, symbolisiert die Auferstehung in der Bibel die des Protagonisten. Denn das ist eine der Hauptaussagen des berühmten Romans: Ein Mensch, der ein Verbrechen begangen und sich vor Gott und der Gesellschaft schuldig gemacht hat, kann durch Sühne moralisch ,wiedergeboren' werden. Es ist Dostojewskijs Ziel, seinen Helden bei der Entwicklung zum geläuterten Menschen zu begleiten und die Möglichkeit zur sittlichen Auferstehung aufzuzeigen. Leitmotivisch wird die Auferweckung des Lazarus als Gleichnis für Raskolnikows Neubesinnung an mehreren Stellen alludiert. ${ }^{35}$

Sonja, in ihrer Rolle als Heldin des Romans, ist die Verkünderin dieser christlichen Lehre und die „Verkörperung der göttlichen Weisheit und Ordnung in einer zeitgemäßen Gestalt“. ${ }^{36} \mathrm{Ihr}$ „Interesse orientiert sich nicht an der Faktizität des an Lazarus geschehenen Wunders, sondern an ihrem symbolischen Gehalt [...] “. ${ }^{37}$ Für sie ist jeder Mensch, auch Raskolnikow, zur Erlösung durch moralische Läuterung fähig.

Geleitet von der bedingungslosen Nächstenliebe, wie im Neuen Testament beschrieben, überschreitet sie aus Mitleid mit ihrer Prostitution sogar eine moralische und christliche Grenze. Doch diese Übertretung bleibt eine rein äußerliche, ihr sittliches Wesen bleibt unangetastet. „Auf das Mordgeständnis Raskolnikows reagiert sie mit moralischer Zurückweisung, die aber übertroffen wird durch unendliches Mitleid mit dem unglücklichen Mörder“". ${ }^{38}$ Sie fällt ihm um den Hals, umarmt ihn ganz fest und sagt: „Was, was haben Sie sich nur angetan?“39 Raskolnikows Zurechtweisung und Rettung vollzieht sich erst durch Sonja auf religiös-anthropozentrischer Ebene.

Ihr Name geht zurück auf

„Sophia, die Bezeichnung für Weisheit, innerhalb der christlichen und besonders der orthodoxen Welt der Göttlichen Weisheit [...]. Sonja verkörpert [diese] göttliche Weisheit, die auch in Knechts- bzw. Magdgestalt, in der Gestalt eines

34 Vgl. Dostojewskij (1997), S. 440 (4, IV).

35 Vgl. Wörn (1998), S. 50.

36 Ebd., S. 53.

37 Konrad Onasch: Der verschwiegene Christus. Versuch über die Poetisierung des Christentums in der Dichtung F.M. Dostojewskis. Berlin 1976, S. 117.

38 Ebd.

39 Dostojewskij (1997), S. 556 (5, IV). 
einfachen, wenig gebildeten, armen und in lächerlicher Aufmachung der Prostitution nachgehenden Mädchens, ihre segensreiche und verwandelnde, zum Guten hinführende Wirkung ausübt“. ${ }^{40}$

Jedoch ist Sonja nicht, wie oft angenommen, als Allegorie für die orthodoxe Kirchlichkeit $\mathrm{zu}$ verstehen, sondern als Vertreterin eines neuen undogmatischen und menschlichen Christentums. Dies wird an der Zeichnung ihrer religiösen Seite sehr deutlich: Sie ist zwar eine "Gottesnärrin“ und "Gerechte“, geht aber selten in die Kirche, um sich dort Predigten anzuhören. Vielmehr trifft sie sich mit Lisaweta (der von Raskolnikow ebenfalls ermordeten Schwester der Pfandleiherin) im Geheimen und liest selbst in der Bibel. Dies steht im heftigen Gegensatz zum orthodoxen Glauben. „Die orthodoxe Kirche gestattete die private Bibellektüre nur unter der Kontrolle eines Geistlichen" ${ }^{41}$ Sonja emanzipiert sich demnach von den festen orthodoxen Regeln und bringt Dostojewskijs neues Verständnis einer Kirchlichkeit und Religiosität zum Ausdruck. Er beschäftigt sich grundsätzlich mit einer Abwendung von oder Hinwendung zu Gott: „Es geht in letzter Instanz immer nur um ein Ja oder Nein zu Gott“.42 Mit dem Mord hat sich Raskolnikow klar von Gott abgewendet und Sonja führt ihn, mit Liebe und Opferbereitschaft, wieder zu ihm.

Ihr Geheimnis liegt in den Worten der Bibel, sie ist im Einvernehmen mit Christus $^{43}$ und schöpft von dort ihre Kraft, ihr Schicksal und Leid zu ertragen sowie Raskolnikow den Weg zur Erlösung zu zeigen. Sie rät:

„Stell dich auf eine Kreuzung, verneige dich, küsse zuerst die Erde, die du geschändet hast, verneige dich dann vor aller Welt, nach allen vier Himmelsrichtungen und sage allen laut: >Ich habe gemordet.< Gott wird dir dann wieder Leben schenken. [...] Du sollst das Leid auf dich nehmen und dadurch die Erlösung finden, das sollst du tun“ ${ }^{4}$.

Raskolnikow findet in ihr die nötige Vergebung und Nächstenliebe, auch wenn er die Wahrhaftigkeit, die in Sonjas religiöser Existenz steckt, nur langsam anerkennt. Doch sie entgegnet ihm auf sein Misstrauen und Unverständnis mit der Feststellung, dass Gott alles für sie tut und ist. ${ }^{45}$ In diesen Worten manifestiert sich die reine religiöse Existenz und eine unglaublich innige Gotteskindschaft. ${ }^{46}$ Romano Guardini beschreibt Sonja folgendermaßen:

\footnotetext{
40 Wörn (1998), S. 53f.

41 Onasch (1976), S. 117.

42 Wörn (1998), S. 61.

43 Vgl. Guardini (1932), S. 77.

44 Dostojewskij (1997), S. 568 (5, IV).

45 Vgl. Dostojewskij (1997), S. 437 (4, IV).

46 Vgl. Guardini (1932), S. 72.
} 
„Sonja ist die innigste aller Frauengestalten Dostojewskijs. Man kann wohl sagen, daß sie sein Ausdruck für das Kind Gottes ist, und für jenes Geheimnis des Gottesreiches, wonach dieses zu den Kleinen und Unmündigen kommt und nicht zu den Großen und Weisen; Zöllner und Dirnen es aufnehmen, die Wohlgeordneten und Achtbaren aber sich ihm verschließen. So ist sie Kind Gottes in jener besonderen Weise, daß auf ihr die Unbegreiflichkeit göttlicher Fügung liegt". 47

Der Autor stattete seine Sonja, eine vor Gott und Welt erniedrigte Prostituierte, mit den Attributen der Läuterung und Erlösung aus, die als Erbe christlicher Lehre eher an männliches Gedankengut erinnern. ${ }^{48}$ Auch hier ist wieder Dostojewskijs Nähe zur Frauenbewegung und Emanzipation (im geschlechtsspezifischen sowie christlichen Sinne) spürbar. Ein Grundpfeiler seines Romans ist die Gegenüberstellung von Raskolnikows rationalem Denken und Sonjas emotionalem Handeln. Einfacher ausgedrückt: Bei dem ,Kampf' zwischen Herz und Kopf kann nur das Herz siegen. Sonjas Weg zur Erlösung ist der richtige und am Ende erkennt auch Raskolnikow, dass er sich mit ihrer Hilfe moralisch erneuern kann.

Für den religiösen Aspekt der Figur Sonjas ist auch der Kreis um sie nicht außer Acht zu lassen. Ihr Vater Marmeladow verkündet in seiner Version der „Wiederbringung aller“ am Tag des „Jüngsten Gerichts“ eine von der Kirche verdammte, von Dostojewskij jedoch befürwortete Lehre von der Liebe und Vergebung Gottes. ${ }^{49}$ In der Kneipe im Gespräch mit Raskolnikow entwickelt der Trinker folgende Gedanken:

„An jenem Tag wird Er kommen und fragen: > Wo ist die Tochter, die sich für die Stiefmutter, die böse und schwindsüchtige, und für die unmündigen Kindlein, die fremden, geopfert hat? Wo ist die Tochter, die sich ihres Vaters auf Erden, des unflätigen Trunkenbolds, ungeachtet des Tiers in ihm, erbarmt hat?< Und Er wird sagen: >Komme! Ich habe dir schon einmal vergeben. [...] So werden dir auch jetzt deine Sünden vergeben, denn du hast viel geliebt! $<$ [...] Er wird ihr vergeben ... Ich habe es vorhin, als ich bei ihr war, in meinem Herzen gespürt! ... Und Er wird uns alle richten und wird allen vergeben, den Guten wie den Bösen, den Weisen wie den Einfältigen ... Und dann, wenn Er alle gerichtet hat, dann wird Er auch zu uns sprechen: >Kommet hervor! < wird Er sagen, >kommet auch Ihr! Kommet, Ihr Trinker, kommet, Ihr Schwachen, kommet, Ihr Schändlichen! $<$ [...] Und Er wird Seine Arme ausbreiten, und wir werden Ihm zu Füßen fallen ... Und weinen ... Und alles erkennen! Dann werden wir alles erkennen" ${ }^{50}$

47 Ebd., S. 62.

48 Vgl. Roth-Müller (1993), S. 132.

49 Vgl. Onasch (1976), S. 105.

50 Dostojewskij (1997), S. 33f. (1, II). 
Diese einem Kirchenhymnus ähnelnde Tirade vom Jüngsten Gericht ${ }^{51}$ bindet der Autor in den Roman ein, um sein religiöses Bewusstsein auszudrücken. Er selbst war unzufrieden mit „der einseitigen Auflösung der Antinomie zwischen der Liebe Gottes und der Unbarmherzigkeit seines Gerichtsspruches über die Sünder" ${ }^{52}$ wie sie die orthodoxe Kirchlichkeit lieferte. Dostojewskij wollte das Bild eines Glaubens schaffen, welches auf Nächstenliebe und Vergebung basiert. Er selbst gewann in der sibirischen Verbannung eine Anschauung von einer alles verstehenden und verzeihenden Humanität ${ }^{53}$ und setzt sie nun der kirchlichen Lehre entgegen.

An dieser Stelle soll noch ein kleiner Exkurs zur symbolischen Verarbeitung biblischer Motive durch drei Aspekte vorgenommen werden.

Erstens hat die dreitägige Bewusstlosigkeit Raskolnikows eine höhere Bedeutung, wenn man entsprechend die Auferstehung des Lazarus zu Rate zieht. Dieser lag vier Tage tot in seinem Grab bevor Jesus ihn auferweckte. Den Zeitraum von vier Tagen betont Sonja besonders bei ihrer Lesung. „Raskolnikow hat durch sein Verbrechen den sittlichen Menschen in sich selber getötet, verfällt deshalb in den todesähnlichen Zustand einer Bewußtlosigkeit, aus der er am vierten Tag erwacht, um ins Leben zurückzukehren und den Sarg seiner gegenwärtigen Existenzform zu verlassen ". ${ }^{54}$ Zwar findet er tatsächlich erst Monate später in Sibirien am Flussufer wieder zurück ins Leben, doch die Motivik der Lazarus-Auferstehung ist nicht von der Hand zu weisen.

Zweitens sind es noch sieben Jahre, die Raskolnikow im Zwangslager in Sibirien bleiben muss, nachdem er langsam und stufenweise moralisch wiedergeboren wurde und endlich Reue, wahrhaftige Schuld, empfindet. Sonja und er haben zueinander gefunden, lieben sich und sehen der ,allmählichen Erneuerung entgegen: „Sieben Jahre, nur sieben Jahre! In der ersten Zeit ihres Glücks, in manchen Augenblicken, waren beide versucht, diese sieben Jahre für sieben Tage zu halten " ${ }^{55}$ Und an dieser Stelle offenbart sich ein Bezug zu der wohl wichtigsten Auferstehungsgeschichte der Bibel. Die Kreuzigung Jesu Christi und seine darauffolgende Auferstehung werden im Christentum in der Osterwoche zelebriert, das heißt in sieben Tagen. Denkbar wäre hier außerdem ein Bezug zur siebentägigen Schöpfungsgeschichte im ersten Buch Mose, da eine Wiedergeburt auch eine Neuschöpfung sein kann. Fest steht, dass die sieben Jahre in Sibirien eine Metapher für den „Prozeß des neuen Lebens" ${ }^{\text {“56 }}$ sind.

Drittens verdient Sonja bei ihrer ersten Prostitution genau dreißig Rubel, welche sie beim Heimkehren wortlos auf den Tisch vor ihre Stiefmutter Katerina Iwanowna legt. Dreißig Taler waren auch der Lohn, den Judas für seinen Verrat an Jesus erhielt. Dostojewskij stellt hier diesen biblischen Bezug her, da sich Sonja gewissermaßen

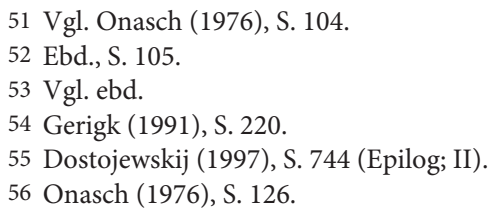


auch des Verrats schuldig macht. Sie wirft sich selbst weg, zwar auf Drängen Katerinas und um der Familie zu helfen, aber sie verrät sich selbst, ihre Ideale und religiösmoralischen Vorstellungen; die dreißig Rubel sind ihr Judaslohn.

Dostojewskij schenkte dem Aspekt der Religion in seinem Roman "Schuld und Sühne" augenscheinlich besondere Aufmerksamkeit. Nun stellt sich die Frage, wie es sich mit dem religiösen Aspekt bei der Theaterinszenierung am Schauspielhaus Magdeburg verhält.

Natürlich wird auch dort Religiöses eingebunden, wenngleich in umgekehrt intendierter Weise. Das Christusbild Dostojewskijs ist das eines humanitären Lichtpunkts, der den Menschen aufrichtet und ihm vergibt. ${ }^{57}$ Der Autor entwirft folglich eine Vorstellung von einer verzeihenden und liebenden Religion. In dem Theaterstück „Schuld und Sühne" nach Dostojewskij kann deshalb das Thema des Glaubens nicht ausgelassen, aber sehr wohl uminterpretiert werden.

Manifestiert sich das Religiöse im Roman größtenteils durch die Auferstehung des Lazarus, so findet sich auch im Theaterstück ein wichtiges Bibelzitat, welches die religiöse Intention der Theatermacher offenbaren könnte. In Szene acht („Blut lecken") möchte Sonja dem verzweifelten Raskolnikow ihre Kreuzkette schenken. Dabei erzählt sie die Geschichte eines Mannes aus dem 15. Kapitel des Lukas-Evangeliums:

Dort steht geschrieben, dass ein Mann zwei Söhne hatte. Der Jüngere verlangte nach seinem Erbteil und der Vater händigte dieses aus. Der Sohn ging daraufhin fort, verprasste das ganze Geld und dachte sich dann, in größter Not, er werde zum Vater zurückkehren und dort als Knecht arbeiten. Als er aber ankam, hatte der Vater großes Mitleid. Er küsste seinen heimgekehrten Sohn und sprach: „Nun lasst uns ein großes Fest feiern, denn mein Sohn war verloren und ist wiedergefunden worden. Er war tot und lebt wieder“ ${ }^{\text {" }}{ }^{58}$ Hier wird also, im übertragenen Sinne, auch eine Geschichte der Auferstehung erzählt. Durch Leid und Mitleid kann der verlorene Sohn neu beginnen, moralisch geläutert und bedingungslos geliebt. Diese Botschaft wird uns auch im Roman mit auf den Weg gegeben und kann auf das Schicksal Raskolnikows übertragen werden. Die Erzählung zeigt, dass dem Menschen vergeben werden kann, wenn er bereut. So kann sich auch Raskolnikow durch Reue und Sühne erneuern. Im Gegensatz zur Lazarus-Geschichte, bei der ein Mann buchstäblich vom Tode aufersteht, passt das Gleichnis vom verlorenen Sohn, welcher gesündigt, aber zum rechten Leben zurückgefunden hat, sogar noch besser zum Protagonisten. Die Betonung liegt hier auf der Humanität, nicht auf dem Gottglauben. Die Religion tritt hinter die Menschlichkeit und Nächstenliebe. Deshalb ist das Gleichnis vom verlorenen Sohn für das Theaterstück durchaus zeitgemäß.

Für Dostojewskij sind gerade seine Figuren Träger einer religiösen Botschaft. Sonja ist Prostituierte und gleichzeitig eine "Gottesnärrin“, die Betonung liegt ein-

57 Vgl. Drewermann (1998), S. 162.

58 Theater Magdeburg (2009), S. 25 (Szene 8). 
deutig auf dem religiösen Aspekt. In der Inszenierung wird dieser Fokus ins Gegenteil verkehrt: Sonja tritt vor allem als Prostituierte auf und weniger als Gläubige. Schon in Szene vier („Haare reißen“) entwickelt sie Zweifel an Gott und seiner Güte $^{59}$ und im Gespräch mit Raskolnikow in Szene acht („Blut lecken“) antwortet Sonja auf die zynische Frage, ob sie an Gott glaube, mit einiger Gefühllosigkeit und ohne wirkliche Überzeugung: „Ja klar! Er ist mir alles. Was wäre ich ohne ihn?"60 Zwar sind das die gleichen Worte wie im Roman, doch durch den Ton und den situativen Zusammenhang entsteht ein neues Bild. Vielleicht ist die Intention der Theatermacher, eine moderne und aktuelle Religiosität darzustellen: In Deutschland war im Jahr 2008 der Großteil der Bevölkerung als konfessionslos gemeldet und selbst wenn man heute einer Konfession angehört, heißt das nicht, dass man wirklich und bedingungslos an Gott glaubt. Wir haben möglicherweise unseren Glauben verloren. Die Religion kann uns keinen Halt geben. Es steht außer Frage, dass sie anwesend ist, aber sie hat ihre Rolle eingebüßt. Die Figur der Sonja könnte die Verkörperung eines solchen modernen Christen sein: Der Glaube existiert nur ,auf dem Papier' und an der Oberfläche; man richtet sich im täglichen Leben nur noch selten nach christlichen Werten.

Raskolnikow wird als überzeugter Atheist dargestellt. Zwar hat er sich auch in der Theaterinszenierung von Gott abgewendet, doch er verspürt hier nicht das Verlangen, sich ihm wieder zuzuwenden. Mit fast schon wahnsinniger Eindringlichkeit äußert er: „Was für ein Gott? Es gibt keinen Gott. Es gibt ihn einfach nicht. Bumm! Raus aus der Menschheitsgeschichte.“, „Wo hat sich dein Gott versteckt?“ und „Es gibt keinen Scheißgott!““ ${ }^{61}$ Raskolnikow vergöttert lieber sich selbst ${ }^{62}$ und entwickelt mit seiner Theorie des außergewöhnlichen Menschen ${ }^{63}$ das Selbstbild eines Erlösers. Dieser Akzent kann auch erklären, warum im Stück ein Bezug zu Martin Scorseses Film „Taxi Driver“ hergestellt wird. Dort wird das Leben des einsamen und isolierten, in einer Großstadt lebenden Taxifahrers Travis Bickle geschildert. Er ist von der Gewalt und dem Schmutz der Stadt in den 1970er Jahren zunehmend angewidert und steigert sich immer weiter in seine Obsession hinein, die Straßen selbst säubern zu müssen. In Szene drei der „Schuld und Sühne“-Inszenierung („Affenschweine“) sagt Raskolnikow: „Endlich hat es geregnet. Dreck und Abfälle wurden von den Bürgersteigen gespült. Eines Tages wird ein großer Regen diesen ganzen Abschaum von der Straße spülen" ${ }^{64}$ Auf der einen Seite erinnert diese Metaphorik stark an die Sintflut im Alten Testament, bei der die in Sünde verfallene Menschheit größtenteils ausgelöscht wurde. Auf der anderen Seite ist es bemerkenswert, dass Raskolnikow ausgerechnet auf dem Weg zur alten Pfandleiherin diese

\footnotetext{
59 Auf die Theodizee wurde in Kapitel zwei schon eingegangen.

60 Theater Magdeburg (2009), S. 25 (Szene 8).

61 Ebd., S. 25f. (Szene 8).

62 Vgl. ebd., S. 32 (Szene 10).

63 Siehe nächstes Kapitel.

64 Ebd., S. 8 (Szene 3).
} 
Überlegungen anstellt. Er will sie ermorden, weil sie seiner Meinung nach eine Laus ist und des Lebens nicht würdig. Lassen wir außer Acht, ob dies wirklich das Motiv Raskolnikows sein kann, so ist in diesem Zusammenhang doch anzumerken, dass sich der Protagonist dazu berufen fühlt, die „Laus“ zu zerstören. Er sieht sich demnach gewissermaßen als Vollzieher des Jüngsten Gerichts. Im Gegensatz zum Roman, in dem Marmeladow die "Wiederbringung aller" durchdenkt, wird im Stück kein Bild eines gütigen Gottes gezeichnet. Raskolnikow, in seiner maßlosen Selbstüberschätzung, redet sich ein, dass er außergewöhnlich sei, die Welt vom Abschaum erlösen müsse und damit rechtfertigt er seinen Doppelmord. Dabei ist es Raskolnikow selbst, welcher erlöst werden muss: von seiner Schuld. Im Roman zeigt Sonja ihm den Weg zur sittlichen Wiedergeburt. Da nun aber der Akzent ihrer Rolle in der Inszenierung nicht auf ihrer Religiosität, sondern auf ihrer Prostitution liegt, kann sie hier nicht die Verkünderin einer moralischen Erneuerung sein. Diese Aufgabe übernimmt scheinbar der Untersuchungsrichter Porfirij, denn in Szene zwölf („Verhör 3“) erwähnt dieser, fast beiläufig, wie sich Raskolnikow zu verhalten habe: „Sie sollten Reue und Leid auf sich nehmen ". ${ }^{65} \mathrm{Im}$ Endeffekt ist das die Essenz dessen, was Sonja dem Schuldigen im Roman rät. Durch die veränderte Verteilung der Rollen und die andere Gewichtung personaler Eigenschaften übernimmt Porfirij im Stück nicht nur die Aufdeckung des Verbrechens im juristischen Sinne, sondern fordert Raskolnikow auch zur Läuterung auf. Doch der Protagonist findet hier einen anderen Ausweg aus seiner Schuld. Er sucht die Vergebung, die er benötigt, um sein Leben sinnvoll weiterzuführen, nicht bei Gott, sondern bei einem Menschen: Sonja. Szene vierzehn („Vergib mir“) zeigt eindrucksvoll, wie schlecht es Raskolnikow nach der Tat mit sich selbst und der Schuld geht. Zuerst fordert er: „Erlöse mich Sonja. [...] Ich bin eine Laus. Töte mich. Erlöse mich “. ${ }^{66}$ Doch dann erkennt er seinen Lebenswillen und fleht Sonja um Vergebung an. Eine Frau, die selbst gesündigt hat, vergibt Raskolnikow seine Sünden und schenkt ihm damit das Leben. Porfirij hingegen, welcher für eine Reue vor dem Gesetz und vor Gott plädierte, wird von beiden symbolisch gekreuzigt. Interpretieren kann man diese Szene wohl, ganz im Sinne Dostojewskijs, als ein ,Nein' zu Gott und ein ,Ja' zum Menschen.

Zusammenfassend lässt sich sagen, dass in beiden Medien versucht wurde, ein aktuelles Bild vom Glauben zu entwerfen: Dostojewskij stellte sich mit seinem christlichen Humanismus gegen die orthodoxe Kirche; die Theatermacher zeigen einen modernen Glauben an den Menschen, welcher über dem an Gott steht. Die Reue im religiösen Sinn bleibt im Stück aus, denn der Protagonist hat durch einen Menschen, dem er sich verbunden fühlt, Vergebung erfahren. Buße vor Gott wird damit hinfällig und eine andere Erkenntnis tritt an diese Stelle: „Leben heißt töten!“67

65 Theater Magdeburg (2009), S. 41 (Szene 12).

66 Ebd., S. 43 (Szene 14).

67 Ebd., S. 44 (Szene 15). 


\section{Der Aspekt des außergewöhnlichen Menschen}

Als Dostojewskij „Schuld und Sühne“ verfasste, kam er in Kontakt mit der Geschichte Julius Cäsars von Napoleon III. (1808-1873), in welcher „sich der Autor überschwenglich zur außergewöhnlichen historischen Rolle von Persönlichkeiten wie Julius Cäsar, Karl der Große und Napoleon bekennt“ ". ${ }^{68}$

Die "Napoleon-Idee“ greift Dostojewskij offensichtlich in seinem Roman auf und gibt sie dem Protagonisten Raskolnikow anheim, der sie als Beweggrund für den Mord an der alten Pfandleiherin Aljona Iwanowna benutzt. Die Orientierung an Napoleon und anderen historischen Persönlichkeiten veranlasst Raskolnikow zwischen außergewöhnlichen und gewöhnlichen Menschen zu unterscheiden. Im ersten Gespräch mit Porfirij Petrowitsch, dem ermittelnden Staatsanwalt, wird Raskolnikow an einen Aufsatz „Über das Verbrechen“ erinnert, den er als Student verfasste. Darin schildert er die Teilung der Menschen in gewöhnliche und außergewöhnliche: Ein außergewöhnlicher Mensch besäße das selbstgesetzte Recht, „gewisse Hindernisse zu überschreiten, und zwar einzig und allein in dem Falle, wenn die Verwirklichung seiner Idee (die vielleicht die ganze Menschheit retten könnte) es erfordert " ${ }^{\prime}{ }^{69}$ Diese Hindernisse können auch andere Menschen sein, die durch Mord beseitigt werden dürften, wenn der außergewöhnliche Mensch etwas Neues zu sagen hätte und wenn jenes der Menschheit und der Verbesserung der Lebensumstände dienlich sei. ${ }^{70}$ Der gewöhnliche Mensch sei nur Material; er sei nur eine Laus. Auch die alte Pfandleiherin Aljona Iwanowna wird später mit dem Begriff der „Laus“ bezeichnet.

Raskolnikow glaubt, sich zu den Außergewöhnlichen zählen zu können. Er plant, die Alte umzubringen, um mit ihrem Geld die Situation vieler anderer Menschen verbessern zu können. Unterstützt wird dieser Gedanke durch das ganze Leid, dass Raskolnikow täglich in Petersburg wahrnimmt. Der Säufer Marmeladow lebt in ärmlichen Verhältnissen. Seine Tochter muss sich für die Familie prostituieren, um ihre drei kleinen Halbgeschwister, ihren Vater und ihre Stiefmutter versorgen zu können. Raskolnikow empfindet

„tiefe Unzufriedenheit [...] mit der ungerechten Struktur der Klassengesellschaft und [...] tiefe Abscheu gegen schmarotzerhafte Aristokraten und Großgrundbesitzer, die skrupellosen Unternehmer, die raffgierigen Bankiers und Kapitalisten, die als herrschende Klasse rücksichtslos über Leben und Tod von Millionen einfacher Menschen entscheiden".71

Dostojewskijs Roman ist antikapitalistisch - im christlichen, nicht im kommunistischen Sinn.$^{72}$ Allerdings ist Raskolnikows Idee unhaltbar, „weil sie sich gegen den Menschen richtet" ${ }^{\text {" }}$

68 Düwel (1986), S. 184.

69 Dostojewskij (1997), S. 350 (3, V).

70 Vgl. ebd., S. 351 (3, V).

71 Düwel (1984), S. 185.

72 Vgl. Gerigk (1991), S. 180. 
Doch ursprünglich ist es nicht sein eigener Gedanke, die Frau zu erschlagen, um anderen mit deren Geld helfen zu können, und möglicherweise Leben zu retten. Im sechsten Kapitel des ersten Teils baut der Autor geschickt einen Rückblick ein: Die dargestellte Handlung liegt einen Monat zurück. Raskolnikow befindet sich in einem Wirtshaus und verfolgt die Unterhaltung eines Studenten mit einem jungen Offizier. Beide reden von der Pfandleiherin, von der Raskolnikow zu diesem Zeitpunkt gerade kam, um etwas zu versetzen. Sie sei reich wie ein Jude und ein schlimmes Luder, berichtet der Student. ${ }^{74}$ Sie schlage ihre Schwester Lisaweta unaufhörlich und habe sie auch in ihrem Testament nicht mit Geld bedacht. ${ }^{75}$ Der Student kommt folglich zu dem Fazit: „Ich könnte diese verdammte Alte ermorden und ausrauben, und zwar ohne die leisesten Gewissensbisse [...]“ ${ }^{\text {“ }}{ }^{76}$ Er erklärt weiterhin: „Auf der einen Seite ein dummes, $[\ldots]$ böses und krankes altes Weib, das kein Mensch braucht und das $[\ldots]$ alle schädigt [...] und auf der anderen Seite junge, frische Kräfte, die einfach zugrunde gehen, weil es für sie keine Hilfe gibt ". ${ }^{77}$ Der Student ist der Überzeugung, mit dem Geld der Pfandleiherin könne das Leben einiger tausend Menschen verbessert werden und er glaubt, ein so „winziges" Verbrechen würde durch zahlreiche gute Taten wettgemacht werden: „Ein Leben als Preis für Tausende von Leben, die vor Verfall und Fäulnis gerettet werden - ein Tod gegen hundert Leben - das ist doch Arithmetik ${ }^{\text {“ }}{ }^{78}$ Bei der an dieser Stelle geäußerten Idee handelt es sich um einen negativen Utilitarismus. Dieser will nicht das Glück vieler vergrößern, sondern beabsichtigt, das Leid vieler zu vermindern. Das utilitaristische Gedankengut wurde zu der Entstehungszeit des Romans „,in Russland rebellisch diskutiert“ ${ }^{79}$

Diese Gedanken sind es, die Raskolnikow aufnimmt, in sich keimen lässt und die ihn schlussendlich zur Mordtat treiben, denn auch er steht der Pfandleiherin mit großer Abneigung gegenüber.

Doch sehr schnell wird deutlich, dass der Mord an Aljona Iwanowna nicht aus utilitaristischen Beweggründen geschah, denn er erschlug nicht nur die Alte, sondern auch deren Schwester, wodurch sich der geplante Mord zum ungeplanten Doppelmord wandelt. Horst-Jürgen Gerigk ist der Meinung, dass Raskolnikows Schuld gewissermaßen in zwei Teile gespalten wird, ${ }^{80}$ nämlich ,in einen Teil, der sich diskutieren läßt, und einen Teil, der sich nicht diskutieren läßt" ${ }^{\text {81 }}$ Sein Gewissen, repräsentiert durch Sonja Marmeladowa, meldet sich. Während der erste Mord sich noch

73 Düwel (1984), S. 185.

74 Vgl. Dostojewskij (1997), S. 88 (1, VI).

75 Vgl. ebd., S. 89.

76 Ebd., S. 90.

77 Ebd.

78 Ebd., S. 91.

79 Fritz R. Glunk: Dostojewskijs Schuld und Sühne. München 2000, S. 55.

80 An dieser Stelle ist zu erwähnen, dass der Name Raskolnikow auf das russische raskol zurückgeht, was soviel bedeutet wie, spalten'.

81 Gerigk (1991), S. 192. 
rechtfertigen lässt, zeigt der Mord an Lisaweta Iwanonwa das Böse in Raskolnikow auf. „Das Böse hat für Dostojewskij sein Wesen darin, um seiner selbst willen gewollt $\mathrm{zu}$ werden - es hat kein vernünftiges Motiv“ ${ }^{82}$ Was Gerigk hier aussagen will, ist, dass der erste Mord durch die dahinter stehende Idee, mit dem Geld der Pfandleiherin Gutes zu tun, „vernünftig“ motiviert werden kann, wohingegen der Mord an Lisaweta geschieht, um die Untat zu verdecken. „Sein [Raskolnikows, J. P.] Handeln hat also hier nur die Perfektion des Verbrechens zum > vernünftigen< Grund. Er öffnet sich damit vollkommen dem Sog des Bösen, das immer nur sich selbst will“". ${ }^{83}$ Auf der anderen Seite ist es eben diese böse Macht, die Raskolnikow in sich trägt und die es gleichzeitig erst möglich macht, überhaupt diesen einen - und ersten Mord zu begehen, nur dass hier ein utilitaristischer, altruistischer „Vorwand ${ }^{\text {“ } 84}$ vorliegt, wodurch der Leser dazu neigt, diese Tat eher zu rechtfertigen und „verstehen“ zu können.

Auch anderweitig wird deutlich, warum Raskolnikow eigentlich gemordet hat: Er wollte feststellen, ob auch er ein außergewöhnlicher Mensch sei, ob auch er eine Grenze überschreiten könne. Untermauert wird diese These dadurch, dass er nicht einmal das gesamte Geld der Pfandleiherin mitnimmt, sondern die Dinge, die er gestohlen hat, versteckt und damit nicht andere Menschen von ihrem Leid befreit, so wie es anfangs geplant war, um den Mord zu rechtfertigen. Im Gespräch mit Sonja gesteht er, warum er getötet hat: „Ich wollte damals in Erfahrung bringen, und zwar so schnell wie möglich, ob ich eine Laus bin wie alle anderen oder ein Mensch" ${ }^{.85}$ Doch er kommt zu der Erkenntnis, dass er „kein Napoleon“" ${ }^{\text {“6 }}$ ist. Die Argumente, die Raskolnikow zunächst hervorbringt, sind nur „unhaltbare Ausflüchte, Selbsttäuschung und Lüge“. 87

Außerdem empfindet Raskolnikow Lust daran, mit dem Verdacht zu spielen: Er geht zurück an den Tatort und auch das Gespräch mit Alexander Samjotow, dem Vorsteher des Polizeibüros, ist von der „Lust am Vernunftwidrigen “88 geprägt. Raskolnikow erzählt ihm ungeniert, wie er vorgegangen wäre, wenn er der Täter gewesen wäre „und dabei erzählt er genau, wie es gewesen ist" [Hervorhebung von mir, J. P.]. ${ }^{89}$

Der Aspekt des außergewöhnlichen Menschen ist auch in die Inszenierung des Magdeburger Schauspielhauses integriert:

Bereits in der ersten Szene („Sibirien“) keimt die Idee der Auserwählten, der außergewöhnlichen Menschen. Raskolnikow träumt von einer Seuche, die die gesamte

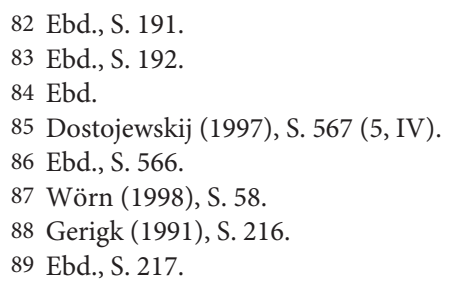


Welt befalle. Nur einige wenige Auserwählte überlebten die Krankheit. Der Traum entspricht dem des Romans, nur dass er dort im Epilog auftaucht. Raskolnikow befindet sich - wie auch in der Theaterinszenierung - in Sibirien, wo er seine Haftstrafe verbüßt, nachdem er den Mord an den zwei Frauen gestanden hat.

In der zweiten Szene („Darwinfalle), fragt sich Raskolnikow - nachdem er aus einer Ohnmacht erwacht - ob er eine Laus oder ein Mensch sei, und ob er eine Grenze überschreiten könne. Erste Andeutungen auf die bevorstehende Tat folgen: „Eine große Sache habe ich vor und fürchte ich mich vor Kleinigkeiten“ ${ }^{90}$ Es folgt ein Dialog zwischen Raskolnikow und seinem Kommilitonen Rasumichin über die Selektionstheorie nach Darwin. In seinem Buch „On the Origin of Species“ von 1859 (also nur wenige Jahre bevor Dostojewskij seinen berühmten Roman verfasste) behauptete Charles Darwin, dass die Evolution das Ergebnis eines Prozesses sei, den Darwin als natürliche Auswahl bezeichnete. ${ }^{91}$ Nur diejenigen Lebewesen, die am besten an die Bedingungen der Umgebung angepasst seien, überleben, wohingegen diejenigen, die nicht mit den nötigen Voraussetzungen versehen sind, nicht bestehen. ${ }^{92}$

Diese Gedanken greift auch Rasumichin auf. Er erläutert: „Die Tauglichsten überleben, die weniger Geeigneten gehen zu Grunde ${ }^{.93}$ Mit der Aufnahme der darwinschen Theorie wird der Aspekt des außergewöhnlichen Menschen in der Inszenierung erweitert. Wie Jan Jochymski selbst äußerte, folgte für die moderne Zeit aus der Diskussion um außergewöhnliche und gewöhnliche Menschen unweigerlich die Diskussion um Darwinismus und Selektion. Dostojewskij verarbeitete in seinem Roman noch nicht die Ideen Darwins, obwohl sie ihm sicherlich bekannt waren.

Raskolnikow stellt Rasumichin die rhetorische Frage, ob er denn nie das Gefühl gehabt habe, besser zu sein, als manch anderer Mensch. „Meinst du nicht, dass alle Menschheitsführer, alle Napoleons zum Beispiel, sich als etwas Besseres gefühlt haben? Und mit Recht, denn sie hatten eine neue Idee!" ${ }^{\text {"94 }}$ Vorher räsonierten Rasumichin und Raskolnikow über die Theorie des Darwinismus. An dieser Stelle werden nun Assoziationen mit der Theorie des Sozialdarwinismus, die Aspekte der Überlegungen Charles Darwins auf das Menschengeschlecht überträgt, geknüpft: Raskolnikow behauptet, dass sich im „Kampf ums Dasein“ die stärkeren Menschen als Folge natürlicher Selektion durchsetzen würden.

Raskolnikow erläutert seine Annahme der „Zweigeteilten“ Menschheit in gewöhnliche und außergewöhnliche Menschen, wobei letztere - genau wie im Roman - das Recht hätten, Gesetze zu übertreten, das Bestehende zu zerstören und Besseres herbeizuführen..$^{95}$

90 Theater Magdeburg (2009), S. 3 (Szene 2).

91 Vgl. Anthony Giddens: Soziologie. Graz, Wien 1995, S. 39.

92 Vgl. ebd.

93 Theater Magdeburg (2009), S. 5 (Szene 2).

94 Ebd.

95 Vgl. ebd., S. 3. 
Im Unterschied zum Roman ist es Raskolnikow selbst, der die utilitaristische und altruistisch begründete Idee hat, die alte Pfandleiherin umzubringen, um mit ihrem Besitz das Leben anderer zu retten:

„Also, auf der einen Seite ein dummes, unnützes, böses altes Weib, das kein Mensch braucht und das selbst nicht wei ${ }^{96}$ wozu es lebt und morgen sowieso sterben wird. Und auf der anderen Seite junge, hoffnungsvolle Kräfte, die einfach zugrunde gehen, weil es für sei [sic!] keine Hilfe gibt, und zwar zu Tausenden, und überall! Hunderte Tausende von guten Taten könnte man in Angriff nehmen und verwirklichen mit dem Geld der Alten! ${ }^{[97}$

In Dostojewskijs Roman waren das noch die Worte des Studenten, die Raskolnikow zufällig gehört hat. ${ }^{98}$

Erneut fragt sich Raskolnikow, wie auch schon in der ersten Szene, ob er eine Laus oder ein Mensch sei; ob er imstande sei, die Grenze zu überschreiten; ob sein Herz zu solch einem Schritt - dem Mord - fähig sei - und er fragt: „Wer bin ich?““.99 An dieser Stelle wird ganz deutlich, dass auch der Raskolnikow des Theaterstückes wahrheitsgemäß nicht aus altruistischen Gründen mordet, sondern weil er für sich begreifen will, ob er dazu die Fähigkeit habe und ob er einer dieser auserwählten, außergewöhnlichen Menschen sei. Er will durch den Mord erkennen, wer er selbst ist. Insgeheim scheint er aber zu wissen, dass die Tat moralisch nicht gutzuheißen ist, denn er fragt sich: „was wäre denn, wenn Napoleon an meiner Stelle gewesen wäre und $[\ldots]$ statt all dieser monumentalen Dinge schlicht und einfach eine dumme Scheißfrau, eine Pfandleiherin [...] hätte umbringen müssen [...]. Napoleon hätte ihr den Hals umgedreht, [...] ohne jedes Überlegen!" 100 Immer wieder muss Raskolnikow seine Gedanken und seine Handlungen mit den großen Persönlichkeiten der Weltgeschichte rechtfertigen. Sein Argument scheint stets zu lauten: Auch Napoleon hätte es getan.

In der 14. Szene („Vergib mir“) gesteht Raskolnikow Sonja, die zwei Frauen ermordet zu haben. Er verlangt von ihr, ihn zu töten und ihn zu erlösen von seinem bösen Herz. ${ }^{101}$ Auch der „Theater-Raskolnikow“ erkennt, dass er kein Napoleon ist.

96 Sämtliche Rechtschreib-, Zeichensetzungs- und Syntaxfehler in der Textfassung des Theaters wurden aufgrund der geltenden wissenschaftlichen Zitierregeln auch so übernommen.

97 Ebd., S. 10 (Szene 3).

98 Überhaupt arbeitet der Autor viel mit dem Prinzip des Zufalls, der Raskolnikow letztlich doch dazu bewegt, seine Tat zu vollziehen: Zufällig erfährt er auf dem Markt, dass Lisaweta am Abend, an dem Rodion Raskolnikow den Mord begeht, nicht anwesend sein wird. Ebenfalls nur zufällig erhascht er das Beil des Hausknechtes seines Wohnhauses: An das Beil, das er aus der Küche seiner Wirtin nehmen wollte, kam er nicht heran, weil sich dort Nastassja, das Dienstmädchen, aufhielt.

99 Ebd., S. 14 (Szene 5).

100 Ebd.

101 Vgl. ebd., S. 43 (Szene 14). 
Er bezeichnet sich selbst als Laus, will dann aber leben und bittet Sonja um Verzeihung.

Doch schlussendlich - wie die letzte Szene zeigt - scheint Raskolnikow seine Taten im Gegensatz zum Roman nicht zu sühnen: Er befindet sich mit Sonja in Sibirien und äußert: „Wir müssen einsehen, eine Gleichheit der Menschen ist sozialer Schwachsinn und unsere verweichlichte Lebensweise wird unweigerlich zum Stillstand und schließlich zum Untergang unserer Art führen. Leben heißt töten!"102

Zusammenfassend kann festgehalten werden, dass das Theaterstück den Aspekt des außergewöhnlichen Menschen übernimmt, ihn sogar teilweise wortwörtlich wiedergibt, aber im Gegensatz zum Roman die Theorien Darwins aufgenommen werden.

\section{Der Aspekt des Todes}

\section{Der Tod Semjon Sacharytsch Marmeladows}

Bevor der eigentliche Tod Marmeladows untersucht werden soll, wird zunächst auf die erste Begegnung zwischen dem Protagonisten und dem Beamten eingegangen, in der sich bereits Andeutungen auf den Tod Marmeladows finden.

Raskolnikow trifft den ehemaligen Titularrat Semjon Sacharytsch Marmeladow in einem Wirtshaus (1, II). Er ist arm und hat infolge seiner Trunksucht auch noch seinen Arbeitsplatz verloren. Er vertrinkt das gesamte Geld der Familie, wodurch seine Tochter gezwungen ist, sich zu prostituieren. „Auf diese Weise zieht Marmeladov im Sog seines eigenen Untergangs den seiner gesamten Familie mit sich". ${ }^{103}$ Der ehemalige Titularrat ist sich dessen bewusst und fühlt sich deswegen schuldig, wodurch der Wille zum Leiden entsteht: ,je mehr ich trinke, desto tiefer fühle ich mit. Deshalb trinke ich ja, weil ich im Trinken Mitleid und Gefühle suche ... Weil ich noch einmal so tief leiden will“" ${ }^{104} \mathrm{Je}$ mehr er sich schuldig fühlt, desto mehr trinkt er, und desto mehr sehnt er sich nach dem Tod. Insofern lässt sich von einem unbewusst herbeigerufenen Selbstmord sprechen, durch den sich Marmeladow „der göttlichen Gerichtsbarkeit zu unterwerfen" ${ }^{105}$ sucht.

Durch den Alkohol verfällt er sowohl innerlich als auch äußerlich: „Er war ein Mann in den Fünfzigern, mittelgroß, korpulent, ergraut, mit großer Glatze, von einem vom Trinken gedunsenen, gelben fast grünlichen Gesicht und geschwollenen Liedern" ${ }^{106}$ Auffällig ist hier vor allem die gelbe Gesichtsfarbe. Im gesamten Roman spielt diese Farbe eine besondere Rolle: Sie steht leitmotivisch für Verfall und Tod. ${ }^{107}$

102 Ebd., S. 44 (Szene 15).

103 Thomas Freynik: Die Todesproblematik im Schaffen von F.M. Dostoevskij. Hamburg 2000, S. 193.

104 Dostojewskij (1997), S. 23 (1, II).

105 Freynik (2000), S. 202.

106 Dostojewskij (1997), S. 18 (1, II).

107 Vgl. Freynik (2000), S. 193. 
In dem Gespräch mit Raskolnikow deutet sich das bevorstehende Ableben Marmeladows bereits an. Sein selbstverschuldeter Verfall ist schleichend und lässt sich als „ein Sterben vor dem natürlichen Tod“"108 beschreiben. Doch er glaubt daran, dass Gott ihm verzeihen wird, so wie er allen verzeihen wird: „Und dann, wenn Er alle gerichtet hat, dann wird Er auch zu uns sprechen: >Kommet hervor! $<$ wird Er sagen, > kommet auch Ihr! Kommet, ihr Trinker, kommet ihr Schwachen, kommet, Ihr Schändlichen!". ${ }^{109}$ An dieser Stelle wird deutlich, wie sehr sich Marmeladow seines nahenden Todes bereits bewusst ist. Er wendet sich an Gott, ${ }^{110}$ in der Hoffnung, auch ihm würde sein Fehlverhalten verziehen werden. Er denkt sich förmlich zu Tode, weil seine Angst vor einer Bestrafung in der Hölle derartig groß ist. ${ }^{111}$

Laut Thomas Freynik deutet auch der Wohnraum, in dem Marmeladow mit seiner Familie haust, auf das bevorstehende Sterben hin. Nach dem Gespräch im Wirtshaus begleitet Raskolnikow den Trinker nach Hause, was folgendermaßen beschrieben wird: „Sie betraten das Haus vom Hof her und stiegen in den vierten Stock hinauf. Je höher man kam, desto finsterer wurde das Treppenhaus. [...] und obwohl es in Petersburg um diese Jahreszeit keine eigentlichen Nächte gibt, war es oben ziemlich dunkel“". ${ }^{112}$ Der Treppenaufstieg wird hier mit Finsternis und somit mit Tod assoziiert. Auch die Art des Zimmers lässt Rückschlüsse zu. Es ist ein Durchgangszimmer, welches „in diesem Sinne einen Übergang als einen vorübergehenden Aufenthaltsort zwischen Tod und Erneuerung die Zwischenlagerung der Seelen "113 symbolisiert. Es könnte aber auch mit dem Fegefeuer - als Station zwischen Himmel und Hölle - gleichgesetzt werden.

Im siebten Kapitel des zweiten Teils erfährt der Leser von Marmeladows Unfall mit der Pferdekutsche. Er blutet stark, sein Gesicht ist durch die Pferdehufe entstellt. Raskolnikow stützt ihn und bringt ihn heim. Dort betrachten lauter Schaulustige das Spektakel. So wie sich die Gäste und der Wirt in der Kneipe über Marmeladow lustig gemacht haben, so wird er auch jetzt - trotz des bevorstehenden Todes - mit Spott gestraft.

Außerdem findet sich bei der Beschreibung des körperlichen Zustandes Marmeladows nach dem Unfall erneut die motivische Farbe Gelb wieder: „rechts waren mehrere Rippen gebrochen, links, direkt über dem Herzen, zeigte sich eine unheimliche, große, gelblich-schwarze Verfärbung ".114 Der Verfall und der Tod stehen unmittelbar bevor. Als letzten Wunsch erbittet sich der Sterbende einen Priester.

108 Ebd.

109 Dostjojewskij (1997), S. 34.

110 Die Zuwendung zu Gott erfolgt, obwohl Marmeladow kein gläubiger Mensch ist. Erst im Angesicht des Todes und einer damit verbundenen Strafe wendet er sich der Religion zu. Hier findet sich eine Parallele zu Raskolnikow.

111 Vgl. Freynik (2000), S. 197.

112 Dostojewskij (1997), S. 35.

113 Freynik (2000), S. 199.

114 Dostojewskij (1997), S. 247. 
Noch einmal wird verdeutlicht, dass er sich nun - im Angesicht des Todes - Gott zuwendet und auf dessen Erlösung hofft.

Die Figur des Trinkers wird im Schauspiel auf vergleichbare Weise übernommen, sein Tod sogar noch offensichtlicher zugespitzt als im Roman.

Auch in der Theater-Inszenierung konstatiert Marmeladow, dass er so viel trinke, damit er tiefer fühle, weil er (Selbst-)Mitleid und Gefühle suche. Außerdem spielt ebenso hier das Motiv des Leidens eine Rolle. ${ }^{115}$

Um seinen persönlichen Verfall, der durch den Alkohol weiter fortschreitet, zu stoppen, lässt sich Marmeladow ein Implantat einsetzen, das sich nicht mit Alkohol verträgt. Er hält fest: „Mit jedem weiteren Schluck, sterbe ich ein Stück früher!“116 Demnach ist er sich bewusst, was das Trinken in Zukunft für Konsequenzen haben kann. Er berichtet seiner Frau, dass die Operation nicht ganz billig war, aber er es für sich und die Familie getan habe. Im Gegensatz zum Roman versucht Marmeladow hier, seine Familie aus dem Sog des Verfalls zu befreien. Doch er hält es nicht beständig aus, wie die Regieanweisung in Szene vier beweist: „Sie [Katerina Iwanowna, J. P.] trinkt, auch Marmeladow greift aus Gewohnheit zur Flasche, es durchfährt ihn. Marmeladow muss sich übergeben ". ${ }^{117}$ Es bleibt nicht bei einer einmaligen alkoholischen Entgleisung.

Genauso wie in Dostojewskijs Roman wird Marmeladow auch in der JochymskiInszenierung Opfer von Hohn und Spott. Hier ist es der ermittelnde Staatsanwalt Porfirij, der über den ehemaligen Titularrat spottet und seine Naivität und seinen Verfall ausnutzt. Obwohl Porfirij bereits weiß, wer der Mörder der beiden Schwestern ist, beschuldigt er Marmeladow, der aufgrund seiner jahrelangen Trunksucht ein verringertes Erinnerungsvermögen besitzt. ${ }^{118}$ Am Anfang der Beschuldigungen bleibt Marmeladow noch standhaft und erzählt von seinem Implantat, das es ihm unmöglich macht, Alkohol zu genießen. Doch je mehr sich Porfirij über Marmeladow amüsiert („Wem soll ich glauben? Einem abgehalfterten Alkoholiker - oder diesem jungen Studenten? ${ }^{\text {“119) }}$, umso unsicherer wird der Trinker. Zum Schluss gesteht er sogar den Mord, weil er seinem eigenen Erinnerungsvermögen nicht trauen kann.

In Szene 13 kauft Marmeladow eine Kiste Wodka. Davon trinkt er etwas und muss sich krümmen. Immer wieder greift er zur Flasche und versucht, seine Frau zu küssen. Sie wehrt sich anfangs, lässt aber dann doch einen Kuss zu, allerdings nur unter der Bedingung, dass er weiter trinkt. Durch dieses „Besäufnis“ kommt er dem Tod aber immer näher und stirbt schlussendlich. ${ }^{120}$ Obwohl Marmeladow genau weiß, welche Konsequenzen der Alkohol für ihn hat, trinkt er immer weiter. Bewusst

115 Vgl. Theater Magdeburg (2009), S. 10 (Szene 3).

116 Ebd., S. 11 (Szene 4).

117 Ebd., S. 12 (Szene 4).

118 Vgl. ebd., S. 37 (Szene 12).

119 Ebd., S. 39 (Szene 12).

120 Vgl. ebd., S. 42 (Szene 13). 
leitet er so seinen Tod früher ein und begeht gewissermaßen Selbstmord. In der Inszenierung ist der Suizid wesentlich bewusster ausgearbeitet worden als im Roman. Marmeladow fühlt sich schuldig, da sich seine Tochter prostituieren muss. Er trinkt deswegen immer wieder Alkohol, der ihn jedoch leiden lässt. Doch danach sehnt er sich - genauso wie nach dem Tod und göttlicher Erlösung.

\section{Der Tod Arkadij Iwanowitsch Swidrigajlows}

Der Gutsbesitzer Arkadij Iwanowitsch Swidrigajlow gilt als „Alter Ego“ von Raskolnikow. Beide Persönlichkeiten sind ambivalent ausgerichtet. Im sechsten Kapitel des letzten Teils des Romans erfährt der Leser von Swidrigajlows Selbstmord. Im Folgenden wird untersucht, welche Bedeutung der Suizid und die Person Swidrigajlow für den Protagonisten haben. Zwar spielt weder der Tod des Gutsbesitzers noch die Person Swidrigajlow in der Aufführung eine Rolle, doch genau das Fehlen dieses Charakters verändert die „Geschichte“ grundlegend.

Wie bedeutend die Persönlichkeit des Swidrigajlows tatsächlich ist, wird daran deutlich, dass er die einzige Figur ist, die vom Erzähler in einzelnen Szenen und Kapiteln genau beschrieben wird (z. B. seine Träume und der Selbstmord im sechsten Kapitel des letzten Teils) und die in dieser Zeit Raskolnikow vertritt. ${ }^{121}$

Dem Leser präsentiert sich Arkadij Iwanowitsch Swidrigajlow „als bekennender Amoralist", ${ }^{22}$ der die Schranken der Gesellschaft bereits offenkundig übertreten ${ }^{123}$ hat, wohingegen Raskolnikow sich gerade erst „auf dem angestrebten Weg zur radikalen, gesellschaftliche Schranken übertretenden Ich-Autonomie “124 befindet.

Als Ursache für die anrüchige Lebensführung des Gutsbesitzers wird die von ihm verspürte Langeweile, die ihn regelrecht in sexuelle Ausschweifungen treibt, um sich seiner Existenz bewusst zu werden, betrachtet. ${ }^{125}$ Swidrigajlow gilt als Kontrastfigur zu Raskolnikow, die das auslebt, was jener eigentlich begehrt: Zwar gibt der Student vor, aus gesellschaftlichen - altruistischen - Gründen agiert zu haben. Es stellt sich jedoch bald heraus, dass das nicht das eigentliche Motiv des Mordes an der alten Frau und ihrer Schwester war, sondern dass Raskolnikow sich testen und erfahren wollte, ob er ein außergewöhnlicher Mensch sei. Swidrigajlow hingegen handelt „aus triebhafter Wollust und ebensolchem [...] Sadismus“. ${ }^{26}$ Er lebt demnach diejenigen Triebe aus, die Raskolnikow unterdrückt.

Raskolnikow und sein Alter Ego verbindet aber noch mehr: Beide stehen in einer engen Verbindung zu einer älteren, vermögenden Frau. Während Raskolnikow die Besitztümer der alten Pfandleiherin entwenden will, es aber nicht schafft, ihr Geld zu

121 Vgl. Gerigk (1991), S. 242.

122 Freynik (2000), S. 251.

123 Vgl. hierzu auch den Original-Titel: Prestuplenie $i$ nakazanie in etwa, ,Übertretung und Zurechtweisung.

124 Freynik (2000), S. 251.

125 Vgl. ebd., S. 254.

126 Ebd., S. 252. 
benutzen, nutzt Swidrigajlow die Reichtümer seiner Frau Marfa Petrowna, die ihn von seinen Schulden entlastet. Für die beiden Männer lässt sich gleichermaßen konstatieren: „Swidrigajlow gerät [...] in die vollkommene Abhängigkeit von einer Frau, die älter ist als er: auf Grund seiner finanziellen Ohnmacht. Dasselbe gilt für Raskolnikow [...] “. ${ }^{127}$ Sowohl der Student als auch der Gutsbesitzer ermorden die Frauen, wodurch aber nur Swidrigajlow seine Freiheit wiedergewinnt, an „der er dann paradoxerweise zugrunde geht". ${ }^{128}$ Raskolnikow hingegen verliert seine Freiheit, nicht nur im übertragenen Sinne, sondern auch tatsächlich durch die Haftstrafe, die er in Sibirien verbüßen muss.

Swidrigajlow gelingt das, was Raskolnikow ursprünglich wollte, aber nie geschafft hat: Das Geld der Marfa Petrowna verteilt Swidrigajlow großzügig, beispielsweise an die drei Kinder der verstorbenen Katerina Iwanowna Marmeladowa oder an Sonja, damit sie sich nicht weiter prostituieren muss und Raskolnikow nach Sibirien folgen kann. ${ }^{129}$

Mehrere Tode werden mit Swidrigajlow verbunden: Zum einen vergewaltigte er ein 14-jähriges Mädchen, das daraufhin Selbstmord verübte, genauso wie ein Bediensteter seines Hauses. Außerdem war er offensichtlich in den Tod seiner Frau Marfa Petrowna verwickelt. ${ }^{130}$ „Im Unterschied zu Raskol'nikov hat Svidrigajlov diese Todesfälle in sein Selbstbewußtsein integriert, verkörpert nach außen somit das, was Raskol'nikov nicht sein kann: ein selbstbewußter, triebhaften Leidenschaften gehorchender Amoralist". ${ }^{131}$

Aber es ist genau dieses amoralische Leben, das Swidrigajlow letztendlich in den Selbstmord treibt: „Er erschießt sich. Warum? Weil er mit dem Mißbrauch der menschlichen Freiheit nicht leben kann. Er verbindet das Glück der Vielen mit dem Tod seiner Ehefrau“. ${ }^{132}$ Nachdem sich Dunja, Raskolnikows Schwester, die er begehrt, ihm nun endgültig verweigert, löst das in ihm die Überzeugung aus, dass er sein Leben beenden muss.

Auch Raskolnikow denkt an Selbstmord, denn dieser ist neben dem Geständnis eine der Optionen, sein psychisches und körperliches Leiden, das aus dem Mord resultiert, zu beenden. Das drückt auch Swidrigajlow in einem Gespräch mit Sonja aus: „Rodion Romanowitsch hat zwei Wege vor sich: entweder eine Kugel in den Kopf oder die Wladimirka“". ${ }^{133}$ Diese Polarität wird eben durch die Figuren Swidrigajlow und Sonja vertreten: Der Gutsbesitzer steht für den Selbstmord, für die eine Option, die auch Raskolnikow offen steht. Oder er entscheidet sich für den Weg, den Sonja symbolisiert: das Geständnis mit anschließender Strafe. „Er kann dem Bösen

127 Gerigk (1991), S. 232.

128 Ebd.

129 Vgl. ebd., S. $232 f$.

130 Vgl. Freynik (2000), S. 252.

131 Ebd.

132 Gerigk (1991), S. 234.

133 Dostojewskij (1997), S. 677 (6, VI). 
folgen, indem er sich das Leben nimmt, oder er kann auf das Gute hören, indem er durch das Bekenntnis seiner Schuld zur Gemeinschaft zurückfindet ${ }^{\text {“ }}{ }^{134}$ Es entwickelt sich demnach eine Trichotomie zwischen Swidrigajlow - Raskolnikow - und Sonja, wobei man noch einen Schritt weitergehen kann: Nimmt man Sigmund Freuds Strukturmodell der Psyche als Grundlage an, stellt Swidrigajlow möglicherweise das ,Es' von Raskolnikow (,Ich') dar, Sonja dagegen das ,Über-Ich'. Raskolnikow entscheidet sich gegen den Selbstmord und für das Geständnis. Wie wichtig Swidrigajlow für diese Entscheidung tatsächlich ist, hat Thomas Freynik konstatiert: „Die Antwort auf die Frage nach Selbstmord oder Selbsterhaltung Raskol'nikovs entscheidet sich im Schicksal Svidrigajlovs. Dessen Selbstmord erweist sich als moralische Notwendigkeit für Raskol'nikovs Rückkehr in die ethische Ordnung “. ${ }^{135}$

Eine weitere Anspielung auf den Selbstmord enthält das Motiv der „Reise nach Amerika“. Swidrigajlow selbst vertuscht seinen Suizid, indem er sagt, er trete bald eine gewisse Reise an, die für den Freitod steht. Auch Raskolnikow rät er zur Reise nach Amerika: „dann machen Sie, daß sie so schnell wie möglich nach Amerika kommen! Verschwinden Sie [...]“. ${ }^{136}$

Swidrigajlow treibt die Handlung des Romans an sich nicht voran. Er erfährt durch Zufall, dass Raskolnikow die Alte umgebracht hat, als dieser es Sonja gesteht. Damit kann er aber das Wissen des Untersuchungsrichters Porfirij nicht erweitern, der ohnedies schon alles ahnt. Auch für das stetige Schwanken und die Wahl zwischen Selbstmord und Geständnis wird Swidrigajlow eigentlich nicht benötigt. ${ }^{137}$ Trotzdem ist er wichtig, um Raskolnikow zu charakterisieren. Swidrigajlow steht für das Skrupellose in Raskolnikow. Ohne ihn würde der innere Kampf im Protagonisten nicht vollständig zum Ausdruck gebracht werden.

Fällt die Figur des Swidrigajlows weg (so wie im Theaterstück), wird die Trichotomie Swidrigajlow - Raskolnikow - Sonja zu einseitig und die Seite der ethischen Ordnung (Sonja) wird überbetont, obwohl es doch im Roman letztlich und ursprünglich um den „Kampf zwischen Gut (verkörpert durch Sonja) und Böse“ (dargestellt durch Swidrigajlow), und vor allem um die Hinwendung zum Guten und Gott, geht. Dieser positive Ausgang kann aber ohne bösen Pol nicht funktionieren. Aus diesem Grund fehlt der Theateraufführung etwas, denn der innere Kampf Raskolnikows kommt nicht ausreichend zur Geltung. Andererseits lässt sich die Abwesenheit der Figur Swidrigajlows wohlmöglich folgendermaßen erklären: Wie wir bereits in den ersten Kapiteln betrachtet haben, werden auch die Apekte der Religion und Prostitution im Stück umgewandelt. Sonja, als naives und stark religiöses Mädchen, das sich nur aus Nächstenliebe prostituiert, wird als Figur in der Inszenierung völlig anders dargestellt. Demnach verliert dieser Pol an Bedeutung. Insofern

134 Harreß (1993), S. 288.

135 Freynik (2000), S. 252.

136 Dostojewskij (1997), S. 657 (6, V).

137 Vgl. Gerigk (2000), S. 230. 
braucht das Stück nicht den Gegenpol des Bösen, weil es auch das Gute nicht gibt. Außerdem sühnt Raskolnikow zum Schluss nicht, wendet sich also im Gegensatz zum Roman nicht Gott und der ethischen Ordnung zu. Wie oben bereits dargestellt, ist der Selbstmord Swidrigajlows die moralische Notwendigkeit für Raskolnikows Entscheidung für die heilsame Ordnung. Da diese Entscheidung, die Hinwendung zum Guten, zu Gott und zur Sühne aber nicht der Ausgang des Theaterstückes ist, braucht es Swidrigajlow und seinen Selbstmord nicht. Insofern wäre der Verzicht auf diese für den Roman so bedeutsame Figur gerechtfertigt.

\section{Schlussbemerkungen}

„Sich mit Dostojewski zu beschäftigen bedeutet, Trennmauern aufzusprengen und Schutzzonen wegzuräumen. [...] Alles, was [er, I. K.] zu sagen hat, ist das, was uns angeht, und es ist nur die Frage, wie viele Sperriegel der Abwehr und wie viele Blendläden des Nichtsehenkönnens oder -wollens wir uns erlauben auf dem Weg der unausweichlichen Selbstbegegnung “. ${ }^{138}$

Wir haben in dieser Arbeit versucht, besagte "Sperriegel“ zu entriegeln und hinter die Mauern des großen Romans „Schuld und Sühne“ zu blicken. Auch Jochymski, Regisseur der Theaterinszenierung, hat sich mit seinem Stück in die "Schutzzone“ gewagt und mit seiner Interpretation des Romans für eine „Selbstbegegnung“ des Zuschauers gesorgt.

Die Erkenntnisse unseres Vergleichs ausgewählter stofflich-thematischer Aspekte in "Schuld und Sühne" sind vielfältig:

Erstens haben wir festgestellt, dass die Inszenierung den Aspekt der Prostitution aus dem Roman übernimmt, ihn aber anders instrumentalisiert. Bei Dostojewskij ist er ein Mittel, dem Protagonisten den Weg zur Auferstehung zu zeigen, im Stück hingegen dient er dazu, die Gemeinsamkeit zwischen Sonja und Raskolnikow aufzuzeigen. Zweitens bedienen sich beide Medien der Religion in ähnlicher Intention und unterschiedlicher Art und Weise. In Buch und Stück wird versucht, ein aktuelles Bild vom Glauben zu entwerfen: Dostojewskij mit seinem humanitären Christentum und die Theatermacher mit ihrem Glauben an das Individuum. Doch der Einsatz und die Verarbeitung des Aspekts unterscheiden sich sehr. Der Roman arbeitet auf eine allmähliche Hinwendung zu Gott hin, Jochymski verharrt in der Abwendung von ihm. Drittens kann festgehalten werden, dass das Theaterstück auch den Aspekt des außergewöhnlichen Menschen aus dem Roman übernimmt, ihn sogar teilweise wortwörtlich wiedergibt und ihn außerdem um sozialdarwinistische Ansichten erweitert. Viertens haben wir erkannt, dass man den Aspekt des Todes in Roman und Theateraufführung differenziert betrachten muss. Die Figur des Trinkers wird im Schauspiel auf vergleichbare Weise übernommen und sein Tod zugespitzt. In beiden Fällen konstatiert Marmeladow, dass er so viel trinke, damit er tiefer fühle, weil er Mitleid suche. Demnach spielt ebenso das Motiv des Leidens eine Rolle. In der

138 Drewermann (1998), S. 133. 
Inszenierung ist der „Suizid“ Marmeladows bewusster hervorgerufen worden als im Roman. Der zweite Unterpunkt der Untersuchung betraf den Tod Swidrigajlows. Dieser gilt als „Alter Ego“ von Raskolnikow und steht in der Trichotomie Swidrigajlow - Raskolnikow - Sonja im Roman für das Böse und Triebhafte. Im Theaterstück fehlt diese Figur. Somit wird die "Geschichte“ grundlegend verändert: Die innere Zerrissenheit Raskolnikows kommt nicht so stark zur Geltung wie im Roman. Da aber auch die Figur der Sonja anders interpretiert wurde, braucht das Stück Swidrigajlow und seinen Tod nicht.

Letztlich ist festzustellen, dass Jochymski den Stoff des großen Romans „Schuld und Sühne" für seine Zwecke nutzt. Um provokant Stellung zur heutigen Zeit zu beziehen, muss er die Motive des Autors übernehmen und verändern. Dostojewskij ruft die "Selbstbegegnung" des Lesers mit sich hervor und auch Jochymski schafft es, das Publikum mit „Fragen zum heutigen Lebensinn [sic!] zu konfrontieren“ ${ }^{139}$

139 Volksstimme vom 18.10.2009 zitiert nach: Magdeburg Schauspielhaus (Hg.): Schuld und Sühne. Fjodor M. Dostojewskij. Auf: http://www.theater-magdeburg.de/front_content.php?idart $=3837$ (letzter Zugriff: 24.02.2010). 


\section{Dostojewskijs „Schuld und Sühne“ (Prestuplenie i nakazanie, 1866) als filmischer Albtraum bei Heithor Dhalia („Nina“ 2004) und Brad Anderson („The Machinist“ 2004)}

\section{Dostojewskijs Bedeutung für den Film - allgemeine Überlegungen}

Seit Anbeginn der Stummfilmära um 1900 spielen Literaturverfilmungen eine wichtige Rolle beim Versuch, das ursprünglich misstrauisch beäugte Unterhaltungsmedium Film von seinem Ruf als Jahrmarktsattraktion zu befreien. Auch Dostojewskijs Werke wurden schon früh verfilmt, so wird etwa die erste Adaptation des Romans „Der Idiot" auf der Webseite "The Internet Movie Database“ (IMDb) bereits auf 1910 datiert. $^{1}$ Ab Ende der 1990er Jahre trugen Dostojewskijs Poetik und seine narratologischen Konzeptionen jedoch auch wesentlich zur Neubelebung eines ganz bestimmten filmischen Genres bei: jenem des Psychothrillers. Im Hinblick auf dieses Genre soll gleich vorab die zugegebenermaßen etwas gewagte These aufgestellt werden, dass Dostojewskijs ausgefeilte, komplexe und nicht selten zu großen Überraschungen führende Erzählstrukturen Filmschaffende rund um den Globus dazu anregten, diese Gestaltungsformen und Kunstgriffe in den Film zu transformieren.

Es ist deshalb auch nicht verwunderlich, dass schon in den 1950er Jahren der wohl berühmteste Altmeister des Psychothrillers Alfred Hitchcock in einem Interview mit François Truffaut explizit auf Dostojewskijs Werke einging. Auf die Frage Truffauts, warum Hitchcock denn nicht auch einmal ein Werk der großen klassischen Literatur wie „Schuld und Sühne“ verfilme, antwortete dieser:

„[...] das werde ich nie tun, weil Schuld und Sühne, das ist schon das Werk eines anderen. Man redet oft über die Regisseure in Hollywood, die literarische Meisterwerke verunstalten. Ich habe nicht die Absicht, je so etwas zu tun. Ich lese eine Geschichte nur einmal. Wenn mir die Grundidee zusagt, übernehme ich sie, ich vergesse das Buch vollkommen und mache Kino. Ich wäre völlig außerstande, Ihnen die Geschichte von The Birds von Daphne du Maurier zu erzählen. Ich habe sie nur einmal, ganz schnell, gelesen. ${ }^{\text {"2 }}$

Und schließlich ergänzt er etwas später erneut im Zusammenhang mit Dostojewskij:

1 Vgl.: http://www.imdb.com/title/tt0330427/ [Zugriff vom 20.03.2011].

2 François Truffaut: Mr. Hitchcock, wie haben Sie das gemacht? München 2005, S. 60. 
„Ich möchte noch hinzufügen, wenn ich Schuld und Sühne drehen würde, käme jedenfalls kein guter Film dabei heraus. [...] Nehmen Sie einen Roman von Dostojewski [...] egal welchen, sie bestehen aus vielen Wörtern, die alle eine Funktion haben. [...] Und um dasselbe nun filmisch auszudrücken, müsste man, wenn man die Wörter durch die Kamerasprache ersetzt, einen Film von sechs oder zehn Stunden drehen. Sonst wäre das nicht ernst zu nehmen. “3

Was heute aus literatur- und filmwissenschaftlicher Perspektive an diesen Zitaten sofort ins Auge sticht, ist Hitchcocks streng kanonisches und hierarchisches Verständnis von Kunst und Literatur. Dieses erlaubt es ihm zwar populäre, künstlerisch „tiefer stehende“ Werke wie Daphne du Mauriers Romane zu „veredeln“, lässt ihn aber gleichzeitig die Literatur des westlichen Kanons als unantastbar deklarieren. Doch damit tabuisiert er diese gleichsam für den intermedialen Austausch zwischen Literatur und Film. Allerdings muss man gerechterweise hinzufügen, dass Hitchcock mit seiner Kritik auch auf eine ganz spezielle Form der Literaturverfilmung abzielt: nämlich auf jene Hollywoodverfilmungen, die in den 1950er Jahren schon längst zu phantasielosen Literaturbebilderungen verkommen waren.

Es ist jedoch durchaus anzunehmen, dass Hitchcock - würde er heute noch leben - den beiden Filmen, die in diesem Beitrag im Zusammenhang mit Dostojewskijs Roman "Schuld und Sühne“ analysiert werden sollen, durchaus einiges Positives abgewinnen könnte. Schließlich gingen deren Drehbuchautoren und Regisseure mit ihrer literarischen Vorlage ähnlich pragmatisch um, wie er selbst mit den Unterhaltungsromanen seiner Zeit. Allerdings haben diese Filmschaffenden - und dies soll im Folgenden noch ausführlich belegt werden - Dostojewskijs Werk nicht bloß schnell gelesen und wieder vergessen wie Hitchcock du Mauriers Roman, sondern sich ganz gezielt dessen narrative Strukturen zu Nutze gemacht. Heitor Dhalias Film „Nina“ und Brad Andersons „The Machinist" können demnach nicht mehr als Literaturverfilmungen im herkömmlichen Sinne bezeichnet werden. Denn sie halten sich weder an die räumliche und zeitliche Verortung des Dostojewskij-Romans, noch orientieren sie sich strikt an dessen Handlungsaufbau und sie versuchen schon gar nicht als bloße Bebilderung der schriftlichen Vorlage zu fungieren.

Regisseure und Drehbuchautoren können demnach bei der filmischen Umsetzung eines literarischen Textes ganz andere Prioritäten setzen als der Schriftsteller. Diesem Umstand trägt die neuere Adaptationsforschung durchaus Rechnung, weshalb in der Regel verschiedene Formen der Literaturverfilmung voneinander abgegrenzt werden. Eine der im deutschsprachigen Raum geläufigsten Begriffstypologien, innerhalb derer sich auch die Filme "Nina“ und „The Machinist" adaptationstheoretisch verortet lassen, soll im folgenden Abschnitt kurz skizziert werden.

3 Ebd. S. 60f. 


\section{Konzepte der Literaturverfilmung nach Michaela Mundt}

In ihrer Studie "Transformationsanalyse" orientiert sich die Adaptationsforscherin Michaela Mundt bei der Typologisierung verschiedener Konzepte der Literaturverfilmung an der Transformationsrelation zwischen Film und Vorlage. Ausgehend von der rezeptionstheoretischen Grundfrage „Welche Art von Botschaft will der Film seinen Rezipienten übermitteln?" unterscheidet Mundt drei Transformationskonzepte: analoge Wiedergabe, konzeptionelle Interpretation und Eigenständigkeit.

Im Fall der analogen Wiedergabe bemüht sich der Film - wie der Name des Konzepts schon intendiert - um eine Analogiebildung. Die Filmschaffenden zielen auf eine „analoge Wiedergabe der strukturellen, funktionalen und konzeptionellen Vorgaben " ${ }^{4}$ der literarischen Vorlage ab, und die Botschaft des Films an den Rezipienten entspricht der „Neuformulierung einer bereits bestehenden literarischen Bot-

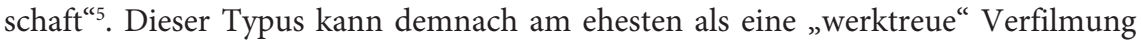
bezeichnet werden. Denn er orientiert sich so eng wie möglich an der Handlung und dem narrativen Aufbau des literarischen Werkes und behält sowohl dessen raumzeitliche Verortung als auch den Großteil des Figurenensembles aus der Vorlage bei.

Was nun "Schuld und Sühne" anbelangt, so handelt es sich bei den meisten Verfilmungen dieses Romans um analoge Wiedergaben. Der chronologische Bogen spannt sich dabei von Robert Wienes berühmtem expressionistischen Stummfilm "Raskolnikow“ (1922) über die von Lew Kulidschanow inszenierte, bekannteste sowjetische Verfilmung „Prestuplenie i nakazanie“ (1969) bis hin zu verschiedensten Fernsehfilmversionen der letzten Jahre, wie etwa die 1998 für NBC produzierte Verfilmung "Crime and Punishment" (Regie: Joseph Sargent) mit Ben Kingsley in der Rolle des Porfirij Petrowitsch.

Beim zweiten Transformationskonzept nach Michaela Mundt, jenem der konzeptionellen Interpretation, liegt der „Vermittlungsschwerpunkt“ des Filmes nun nicht mehr „auf dem Aspekt einer vorgefundenen literarischen Botschaft, sondern primär auf dem Umstand der Rezeption dieser Botschaft "6. Die Filmschaffenden orientieren sich demnach „vor allem an den Ergebnissen einer subjektiven Sinnbildung" und leisten in erster Linie „eine bestimmte Interpretation des Vorgegebenen “7. Dieser Transformationstypus bedient sich somit auch nur jener narrativen und strukturellen Aspekte der Vorlage, die eine bestimmte Deutung unterstützen, und erfindet durchaus auch eigene Handlungs- und Formelemente hinzu. Von einer konzeptionellen Interpretation kann demnach bereits bei jeder Art von inhaltlichem „Modernisierungsversuch" gesprochen werden: Passt ein Regisseur z.B. einen literarischen Stoff an seine eigene, unmittelbare räumliche und historische Umgebung an, verschwinden Nebenhandlungsstränge, die nicht unmittelbar mit einer bestimmten

4 Michaela Mundt: Transformationsanalyse. Methodologische Probleme der Literaturverfilmung. Tübingen 1994, S. 38.

5 Ebd.

6 Ebd.

7 Ebd. 
Interpretation kompatibel sind oder werden Namen, Charaktereigenschaften oder wie im Falle von „Nina“ - gar das Geschlecht der handelnden Personen geändert, so haben wir es mit einer konzeptionellen Interpretation zu tun. In der Regel taucht in diesen Fällen auch der Name der literarischen Vorlage im Vorspann des Films nicht mehr an so prominenter Stelle auf wie bei einer analogen Wiedergabe. Meist sind in Vor- und Abspann nur mehr Hinweise wie „Nach Motiven von..." zu lesen.

Auch einige sehr berühmte Verfilmungen von "Schuld und Sühne“, wie etwa Robert Bressons „Pickpocket“ (Der Taschendieb; 1959) oder Aki Kaurismäkis Filmdebüt „Rikos ja rangaistus“ (Verbrechen und Strafe; 1983), fallen in die Rubrik der konzeptionellen Interpretation. Sowohl in Bressons als auch in Kaurismäkis Film steht der Weg zur Selbsterkenntnis eines jungen Protagonisten im Mittelpunkt, der ein oder mehrere Verbrechen begeht, weil er sich selbst für einen außergewöhnlichen Menschen hält. Die Charakterzüge dieser Protagonisten weisen deutliche Parallelen zu Raskolnikow und dessen Theorie vom Napoleonischen Übermenschen auf. Anhand dieser Theorie, die Raskolnikow noch während seiner Studienzeit entwirft, teilt er die Menschheit in gewöhnliche und außergewöhnliche Menschen ein. Die gewöhnlichen Menschen, die breite Masse, die Raskolnikow auch abschätzig als Läuse bezeichnet, müssen sich an die Gesetze und gesellschaftlichen Regeln halten, während die außergewöhnlichen Menschen - wie Lykurg, Cäsar und Napoleon - das Recht haben, diese Gesetze zu übertreten, um dadurch die Entwicklung der Menschheit voranzutreiben. Mit dem Mord an der Pfandleiherin Aljona will sich Raskolnikow nun selbst beweisen, dass er zu den außergewöhnlichen Menschen zählt, und dass sein Gewissen die Last eines Mordes auszuhalten vermag. Bresson und Kaurismäki gestalten nun zwar ihre Protagonisten nach Raskolnikows Vorbild, versetzen die Handlung aber ins Frankreich der späten 1950er bzw. ins Finnland der frühen 1980er Jahre.

Heitor Dhalias Film „Nina“, der im Rahmen dieses Beitrages eingehender analysiert werden soll, lässt sich ebenfalls als konzeptionelle Interpretation bezeichnen. In Dhalias Film wird der Haupthandlungsstrang um einen Menschen, der ein Verbrechen begeht und diese Last psychisch und auch physisch nicht auszuhalten vermag, vom St. Petersburg des Jahres 1865 ins São Paulo des Jahres 2004 verlegt. Und der ehemalige Student Rodion Romanowitsch Raskolnikow wird in die aufmüpfige junge Kellnerin Nina transformiert. Anspielungen auf und Analogien zu Dostojewskijs Roman lassen sich bereits in den ersten drei Filmminuten von „Nina“ deutlich erkennen. Noch ehe die Protagonistin selbst im Bild erscheint, wendet sich bereits ihre Stimme aus dem Off an die Zuseher. Und sie fasst Raskolnikows Theorie vom Napoleonischen Übermenschen, die er im fünften Kapitel des dritten Teils von „Schuld und Sühne“ ausführlich mit Porfirij Petrowitsch diskutiert, in einigen prägnanten Sätzen zusammen:

„I've got a theory. Individuals are divided in two categories: the ordinary and the extraordinary. Ordinary people are correct ... those living in obedience and 
who like living like that. Now, the extraordinary are those who create something new ... all those who break the old laws, the destroyers. The first maintain the world as it is. The others will move the world to attain to their objectives ... even if to do so, they have to commit a crime. ${ }^{\text {" }}$

Diese Sätze werden gleichsam als Motto dem Film vorangestellt. Noch ehe eine einzige handelnde Person im Bild erscheint, ja ehe überhaupt noch der Vorspann mit dem Filmtitel gezeigt wurde, konfrontiert Dhalia die Rezipienten bereits mit der grundlegenden Problematik des Films: der Transformation der Raskolnikowschen Idee vom Napoleonischen Übermenschen ins 21. Jahrhundert. Diese Problematik geht in Dhalias Film Hand in Hand mit zwei wesentlichen Fragen, die auch Dostojewskijs Roman wie ein roter Faden durchziehen: Wohin führt die Hauptfigur diese Theorie? Und kann sie tatsächlich auch selbst ohne Gewissensbisse ein Verbrechen begehen?

Im Gegensatz zu Dostojewskij deutet Heitor Dhalia bereits einige Sekunden nach der Verkündung der Theorie des Übermenschen eine Antwort auf diese Fragen an. Unmittelbar nach dem Vorspann erscheint die Protagonistin Nina erstmals direkt im Bild. Die Kamera zeigt Großaufnahmen ihres Gesichts, während sie sich schweißgebadet im Schlaf auf ihrem Bett wälzt und immer wieder mit weinerlicher Stimme die Worte „Daddy don't let them“ wiederholt. Nina hat ganz offensichtlich einen Albtraum, und über diesen führt Dhalia sie in die Filmhandlung ein. Abwechselnd mit den Großaufnahmen ihres Gesichts sind Bilder von einer wild johlenden Menge, die ein Pferd misshandelt, zu sehen. Die Protagonistin erscheint damit als schwaches und hilfloses Häufchen Elend, das nichts von einem außergewöhnlichen Menschen an sich hat. Nina, die später so frech und unangepasst auftritt, wird somit zu Beginn des Filmes von Dhalia im Kontrast zu ihrer eigenen Theorie vorgestellt. Und die Rezipienten können ihr späteres Scheitern am Verbrechen im Grunde schon vorausahnen.

Der zweite Film, der in diesem Beitrag mit Dostojewskijs Roman „Schuld und Sühne“ verglichen werden soll, Brad Andersons „The Machinist“ (2004), lässt sich am ehesten dem dritten Transformationskonzept nach Michaela Mundt zuordnen: jenem der Eigenständigkeit. Von diesem Konzept spricht Mundt, wenn die „dominante Absicht des Films“ darin besteht, „selbst eine originäre Botschaft als Signal zu formulieren". Da sich dabei der Schwerpunkt von der „vorangegangenen literarischen Kommunikation" hin zu einem eigenständigen filmischen Austausch verlagert, stellt der „literarische Vorlagetext“ nur mehr einen „Bezugspunkt unter vielen “10 dar. In diesem Fall lässt sich nur mehr im weitesten Sinne von einer Literaturverfilmung

8 Zitiert nach den Untertiteln der offiziellen Kauf-DVD. Heitor Dhalia: Nina. Brasilien 2004 (Sony Pictures Home Entertainment 2005).

9 Mundt 1994, S. 39.

10 Ebd. 
sprechen, denn die literarischen Bezüge beschränken sich in der Regel nicht mehr nur auf ein einziges Werk. Beim Konzept der Eigenständigkeit fehlen deshalb auch meist Hinweise auf den literarischen Bezugstext im Vorspann. In der Forschungsliteratur, in Making-Offs oder Interviews mit Drehbuchautoren und Regisseuren werden jedoch immer wieder Hinweise auf literarische Inspirationsquellen gegeben. Dies gilt auch für „The Machinist“, denn Regisseur Brad Anderson bezeichnet in einem Interview mit Thomas Abeltshauser Dostojewskijs Werke als wichtigste Inspirationsquelle für seinen Drehbuchautor Scott Kosar. ${ }^{11}$

Anders als in "Nina“ sind die Parallelen zu Dostojewskijs Roman im Falle von „The Machinist" jedoch nicht bereits von Beginn an ersichtlich. In den ersten Filmminuten werden die Zuseher lediglich mit einem völlig ausgezehrten und erschöpften Menschen konfrontiert, der eine Leiche entsorgen möchte. Der geheimnisvolle namenlose Mann rollt - nachdem er im Badezimmer seiner Wohnung ein rätselhaftes Post-it mit der Aufschrift „Who are you?" entdeckt hat - einen Toten in seinen Wohnzimmerteppich. Er bringt die Leiche in seinem Truck ans Meer und will sie dort entsorgen, als ihn plötzlich eine Person mit einer Taschenlampe anspricht und ihm dieselbe Frage stellt, die vorher auf dem Post-it in seiner Wohnung zu lesen war: „Who are you?“. Diese Eröffnungsszene lässt nun die meisten Filmzuseher annehmen, dass der ausgemergelte, namenlose Protagonist den Toten im Teppich auch ermordet hat. Doch auch die Zuseher wissen noch nicht, wer der Mann am Strand tatsächlich ist und wiederholen die Frage nach seiner Identität damit außerfiktional ein drittes Mal.

In den anschließenden Szenen löst sich das Rätsel um die Identität des Protagonisten nur partiell auf: Man erfährt, dass er Trevor Reznick heißt und ein in Los Angeles lebender Maschinenschlosser ist. Doch die Fragen nach dem Grund für seinen erschreckenden physischen Zustand, nach den Umständen des offensichtlichen Mordes und nach der Identität der Leiche lässt der weitere Handlungsverlauf lange Zeit unbeantwortet. Was Trevor mit Dostojewskijs Raskolnikow gemein hat, lässt sich aber - zumindest in Ansätzen - bereits zu Beginn erahnen: Schon von den eben geschilderten ersten Filmminuten an weiß man, dass Trevor - wie die Medienwissenschaftlerin Sascha Keilholz in einer Internet-Rezension so treffend feststellt eine „Leiche im Keller"12, d.h. eine noch nicht näher bekannte Schuld auf sich geladen hat. Die Zuseher stellen deshalb, zumindest implizit, einen kausallogischen Zusammenhang zwischen der Leiche im Teppich und dem mitleiderregenden Äußeren des Protagonisten her.

Da es sich bei den beiden Filmen „Nina“ und „The Machinist" um kaum bekannte Autorenfilme handelt, werden in den folgenden beiden Abschnitten die wichtigsten

11 Vgl. Thomas Abeltshauser: Es macht Spaß eine Figur zu peinigen. Interview mit Brad Anderson $\mathrm{zu}$ „The Machinist“. In: critic.de: http://www.critic.de/special/es-macht-spass-eine-figur-zupeinigen-1302/ [Zugriff vom 20.3.2011].

12 Sascha Keilholz: Der Maschinist. Rezension. In: critic.de: http://www.critic.de/film/dermaschinist-47/ [Zugriff vom 20.03.2011]. 
inhaltlichen Grundzüge der beiden Werke zum besseren Verständnis der späteren komparatistischen Analysen in kurzen Synopsen vorgestellt.

\section{Synopse zu Heitor Dhalias „Nina“ (2004)}

In „Nina“, dem Spielfilmdebüt des jungen brasilianischen Regisseurs Heitor Dhalia, schlägt sich die aufmüpfige junge Titelheldin (gespielt von der in Brasilien sehr bekannten Fernsehschauspielerin Guta Stresser) im São Paulo des Jahres 2004 mehr schlecht als recht als Kellnerin in einem Fast-Food-Restaurant durch. Ihre Freizeit verbringt sie mit dem Zeichnen blutrünstiger Comics oder auf Techno-Partys, die ihre Freundinnen, die Drogendealerin Ana und die Prostituierte Alice, organisieren. Nach einer dieser Partys taucht Nina völlig übermüdet und unter Drogen stehend an ihrem Arbeitsplatz auf. Als sich die Kunden im Restaurant über ihren Zustand und die schlechte Bedienung beschweren, kündigt Nina kurzerhand ihren Job. Doch damit manövriert sie sich in eine prekäre finanzielle Situation. Da Nina ihre Miete nicht mehr bezahlen kann, droht ihre geizige Vermieterin Dona Eulália (Myriam Muniz), sie aus der Wohnung zu werfen, und entwickelt sich damit zum existenzbedrohenden Feindbild für die Protagonistin.

Dona Eulália lässt keine Gelegenheit aus, um Nina zu quälen und zu schikanieren: sie stiehlt Geld aus einem Brief, den Nina von ihrer Mutter erhalten hat, sie erlaubt ihr nicht mehr, sich Lebensmittel aus dem Kühlschrank zu nehmen, und zwingt sie, als sie sie trotz des Verbots beim Milchtrinken ertappt, zum Putzen der Wohnung. Ninas Hass auf ihre Vermieterin wächst stetig an, und sie träumt schließlich mehrmals davon, Dona Eulália umzubringen: Einmal stellt sie sich vor, sie - wie Raskolnikow Aljona Iwanowna - mit einer Axt zu erschlagen. Ein anderes Mal träumt sie davon, sie mit einem Messer zu erstechen. Und schließlich setzt sie ihre Mordphantasien in die Tat um, als Dona Eulália ihre Drohung wahr macht und sie endgültig aus ihrer Wohnung wirft. Nina nimmt daraufhin eine Plastiktüte und erstickt ihre Vermieterin.

Die beiden Mordphantasien und die Tat selbst werden von Dhalia auf filmtechnischer Ebene höchst eindrücklich gestaltet. Die Spielfilmhandlung wird durch düstere Manga-Zeichnungen, die vom brasilianischen Maler Lorenço Mutarelli stammen, unterbrochen. Dhalia kontrastiert und verfremdet die Filmhandlung durch diese, an Ninas eigene Zeichnungen gemahnenden Schwarz-Weiß-Bilder. Ohne innerfiktionale Motivation und damit für die Zuseher völlig unerwartet wechseln sich somit Zeichnungen und Filmbilder ab. (Abb. 1) 


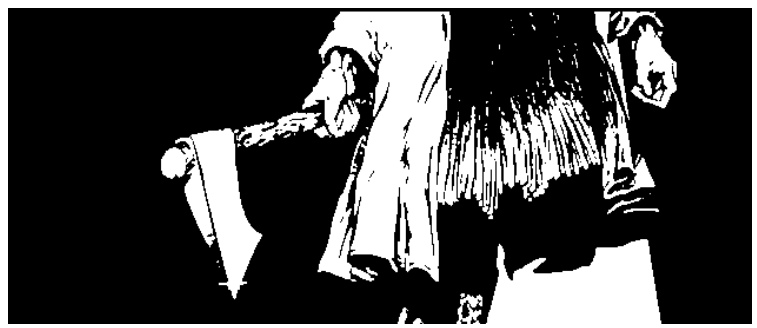

(Abb. 1: Manga-Zeichnung aus Ninas erster Mordphantasie)

Der Mord an Dona Eulália wird jedoch nicht zum erhofften Befreiungsschlag für Nina. Ganz im Gegenteil, nun bricht für sie erst die wahre Hölle in Form ihrer Gewissensbisse los. Wie Raskolnikow in "Schuld und Sühne“ befindet sich auch Nina nach der Tat in einem Schockzustand, der sie nicht mehr zwischen Albtraum und Wirklichkeit unterscheiden lässt. So fühlt sie sich etwa ständig von den Blicken ihr völlig unbekannter älterer Menschen verfolgt, erlebt unheimliche surreale Begebenheiten, wie den unerklärlichen Kampf zwischen zwei Malern, die gerade die Nachbarwohnung streichen (die Szene ist natürlich ebenfalls an „Schuld und Sühne“ angelehnt). Schließlich glaubt sie sogar, dass zwei Polizisten sie verfolgen und des Mordes verdächtigen. Als sie die Last ihres Gewissens nicht mehr aushält und die Polizei ruft, kommt es zu einer unerwarteten Handlungswendung. Es stellt sich heraus, dass Nina Dona Eulália gar nicht erstickt hat, sondern dass diese an Herzversagen verstoben ist.

\section{Synopse zu Brad Andersons „The Machinist“ (2004)}

Im Gegensatz zu „Nina“ fand „The Machinist“, der sechste Spielfilm des US-amerikanischen Independent-Regisseurs Brad Anderson, auch in Europa seinen Weg in den regulären Filmvertrieb. In den USA hatte sich Brad Anderson bereits mit früheren Filmen, wie etwa dem viel beachteten Krimi „Session 9“ (2001), einen Namen als innovativer Spezialist für Psychothriller gemacht. ${ }^{13}$

In „The Machinist“ fristet der titelgebende Maschinenschlosser Trevor (Christian Bale) ein abgekapseltes und eintöniges Dasein in einem tristen Vorort von Los Angeles. Seine einzigen sozialen Kontakte unterhält er zur Prostituierten Stevie (Jennifer Jason Leigh) und zur Kellnerin Maria (Aitana Sánchez-Gijón). Neben den beiden Frauen machen sich aber auch Trevors Chefs Tucker und Furmann sowie seine Kollegen in der Maschinenfabrik allmählich Sorgen um den Gesundheitszustand ihres Mitarbeiters, denn Trevor ist nur mehr ein Schatten seiner selbst und bis aufs Skelett abgemagert. Stevie gegenüber behauptet er, schon seit einem Jahr nicht mehr geschlafen zu haben. Und obwohl jedem Filmzuseher klar sein muss,

13 Vgl. Markus K. Korb: The Machinist (Kritik). In: Roter Dorn. Das Medienportal: http://www. roterdorn.de/inhalt.php?xz=rezi\&id=5159 [Zugriff vom 04.04.2011]. 
dass dies rein biologisch nicht möglich ist, glaubt man Trevor angesichts seines erbärmlichen physischen Zustandes aufs Wort. (Abb. 2)

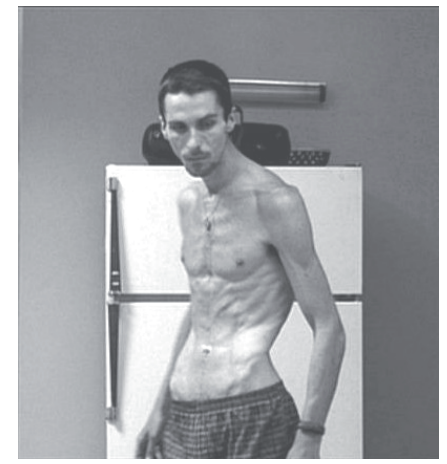

(Abb. 2: Christian Bale als abgemagerter Trevor Reznick)

Ein erster deutlicher Hinweis bzw. eine erste intermediale Referenz auf Dostojewskij findet sich bereits zu Beginn des Films, denn Trevor liest, wenn er nachts nicht schlafen kann, in Dostojewskijs zweitem großen Roman „Der Idiot“. Und ebenso wie sich das Beziehungsgeflecht im Roman immer konkreter auf eine zwischenmenschliche Katastrophe zuspitzt, entwickelt sich auch der Handlungsverlauf des Films auf die Enthüllung eines schrecklichen Geheimnisses hin. Trevors gleichförmiges Leben wird zunächst durch mysteriöse Post-its gestört, die er an seinem Kühlschrank findet, und auf die in Form des bekannten Galgenmännchen-Spiels ein Buchstabenrätsel geschrieben ist. Trevor kann sich die Herkunft dieser Klebezettel nicht erklären und beginnt, seine Umgebung argwöhnisch zu beobachten.

Bald taucht außerdem ein mysteriöser neuer Kollege namens Ivan (man beachte auch hier wieder die Anspielung auf einen russischen Hintergrund) an Trevors Arbeitsplatz auf, dessen Existenz jedoch außer Trevor niemand zu bemerken scheint. Doch Ivan macht Trevor allmählich das Leben zur Hölle: So lenkt er ihn etwa während Wartungsarbeiten an einer Maschine ab, was Trevors Kollegen Miller einen Arm kostet und auch alle anderen Arbeitskollegen gegen Trevor aufbringt. Dieser glaubt, dass eine Intrige gegen ihn im Gange sei und hält Ivan für den Kopf der Verschwörung. Am Ende gelingt es Trevor schließlich Ivan zu stellen, und im darauf folgenden Kampf schneidet er seinem Widersacher die Kehle durch.

Aber ebenso wie in „Nina“ kommt es auch am Ende von „The Machinist“ zu einer überraschenden, die bisherige Logik der Handlung auf den Kopf stellenden Wendung. Als Trevor Ivans Leiche entsorgen will, stellt sich heraus, dass der Teppich, in den er den Toten gewickelt hatte, leer ist. Ivan hat niemals existiert, und auch die Treffen mit Maria und Nicholas hat Trevor nur geträumt. Fakt ist hingegen, dass er ein Jahr zuvor einen Autounfall mit Fahrerflucht verursacht hat, bei dem ein kleiner 
Junge zu Tode kam. Mit dieser Schuld konnte Trevor nicht leben, und seine Gewissensbisse führten zu seinem selbstzerstörerischen Verhalten und seinen Wahnvorstellungen.

\section{Dostojewskijs Roman „Schuld und Sühne“ (1866) im Film}

Aus transmedialer, auf Literatur und Film fokussierender Perspektive ist interessant, dass es sich bei „Schuld und Sühne“ nicht nur um das am häufigsten verfilmte Werk Dostojewskijs handelt, sondern - ganz generell - um den bislang am häufigsten verfilmten Roman in russischer Sprache. Wie schon eine kurze Recherche auf IMDb (The Internet Movie Database) belegt, finden sich zwischen 1910 und 2010 allein 29 eingetragene Filme, die sich direkt auf diesen Roman beziehen. Damit liegt er noch vor Tolstojs „Anna Karenina“ mit 24 eingetragenen Verfilmungen. Interessant ist außerdem, dass von diesen 29 Filmen allein 10 zwischen 1994 und 2008 entstanden sind, womit bewiesen sein dürfte, dass „Schuld und Sühne“ auch im Umbruch zum 21. Jahrhundert nichts an Aktualität eingebüßt hat.

Weshalb ist aber gerade dieses Werk eine so beliebte Inspirationsquelle für den Film? Vorab soll als erste grobe Antwort auf diese Frage eine These skizziert werden. Meines Erachtens beruht ein wesentlicher Grund für die große Beliebtheit von „Schuld und Sühne" bei vielen Filmemachern in ganz unterschiedlichen Ländern auf einem in diesem Roman explizit zutage tretenden poetologischen Aspekt, der in beträchtlichem Maße zur Erschaffung einer albtraumhaften Atmosphäre in diesem Werk beiträgt. Diese besondere Atmosphäre basiert wiederum auf der Konzeption von "Schuld und Sühne" als Kriminalroman, in dem nicht das Aufdecken des Verbrechens im Vordergrund steht, sondern - wie Rudolf Neuhäuser feststellt - die „Analyse eines Erkenntnisprozesses, der sich nach vollbrachter Tat im Täter vollzieht ${ }^{\text {“14. }}$.

Der Läuterungsweg Raskolnikows wird jedoch von einer Krise begleitet, die den Mörder auch körperlich erkranken lässt. Er leidet an heftigen Fieberschüben, Ohnmachtsanfällen, Halluzinationen und Angstzuständen und befindet sich deshalb beinahe ständig in einem psychosomatischen Ausnahmezustand. Dieser wiederum beeinträchtigt Raskolnikows Wahrnehmung und lässt ihn oftmals nicht mehr klar zwischen Wahnvorstellung, Traum und Realität unterscheiden. Dostojewskij gelingt es nun, diesen psychosomatischen Ausnahmezustand seines Helden mit Hilfe einer ganz spezifischen Erzählinstanz äußerst eigenwillig zu gestalten. ${ }^{15}$ Sein ,unzuverlässiger" Erzähler verleiht dem gesamten Roman die besagte albtraumhafte Atmosphäre,

14 Rudolf Neuhäuser: F. M. Dostojevskij. Die großen Romane und Erzählungen. Interpretationen und Analysen. Wien, Köln, Weimar 1993, S. 62.

15 Zur Erzählerinstanz in „Schuld und Sühne“ vgl. Horst-Jürgen Gerigk: Nachwort. In: Fjodor M. Dostojewskij: Schuld und Sühne. München 1977, S. 720ff; sowie Horst Jürgen Gerigk: Die Sache der Dichtung. Dargestellt an Shakespeares "Hamlet", Hölderlins "Abendphantasie" und Dostojewskijs "Schuld und Sühne". Hürtgenwald 1991. 
die wiederum dem Film - und hier vor allem der Gattung des Psychothrillers - eine Vielzahl höchst innovativer Optionen eröffnet.

\section{Der unzuverlässige Erzähler}

Der Erzähler in „Schuld und Sühne" nähert sich bei der Beschreibung der Geschehnisse rund um Raskolnikow meist sehr eng an dessen Wahrnehmungsperspektive an. Bis auf wenige Ausnahmen versucht er die Ereignisse so subjektiv als möglich von der Warte des Helden aus zu schildern. Da sich Raskolnikow aber so gut wie ständig in einer psychischen Ausnahmesituation befindet und nicht mehr zwischen Einbildung und Wirklichkeit unterscheiden kann, verirrt sich auch der Erzähler immer öfter im Wahrnehmungslabyrinth des Protagonisten. Häufig kann er deshalb die von ihm beschriebenen Ereignisse nicht mehr objektiv bewerten und lässt damit auch die Leser des Romans im Ungewissen darüber, ob sich das eben Beschriebene nur im Kopf Raskolnikows abgespielt, oder ob es sich tatsächlich in der konkreten Erlebniswirklichkeit des Protagonisten zugetragen hat.

Hinzu kommt außerdem, dass Raskolnikow selbst - wie im Übrigen auch die beiden Hauptfiguren in "Nina“ und "The Machinist“ - angesichts seiner psychosomatischen Wahrnehmungsstörungen an seinem Verstand zu zweifeln beginnt. In "Schuld und Sühne" gehen damit oftmals Erlebniswirklichkeit und Traum bruchlos ineinander über, und dieses durchaus auch im filmischen Psychothriller gängige Gestaltungsmittel verleiht dem Roman seine besondere albtraumhafte Atmosphäre.

„Schuld und Sühne" wird aber auch von einer Reihe innerfiktionaler Albträume durchzogen, die vom Erzähler ebenfalls nicht immer eindeutig von der Erlebniswirklichkeit des Helden geschieden werden. Zwei dieser Träume, die im Roman von Raskolnikow geträumt werden, spielen auch in „Nina“ und in „The Machinist" eine wesentliche Rolle.

\section{Der gekennzeichnete Albtraum in „Schuld und Sühne“}

Der erste Albtraum, den Raskolnikow im fünften Kapitel des ersten Teils durchleidet, wird vom Erzähler noch ganz eindeutig als Traum ausgewiesen. Ehe dessen Inhalt beschrieben wird, heißt es: „Einen schrecklichen Traum hatte Raskolnikow. Ihm träumte von seiner Kindheit, noch in seiner kleinen Heimatstadt. "16 Über mehrere Seiten beschreibt der Erzähler daraufhin äußerst plastisch den Inhalt des Traumes, dessen Quintessenz darin besteht, dass ein kleines fuchsbraunes Bauernpferdchen von einer wild johlenden betrunkenen Menge zu Tode geprügelt wird. Im Traum erkennt sich Raskolnikow auch selbst, denn er musste diese grausige Begebenheit als kleiner Junge an der Hand seines Vaters mit ansehen. Nach dem Albtraum lässt der Erzähler Raskolnikow erwachen und kennzeichnet auch das Ende des Traumes ganz unmissverständlich: „Er will Atem holen, schreien - und erwacht.

16 Fjodor Dostojewskij: Verbrechen und Strafe. In der Neuübersetzung von Swetlana Geier. Frankfurt a. M. 1996, S. 76. 
Er war schweißgebadet, auch sein Haar war nass, er rang nach Luft, richtete sich entsetzt auf. ${ }^{\text {"17 }}$ Dostojewskijs unzuverlässiger Erzähler verfährt in diesem Falle also noch gnädig mit seinen Lesern: durch eindeutige narrative Markierungen erfahren diese genau, wo sie die geschilderten Ereignisse verorten müssen: nämlich in Raskolnikows Traumwelt.

\subsection{Der (un)gekennzeichnete Albtraum in „Nina“}

Wie verfährt nun aber Heitor Dhalia mit diesem von Dostojewskij eindeutig gekennzeichneten Albtraum? Und wie transferiert er diesen in seinen Film? Unter 2. wurde bereits kurz skizziert, dass die Protagonistin Nina schon in den ersten Filmbildern über den Albtraum vom zu Tode geprügelten Pferd in die Handlung eingeführt wird: Sie liegt schweißgebadet auf ihrem Bett und murmelt im Traum verzweifelt: „No, Daddy don't let them“, während mittels schneller Schnitte immer wieder kurze Bilder aus ihrem Traum eingeblendet werden. Der Albtraum erfüllt somit von Beginn an eine bedeutungskonstituierende Funktion, indem er unauflöslich mit Ninas Kindheit verbunden ist und ein erstes, traumatisches Ereignis im Leben der Filmheldin markiert. Was Nina in diesem Traum sieht, verfolgt sie auch später während des gesamten Films. Je fataler und bedrohlicher ihre Lebensumstände werden, desto häufiger blitzen Bilder aus diesem Albtraum durch ihren Kopf. Und schließlich verfolgt sie der Anblick des gequälten Pferdes auch im Wachzustand (Abb. 3-5).

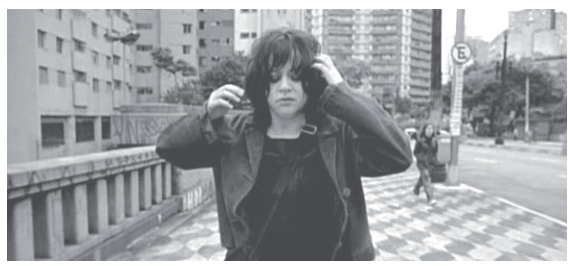

(Abb. 3: Nina wird von Bildern und Stimmen aus dem Albtraum heimgesucht.)
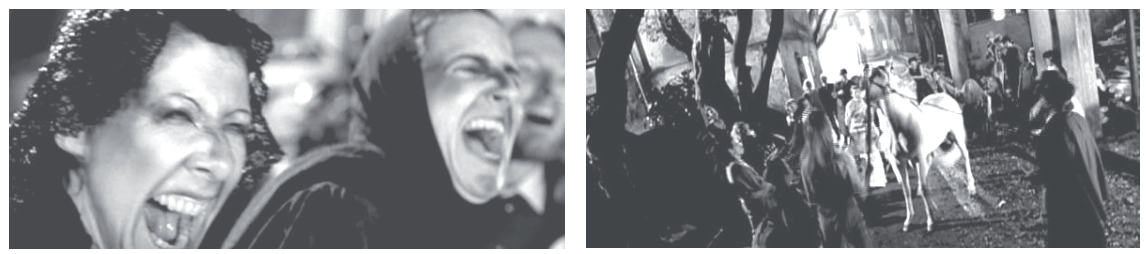

(Abb. 4 und Abb. 5: Der Traum vom zu Tode geprügelten Pferd aus „Schuld und Sühne“ wird in „Nina“ zunächst in Schwarz-Weiß-Bildern wiedergegeben.)

17 Ebd. S. 82. 
Heitor Dhalia rekurriert aber nicht nur auf narratologischer Ebene auf Raskolnikows Albtraum vom zu Tode geprügelten Pferd, sondern versucht diesen auch durch besondere formal-technische Mittel zu gestalten. Wenn Dostojewskijs Erzähler das Traumgeschehen eindeutig durch Hinweise wie „einen schrecklichen Traum hatte Raskolnikow “18 kennzeichnet, so macht Dhalia diesen auf der filmsprachlichen Gestaltungsebene sichtbar, indem er die Traumsequenzen in Schwarz-Weiß-Bildern dreht. Somit hebt er diese eindeutig von den übrigen, in Farbe aufgenommenen Ereignissen ab. Schon zu Beginn des Films sehen die Zuseher somit abwechselnd die im Schlaf weinende Nina in Farbe und die Tötung des Pferdes in schwarz-weiß und können dadurch den Albtraum problemlos als solchen dekodieren.

Nach Dona Eulálias Tod kommt es jedoch zu einem Bruch mit diesem filmsprachlichen Gestaltungskode: Als Nina am nächsten Morgen wieder aus ihrem obligatorischen Albtraum erwacht, findet sie die Mörder des Pferdes aus ihrem Traum plötzlich allesamt in Farbe in ihrem Zimmer sitzend vor. Von diesem Moment an gibt es im Film keine Schwarz-Weiß-Bilder mehr, und Ninas Albträume und Halluzinationen werden ebenso wie die Geschehnisse in ihrer Erlebniswirklichkeit bruchlos und ohne filmtechnische Markierung in Farbe gezeigt. Da sich Nina aber nach dem Mord wie Raskolnikow in einer psychischen Ausnahmesituation befindet und nicht mehr zwischen Erlebniswirklichkeit und Albtraum unterscheiden kann, wird im Film ein ähnlicher Effekt wie im späteren Verlauf des Romans erzielt: Nun, da die Kennzeichnung der Albträume fehlt, können die Zuseher ebenfalls nicht mehr zwischen diesen und den von Nina im Wachzustand durchlebten Ereignissen unterscheiden. Durch den eindeutigen Bruch mit der ursprünglichen filmsprachlichen Kodierung gelingt es Dhalia, Dostojewskijs unzuverlässigen Erzähler in den Film zu transferieren.

\subsection{Der (un)gekennzeichnete Albtraum in „The Machinist“}

In "The Machinist" gibt es keinen filmsprachlich markierten Übergang zwischen gekennzeichnetem und ungekennzeichnetem Albtraum wie in „Nina“. Das gesamte Albtraumszenario bleibt zunächst der Erlebniswirklichkeit des Helden verhaftet, und erst ganz am Ende des Films wird den Zusehern in einer unerwarteten, alles auflösenden Wendung die Wahrheit über den psychischen Zustand des Protagonisten enthüllt. Brad Andersons Film ist somit - im Gegensatz zu „Nina“ - in seiner Gesamtgestaltung als ungekennzeichneter Albtraum aufgebaut.

Es lässt sich jedoch beobachten, dass Anderson auf filmsprachlicher Ebene schon im Vorfeld, lange bevor es zur Enthüllung aller Rätsel durch die unerwartete Handlungswendung am Schluss kommt, implizite Kennzeichnungen der Traumsequenzen vornimmt und damit die Auflösung der Geheimnisse um Trevor geschickt vorbereitet. Um dies zu erreichen, setzt er ein in Literatur und Film weit verbreitetes Stilmittel ein: die sogenannten „Tschechowschen Pistolen“. Darunter versteht man

18 Ebd. S. 76. 
in der Regel bestimmte narrative Elemente oder auch Requisiten, die relativ früh in den Handlungsverlauf eines literarischen Werkes, eines Theaterstückes oder eines Films eingeführt werden, ohne dass ihnen zunächst besondere Aufmerksamkeit zuteil wird. Am Ende des Films oder Theaterstücks wird dann jedoch die wahre, meist äußerst wesentliche Bedeutung dieser Elemente enthüllt. Bei „Tschechowschen Pistolen" handelt es sich also um bestimmte narrative Indikatoren, die auf spätere unerwartete Wendungen im Handlungsverlauf vorausweisen.

Brad Anderson hüllt seinen Film nun gleichsam in ein feingesponnenes Netz aus „Tschechowschen Pistolen“ ein: So wird z. B. immer wieder der Zigarettenanzünder in Trevors Auto in Großaufnahme gezeigt, oder ein Wassertank an einer Kreuzung, an der Trevor des Öfteren vorbeifährt. In einer Szene, die sich in Marias Wohnung abspielt, verweilt die Kamera außerdem unverhältnismäßig lange auf einer Glasschüssel und einer roten Clownsfigur. Die Zuseher werden durch diese Bilder sukzessive irritiert, denn sie wissen nicht, was es mit diesen Gegenständen auf sich hat. Wie Dostojewskijs Erzähler in „Schuld und Sühne“ lässt also auch Brad Andersons Kameraführung die Rezipienten im Dunkeln tappen. Man nimmt lediglich wahr, dass den immer wieder ohne Erklärung eingeblendeten Requisiten in „The Machinist" - sowohl auf narratologischer als auch auf formal-gestalterischer Ebene - eine Spur zu viel Aufmerksamkeit geschenkt wird.

Auf narratologischer Ebene fällt etwa auf, dass Trevor jedes Mal, wenn er den Zigarettenanzünder in seinem Wagen bewusst wahrnimmt, überrascht innehält, oder plötzlich ohne ersichtlichen Grund mitten auf der Kreuzung anhält, sobald er den Wasserspeicher erblickt. Auf filmtechnischer Ebene irritiert außerdem, dass diese Gegenstände unverhältnismäßig häufig und auch - dem gängigen Verfahren zuwiderlaufend - um einige Sekundenbruchteile zu lange in Groß- oder Detailaufnahmen im Bild erscheinen. Welche Bewandtnis es mit diesen auf den ersten Blick so nebensächlichen Gegenständen hat, erfahren die Zuseher - wie es sich für ausgeklügelte „Tschechowsche Pistolen“ gehört - aber erst ganz am Ende des Films.

In den letzten Filmminuten greift Brad Anderson zunächst wieder auf die Bilder aus der Anfangsszene zurück, und Trevors Versuch, die Leiche im Teppich zu entsorgen, wird zur erzähltechnischen Klammer, die die restliche Filmhandlung umschließt. Die Anfangsszenen werden nun aber um wesentliche, erklärende Bilder ergänzt: Zum einen wird in einer halbtotalen Bildeinstellung und in der Kameraperspektive der leichten Aufsicht gezeigt, dass der aufgerollte Teppich leer ist, woraus die Rezipienten sofort schließen, dass sich die Ermordung Ivans nur in Trevors Phantasie abgespielt hat, und zum anderen wird am Ende des Films in einem SchussGegenschuss-Verfahren der ominöse Mann hinter der Taschenlampe gezeigt, der Trevor schon zu Beginn des Films durch die Frage "Who are you?" vor Schreck erstarren ließ. Bei diesem Mann handelt es sich um Ivan, dessen Ermordung noch in der vorherigen Szene absolut glaubhaft gezeigt wurde. Durch diese überraschende Wendung wird das Vertrauen der Zuseher in die Wahrnehmung des Protagonisten nachhaltig erschüttert, und mit einem Schlag wird klar, dass Trevors Leben nicht 
vom unheimlichen, unfassbaren Außen einer feindlichen Umgebung bedroht wird, sondern vom labilen Geisteszustand und den Wahnvorstellungen des Helden selbst.

Auch der wahre Grund für Trevors erschreckenden psychischen und physischen Zustand, der von ihm verursachte Unfall mit Fahrerflucht, wird den Rezipienten erst ganz am Ende des Films enthüllt. In „The Machinist“ wird damit der psychische Ausnahmezustand des von seiner Schuld gemarterten Dostoevskijschen Helden endgültig zum postmodernen Albtraum verdichtet. Außerdem werden auch all die „Tschechowschen Pistolen“, die die Rezipienten im Laufe der vorhergegangenen 90 Filmminuten immer wieder irritierten, am Ende des Films zu einem Sinnganzen zusammengefügt: So war etwa der herausspringende Zigarettenanzünder einst die Ursache für den verhängnisvollen Unfall gewesen. Durch ihn war Trevor für einige Sekunden vom Straßenverkehr abgelenkt worden. Er hatte den kleinen Jungen am Fußgängerüberweg zu spät wahrgenommen, konnte nicht mehr bremsen und überfuhr ihn. Den Wasserspeicher sah Trevor unmittelbar nach dem Unfall, als die Mutter des kleinen Jungen, die wie Maria, die Kellnerin im Flughafencafé, aussieht, auf ihr leblos am Boden liegendes Kind zulief. Somit gemahnt der Wasserspeicher Trevor ebenfalls ständig an seine Schuld.

Auch die Bedeutung der Glasschüssel und der Clownsfigur wird am Ende des Films enthüllt: Als Trevor beschließt, sich der Polizei zu stellen, und seiner Vermieterin Mrs. Shrike mitteilt, dass er den Mietvertrag kündigt, stellt sich heraus, dass die beiden Gegenstände, die einige Szenen vorher noch in Marias Wohnung standen, in Wahrheit Trevor selbst gehören. Mrs. Shrike bewundert die Schüssel und wirft einen Blick auf den Clown, den Trevor in einen Umzugskarton gepackt hat. Erneut wird das Vertrauen der Filmzuseher in Trevors Wahrnehmung erheblich erschüttert, denn durch die Enthüllung dieser „Tschechowschen Pistolen“ werden auch alle Szenen um Maria und Nicholas im Nachhinein als Trevors Phantasieprodukte entlarvt. (Abb. 6 und 7)
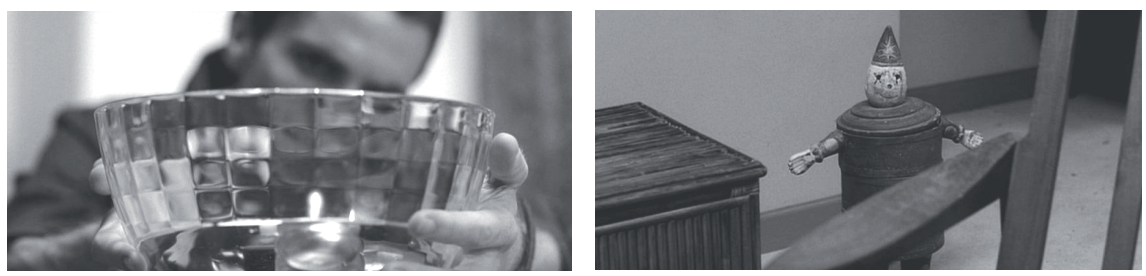

(Abb. 6 und 7: Während eines Besuchs bei Maria bewundert Trevor eine Glasschüssel und entdeckt eine Clownsfigur. Beide Gegenstände entpuppen sich später als sein Eigentum.)

„The Machinist“ ist somit nicht durchgängig als ungekennzeichneter Albtraum gestaltet, denn Brad Anderson spickt den gesamten Film mit „Traumindikatoren“, die den Blick der Zuseher irritieren und auf die unerwartete Wendung am Ende des Films vorausdeuten. Natürlich kennzeichnet Anderson damit Trevors Albträume 
auf filmsprachlicher Ebene nicht so explizit wie Heitor Dhalia jene von Nina mit den Schwarz-Weiß-Bildern; er erschafft aber ein implizites Netz von Hinweisen, welches die Sehgewohnheiten der Rezipienten ständig irritiert und das Vertrauen in den Protagonisten permanent in Frage stellt.

\section{Der ungekennzeichnete Albtraum in „Schuld und Sühne“}

Es gibt jedoch noch einen zweiten Albtraum in „Schuld und Sühne“, der für den narratologischen Aufbau von "Nina“ und „The Machinist“ von großer Bedeutung ist. Dieser Traum, in dem Raskolnikow ein zweites Mal mit der Ermordung Aljona Iwanownas konfrontiert wird, findet im sechsten Kapitel des dritten Teils statt und weist eine äußerst eindrückliche erzähltechnische Gestaltungsform auf.

Bereits vor dem Traum widerfährt Raskolnikow in diesem Kapitel etwas äußerst Unheimliches: Ein ihm völlig fremder Mann beschimpft ihn plötzlich mitten auf der Straße als Mörder. Schockiert von dieser Begegnung geht Raskolnikow daraufhin nach Hause und legt sich auf sein Bettsofa. Er denkt über die unheimlich Begegnung, den Mord und seine Napoleonische Idee nach, als er sich plötzlich vor seinem Haus wieder findet, „ohne sich zu erinnern, wie er dort hingekommen “ ist ${ }^{19}$. Doch da trifft er erneut auf den zwielichtigen Mann, der ihn einen Mörder nannte, und beschließt ihm zu folgen. Der Mann führt Raskolnikow in Aljona Iwanownas Wohnung, wo sich der Mord auf folgende Weise wiederholt:

„Vorsichtig schob er mit der Hand den Mantel zur Seite und sah dahinter einen Stuhl und auf dem Stuhl in der Ecke ein altes Weib, zusammengekrümmt und mit gesenktem Kopf, so, dass er das Gesicht nicht erkennen konnte, aber sie war es. Eine Weile blieb er vor ihr stehen: »Sie fürchtet sich!« dachte er, löste behutsam das Beil aus der Schlinge und schlug die Alte auf den Scheitel, einmal und noch einmal. Aber seltsam: Sie rührte sich nicht einmal unter den Schlägen, als wäre sie aus Holz. Er erschrak, bückte sich, wollte sie genau ansehen; sie aber ließ den Kopf noch tiefer sinken. Da bückte er sich fast bis zum Boden und schaute ihr von unten ins Gesicht, schaute und erstarrte: Das alte Weib saß da und lachte - sie schüttelte sich vor leisem, unhörbarem Lachen, wobei sie sich sichtlich Mühe gab, dass er sie nicht hörte. ${ }^{\text {"20 }}$

Es handelt sich bei dieser Begebenheit erneut um einen Albtraum Raskolnikows, doch der Erzähler eröffnet dies den Lesern erst ganz am Ende der Traumsequenz mit den Worten: „Er wollte schreien und - erwachte ${ }^{{ }^{21}}$. Bis dahin müssen sich die Rezipienten die Tatsache, dass Raskolnikow träumt, selbst erschließen. Und genau genommen steht dies erst, als die alte Pfandleiherin wieder in ihrer Wohnung sitzt, mit letzter Gewissheit fest.

19 Dostojewskij (1996), S. 373.

20 Ebd. S. 374f.

21 Ebd. S. 375. 
Auf ganz ähnliche, im Vorhinein nicht als solche gekennzeichnete Albträume treffen wir auch in den beiden Filmen, und sowohl in "Nina“ als auch in „The Machinist" wird deren Verortung innerhalb der Traum- und Phantasiewelt der beiden Hauptfiguren durch geschickte Bildgestaltung noch länger verschleiert als in Dostojewskijs Roman.

\subsection{Der ungekennzeichnete Albtraum in „Nina“}

Auch Heitor Dhalias Hauptfigur wird, nachdem sie die Wirtin Dona Eulália umgebracht hat, von einem Unbekannten aufgesucht, der offensichtlich etwas über ihre Tat weiß, und ebenso wie Raskolnikow gerät auch Nina über diese rätselhafte Begegnung in Panik. Ein alter Mann, den sie noch nie zuvor gesehen hat, erkundigt sich beim Portier nach ihr. Doch als Nina ihn anspricht und fragt, was er von ihr wolle, wirft er ihr lediglich einen hasserfüllten, verächtlichen Blick zu und geht weiter. Damit verhält sich der alte Mann zwar ganz ähnlich wie jener in "Schuld und Sühne“, ein wesentliches Detail wird im Film jedoch vom verbalen in den nonverbalen Bereich transferiert: Im Gegensatz zu Dostojewskij lässt Dhalia den alten Mann das Wort „Mörder!“ gar nicht erst aussprechen; stattdessen zeigt dieser nur demonstrativ mit seinem Stock auf Nina. (Abb. 8)

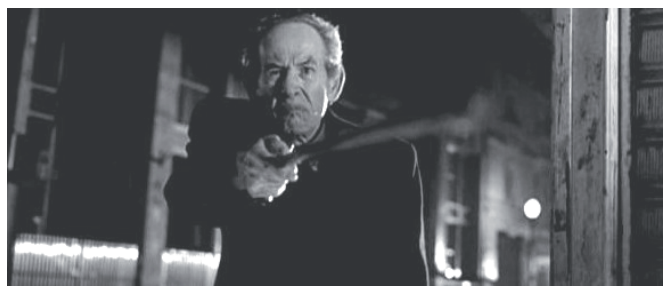

(Abb. 8: Ein alter Mann klagt Nina demonstrativ, aber ohne Worte an.)

Nach dieser unheimlichen Begegnung wandert Nina nachdenklich durch die nächtlichen Straßen São Paulos, als plötzlich wie aus heiterem Himmel zwei Polizisten vor ihr auftauchen. Nina versucht davonzurennen, doch die beiden holen sie immer wieder ein und stehen hämisch und siegessicher grinsend vor ihr. Schließlich findet sich Nina in einem verrauchten Büro beim Verhör mit einem der beiden Polizisten wieder. Gerade diese Verhörszene enthält eine Reihe narrativer Elemente, die direkt aus "Schuld und Sühne" transferiert wurden. Ebenso wie Porfirij Petrowitsch im letzten seiner insgesamt drei Gespräche mit Raskolnikow sagt auch der Polizist im Film der von ihm verdächtigen Nina ganz unerwartet mitten ins Gesicht, dass er sie für die Mörderin ihrer Vermieterin halte. Auf filmtechnischer Ebene wird das Unwirkliche der Verhörszene sowohl durch die Dunkelheit des Büros als auch ganz besonders durch die abschließende Detailaufnahme vom Mund des Polizisten getragen, der droht, Nina wie eine Motte zu verschlucken. Auch dieser Satz findet seine Entsprechung in „Schuld und Sühne“, wenn nämlich Porfirij im zweiten 
Gespräch mit Raskolnikow erklärt, dass ihn manchmal bestimmte Verdächtige umflattern wie ein Falter die Kerze, bis sie ihm schließlich direkt in den Mund fliegen und er sie nur mehr zu schlucken braucht. ${ }^{22}$ (Abb. 9)

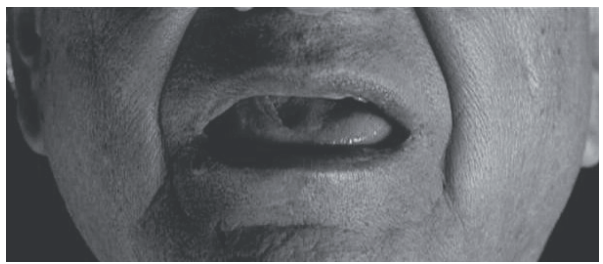

(Abb. 9: Einer der Polizisten droht Nina wie eine Motte zu verschlucken.

Dabei wird sein Mund in Detailaufnahme gezeigt.)

Diese Szene weist aber auch auf außerfiktionaler Ebene eine besondere Parallele zu "Schuld und Sühne“ auf, da sich Heitor Dhalias filmtechnische Gestaltung am unzuverlässigen Erzähler des Dostojewskijschen Traumkapitels orientiert. Die Szene erscheint zu Beginn, als der Portier Nina auf den alten Mann aufmerksam macht, noch völlig realistisch, wird jedoch von Einstellung zu Einstellung immer unheimlicher und surrealer. Den Zusehern wird schließlich - wie den Lesern von „Schuld und Sühne" - erst im Nachhinein klar, dass Nina die Verhörszene mit den Polizisten nur geträumt haben kann, denn bereits in der folgenden Szene wird gezeigt, wie sie Dona Eulálias Leiche vom Wohnzimmer ins Schlafzimmer schleppt. Dies wäre aber völlig sinnlos und auch unlogisch, wenn die Polizei tatsächlich schon über Dona Eulálias Tod Bescheid wüsste.

Allerdings können auch die Zuseher im Nachhinein nicht mehr exakt eruieren, wann Nina überhaupt zu träumen begann. Denn ob bereits die Begegnung mit dem alten Mann nur in ihrem Kopf stattfand, oder ob der Traum mit dem Auftauchen der Polizisten einsetzte, kann man nicht mehr mit letzter Gewissheit feststellen. Sowohl in Dostojewskijs Roman als auch in Dhalias Film gehen Realität und Traum bruchlos ineinander über. Und wenn dieser narratologische Kunstgriff im Roman von einem unzuverlässigen Erzähler umgesetzt wird, so übernimmt diese Aufgabe im Film eine unzuverlässige Kamera. Dank dieser stellt sich am Ende von „Nina“ ein ganz besonderer Effekt ein, denn die beiden Polizisten aus dem Traum, die im Verlauf des Filmes öfters und durchaus in ganz realistisch anmutenden Szenen auftauchten, erweisen sich völlig unerwartet als reine Phantasieprodukte Ninas.

Als sie am Ende des Films die Polizei und Dona Eulálias Hausarzt verständigt, weil ihre Gewissensbisse sie allmählich in den Wahnsinn treiben, geht aus der Körpersprache aller Protagonisten deutlich hervor, dass weder der Arzt noch die beiden echten Kommissare die anderen beiden, ebenfalls anwesenden Polizisten sehen können. Der Hausarzt und die echten Polizisten wechseln zunächst vielsagende, stumme Blicke als Nina fragt, welches Polizisten-Duo sie denn nun verhaften würde.

22 Vgl. ebd. S. 460. 
Und nach einer kurzen Pause antwortet ihr der Hausarzt mit ruhiger, betont vorsichtiger Stimme, dass niemand sie verhaften wird. Die beiden, nur in Ninas Phantasie existierenden Polizisten durchqueren daraufhin schweigend den Raum, wobei ihnen aber ausschließlich Ninas Augen folgen. Sowohl der Arzt als auch die anderen beiden Polizisten nehmen sie nicht wahr und blicken durch sie hindurch.

Am Ende des Films ergibt sich aber noch eine weitere unerwartete Wende im Handlungsverlauf, denn der Hausarzt kann kein Fremdverschulden am Tode Dona Eulálias feststellen und gibt Herzversagen als Todesursache an. Im Gegensatz zu Raskolnikow ist Nina also tatsächlich ein perfekter Mord gelungen. Ihre Tat wird nicht erkannt und sie muss nicht ins Gefängnis. Die Zuseher wissen jedoch, dass Nina an Dona Eulálias Tod Schuld trägt und haben auch ihre schlimmen Albträume und Angstzustände miterlebt. Die Tatsache, dass Nina nun mit ihrem Gewissenskonflikt leben muss, erscheint deshalb als eine noch schlimmere Strafe als Raskolnikows acht Jahre Haft in Sibirien.

\subsection{Der ungekennzeichnete Albtraum in "The Machinist“}

Wie bereits unter 7.2. ausgeführt wurde, stellt der ungekennzeichnete Albtraum das mit Abstand wichtigste narratologische Gestaltungsmittel in „The Machinist“ dar: Der gesamte Handlungsaufbau zielt auf die Demontage von Trevors Glaubwürdigkeit ab und auf die Entlarvung seiner Traumwelt. Im Nachhinein wird damit gut die Hälfte der Filmhandlung als Wahn- und Traumvorstellung gekennzeichnet. Die ursprünglich in der Erlebniswirklichkeit des Helden verankerten Ereignisse erfahren einen Perspektivenwechsel und zerfallen in viele kleinere Albtraumszenen.

Einer dieser ungekennzeichneten Albträume weist besonders auffällige Parallelen zu Raskolnikows Traum von der Ermordung Aljona Iwanownas auf. Es handelt sich dabei um eine Szene, in der Trevor mit Maria und deren kleinem Sohn Nicholas einen Muttertagsausflug auf den Rummelplatz unternimmt. Während einer Geisterbahnfahrt wird Trevor plötzlich mit all jenen Bildern konfrontiert, die sein Gewissen und sein Unterbewusstsein schon seit geraumer Zeit quälen. Jede der dargestellten Gruselszenen gemahnt ihn an seine Schuld. Schon der Name der Geisterbahn „Route 666“ erinnert Trevor an die verhängnisvolle Unfallfahrt, denn am Rückspiegel seines Wagens hing ein Anhänger der "Route 66“. Durch den Unfall mit Fahrerflucht verwandelt sich das berühmte Symbol für den amerikanischen Freiheitsgedanken - die Route 66 - für Trevor buchstäblich in eine Höllenstraße, in eine Route 666, die ihn bis in seine Träume verfolgt (Abb. 10). Während der Fahrt in der Geisterbahn lenkt Nicholas außerdem ein kleines rotes Auto, das Trevor wiederum an seinen Unfallwagen, einen roten 69er Pontiac Firebird, erinnert. Auch hält eine der Wachsfiguren in der Geisterbahn plötzlich einen abgetrennten Arm hoch, was Trevor wiederum jenen Unfall in der Maschinenfabrik ins Gedächtnis ruft, bei dem sein Kollege Miller einen Arm verlor. 


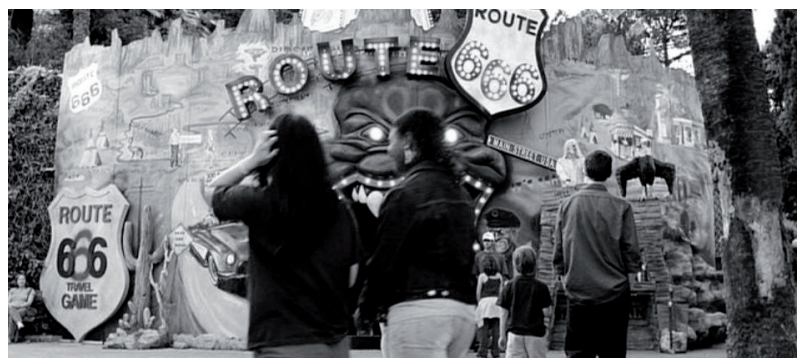

(Abb. 10: Trevor und Nicholas beschließen eine Fahrt mit der Geisterbahn „Route 666“ zu unternehmen.)

Die gesamte Geisterbahnszene ist mit unzähligen Hinweisen auf Trevors Schuld gespickt und ebenso wie Raskolnikow im Traum von Aljona wird Trevors Psyche dadurch einer extremen Belastung ausgesetzt. Auch gibt es in dieser Szene einen ganz direkten Hinweis auf Dostojewskijs Roman: Während der Geisterbahnfahrt erscheint für Sekundenbruchteile im Hintergrund ein Schild mit der Aufschrift "Crime and Punishment" (Abb. 11). Brad Anderson rekurriert somit ganz bewusst auf Dostojewskijs Roman und setzt die Gewissensbisse seines Helden, die diesen beinahe das Leben kosten, in Beziehung zu jenen Raskolnikows.

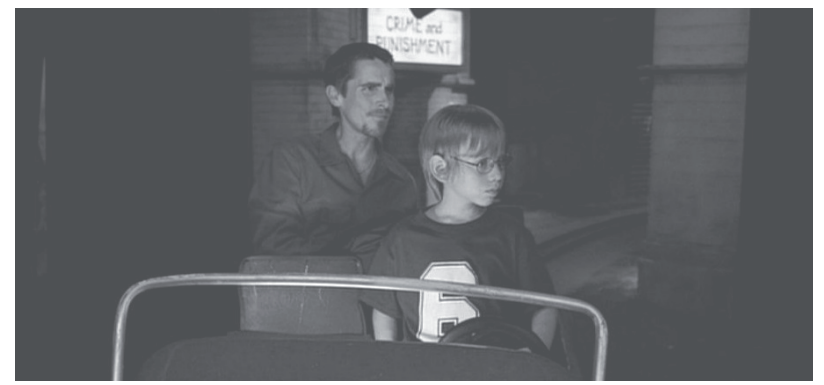

(Abb. 11: Auf dem Schild im Hintergrund ist die Aufschrift „Crime und Punishment“ zu lesen.)

Was die Zuseher zum Zeitpunkt der Geisterbahnfahrt aber noch nicht ahnen, ist, dass der gesamte Muttertagsausflug, ja generell jede Begegnung mit Maria und Nicholas, nur in Trevors Traumwelt stattfanden. Nicholas ist jener kleine Junge, den Trevor bei seinem Unfall mit Fahrerflucht ein Jahr zuvor getötet hat, und dessen Mutter Maria, die Trevor nur flüchtig sah, als sie nach dem Unfall zu ihrem Kind lief, hat er in Wahrheit niemals kennen gelernt.

Brad Anderson treibt damit das Dostojewskijsche Gestaltungsmittel des ungekennzeichneten Albtraums auf filmsprachlicher Ebene bis an seine äußersten Grenzen. Die Zuseher werden in „The Machinist“ noch weit länger im Ungewissen über den psychischen Zustand des Helden gelassen als in "Schuld und Sühne“ und in 
„Nina“. Während bei Dostojewskij die Kennzeichnung des Albtraums bereits erfolgt, als der Erzähler vom Erwachen Raskolnikows berichtet, und bei Dhalia schon eine Szene später deutlich wird, dass das Verhör nicht tatsächlich stattgefunden haben kann, hält Brad Anderson die Tatsache, dass die Geisterbahnfahrt ein Albtraum Trevors war, bis zum Schluss vor den Filmzusehern geheim. Hier gilt es auch festzuhalten, dass Trevors Albtraum auf inhaltlich-thematischer Ebene stärker mit Raskolnikows Traum verwandt ist als derjenige Ninas. In Trevors Traum wiederholt sich jene Tat, mit der er sich schuldig gemacht hat: Er wird - wenn auch in die Allegorie der Geisterbahnfahrt eingebettet - mit der Unfallfahrt konfrontiert, bei der Nicholas getötet wurde. Im Gegensatz dazu träumt Nina von ihren vermeintlichen Verfolgern und nicht mehr vom Mord an Dona Eulália. Heitor Dhalia stellt damit die Angst seiner Heldin vor der Strafe ins Zentrum des ungekennzeichneten Albtraums, während Brad Anderson wie Dostojewskij den Gewissenskonflikt seines Protagonisten in den Mittelpunkt des Traumgeschehens rückt.

Was „Nina“ und „The Machinist" nun zu gelungenen filmischen Neubelebungen der Dostojewskijschen Albtraumszenarien macht, sind eine Kameraführung und ein Handlungsverlauf, die lange Zeit, ja beinahe bis zum Schluss, konsequent an der subjektiven Wahrnehmungsperspektive der Protagonisten orientiert bleiben. Sie geben somit die psychosomatische Ausnahmesituation eines zu Tode erschöpften und verwirrten Menschen wieder, ohne die Zuseher darüber explizit in Kenntnis zu setzen.

Im Falle von „The Machinist“ enthüllt sich dadurch erst ganz am Ende, dass mehr als die Hälfte der im Film gezeigten Ereignisse ausschließlich in Trevors Traumwelt stattfanden. Brad Anderson führt damit Dostojewskijs unzuverlässigen Erzähler und den von diesem gestalteten ungekennzeichneten Albtraum auf filmischer Ebene an seine äußersten Grenzen. In „Nina“ erfolgt nun zwar vorab durch die in SchwarzWeiß-Bildern gedrehten Albträume eine gewisse Form der Kennzeichnung, diese entpuppt sich jedoch im Nachhinein als trügerisch. Denn zum einen werden ja nicht alle Albträume Ninas auf dieser filmsprachlichen Ebene markiert und zum anderen verunsichert Dhalia seine Zuseher später durch den bewussten Bruch mit dieser Kodierung ja mindestens ebenso sehr, wie Dostojewskij mit seinem unzuverlässigen Erzähler die Leser. 
Thomas Blume

\title{
Wie viel Dostojewskij steckt in Tarkowskij?
}

\author{
Eine Annäherung
}

Gibt es so etwas wie ein Spiegelbild von zwei so unterschiedlichen Künstlern wie Dostojewskij und Tarkowskij? Der eine ein Dichter, stark verwurzelt im zaristischen Russland des 19. Jahrhunderts, der andere ein Filmemacher, verstrickt in die Wirren des sowjetischen Parteiapparates des 20. Jahrhunderts? Es gibt Parallelen zwischen dem Dichter und dem Filmemacher und es gibt Dostojewskijsche Motive in den Filmen von Tarkowskij.

Zunächst möchte ich auf einige Lebens- und Werkdaten des 1986 verstorbenen russischen Meisterregisseurs, der nach den Worten des Regisseurs Alexander Sokurow „ein Denkmal der russischen Filmkunst in der zweiten Hälfte des 20. Jahrhunderts" darstellt, Andrej Tarkowskij, hinweisen.

Andrej Tarkowskij wurde am 4. April 1932 in Zawrashje, nordöstlich von Moskau geboren. Sein Vater, der Lyriker und Übersetzer Arsenij Tarkowskij, verließ die Familie früh, so dass Andrej und seine Schwester Marina mit ihrer Mutter ohne den Vater aufwuchsen.

1939 kommt Tarkowskij auf eine Moskauer Schule, die er aber wegen des Kriegsausbruchs wieder verlassen muss. Im Kriegsverlauf wird die Familie evakuiert und lebt bis 1943 bei Verwandten. Ab diesem Jahr geht er wieder zur Schule, eine musische Ausbildung erhält er an einer Stadtbezirks-Musikschule, Zeichenunterricht nimmt er in der Klasse der Kunstschule „1905“. Diese frühkindliche musische Erziehung beeinflusst Tarkowskij stark. Musik und Zeichnen werden später in seinem Leben als Filmregisseur noch eine wichtige Rolle spielen, weil Tarkowskij selbst seine eigene Filmkunst „als einer Bildhauerei aus Zeit“ ansieht. Er führt seinen Zuschauern in seinen Filmen immer wieder Meisterwerke der Malerei vor, von denen jedes einzelne dazu bestimmt ist, die Idee eines Films oder einer bestimmten Szene zum Ausdruck zu bringen.

Im Jahre 1951 deutet noch nichts darauf hin, dass Tarkowskij einmal der berühmteste Filmregisseur seines Landes nach dem Zweiten Weltkrieg werden sollte. In jenem Jahr beginnt er zunächst ein Studium am Moskauer Institut für östliche

1 Alexander Sokurow: Die banale Gleichmacherei des Todes. In: Wolfgang Jacobsen (Hg.): Andrej Tarkowskij. München 1987, S. 19. 
Sprachen, das er aber schon bald wegen einer Gehirnerschütterung unterbrechen und anschließend ohne Abschluss beenden muss.

Nach einigen Jahren als Arbeiter in einer Forschungsgruppe des Kirgisischen Gold-Instituts nimmt er 1954 das Studium an der renommierten Moskauer Filmhochschule WGIK auf, wo der Regisseur Michail Romm sein Mentor und Lehrer wird. Besonders faszinieren ihn zu dieser Zeit die Filme von Ingmar Bergman, Akira Kurosawa und Robert Bresson, die er zusammen mit seinem Kommilitonen Andrej Michalkow-Konschalowskij analysiert. Gemeinsam schreiben die beiden Freunde zwei Drehbücher zu Tarkowskijs Filmen: zu seinem halbdokumentarischen Diplomfilm „Die Straßenwalze und die Geige“ (1961) und zu „Andrej Rubljow“ (1966/69).

1960 beendet Tarkowskij sein Studium mit Auszeichnung. Sein erster größerer Spielfilm „Iwans Kindheit“, nach einer Erzählung von Wladimir Bogomolow, erhält im selben Jahr bei den Filmfestspielen in Venedig den "Goldenen Löwen“.

Von nun an geht Tarkowskij seinen eigenen Weg, der bis zu seinem Tod 1986 beschwerlich und kompromisslos sein wird. Dies zeigt sich allein schon darin, dass er in den 26 Jahren als Filmregisseur nur sieben Spielfilme drehen durfte, wovon er zwei im Ausland realisierte. Hinderlich war das allzu enge sowjetische Zensursystem, dem sich Tarkowskij nicht bedingungslos unterordnete. So durfte beispielsweise sein zweiter Film „Andrej Rubljow“ erst nach jahrelangen Behinderungen seitens der sowjetischen Zensoren aufgeführt werden. Der Grund des Anstoßes für die Moskauer Bürokraten war, dass Tarkowskij einen Film über das russische Mittelalter gedreht hatte, in dem dieses Mittelalter apokalyptisch und düster geschildert wurde, was die Zensur so verstand oder verstehen wollte, dass dieses Mittelalter als Allegorie für die Gegenwart steht. Hinzu kam, dass man dem Streifen unterstellte, er sei „schwierig“ und „unverständlich“. Tarkowskij erzählt in „Andrej Rubljow“ die Geschichte des mit Abstand berühmtesten russischen Fresken- und Ikonenmalers Rubljow, der in der Zeit von 1360 bis 1430 lebte, in einer Folge von acht miteinander korrespondierenden Novellen. Hintergrund des gesamten Geschehens sind Bürgerkriege, Bruderfehden, Tatarengemetzel, Hungersnöte und brutale Strafaktionen der jeweils Herrschenden, die wir immer durch die Augen Rubljows sehen. Aus diesem Grund ist nach den Worten des Filmhistorikers Ulrich Gregor „das eigentliche Thema dieses Films die Position des Künstlers und Intellektuellen in der Welt. Sie erscheint aus der Sicht dieses Films als prekär und jederzeit bedroht “2.

Andrej Rubljow begründete die Moskauer Malschule. Seine zweifellos berühmteste Ikone ist die der Dreifaltigkeit im Troiza-Sergejewskij-Kloster in Moskau, die das Ideal der Brüderlichkeit, der Liebe und des versöhnenden Glaubens darstellt.

Nach einer Hamlet-Inszenierung an einem Theater in Moskau mit seinem Lieblingsschauspieler Anatolij Solonizyn in der Titelrolle reiste Tarkowskij $1982 \mathrm{zu}$ den Dreharbeiten seines vorletzten Films nach Italien; von dort kehrte er nicht mehr in die Sowjetunion zurück. Diesen Schritt begründete der Regisseur mit künstlerischen

2 Ulrich Gregor, Enno Patalas: Geschichte des Films. Ab 1960. Reinbek bei Hamburg 1983, S. 335. 
und persönlichen Schwierigkeiten in seiner ehemaligen sowjetischen Heimat. Seine Emigration erlebte der Filmemacher abwechselnd in Italien und Frankreich.

1985 wird Tarkowskij Stipendiat des Deutschen Akademischen Austauschdienstes und Gast des Künstlerhauses Bethanien in Berlin. Schon von einer Krebskrankheit gezeichnet, beginnt er im selben Jahr in Schweden mit der Realisierung seines letzten Films.

Am 29. Dezember 1986 stirbt Tarkowskij in Paris an Lungenkrebs. Begraben wird er auf dem Friedhof Sainte Geneviève des Bois.

Schon kurz nach seinem Tod vollzieht sich in der Sowjetunion eine radikale Neubewertung seines Werks, zu der nicht zuletzt die neue Kulturpolitik Michail Gorbatschows beiträgt.

Andrej Tarkowskijs Filme im Einzelnen sind: „Iwans Kindheit“ (1962), „Andrej Rubljow“ (1966/69), „Solaris“ (1972), „Der Spiegel“ (1975), „Stalker“ (1979), „Nostalghia“ (1983), „Opfer“ (1986).

Tarkowskij hat nicht nur Filme gedreht, sondern sich zu Kunst und Ästhetik des Films artikuliert. Diese Schriften sind in dem Buch „Die versiegelte Zeit“, erschienen 1985, zusammengeführt. ${ }^{3}$ Dieses Buch ist auch als ein Bekenntnis eines Künstlers und Intellektuellen zu Fragen der Zeit anzusehen. Der österreichische Schriftsteller Gerhard Roth wählte dieses Buch 1999 in einer Umfrage der Wochenzeitung „Die Zeit“ in die Liste seiner Jahrhundertbücher. „Ich habe den Essays von Tarkowskij vor anderen Büchern deshalb den Vorzug gegeben, weil sie - auch wiederum wie seine Filme - Energiequellen sind, die aus der duchownost, der Spiritualität und mystischen Geistigkeit, heraus schöpfen und dabei eigentlich gar nicht zeitgemäß zu sein scheinen." 4

\section{Tarkowskij und Dostojewskij}

Andrej Tarkowskijs Filmwerk ist tief in der klassischen russischen Kultur verwurzelt. Ohne leidenschaftlichen Bezug zu dem Ikonenmaler Andrej Rubljow, wie bereits dargelegt, zu Alexander Puschkin, Leo Tolstoj, Fjodor Dostojewskij, Osip Mandelstam, Alexander Grin sowie den russischen Filmpionieren Alexander Dowshenko, Sergej Eisenstein und Dziga Vertov und besonders zu seinem Vater, dem Lyriker und Übersetzer Arsenij Tarkowskij, ist der russische Meisterregisseur nicht denkbar. Besonders die Person und das Werk Dostojewskijs haben Tarkowskij ein Künstlerleben lang begleitet. Dies belegen allein schon die zahlreichen Aufzeichnungen in

3 Auch in seinem Essayband „Die versiegelte Zeit“ (Berlin 1988) kommt Tarkowskij oft auf Dostojewskij zu sprechen. Beide, Tarkowskij und Dostojewskij, sind Künstler der Krise, die aber zugleich die Chancen einer Krise begreifen. Die Darstellung eines neuen Typus des geistig suchenden Menschen war bei beiden Künstlern gleichermaßen stark ausgeprägt. Beiden geht es in ihren Werken um existentielle, ethische und religiöse Fragen. Häufig stellen sie die Welt der Dinge und Menschen, so wie wir sie zu sehen glauben, auf den Kopf.

4 Gerhard Roth: Die versiegelte Zeit. In: Iris Radisch (Hg.): Mein Jahrhundertbuch. Frankfurt am Main 2003, S. 107. 
seinem Tagebuch, aus denen ich zunächst im Folgenden zitieren werde. Die Eintragungen zeigen, dass sich Tarkowskij offenbar stark mit der Geisteshaltung und dem Schicksal Dostojewskijs identifizieren konnte. Besonders die Figur des Fürsten Myschkin war Tarkowskij wichtig. Ein geplantes Filmprojekt des Romans „Der Idiot“ für das Fernsehen scheiterte an der sowjetischen Zensur.

Tarkowskij nennt seine Tagebuchaufzeichnungen selbst „Martyrolog“. Die Tagebuchaufzeichnungen setzen am 30. April 1970 ein. Der erste Eintrag gilt Dostojewskij:

„Wir haben wieder einmal mit Sascha Mischarin über ,Dostojewskij‘ gesprochen. Da müsste man natürlich erst seine Ideen zu Papier bringen. Und vorläufig nicht an Regie denken. Es hat wohl wenig Sinn, Dostojewskij verfilmen zu wollen. Über Fjodor Michailowitsch selbst müsste man einen Film drehen ... über seinen Charakter, seinen Gott, seine Dämonen, über sein Schaffen. Tolja Solonizyn könnte einen wunderbaren Dostojewskij abgeben. Jetzt muß ich zuerst einmal alles lesen, was Dostojewskij selbst geschrieben, und auch alles, was man über ihn geschrieben hat, und dazu noch die russischen Religionsphilosophen: Solowjew, Berdjajew, Leontjew. Dostojewskij könnte zum Inbegriff all dessen werden, was ich im Film verwirklichen will. ${ }^{\text {"5 }}$

Nebenbei sei bemerkt, dass Tarkowskijs Worte hier nahezu prophetische Züge hatten, denn in dem wunderbaren Film „26 Tage aus dem Leben Dostojewskijs“ von Alexander Sarchi spielt Anatoli Solonizyn tatsächlich Dostojewskij.

Am 7. September heißt es im Tagebuch lapidar: „Worüber ich gerne einen Film drehen würde“. Das Tagebuch versammelt hier insgesamt 13 Eintragungen, u. a. heißt es: „Über Dostojewskij“, an zehnter Stelle: „Der Jüngling“ von Dostojewskij. Am 13. September notiert er ganz am Schluss seiner Aufzeichnungen: „Versuchte wiederum, die Briefe D.s an seine Frau zu lesen. Stieß sofort auf seine Qualen beim Spielen und seine riesigen Verluste dabei. Unmöglich zu lesen. Gab die Lektüre auf.“

Am 18. Februar 1971 exzerpiert Tarkowskij aus dem Notizbuch von Dostojewskij zu „Schuld und Sühne“ folgendes: „Die Angst vor der Ästhetik ist das erste Merkmal von Schwäche. Der Sozialismus ist ein Räderwerk. Der Mensch ist darin nur ein Rädchen und wird zu etwas Mechanischem degradiert. Nach allen Regeln der Kunst. So wird er sich selbst entfremdet. Man hat ihm seine lebendige Seele geraubt. Da kann einer getrost sagen, dass es sich um das reinste Chinesisch handelt, und diese Herren behaupten noch, dass sie den Fortschritt verkörpern! Mein Gott! Wenn das der Fortschritt ist, was soll man denn dann erst als Chinesisch bezeichnen? Sozialismus ist der verzweifelte Versuch, irgendwann einmal das Leben der Menschen zu regeln. Es regelt sich durch den Despotismus und behauptet dann, eben das ist die Freiheit.“

5 Andrej Tarkowskij: Tagebücher 1970 - 1986. Martyrolog. Berlin 1989, S. 33. Die folgenden Eintragungen aus dem Tagebuch ebd., aber ohne Seitenangabe 
Am 17. März 1971 wird hervorgehoben: „Ich muß unbedingt damit beginnen, Material, alles nur verfügbare Material über Dostojewskij zu sammeln.“

Am 24. April hat er sich wahrscheinlich immer noch nicht darum gekümmert, wieder schreibt er: „Ich muß unbedingt damit beginnen, Material zum ,Dostojewskij‘ zu sammeln. Es soll da einen gewissen Schwarzhändler, genannt ,Nilpferd" geben, der auch mit Büchern handelt. Die gesammelten Werke von D., einschließlich der Tagebücher, kosten 250 Rubel. Ich muß sie unbedingt kaufen."

Am 13. September notiert Tarkowskij in sein Tagebuch: „Ljuka Feit hat die ersten Bücher über Dostojewskij auf den Set mitgebracht.

1. Aufsätze von Cornfeld und A. Remisow über D. von 1921

2. D. in der Darstellung seiner Tochter L. Dostojewskaja von 1922

3. Band 1 der Gesamtausgabe von 1883

4. $\mathrm{Zu}$ Hause habe ich Briefe an seine zweite Frau."

Einen Tag darauf, am 14. September, offenbar unter dem Eindruck der vorangegangenen Lektüre von Cornfeld oder Remisow: „F. M. schrieb beim Licht zweier Kerzen. Er liebte keine Lampen. Während der Arbeit hat er viel geraucht und immer wieder starken Tee getrunken. Sein Leben war monoton in Staraja Russa, dem Urbild des Städtchens, in dem Karamasow wohnt. F. M.s Lieblingsfarbe war die der Meereswellen. Seine Heldinnen trugen oft Kleider dieser Farbe."

Am 19. September heißt es: „Ich komme immer mehr zu dem Schluß, dass D. einen außerordentlich verschlossenen und pedantischen Charakter hatte. Vielleicht war er sogar langweilig, von außen betrachtet. Es wird schwer werden, das Drehbuch zu schreiben. Für das Drehbuch: Der Anfall auf der Treppenstufe. Realität vermischt mit einer Szene aus dem ,Idiot‘ - Rogoschin und Fürst Myschkin. Das Gartenmesser. Ärger über die Europäisierung von Turgenjew - „Geschichte einer Feindschaft“. Briefe. Akademie. Karmazinow in den ,Dämonen'."

Am 1. Februar 1973 schreibt Tarkowskij, nachdem er 1972 in seinem Tagebuch keine Gedanken über Dostojewskij festgehalten hatte, dass ihm da eine Idee gekommen sei: „Ich könnte den ,Idiot' für das Fernsehen inszenieren, in sieben Teilen und in Farbe. Darüber muss ich aber unbedingt zuerst direkt mit Lapin sprechen. Ohne Vermittler und ohne überflüssige Bürokraten. Die Idee ist nicht schlecht.“

Am 2. Februar findet sich der Eintrag: „Den ,Idiot“ als mehrteiligen Fernsehfilm inszenieren. Einen Film über D. und ,Vater Sergej ${ }^{`}$ - auch fürs Fernsehen. Den "Idiot' ${ }^{`}$ u verfilmen wäre wirklich nicht schlecht, es würden sieben Teile werden.“

Am 4. Februar folgt die inhaltliche Fortsetzung: „Ich lese gerade noch einmal den ,Idiot' ${ }^{`}$ Meiner Meinung nach wird die Verfilmung keine leichte Sache werden. Besonders schwierig wird sich die Arbeit am Drehbuch gestalten. Das Romanmaterial unterteilt sich vor allem in Szenen und die Beschreibung der Szenen, das heißt in eine Aufzählung alles dessen, was an Wichtigem für die Entwicklung der Geschichte passiert ist. Diese Beschreibung gänzlich aus dem Drehbuch auszuklammern ist natürlich unmöglich. Einiges davon muß in Szenen umgesetzt werden."

Am 15. Februar notiert Tarkowskij, der seit über einem Monat krank im Bett liegt: 
„Ich las wiederum den ,Idiot', und aus irgendeinem Grund ließ in mir das Interesse nach. Ich weiß nicht warum, aber ich empfand bei seiner Lektüre nur Langeweile... In seiner Jugend hinterließ Dostojewskij, bevor er zu Bett ging, Zettel ungefähr solchen Inhalts: ,Heute kann mich ein lethargischer Schlaf überkommen, daher soll man soundso viele Tage warten, ehe man mich begräbt ... '

F. M. behauptet selbst, dass, wäre nicht die Katastrophe im Zusammenhang mit dem Prozeß um den Petraschewskij-Zirkel gewesen, er mit Gewissheit den Verstand verloren hätte. Es gibt andere Anzeichen für den ernsthaft gefährdeten Gesundheitszustand D.s noch vor jenem Zeitpunkt. Die Entscheidung Nikolais I. bezüglich D.: ,Statt acht Jahren Verbannung nur vier und danach gemeiner Soldat' bedeutete für ihn die Bewahrung seiner bürgerlichen Rechte und war somit der erste Fall dieser Art in Russland; denn wer früher zur Zwangsarbeit verurteilt worden war, ging seiner Bürgerrechte für immer verlustig. Als das Urteil verlesen wurde, kam die Sonne heraus, und F. M. sagte zu Durow, der neben ihm stand: ,Es kann nicht sein, daß sie uns hinrichten.' (Es existiert eine Parallele zwischen dem Schafott und der Erzählung über den Verurteilten aus dem ,Idiot'. Sofort herausfinden, welche Ausgabe von D. die kompletteste ist.) Auf dem Schafott bemerkt Kaschkin, daß der Priester ohne die heiligen Sakramente gekommen war, und er wandte sich daraufhin um und fragte mit flüsternder Stimme den kommandierenden Offizier auf französisch: ,Wird man uns denn wirklich nicht einmal die letzte Beichte abnehmen und die Absolution erteilen?' Worauf ihm General Glachow erwiderte: ,Ihr werdet alle begnadigt werden.' Seltsam, warum Kaschkin diese Nachricht nicht sogleich seinen Freunden übermittelte. F. M. erzählt von der fast mystischen Angst in dem Augenblick, als er seine Hinrichtung erwartete, als er darauf wartete, in die andere Welt hinüberzugehen! Er glaubte an die Unsterblichkeit.“

Am 16., 17. und 18. Februar exzerpiert Tarkowskij sowohl einige Aphorismen aus den "Aufzeichnungen aus dem Totenhaus" als auch Aufzeichnungen von Nicolai Strachow. Am 18. Februar notiert er: „Nach der unbefriedigenden Lektüre des ,Idiot habe ich mir vorgenommen, den ,Jüngling zu lesen. Das Gespräch mit Lapin über den ,Idiot" erübrigt sich vorerst."

An diese Tagebuchaufzeichnung schließt Tarkowskij ein Gesuch an den leitenden Redakteur von Mosfilm W. S. Beljajew an, das er am 2. Februar an diesen gesandt hat: „Ich bitte um die Genehmigung für einen zweiteiligen Film nach dem Originaldrehbuch von A. Tarkowskij und Alexander Mischarin über Werk und Persönlichkeit des großen russischen Schriftstellers F. M. Dostojewskij. Das Drehbuch ist eher als poetische Untersuchung denn als Biografie angelegt. Es geht mir sowohl um die Untersuchung der schöpferischen Voraussetzungen, die im Charakter Dostojewskijs begründet liegen, um eine Analyse seiner philosophischen und ethischen Konzeptionen, als auch um eine spannende, interessante Reise in das Reich der Gedankenwelt seiner bedeutendsten Werke."

Bis zum 29. Dezember 1973 findet sich keine Notiz mehr über den Schriftsteller Dostojewskij oder über das zitierte Gesuch. An diesem Tag schreibt er aber: „Ich 
muß die Dostojewskij-Verfilmung durchboxen. Die Terechowa wäre eine ideale Besetzung für Nastassja Filippowna. Wenn das Komitee keine Entscheidung fällt, gehe ich zu Demitschew. Für das Frühjahr und Sommer habe ich mir viel vorgenommen: u. a. das Drehbuch für den ,Idiot' zu schreiben, damit ich im Herbst mit der neuen Arbeit beginnen kann... Das Drehbuch zum ,Idiot könnte mit einem Rückblick auf die Kindheit von Nastassja und ihre Bekanntschaft mit Tozkij beginnen. Wie sich Myschkin und Rogoschin kennengelernt haben, ist jedoch nicht wichtig. Diese Stellen müssen gestrichen werden. Wenn der Film allzu sehr Wert legt auf große Raumtiefe und auf Massenszenen, bleibt kaum etwas von dem wahren Charakter des Werkes übrig - deshalb sollte man lieber darauf verzichten. Auch die Geschichte mit dem Skandal am Bahnhof ist überflüssig. Welche Szenen des Romans fallen mir eigentlich spontan ein (und das natürlich nicht zufällig; ich habe den ,Idiot' ja des öfteren gespielt): die Bekanntschaft Fürst Myschkins mit den Jepantschins und sein Bericht über die Hinrichtung, Ganjas Ohrfeige, Nastassja Filippowna bei den Iwolgins, das Schicksal Nastassjas, die hunderttausend Rubel, Ippolits Traum, die chinesische Vase, Aglaja und Nastassja, Nastassjas Tod, der Fürst bei Rogoschin, Myschkins epileptischer Anfall und seine Wahnvorstellung von Rogoschins Mordanschlag, der Fürst und die Kinder."

In einem von ihm selbst gestalteten Fragebogen (1974) zu seinen Interessen gibt Tarkowskij unter der Frage, welches Werk der russischen Literatur er am liebsten gelesen habe, den Roman „Schuld und Sühne“ von Dostojewskij sowie die Erzählung „Der Tod des Iwan Iljitsch“ von Leo Tolstoj an. Als sein Lieblingsdichter gilt allerdings Alexander Puschkin.

Am 27. Januar notiert er: „Smoktunowskij versucht die Inszenierung des ,Idiot durchzusetzen. Dafür ist er nach Leningrad gefahren. Warum ausgerechnet nach Leningrad? Scheinbar ist diesbezüglich seitens der Obrigkeit noch gar keine Entscheidung gefallen. Ich muß unverzüglich selbst den ,Idiot' durchzukriegen versuchen. Hoffentlich verdirbt Smoktunowskij die ,Dostojewskij-Angelegenheit' nicht. Das muß verhindert werden."

Am 3. Februar erklärt er die Lösung des diskutierten Problems: „Ich habe Sisow in dieser Woche das Exposé zum ,Idiot' gegeben. Wenn ich es schaffe, gebe ich auch Schauro eine Kopie.“ Am 23. Februar heißt es weiter: „Was den ,Idiot‘ betrifft, so habe ich Sisow das Exposé für einen zweiteiligen Film unterbreitet. Außerdem hat die Lollobrigida, als sie in Moskau war, Sisow eine Gemeinschaftsproduktion des ,Idiot' vorgeschlagen (sie würde dabei gern die Nastassja Filippowna spielen). Die Regie sollte ihrer Meinung nach Kontschalowskij übernehmen. Darauf soll Sisow gesagt haben, daß es da noch Tarkowskij gäbe. Sie hat sich angeblich sehr gefreut, es aber gleich darauf Kontschalowskij weitergegeben. Das muß verhindert werden und der ,Idiot' bei Mosfilm gedreht werden."

Noch immer ohne eine Entscheidung betreffs der Verfilmung des „Idiot" reflektiert Tarkowskij am 25. Dezember: „Liegt mir denn wirklich so sehr an der Verfilmung des ,Idiot'? Wird sie denn nicht auf eine reine Illustration meiner Prinzipien 
hinauslaufen, die auf dem Hintergrund der Romanstruktur einfach nicht organisch wirken können? Vielleicht wäre sogar (unter Zuhilfenahme der Klassik) ,Der Tod des Iwan Iljitsch', der eine äußerst sorgfältige ,Überholung' erfordert, viel zweckmäßiger für mich? Dort muß, nachdem es von mir aufs neue durchlebt worden ist, alles wiedererweckt werden. Das ist wesentlich. Natürlich, ,Über Dostojewskij' ist das zweckmäßigste Vorhaben für mich, obgleich es ebenfalls unter einer gewissen konstruktivistischen Absicht leidet. Mir schweben sogenannte Schichten vor - Gegenwart, Gewesenes, Ideales und deren Verschmelzung.“”

Offenbar zweifelt Tarkowskij selbst immer mehr an dem Idiot-Projekt. Am 6. Januar 1975 notiert er ungeduldig: „Habe Jermasch einen Brief geschrieben, in dem ich ihn ersuche, unverzüglich das Problem mit meinen künftigen Arbeitsaussichten zu entscheiden. Ich dachte dabei an eines von beiden: entweder den ,Idiot' oder den Film über Dostojewskij. Aber wahrscheinlich wird er ohnehin nein sagen. Dann schicke ich ihm noch einen Brief mit dem Exposé (eine Kopie davon geht zugleich an das Studio) zum ,Tod des Iwan Iljitsch' und ,Picknick am Wegesrand“.”

Am 2. März erfahren wir, dass von Seiten des Komitees noch nichts entschieden und für Tarkowskij weiterhin „Schweigen im Walde“ herrscht. Erst am 21. Juli widmet sich der Regisseur wieder dem Problem Dostojewskij: „Gestern hat Larissa mit Moskau telefoniert. Sascha Mischarin hat das Exposé geschrieben. Sascha zufolge (er übertreibt aber stets, wenn es um Erfolge geht, Misserfolge dagegen verschweigt er) ist Felix Kusnezow vom Exposé des ,Idiot' hell begeistert. Wenn doch auch Barabasch begeistert wäre! Sie ist Redakteurin des Komitees und soll für den Schnitt beim ,Idiot 'verantwortlich sein - sie wurde von Jermasch eingesetzt, wobei unsere Gruppe und Mosfilm übergangen wurden."

Nur ein paar Tage später, am 25. Juli, zweifelt Tarkowskij aber wieder, ob das Projekt wirklich zustande kommen könnte: „Ob man mir wirklich gestatten wird, den ,Idiot' zu verfilmen? Auf dem Moskauer Festival war allein Antonioni so anständig zu erklären, daß er das Festival verlassen würde, wenn man ihm den ,Spiegel nicht zeigt. Man wollte das lange nicht, dann blieb ihnen aber nichts anderes übrig. Der Film hatte ihm sehr gut gefallen. Er wollte sich sogar mit mir treffen. Unsere Beamten haben mich aus diesem Anlaß beinahe aus dem Dorf abgemeldet."

Am 21. September erfährt er, dass sein Projekt nicht zustande kommt: „Der „Idiot ist geplatzt. Sascha Mischarin schrieb mir. Er hat sich an die Strugazkijs gewandt, damit sie etwas unternehmen. Als ob die allein etwas ausrichten können ..."

Das ganze übrige Jahr 1975 findet sich kein Eintrag mehr zu Dostojewskij.

Am 17. und 18. August 1976 exzerpiert Tarkowskij wieder aus den Notizbüchern Dostojewskijs Passagen, die auf seine eigene Situation in Russland und die der „verfilzten“ Filmbehörde passen: „Es muß für sie nur - und dies ausgiebigst - Blut fließen. Die Schurken pflegen nur eines zu vergessen, daß dieses Blut niemals stark bei jenen fließt, die das Blut vergießen, sondern nur bei denen, deren Blut vergossen wird. Das ist das Gesetz des Blutes.“ 
Am 7. September notiert Tarkowskij stolz: „Larissa ist am Mittwoch gekommen. Der Vertrag über den ,Idiot' ist abgeschlossen. Jetzt können wir Iwan die Schulden zurückzahlen".

In den Tagebüchern der Jahre 1977 und 1978 finden sich keine Einträge über das geplante Projekt des Films „Idiot“ oder über Dostojewskij. Erst 1979 kommt Tarkowskij wieder auf Dostojewskij zu sprechen. Am 21. Januar äußert er sich nach der Lektüre von Friedrich Gorensteins Roman „Psalm“: „Über die Idee von den fünf Leiden Christi und den Durst nach Glauben und nach der Erkenntnis Gottes hat Dostojewskij bereits reflektiert.“

Am 3. Dezember 1979 überreicht Tarkowskij einem Filmfunktionär von Mosfilm eine Liste der in Frage kommenden Klassiker, die er gerne verfilmen will. Darunter taucht wieder das Projekt des „Idiot“ auf, sowie „Der Doppelgänger“, der zugleich ein Film über Dostojewskij werden soll. Auch zwei Werke von Tolstoj erwähnt Tarkowskij, neben dem „Tod des Iwan Iljitsch“ will er auch einen Film über das letzte Lebensjahr von Tolstoj drehen.

Bereits zu Dreharbeiten in Italien weilend, kommt er am 25. Juli 1980 in Taormina auf Sizilien noch einmal auf das Projekt „Idiot“ zu sprechen: „Bei meinen Überlegungen zum ,Idiot' komme ich zu der Ansicht, daß man die logische Abfolge von Sujet und Episoden ebenfalls getrost zerstören kann, da ja der Aufbau bei Literatur und Film ganz verschieden ist."

Die letzte Aufzeichnung zu Dostojewskij datiert vom 10. November 1980. Tarkowskij übernimmt einen Aphorismus des Dichters in sein Tagebuch: „Unsere Welt ist ein Fegefeuer himmlischer Seelen, die von sündhaften Gedanken getrübt sind.“

Die verschiedenen Eintragungen im Tagebuch von Tarkowskij wirken fragmentarisch und ergeben kein vollständiges Bild über Tarkowskijs künstlerische Rezeption der Werke Dostojeswkijs, weil sich kein wirkliches Gesamtbild auf der Grundlage der zitierten Tagebücher ergeben kann. Allerdings offenbaren diese Eintragungen doch die starke Antizipation des Filmemachers mit den Romanen und Erzählungen des russischen Dichters.

\section{Motive Dostojewskijs bei Tarkowskij}

Tarkowskij äußert sich in seinem Band „Die versiegelte Zeit“ zu Dostojewskijs Rezeption in Russland: „Ganz außerordentlich bedeutsam sind für mich die von Dostojewskij herkommenden russischen Kulturtraditionen. Im wesentlichen sind diese allerdings im modernen Rußland nicht zu voller Entfaltung gekommen. Ja, man vernachlässigt sie dort eher oder ignoriert sie sogar völlig. Dafür gibt es mehrere Gründe, von denen wohl der wichtigste der ist, daß diese Tradition prinzipiell mit dem Materialismus unvereinbar ist. Eine weitere Ursache dieser zurückhaltenden Dostojewskij-Rezeption im heutigen Rußland ist sicher die geistige Krise, die für die Helden dieses Schriftstellers, für dessen eigenes Werk insgesamt, aber auch für das seiner Nachfolger so bezeichnend ist. Warum fürchtet man diesen Zustand einer ,geistigen Krise' im modernen Rußland so sehr? Für mich ist eine geistige Krise 
immer ein Zeichen von Gesundheit. Denn meiner Meinung nach bedeutet sie ein Versuch, zu sich selbst zu finden, einen neuen Glauben zu erlangen. In den Zustand einer geistigen Krise gerät jeder, der sich geistigen Problemen stellt. Wie sollte es auch anders sein? Schließlich dürstet die Seele nach Harmonie, während das Leben voller Disharmonien ist. In diesem Widerspruch liegt das Stimulans für Bewegung, zugleich aber auch die Quelle unseres Schmerzes und unserer Hoffnung. Er ist eine Bestätigung unserer geistigen Tiefe, unserer spirituellen Möglichkeiten." ${ }^{\text {" }}$

Auch „im Kosmos Dostojewskijs ist das Leid ein Urphänomen“7, wie Zenta Maurina schreibt. „Leid ist ein Hinweis auf Tiefe" ${ }^{\text {, }}$, sagt als profunder Deuter Dostojewskijs auch Nikolai Berdjajew. In den „Aufzeichnungen aus dem Kellerloch“ heißt es einmal: „Das Leid ist der einzige Ursprung der Erkenntnis.“9 Das Leid leugnen, es aus dem Leben verbannen, heißt nach Dostojewskij, dem Menschsein entsagen. Das gleiche gilt für nahezu alle Protagonisten Tarkowskijs.

Die Hauptfiguren seiner Filme nach „Iwans Kindheit" sind Menschen (Männer), welche die Welt wieder einzurichten haben: so der Malermönch Andrej Rubljow, der Psychologe Kris Kelvin in „Solaris“, der Stalker, der russische Schriftsteller in der Fremde Andrej Gortschakow und der Verrückte Domenico in „Nostalghia“, ebenso Alexander in „Opfer".

Der Regisseur Tarkowskij ist ein Nachgeborener: Verglichen mit Dostojewskijs Zeitalter ist die Zerstörung, der Zynismus und der Nihilismus, die beide Künstler konstatieren, fortgeschritten, die Katastrophe ist universell geworden. Dafür steht bei Tarkowskij das Bild der zerstörten Natur, man denke an die Filme "Stalker“ oder „Opfer“. Auch deshalb kann man die Filme Tarkowskijs als Menetekel des Atomzeitalters betrachten, aus dem er aber einen Ausweg zeigt, der heißt: Spiritualismus, Besinnung, Christentum sowie Protest. Im Tagebuch verzeichnet er einmal: „Das einzige, was uns jetzt retten kann, ist eine neue Ketzerei, die alle ideologischen Gebäude unserer unglückseligen, barbarischen Welt zum Einsturz bringen wird. Die Größe des heutigen Menschen liegt im Protest. Ruhm gebührt dem, der sich aus Protest vor dem Antlitz einer stumpfen, schweigenden Menge verbrennt - demjenigen, der auf den Platz hinaustritt, bewaffnet mit Plakaten und Losungen, und sich so den schlimmsten Repressalien ausliefert, auch all jenen, die nein sagen zum Egoismus und zur Gottlosigkeit.“ Dieser Eintrag datiert vom 9. September 1970. Zwölf Jahre später realisiert Tarkowskij diesen Gedanken in der Figur des Domenico in „Nostalghia“. Dieser „Narr in Christo“ trägt zusammen mit dem Stalker und Alexander in „Opfer" unübersehbar Züge Dostojewskijs. Es hat eine lange russische Tradition, den „guten Menschen“, der Christus am nächsten kommt, in der Gestalt

6 Andrej Tarkowskij: Die versiegelte Zeit. Gedanken zur Kunst, zur Ästhetik und Poetik des Films. Berlin 1988, S. 198.

7 Zenta Maurina: Dostojewskij. Menschengestalter und Gottsucher. Memmingen 1960, S. 285 ff.

8 Nikolai Berdjajew: Die Weltanschauung Dostojewskijs. München 1925, S. 76.

9 Fjodor Dostojewskij: Aufzeichnungen aus dem Kellerloch. Aus dem Russischen von Hermann Röhl. Frankfurt am Main 1988, S. 55. 
des „heiligen Toren“ zu sehen, der sozusagen seine Geistesschwäche nur vorgibt, um seinen Stolz zu demütigen. In der Figur des Fürsten Myschkin hat Dostojewskij eine besonders ausgeprägte Gestalt im „Idiot“ geschaffen.

Die Figur Domenico aus „Nostalghia“, dargestellt von dem langjährigen IngmarBergman-Schauspieler Erland Josephson, ist die vielleicht radikalste Person Tarkowskijs. Natürlich huldigt Tarkowskij damit nicht dem Tod an sich, sondern mit der Figur des Domenico wollte Tarkowskij einen Menschen darstellen, der die Verfehlungen unseres modernen Lebens nicht nur „den anderen“ anlastet, sondern der den Kreislauf mit seinem dargebrachten Opfer selbst durchbricht. Seine „höhere Tat“ zeigt, was Dasein auch sein kann. In der „Versiegelten Zeit“ schreibt er dazu: „Domenico entschließt sich zur Selbstverbrennung, um den Menschen mit dieser extremen Aktion seine Selbstlosigkeit zu demonstrieren. Und zwar in der wahnwitzigen Hoffnung, dass sie auf diesen letzten, warnenden Schrei hören werden [...] Domenico verspürt eine echte Verantwortung gegenüber dem Leben, als er den Mut zu einer solchen Tat aufbringt. [...] Ähnlich wie Stalker erdenkt sich auch Domenico eine eigene Philosophie. Um nur ja nicht dem allgemeinen Zynismus, der Jagd nach persönlichen materiellen Vorteilen anheimzufallen, wählt er einen eigenen, qualvollen Weg und unternimmt mit dem Beispiel seines Opfertodes noch einmal einen Versuch, die verrückt gewordene Menschheit auf ihrem Weg in den eigenen Untergang aufzuhalten. Das Wichtigste, was ein Mensch besitzt, ist sein ewig unruhiges Gewissen, das ihn einfach nicht in aller Gemütsruhe ein fettes Stück von diesem Leben verzehren lässt. [...] in diesem Sinne interessieren mich Menschen mit der Bereitschaft, Höherem zu dienen, seine Ablehnung, ja Unfähigkeit, sich mit der gewöhnlichen Spießbürger-Moral abzufinden. Mich interessiert ein Mensch, der den Sinn seiner Existenz im Kampf gegen das Böse sieht und so im Laufe seines Lebens zumindest eine geistig ein klein wenig höhere Stufe erklimmt."

Kann man diese Sätze nicht auch auf viele Romanpersonen Dostojewskijs übertragen? Ich denke hier besonders an Raskolnikow, Kyrillow, Wersilow und vor allem an Iwan Karamasow. Sie alle befinden sich wie die Protagonisten Tarkowskijs „in einem existentiellen Zustand jenseits jeder, normalen' Geschehenslogik ${ }^{“ 10}$.

Ein solcher Mensch ist auch Stalker aus dem gleichnamigen Film, der auf der literarischen Vorlage „Picknick am Wegesrand“ der Brüder Strugatzkij basiert. Stalker, zu Deutsch etwa Fährtensucher, ist die spirituellste Figur im ganzen TarkowskijKosmos und ähnelt am meisten dem guten Menschen Fürst Myschkin in seinem religiösen Glauben. Aglaja definiert Myschkin einmal so: „Alle, die hier anwesend sind, sind nicht so viel wert wie Ihr kleiner Finger und reichen an Ihren Verstand und an Ihr Herz nicht heran; Sie sind ehrlicher als sie alle, edler als sie alle, klüger als sie alle...!"11 Ähnlich wie Myschkin ist auch der Stalker ein Stigmatisierter, leidend,

10 Vgl. hierzu auch: Hans-Dieter Jünger: Kunst der Zeit und des Erinnerns. Andrej Tarkowskijs Konzept des Films. Ostfildern 1995, o. S.

11 Fjodor Dostojewskij: Der Idiot. Frankfurt am Main 2003, S. 530. 
geplagt von Schuld, Sühne und Erlösungs-Besessenheit. Er trägt ein seltsames Zeichen an der Stirn, vielleicht heiliges Wundmal, vielleicht die Narbe einer Gehirnoperation in einem Gulag.

Worum geht es in dem Film? Zunächst einmal um eine Expedition in die ZONE, die drei Männer am Anfang des Films starten: neben dem Stalker, der ihnen den Weg dorthin weist, reisen ein zynischer Schriftsteller und ein sarkastischer Wissenschaftler mit. Ihr Ziel ist ein geheimnisvolles Zimmer innerhalb der ZONE, das den Eintretenden alle unterbewussten Wünsche erfüllt. Die ZONE ist ein Niemandsland voller Ruhe und Frieden, in dem vor mehr als 20 Jahren ein Meteor oder ein Atomschlag niederging und aus dem Soldaten nicht zurückkamen, die das Terrain erkunden sollten. Seither ist der Zugang offiziell verboten. Die drei Protagonisten müssen einige gefährliche Hindernisse überwinden, um hineinzugelangen. Auf einer Draisine gleiten sie ins Nichts, in eine romantische Metamorphose. Aus der düsteren Landschaft, die in sepiafarbenem Schwarzweiß gedreht wurde, wird mit zunehmender Fahrt eine bunte und sonnige Landschaft. Als sie in der ZONE angekommen sind, taucht unter einer Telefonstange die Form eines Kreuzes auf. Von dort aus begeben sich die drei auf die Suche nach dem Zimmer. Dabei bewegen sie sich durch eine Unterwelt aus Stollen, Tunneln und Kanälen, waten durch Wasser, Schlamm und herumliegenden Zivilisationsmüll. Es wirkt wie eine spirituelle Phantasmagorie, in der überdeutlich wird, dass der Glaube aus der Welt verschwunden ist und nur noch komische Heilige an ihm festhalten.

Hier wird eine Heilsgeschichte gezeigt, die sich aber einer dezidiert religiösen Interpretation verweigert und verweigern will. Der Stalker erfährt die Verluste der heutigen Zivilisation wie in einem Prisma gebündelt und steht deshalb ganz im Zeichen einer Sehnsucht nach dem Anfang und nach einem sinnerfüllten Dasein. Aus dem Off gibt ein Gedicht Arsenij Tarkowskijs dieser erfahrenen Seinsverlassenheit Ausdruck, wie sie uns Zuschauern auch in der Ödnis der menschenleeren Fabrik-Landschaften des Films begegnet: „Draußen fliesst der Fluß Vergessen, I Treibt von Sümpfen grauer Rauch, / Lärmen fremde Interessen ..."

Ist es nicht diese Seinsverlassenheit, die Kirillow einmal sagen lässt: „Gott hat mich mein Leben lang gequält?"12 Diese Erfahrung einer außerordentlichen Seinsferne ist es, die den Protagonisten mit allem Gewohnten brechen und ihn als Abgesonderten den Sprung in den Abgrund der ZONE des Seins wagen lässt. Der Protagonist des Films Stalker erlebt in der ZONE eine spirituelle Erfahrung, die ihn freilich zu einem Abhängigen der ZONE macht, weshalb es ihn immer wieder dorthin drängt. Den anderen beiden Weggefährten, dem Wissenschaftler und dem Schriftsteller, widerfahren solche Erfahrungen nicht. Diese beiden Figuren sind vergleichbar mit jenen Menschen in dem Roman von Dostojewskij, die Zenta Maurina zu der Gruppe der niedrigsten Gotteslästerer zählt, also den alten Karamasow,

12 Vgl. hierzu auch: Zenta Maurina: Dostojewskij. Menschengestalter und Gottsucher. Memmingen 1960, S. 184. 
Smerdjakow, Rakitin oder Pjotr Werchowenski. In ihnen ist das Gefühl für andere verkümmert und sie vermögen Gut und Böse nicht mehr zu unterscheiden. Tarkowskij zeigt diese beiden Helden als entseelte Intellektualisten: Der Wissenschaftler schickt sich an, das rätselhafte Zimmer mit einer Bombe, die er ständig mit sich geführt hat, zu zerstören, weil es nach seinen Worten die Brutstätte von Gesindel werden könnte, und auch der Schriftsteller tritt nicht in das Zimmer ein, weil er sich vor seinem Unterbewussten fürchtet. Beide verstricken sich in intellektuellem Gerede, wobei sie den reinen Toren verhöhnen, der ihnen innere Einkehr und Läuterung predigt - ein Bild, das oft auch im Roman „Der Idiot“ vorkommt.

\section{Die Kunst Tarkowskijs}

Andrej Tarkowskijs Filme „sind sehr persönliche, poetische Schöpfungen, die sich um existentielle und ethische Fragen drehen und in künstlerischen, philosophischen sowie religiösen Traditionen Europas wurzeln. ${ }^{" 13}$

In seinem Essayband legt Tarkowskij ausführlich seine Kunstauffassung dar. Darin heißt es einmal: „In jedem Fall steht für mich ganz außer Zweifel, daß es das Ziel jedweder Kunst ist, [...] sich selbst und der Umwelt den Sinn des Lebens und der menschlichen Existenz zu erklären. Also den Menschen klarzumachen, was der Grund und das Ziel ihres Seins auf unserem Planeten ist. Oder es ihnen vielleicht gar nicht erklären, sondern sie nur vor diese Frage zu stellen." ${ }^{14}$

Damit ist die Richtung klar umrissen und ohne Frage ist das Gesamtwerk Andrej Tarkowskijs eschatologisch begründet. Genau wie in Dostojewskijs Spätwerk ist das gesamte Weltbild göttlich zentriert.

Die Kritikerin Maja Josifowna Turowskaja beschrieb dieses Weltbild so: „Tarkowskijs Welt lässt sich also mit einer eigenen kosmischen Sphäre vergleichen. Sie ist verschlossen, nicht kommunikativ, sich selbst, dem ,Einödhof der Gefühle zugewandt' (M. Zwetajewa). Vielleicht liegt eben hierin das Geheimnis ihrer Anziehungskraft. Dem Empfindungsvermögen des Zuschauers entsprechend läßt sie sich auf mannigfaltige Weise betrachten und interpretieren. In sensiblen, einfühlsamen Menschen erzeugt Tarkowskij Gefühle des Mit-Empfindens, der Mit-Spannung, des MitExistierens. ${ }^{15}$

Auch Dostojeswskijs Werk soll die Gesellschaft erregen und zu einem Ideal aufrufen, die Menschen sollen einer „stinkenden Grube“ entsteigen. Diese „stinkende Grube" ist nach Tarkowskij die disharmonische Welt.

Die „stinkende Grube“ ist die disharmonische Welt, in der die moderne Massenkultur die Seele des Einzelnen verkrüppelt und damit dem Menschen immer häufiger

13 Andrej Tarkowskij: Film als Poesie - Poesie als Film. Hg. von Maja Josifowna Turowskaja u.a. Bonn 1981, S. 9.

14 Andrej Tarkowskij: Die versiegelte Zeit. Gedanken zur Kunst, zur Ästhetik und Poetik des Films. Berlin 1988, S. 198.

15 Andrej Tarkowskij: Film als Poesie - Poesie als Film. Hrsg. von Maja Josifowna Turowskaja u.a. Bonn 1981, S. 96. 
den Weg zu den Grundfragen seiner Existenz, zur Bewusstwerdung seiner selbst als eines geistigen Wesens verstellt. Tarkowskij-Filme sehen heißt dagegen, eine Vernunft kennenzulernen, die eine Alternative zu dieser „stinkenden Grube“ unserer Nachmoderne darstellt, weil sie für eine Vernunft plädieren, die Menschen wach und lebendig macht.

Mit seinem „Meister“ Dostojewskij verbindet Tarkowskij also etwas Wesentliches. Für beide hat Kunst die hohe Aufgabe, den Sinn menschlichen Daseins zu erklären oder zumindest die Frage danach zu provozieren.

In einem Interview mit dem italienischen Fernsehen bekräftigte Tarkowskij noch einmal seine These, die relativ einfach klingt: „Es ist ganz offensichtlich: Wäre die Welt in Ordnung und harmonisch, dann bräuchte es keine Kunst, dann würde der Mensch nicht in seinen nebensächlichen Beschäftigungen Harmonie suchen, sondern er würde ein harmonisch erfülltes Leben führen, was auch, wie ich meine, völlig ausreichen würde. Die Kunst gibt es nur deshalb, weil die Welt schlecht eingerichtet ist. "16

Diese Thematik konzentriert sich in Tarkowskijs zweitem Film „Andrej Rubljow“. Der Protagonist erscheint uns darin als Künstler und Philosoph in einer Person, also als ein Suchender, für den Schönheit und Wahrhaftigkeit nicht zu trennen sind.

Weil die Welt schlecht eingerichtet ist und darin Kinder zu Tode gequält werden, will Iwan Karamasow Gott seine Eintrittskarte ehrerbietig zurückgeben, Andrej Rubljow hingegen legt ein Gelübde ab, nie mehr zu malen und nie mehr zu sprechen.

Doch Verzweiflung am Menschen ist heilbar. Dem in seiner inneren Emigration elenden und stummen Rubljow erlöst ein junger Mensch, beinahe noch ein Kind: der junge Glockengießer Boris. Dieser schmächtige Junge, der in einer Art seherischer Begeisterung die große Glocke erschafft, „vermittelt Rubljow die Erkenntnis, dass die Kräfte des Geistes, dass Zielstrebigkeit und Opferbereitschaft über die rohe Materie und über die rohen Kräfte der Geschichte, immer wieder den Sieg davontragen werden. ${ }^{17}$ Unter dem Klang der Glocke erwacht Rubljow aus seiner schöpferischen Trance und bricht sein Schweigen, er will wieder Ikonen malen und mit den Menschen zusammen eine Glocke gießen.

Hier schließt sich der Kreis zu Dostojewskij und dessen Kinderliebe. Auch Fürst Myschkin und Aljoscha Karamasow lieben Kinder und beide haben die Idee, einen brüderlichen Bund der Kinder als Grundstein künftiger Harmonie zu stiften. In den „Brüdern Karamasow“ ist das gesamte zehnte Buch mit seinen sieben Kapiteln Kindern gewidmet und überhaupt sind Kinder ein konstantes Thema in Dostojewskijs Werk wie auch bei Tarkowskij.

16 Dokumentation des italienischen Fernsehens über Tarkowskijs Exilaufenthalt in Italien. Im Privatbesitz des Verfassers.

17 Klaus Kreimeier: Andrej Rubljow. In: Wolfgang Jacobsen (Hg.): Andrej Tarkowskij. München 1987, S. 107. 
Außer in „Solaris“ und „Nostalghia“ spielen Kinder eine große Rolle im Werk des Regisseurs. Kinder verkörpern für ihn das Prinzip des Guten sowie die Idee des „neuen Menschen“, der Erlösung und Errettung verspricht. Von Tarkowskijs erstem Film „Iwans Kindheit“ führt somit eine direkte Linie zu „Andrej Rubljow“, in dem der Darsteller des Iwan, Kolja Burljajew, den Boris verkörpert, zu den Spätwerken "Stalker" und „Opfer", in denen kranke und verkrüppelte Kinder erscheinen, die leiden, aber auch zugleich magische Kräfte besitzen. Klaus Kreimeier weist darauf hin, dass diese „stummen, kranken, behinderten oder ermordeten Kinder in Tarkowskijs Vorstellung auch Ebenbilder des Jesuskindes sind und auf dessen Mission deuten. ${ }^{\text {18 }}$

18 Ebd. 
Clemens Heithus

\section{Deutsche Dostojewskij-Bibliographie 2010}

(mit Nachträgen aus den Jahren 2007 - 2009)

\section{WERKE IN DEUTSCHEN ÜBERSETZUNGEN}

a) Einzelne Romane und Erzählungen

\section{BEDNYE LJUDI [ARME LEUTE]. 1846}

1 Arme Leute. Übersetzt von Christine Ganzer. Nachwort von Martin Schneider. [Nachdruck]. Stuttgart: Philipp Reclam jun., 2007. 181 S. (Universal-Bibliothek, 8047). ISBN 978-3-15-008047-4

\section{DVOJNIK [DER DOPPELGÄNGER]. 1846}

2 Der Doppelgänger. Ein Petersburger Poem. Aus dem Russischen von Hermann Röhl. 3. [Auflage]. Frankfurt am Main; Leipzig: Insel Verlag, 2010. 217 S. (Insel Taschenbuch, 2885). ISBN 978-3-458-34585-5

\section{BELYE NOČI [WEISSE NÄCHTE]. 1846}

3 Weiße Nächte. Ein empfindsamer Roman. Aus den Erinnerungen eines Träumers. Aus dem Russischen übertragen von Johannes von Guenther. Um Anmerkungen und ein Nachwort vermehrte Ausgabe 1999. Anmerkungen und Nachwort von Angela Martini. [Nachdruck]. Stuttgart: Philipp Reclam jun., 2010. 104 S. (Universal-Bibliothek, 2126). ISBN 978-3-15-002126-2

\section{ZAPISKI IZ MERTVOGO DOMA [AUFZEICHNUNGEN AUS EINEM TOTENHAUS]. 1861}

4 Aufzeichnungen aus einem Totenhause. Übersetzt von Hermann Röhl. Nachwort von Birgit Harreß. [Nachdruck]. Stuttgart: Philipp Reclam jun., 2010. 511 S. (Universal-Bibliothek, 2647). ISBN 978-3-15-002647-2 


\section{ZAPISKI IZ PODPOL'JA [AUFZEICHNUNGEN AUS DEM KELLERLOCH]. 1864}

5 Aufzeichnungen aus dem Kellerloch. Übersetzung von Swetlana Geier. Nachwort von Hans Walter Poll. [Nachdruck]. Stuttgart: Philipp Reclam jun., 2010. 163 S. (Universal-Bibliothek, 8021). ISBN 978-3-15-008021-4

\section{PRESTUPLENIE I NAKAZANIE [SCHULD UND SÜHNE]. 1866}

6 Schuld und Sühne. Roman. Aus dem Russischen von Hermann Röhl. 2. [Auflage]. Frankfurt am Main; Leipzig: Insel Verlag, 2010. 801 S. (Insel Taschenbuch, 3513). ISBN 978-3-458-35213-6

7 Verbrechen und Strafe. Roman. Aus dem Russischen neu übersetzt von Swetlana Geier. 3. Auflage. Frankfurt am Main: Fischer Taschenbuch Verlag, 2010. 746 S. (Fischer, 90010). ISBN 978-3-596-90010-7

Mit dem Werkbeitrag aus dem Neuen Kindlers Literatur-Lexikon.

8 Verbrechen und Strafe. Roman. Aus dem Russischen von Swetlana Geier. 7. Auflage. Frankfurt am Main: S. Fischer Verlag, 2010. 766 S. ISBN 978-3-10015403-3

\section{IGROK [DER SPIELER]. 1867}

9 Der Spieler. Roman. Aus dem Russischen übersetzt von Swetlana Geier. Frankfurt am Main: S. Fischer Verlag, 2009. 240 S. ISBN 978-3-10-015410-1

\section{IDIOT [DER IDIOT]. 1868}

10 Der Idiot. Roman. Aus dem Russischen neu übersetzt von Swetlana Geier. Ungekürzte Ausgabe, 2. Auflage. Frankfurt am Main: Fischer Taschenbuch Verlag, 2010. 879 S. (Fischer, 90186). ISBN 978-3-596-90186-9

11 Der Idiot. Roman. Aus dem Russischen von Swetlana Geier. 4. Auflage. Frankfurt am Main: S. Fischer Verlag, 909 S. : Ill. ISBN 978-3-10-015402-6

12 Der Idiot. Roman. Aus dem Russischen übertragen von Artur Luther. Mit einem Nachwort von Ludolf Müller und einer Zeittafel von Barbara Conrad. Vollständige Ausgabe, 21. Auflage. München: Deutscher Taschenbuch Verlag, 2010. 842 S. (dtv, 12407). ISBN 978-3-423-12407-2

13 Der Idiot. Fjodor Dostojewskis Literaturklassiker auf 2 DVDs. Regie : Rolf von Sydow. Drehbuch: Leo Lehmann. Mit Gerd Baltus, Karin Hübner, Anne Stegmann ...o.O.: More Brands and Products, 2010. 2 DVD Videos : farbig Fernsehserie. Entstanden 1968. 


\section{BESY [DIE DÄMONEN]. 1872}

14 Böse Geister. Roman. Aus dem Russischen neu übersetzt von Swetlana Geier. Frankfurt am Main: Fischer Taschenbuch Verlag, 2010. 954 S. (Fischer, 90245). ISBN 978-3-596-90245-3

Mit dem Werkbeitrag aus dem Neuen Kindlers Literatur-Lexikon.

15 Böse Geister. Roman. Aus dem Russischen von Swetlana Geier. 3. Auflage. Frankfurt am Main: S. Fischer Verlag, 2010. 962 S. ISBN 978-3-10-015401-9

\section{PODROSTOK [DER JÜNGLING]. 1875}

16 Der Jüngling. Roman. Aus dem Russischen von Marion Gras-Racić. Mit einem Nachwort von Rudolf Neuhäuser. Neuausgabe. München: Deutscher Taschenbuch-Verlag, 2010. 777 S. (dtv, 12409). ISBN 978-3-423-12409-6

\section{KROTKAJA [DIE SANFTE]. 1876}

17 Die Sanfte. Eine fantastische Erzählung. Aus dem Russischen von Alexander Eliasberg. Köln: Anaconda, 2010. 78 S. ISBN 978-3-86647-501-4

\section{MAL'ČIK U CHRISTA NA ËLKE}

[DER KNABE AM WEIHNACHTSABEND BEIM HERRN JESU]. 1876

18 Der Junge beim Herrn Jesus zur Weihnacht. In: Weihnachtsgeschichten aus dem alten Russland. Erzählungen für nachdenkliche Stunden. Gelesen von Helbert Häberlin. Landsberg am Lech: Literarisches Kabinett, 2010. 1 CD. ISBN 978-39812664-0-5

\section{BRAT'JA KARAMAZOVY [DIE BRÜDER KARAMASOW]. 1880}

19 Die Brüder Karamasow. Roman. Aus dem Russischen von Hans Ruoff. Mit einem Nachwort von Horst-Jürgen Gerigk und einer Zeittafel. Düsseldorf; Mannheim: Albatros, 2010. 1212 S. ISBN 978-3-491-96251-4

20 Die Brüder Karamasow. Roman in vier Teilen und einem Epilog. Aus dem Russischen übersetzt von Hermann Röhl. Köln: Anaconda, 2010. 1148 S. ISBN 978-3-86647-477-2

21 Die Brüder Karamasow. Roman. Aus dem Russischen neu übersetzt von Swetlana Geier. 2. Auflage. Frankfurt am Main: Fischer Taschenbuch Verlag, 2010. 1255 S. (Fischer, 90114). ISBN 978-3-596-90114-2

22 Die Brüder Karamasow. Roman. Aus dem Russischen übersetzt von Swetlana Geier. 2. Auflage. Frankfurt am Main: S. Fischer Verlag, 2010. 1271 S. ISBN 978-3-10-015405-7 
b) Sammlungen und Auszüge

23 Der Grossinquisitor. Peter Matić liest. Kilchberg: Sinus Verlag, 2010. 1 CD + Textbuch (80 S. : Ill.). (Sinus Literatur). ISBN 978-3-905721-94-2 Übersetzer: Albert Bolliger.

24 Kennst du Fjodor Dostojewski? Texte von Fjodor Dostojewski für junge Leser. Ausgewählt und vorgestellt von Roland Opitz. Weimar: Bertuch, 2010. 137 S. : Ill. (Bertuchs Weltliteratur für junge Leser, 9). ISBN 978-3-937601-75-5

\section{DOSTOJEWSKIJ IN WERKEN DER SCHÖNEN LITERATUR. VARIA}

25 ZWEIG, STEFAN: Balzac, Dickens, Dostoevsky. Three masters. Vol. 1 of Master builders of the spirit. With a new introduction by Laurence Mintz. New Brunswick, NJ: Transaction Publishers, 2010. LIII, 238 S. ISBN 1-412-81047-7. - 978-1-412-81047-0

Zuerst: New York: Viking Press, 1930.

26 ZWEIG, STEFAN: Grandes momentos da história da humanidade. Catorze miniaturas. 1. ed. Lisboa: Esfera dos Livros, 2009. 294 S. ISBN 978-989-626175-7 Darin: „Heroischer Augenblick“ (Schilderung der Scheinhinrichtung Dostojewskijs in Gedichtform).

\section{SEKUNDÄRLITERATUR}

27 ALEKSEEVA, M. L.: Vvedenie priema opisanija v nemeckich perevodach proizvedenij F. M. Dostoevskogo. In: Aktual'nye voprosy lingvistiki i lingvodidaktiki. Vyp. 1. Nazran', 2009, S. 26-36

28 ALEKSEEVA, M. L.: Vvedenie priema opisanija v nemeckich perevodach proizvedenij F. M. Dostoevskogo. In: Jazykovaja ličnost' $v$ sovremennom mire. Nazran', 2009, S. 12-14

29 BAHR, HERMANN: Dostojewski und Marsyas. Ein Dialog über die Kunst und ein Essay über die Literatur. 1. Auflage. Bremen: Europäischer Hochschulverlag, 2010. $80 \mathrm{~S}$. (classic pages). ISBN 978-3-86741-566-8

30 BANGERT, NATALIA: Selbstentfremdung als Folge von Wahn im russischen Realismus. Am Beispiel von Dostoevskijs „Netočka Nezvanova“. Salzburg, 2010. $2,98 \mathrm{Bl}$.

Salzburg, Univ., Diplomarbeit.

31 BARTSCHERER, CHRISTOPH: Dostojewskijs Erben. [Rezension von] HorstJürgen Gerigk, Rudolf Neuhäuser: Dostojewskij im Kreuzverhör. Zwei Abhandlungen. Mattes Verlag, Heidelberg 2008. In: Deutsche Dostojewskij-Gesellschaft. Jahrbuch 16. 2009 (2010) [vgl. Nr. 36], S. 146-150

Zuerst veröffentlicht in: Landshuter Zeitung, Magazin zum Wochenende, Feuilleton, Samstag, 28. Februar 2009. 
32 BRIDGE, HELEN: [Rezension von] Hanna Klessinger: Krisis der Moderne. Georg Trakl im intertextuellen Dialog mit Nietzsche, Dostojewskij, Hölderlin und Novalis. Würzburg: Ergon-Verlag, 2007. 174 S. (Klassische Moderne, 8). Zugl.: Freiburg im Br., Univ., Diss., 2006. In: The modern language review 105 (2010), 1, S. 282-283

33 BRÖTZ, DUNJA: Dostojewskij in Brasilien: Raskolnikows Wiederkehr in Heitor Dhalias Film „Nina“ (2004). In: Dostoevsky studies. The journal of the International Dostoevsky Society 14 (2010), S. 43-88

34 CICOVACKI, PREDRAG: The role of Goethe's „Faust“ in Dostoevsky's opus. In: Dostoevsky studies. The journal of the International Dostoevsky Society 14 (2010), S. 153-163

35 CLINGER, CATHERINE: Theory of the ridiculous. Jean Paul, Max Beckmann, and Dostoevsky's donkey. In: Art history. Journal of the Association of Art Historians 33 (2010), 3, S. 512-533

Deutsche Dostojewskij-Gesellschaft. Jahrbuch. Herausgegeben von Gudrun Goes. München; Berlin: Verlag Otto Sagner. Bd. 16. 2009 (2010). 157 S. : Ill. ISBN 386688-093-6=978-3-86688-093-1

Thema des Jahrbuches: Die Geschichte eines Verbrechens. Über den Mord in der Romanwelt Dostojewskijs. Erschienen 2010. Die F. M. Dostojewskij betreffenden Beiträge des Jahrbuchs sind in der vorliegenden Bibliographie einzeln verzeichnet. Außerdem enthalten: „Vorwort“ von Gudrun Goes, S. 7-8; „Laudatio für Swetlana Geier" von Rudolf Neuhäuser, S. 9-15; „Nachruf auf Ludolf Müller“ von Rolf-Dieter Kluge, S. 129-133, „Autorenverzeichnis“, S. 156.

37 Deutsche Dostojewskij-Gesellschaft. Jahrbuch. Herausgegeben von Gudrun Goes. München; Berlin: Verlag Otto Sagner. Bd. 17. 2010. 189 S. : Ill. ISBN 3-86688$128-2=978-3-86688-128-0$

Thema des Jahrbuches: Dostojewskij und Europa. Die F. M. Dostojewskij betreffenden Beiträge des Jahrbuchs sind in der vorliegenden Bibliographie einzeln verzeichnet. Außerdem enthalten: „Vorwort" von Gudrun Goes, S. 7-9; „Nachruf auf Swetlana Geier“ von Maike Schult, S. 185-187; „Autorenverzeichnis“, S. 188.

38 DUDKIN, V. V.: Dostoevskij v poètologičeskoj optike Nicše. In: Poètika Nič̌e. SPb., 2010, S. 99-113

39 EFIMOVA, S. N.: L. N. Tolstoj i F. M. Dostoevskij v publicistike Genricha i Tomasa Mannov. In: Sravnitel'noe i obščee literaturovedenie 3 (2010), S. 52-61

40 EGOROVA, E. V.: Šillerovskie motivy v romane F. M. Dostoevskogo „Brat'ja Karamasovy“. In: Sravnitel'noe i obščee literaturovedenie 3 (2010), S. 46-51

41 ELENDT, DIETER: Die Seelenerrater. Dostojewski - Nietzsche - Freud. Drei Betrachtungen vom Blickwinkel der psychodynamischen Homöopathie. 1. Auflage. Norderstedt: Books on Demand, 2010. 376 S. : Ill. ISBN 978-3-8391-3108-4

42 ENGEL-BRAUNSCHMIDT, ANNELORE: Methoden der Umgehung des Fünften Gebots: F. M. Dostojewskij, Vladimir Makanin, Woody Allen. In: Deutsche Dostojewskij-Gesellschaft. Jahrbuch 16. 2009 (2010) [vgl. Nr. 36], S. 50-70 
43 ENGELHARDT, DIETRICH v.: F. M. Dostojewskij: „Der Spieler“. Phänomene, Ursachen, Ziele und Symbolik einer Sucht. In: Dostoevsky studies. The journal of the International Dostoevsky Society 14 (2010), S. 89-114

44 Feodor M. Dostojewski. Von und mit Tilman Spengler. München: BR, 2010. 1 DVD-Video : farbig. (Klassiker der Weltliteratur)

45 Die Frau mit den 5 Elefanten. Swetlana Geier - Dostojewskijs Stimme = Odna ženščina i 5 slonov. Ein Film von Vadim Jendreyko. Mit Swetlana Geier, Anna Götte, Hanna Hagen ... Zürich: Mira Film; Berlin: Good!Movies, 2010. 1 DVDVideo (PAL, 93 Min.) + Beiheft (19 S. : Ill.)

46 GARSTKA, K.: „Ponjat' glubiny Vostoka“. „Nemeckij Dostoevskij“ v izdatel'stve „Piper“. In: Rossija i Germanija v XX veke. Pod red. Karla Ajmermachera. T. 2. Moskva: AIRO-XXI u.a., 2010. ISBN 978-5-910221-16-5, S. 596-624

47 GERIGK, HORST-JÜRGEN [Chorst-Jurgen Gerigk]: Čto takoe klassik? (Meždunarodnoe prisutstvie Dostoevskogo v taksonomičeskoj perspektive). Avtorizovannyj perevod s anglijskogo Aleksandry Toičkinoj. In: Dostoevskij i mirovaja kul'tura 25 (2009), S. 68-78

48 GERIGK, HORST-JÜRGEN: Dostojewskijs Tatorte. In: Deutsche DostojewskijGesellschaft. Jahrbuch 16. 2009 (2010) [vgl. Nr. 36], S. 16-31

49 GERIGK, HORST-JÜRGEN: [Rezension von] Verbrechen und Strafe. Fassung von Andrea Breth nach der Übersetzung von Swetlana Geier. Zürich: Ammann Verlag 2009. In: Dostoevsky studies. The journal of the International Dostoevsky Society 14 (2010), S. 232-237

50 GERIGK, HORST-JÜRGEN: Ein Meister aus Russland. Beziehungsfelder der Wirkung Dostojewskijs. Vierzehn Essays. Heidelberg: Winter, 2010. 215 S. (Beiträge zur neueren Literaturgeschichte, 275). ISBN 978-3-8253-5782-5

51 GOES, GUDRUN: [Rezension von] Eberhard Th. Haas: Transzendenz Verlust und Melancholie. Depression und Sucht im Schatten der Aufklärung. Gießen 2006. In: Deutsche Dostojewskij-Gesellschaft. Jahrbuch 16. 2009 (2010) [vgl. Nr. 36], S. 151-155

52 GRÜBEL, RAINER: Dostojewskijs "Großinquisitor" in literaturwissenschaftlicher Sicht - Legende oder Parabel? In: Deutsche Dostojewskij-Gesellschaft. Jahrbuch 16. 2009 (2010) [vgl. Nr. 36], S. 92-117

53 GRÜBEL, RAINER: V kotlovane prozy. Platonov, Rozanov i Dostoevskij na fone religii i iskusstva. In: Wiener slawistischer Almanach 61 (2008), S. 39-69

54 GÜNTHER, HANS: Der Kristallpalast der modernen Zivilisation - Utopiekritik nach Dostoevskij. In: Deutsche Dostojewskij-Gesellschaft. Jahrbuch 17. 2010 [vgl. Nr. 37], S. 151-169

55 GUSEV, JU.: Dostoevskij glazami D. Lukača. In: Voprosy literatury 2009, 1, S. $34-54$

56 GUSKI, ANDREAS: Die Konstruktion Westeuropas in Dostoevskijs „Winteraufzeichnungen über Sommereindrücke“. In: Deutsche Dostojewskij-Gesellschaft. Jahrbuch 17. 2010 [vgl. Nr. 37], S. 123-139 
57 HEITHUS, CLEMENS: Deutsche Dostojewskij-Bibliographie 2008 (mit Nachträgen aus den Jahren 2002-2007). In: Deutsche Dostojewskij-Gesellschaft. Jahrbuch 16. 2009 (2010) [vgl. Nr. 36], S. 134-145

58 HEITHUS, CLEMENS: Deutsche Dostojewskij-Bibliographie 2009 (mit Nachträgen aus den Jahren 2003-2008). In: Deutsche Dostojewskij-Gesellschaft. Jahrbuch 17. 2010 [vgl. Nr. 37], S. 170-181

59 HERRMANN, DAGMAR: Die neue europäische Ordnung - eine Vision Dostoevskijs. In: Deutsche Dostojewskij-Gesellschaft. Jahrbuch 17. 2010 [vgl. Nr. 37], S. 61-122

Zuerst erschienen in: Dagmar Herrmann, Mechthild Keller (Hg.): Zauber und Abwehr. Zur Kulturgeschichte der deutsch-russischen Beziehungen. München 2003, S. 202-263.

60 HIELSCHER, KARLA: Die „russische Idee“ - made in Florenz. Dostoevskijs antiwestlich-russophile Ideologie in seinen Briefen aus Italien. In: Deutsche Dostojewskij-Gesellschaft. Jahrbuch 17. 2010 [vgl. Nr. 37], S. 140-150

61 HOLZWARTH, SEBASTIAN: Schuld. Die Bedeutung der literarischen Auseinandersetzung mit dem Thema Schuld von F. M. Dostojewskij für die Soziale Arbeit. Berlin, 2010. Online-Ressource, 44 S.

Berlin, KHSB, Bachelor-Thesis.

62 IL’ČENKO, N. M.: „Sikstinskaja madonna“ Rafaèlja v romane F. M. Dostoevskogo „Besy“. In: Sintez kul'turnych tradicij v chudožestvennom proizvedenii. Nižnij Novgorod, 2009, S. 24-30

63 KOGUT, MARINA: Dostoevskij auf Deutsch. Vergleichende Analyse fünf deutscher Übersetzungen des Romans „Besy“. Frankfurt a.M. u.a.: Lang, 2009. 300 S. (Heidelberger Publikationen zur Slavistik. B, Literaturwissenschaftliche Reihe, 35). ISBN 978-3-63156660-2

Im Anhang Interviews der Autorin mit Swetlana Geier und Egon Ammann.

64 KOSCHMAL, WALTER [Val'ter Košmal']: Ėksentričnyj roman Dostoevskogo „Idiot“. In: Wiener slawistischer Almanach 61 (2008), S. 109-139

65 KRAFT, TOM: Raskol'nikovs Beil - Opfermesser, Schwert der Gerechtigkeit oder Messer für den Kaiserschnitt? In: Deutsche Dostojewskij-Gesellschaft. Jahrbuch 16. 2009 (2010) [vgl. Nr. 36], S. 32-49

66 LACHMANN, RENATE: Die Lehre der Affekte und ihre Rolle im Werk Dostoevskijs. In: Arcadia. Internationale Zeitschrift für Literaturwissenschaft 44 (2009), 1, S. 121-136

67 MEYER, HOLT: Was „Schillers“ sind und was „ein Schiller“ (wert) ist. Einund Wiederkehr als Nicht-Wiederholung in Dostoevskijs russischer Philologie als monumentale Intertextualität. In: Schiller. Gedenken - Vergessen - Lesen. Rudolf Hermstetter ... (Hrsg.). München u.a.: Fink, 2010. ISBN 978-3-77054720-3, S. 175-197

68 NEUFELD, JOLAN: Dostojewski. Skizze zu seiner Psychoanalyse. 1. Auflage. Bremen: Europäischer Hochschulverlag, 2010. 92 S. ISBN 978-3-86741-578-1 
69 NEUHÄUSER, RUDOLF: [Rezension von] Joseph Frank. Dostoevsky: A writer in his time. Princeton and Oxford. Princeton University Press 2010 (edited by Mary Petrusewicz). In: Dostoevsky studies. The journal of the International Dostoevsky Society 14 (2010), S. 224-232

70 NEUHÄUSER, RUDOLF: Der Lohn des Glaubens und der Bürger des Kantons Uri. Dostojewskijs „Böse Geister“ (Kurzfassung). In: Deutsche DostojewskijGesellschaft. Jahrbuch 16. 2009 (2010) [vgl. Nr. 36], S. 83-91

71 NEUHÄUSER, RUDOLF: Der Lohn des Glaubens und der Bürger des Kantons Uri: F. M. Dostojewskij und seine „Bösen Geister“. In: Dostoevsky studies. The journal of the International Dostoevsky Society 14 (2010), S. 115-144

72 NEUHÄUSER, RUDOLF: [Rezension von] Marina Kogut: Dostoevskij auf Deutsch. Vergleichende Analyse fünf deutscher Übersetzungen des Romans „Besy“. Im Anhang Interviews der Autorin mit Swetlana Geier und Egon Ammann. Frankfurt am Main: Peter Lang 2009. In: Dostoevsky studies. The journal of the International Dostoevsky Society 14 (2010), S. 221-224

73 OLIVIER, SOPHIE [Sofi Oliv'e]: Kniga Iova v tvorčestve Dostoevskogo i u Fomy Akvinskogo, Kanta, K’erkegora. In: Dostoevskij i mirovaja kul'tura 25 (2009), S. 395-411

74 ORLOVA, TATIANA: Das nichtstattgefundene Duell und seine Folgen in der Erzählung von F. M. Dostoevskij „Die Sanfte“. München: GRIN Verlag, 2009. ISBN 978-3-640-25176-6

Online-Ressource. Vom Verlag auch als Druckwerk on demand angeboten.

75 POPOVA-BONDARENKO, I.: Gesse i Dostoevskij. Kommunikacija „zerkal'nosti“. In: Studia Rossica Posnaniensia 34 (2008), S. 34-44

76 PICKUS, DAVID: Paperback authenticity. Walter Kaufmann and existentialism. In: Philosophy and literature 34 (2010), 1, S. 17-31

Betr. u.a. Dostojewski, Nietzsche und Rilke.

77 REDEPENNING, DOROTHEA: Dostojewskij auf der Opernbühne. In: Dostoevsky studies. The journal of the International Dostoevsky Society 14 (2010), S. 13-42 : Notenbeispiele

78 ROTHE, HANS: Ivan Karamazovs Gespräch mit dem Teufel (Buch XI cap. 9) im Zusammenhang mit Dostoevskijs Gesamtwerk. In: Deutsche DostojewskijGesellschaft. Jahrbuch 17. 2010 [vgl. Nr. 37], S. 43-60

79 RUDEK, CHRISTOF: Die Gleichgültigen. Analysen zur Figurenkonzeption in Texten von Dostojewskij, Moravia, Camus und Queneau. Berlin: Schmidt, 2010. 164 S. (Allgemeine Literaturwissenschaft - Wuppertaler Schriften, 14). ISBN 978-3-503-09896-5

Mainz, Univ., Diss., 2008.

80 SAZEEVA, I. B.: Problema vychoda za granicy čelovečeskogo v tvorčestve F. M. Dostoevskogo i F. Nicše. In: O dostoinstve, svobode i pravach čeloveka. Nižnij Novgorod, 2009, S. 213-222 
81 SCHMID, ULRICH: Das religiöse Amt des Schriftstellers. Häresien bei Gogol', Dostoevskij und Tolstoj. In: Osteuropa. Zeitschrift für Gegenwartsfragen des Ostens 59 (2009), 6, S. 261-275

82 SCHMID, WOLF: Die Schönheit der Welt in Dostoevskijs ästhetischem Gottesbeweis. In: Wiener slawistischer Almanach 66 (2010), S. 59-72

83 SCHULT, MAIKE: Im Banne des Poeten. Die theologische Dostoevskij-Rezeption und ihr Literaturverständnis. Göttingen: Vandenhoeck \& Ruprecht, 2010. 430 S. (Forschungen zur systematischen und ökumenischen Theologie, 126). ISBN 978-3-525-56349-6

84 SCHULT, MAIKE: Tod und Leben mit Dostoevskij: Der Fall Schümer. Ein Beitrag zur theologischen Dostoevskij-Rezeption während des Nationalsozialismus. In: Deutsche Dostojewskij-Gesellschaft. Jahrbuch 16. 2009 (2010) [vgl. Nr. 36], S. 118-128

85 SCHULZ, CHRISTIANE: „Ich habe Schiller auswendig gelernt“. Das geistige Ferment Schiller im Erzählwerk Dostoevskijs. In: Deutsche Dostojewskij-Gesellschaft. Jahrbuch 17. 2010 [vgl. Nr. 37], S. 10-41

86 SPENGLER, MARIE: Wahnsinnsdarstellungen im frühen Petersburger Text. Puškin, Gogol', Lermontov und Dostoevskij. Hamburg, 2008. 101 S. Hamburg, Univ., Magisterarbeit.

87 STONE, JONATHAN: Polyphony and the atomic age. Bakhtin's assimilation of an Einsteinian universe. In: Publications of the Modern Language Association of America 123 (2008), 2, S. 405-421, 535

88 ŠUMKO, V. V.: K voprosu o fantastičeskom realizme v russkoj literature. Pozdnie romantiki i rannee tvorčestvo F. Dostoevskogo. In: Kul'tura i pis'mennost' slavjanskogo mira 10 (2008), S. 102-109

Betr. u.a. E. T. A. Hoffmann.

89 TARASOVA, N. A.: Faustovskaja scena v romane Dostoevskogo „Podrostok“. In: Russkaja literatura 2010, 1, S. 171-187

90 TOIČKINA, A. V.: Tragedija Šillera „Marija Stjuart“v tvorčestve Dostoevskogo. (Roman „Idiot“). In: Dostoevskij i mirovaja kul'tura. Al'manach 26 (2008), S. 101-107

91 UFFELMANN, DIRK: [Rezension von] Raimund Johann Weinczyk: Myškin und Christus. Ein fiktives Gespräch mit J. Ratzinger auf der Basis von F. M. Dostoevskijs Roman Idiot. Heidelberg: Winter 2006 (Beiträge zur slavistischen Philologie 13). 870 S. In: Deutsche Dostojewskij-Gesellschaft. Jahrbuch 17. 2010 [vgl. Nr. 37], S. 182-184

Zuerst erschienen in: Osteuropa 3/2008, S. 171-173.

92 ZEMLJANOJ, SERGEJ: Pobedonosnoe poraženie. Nenapisannaja kniga Georga Lukača o Dostoevskom. In: Voprosy literatury 2009, 1, S. 9-33

93 ŽEREBIN, A. I.: Markiz Poza i „russkie mal’čiki“. (K 750-letiju so dnja roždenija Fridricha Šillera). In: Izvestija Akademii Nauk. Serija literatury i jazyka 68 (2009), 6, S. 3-7 
94 ZINK, ANDREA: Der Diskurs über Todesstrafe und Haft. Zum europäischen Geist in Dostoevskijs „Der Idiot“. In: Deutsche Dostojewskij-Gesellschaft. Jahrbuch 16. 2009 (2010) [vgl. Nr. 36], S. 71-82 : Ill.

95 ŽIVOTJAGINA, S. A.: Švejcarija i Peterburg- Dinamika pejzaža i portreta v romane F. M. Dostoevskogo „Idiot“. In: Peterburgskie čtenija 2008, č. 2. SPb., 2009, S. 69-73

96 ZVEREVA, T. V.: „Gol'bejnov sjužet“ v romane F. M. Dostoevskogo „Idiot“. In: Aktual'nye problemy filologii i metodiki ee propodavanija $v$ vuzach $i v$ škole. Materialy Vserossijskoj Naučno-praktičeskoj Konferencii s Meždunarodnym Učastiem, Posvjaščennoj55-letiju Filologičeskogo Fakul'teta, Elabuga, 20-21 Nojabrja 2008 goda. Redkoll.: A. M. Kalimullin ... Elabuga, 2008, S. 169-174 


\title{
Rezensionen
}

\author{
Lizenz zum Mord für den Fortschritt. Thomas Bischoff inszeniert Dostojewskijs \\ "Verbrechen und Strafe" im Deutschen Theater
}

„Ein Tod gegen 100 Leben - das ist doch Arithmetik." Oft spricht Raskolnikow diesen Satz. Er soll den Mord rechtfertigen, den der junge Mann begeht. Schon fast gebetsmühlenartig sagt er die Worte auf. Also sind Zweifel angebracht. Es geht nicht nur um diesen einen Mord in dem Roman „Verbrechen und Strafe" von Fjodor Dostojewskij, ein Titel, den er erst seit der Neuübersetzung von Swetlana Geier aus dem Jahr 1994 trägt. Bekannter ist das 1866 veröffentlichte Werk unter dem Titel "Schuld und Sühne“. Für das Deutsche Theater (DT) Göttingen hat Thomas Bischoff eine Bühnenfassung geschrieben, die er auch selbst inszenierte. Premiere war am Sonnabend: 225 Minuten kompaktes und atmosphärisch enorm dichtes Theater in einem beeindruckenden Bühnenraum.

Raskolnikow steht im Zentrum der Geschichte. Er musste sein Jurastudium aufgeben, weil ihm das Geld zum Leben fehlte. Jetzt verfügt er über noch weniger Bares, weil er ohne Studium auch keine Nachhilfeschüler mehr hat. Der Mord an der wucherischen Pfandleiherin Iwanowna soll den Befreiungsschlag bringen, nicht nur finanziell, sondern auch intellektuell. Denn schon länger treibt ihn der Gedanke um, dass genialische Menschen für den Fortschritt morden dürfen. Die Tat soll zeigen, ob auch er zu einer solchen Elite zählt. „Ein Tod gegen 100 Leben - das ist doch Arithmetik."

Mit großem Ensemble hat Bischoff den Roman auf die Bühne gebracht. Das ist auch notwendig, denn Nebenrollen oder Füllfiguren hat der Regisseur nicht vorgesehen. Selbst kleinere Rollen sind unersetzlich und auch in ihrer Kürze eher wie Hauptrollen angelegt. Um Alois Reinhardt, der den Raskolnikow sehr leidensstark spielt, hat er ein Personal versammelt, das Großes leistet. Paul Wenning ist mit bemerkenswerter Selbstverständlichkeit Staatsanwalt Petrowitsch, der mit an Überheblichkeit grenzender Lässigkeit die Schlinge um den Täter enger und enger zieht. Philip Hagmann steht leidenschaftlich und bis zur Selbstaufgabe an der Seite seines Freundes Raskolnikow. Marie-Isabel Walke zeigt große Kraft als Raskolnikows Schwester, die so unentrinnbar verstrickt ist im fatalen Gespinst zwischen Familie und eigenem Leben. Ihren ersten Auftritt am DT hat Paula Hans als „Die Fremde“. Die junge Schauspielerin gehört ab der kommenden Spielzeit fest zum DT-Ensemble.

Mit großer Intensität hat Regisseur Bischoff ganz im Sinne Dostojewskijs diese Geschichte voller psychologischer, philosophischer, soziologischer und kriminalistischer Motive entwickelt und dabei auf verlässliche Partner vertrauen können. Aus- 
statterin Isabelle Krötsch hat ein Bühnenbild erdacht, das mit minimaler Requisite maximale Räume schafft. Mit Projektionen von Fotografien, überwiegend von ihr selbst an Orten wie St. Petersburg oder Paris aufgenommen, suggeriert sie Stadtraum, federleichte textile Wände schaffen Wohnraum. Viel Welt auf einer Bühne. Mit ihr hat Bischoff schon mehrfach zusammengearbeitet, mit dem Musiker FM Einheit auch. Der Ex-Schlagwerker der Band „Einstürzende Neubauten“, mit der er in den 1980er Jahren Lärm zu Musik organisierte, hat zu der Inszenierung Musik komponiert, die wie ein Puls den Lauf der Geschichte meist begleitet, manchmal forciert. Bässe dröhnen wie der Schmerz in Raskolnikows Schädel, schrill kreischen Übersteuerungen, wie sie Gitarren auslösen, die zu dicht an Lautsprecher gehalten werden. Grenzen der Akustik, Grenzen der Erträglichkeit für Dostojewskijs Figuren.

Leichte konsumierbare Kost ist es gewiss nicht, die Bischoff mit dem DT-Ensemble auf die Bühne gebracht hat. Das spürte auch das Premierenpublikum: Einige Stühle blieben nach der Pause unbesetzt. Doch wer sich dem intensiven Spiel des Ensembles bis zum Ende ausgesetzt hatte, hatte einen düster-berührenden, lange nachwirkenden Theaterabend erlebt.

Rezensiert von Peter Krüger-Lenz in: Göttinger Tageblatt vom 02.05.2010. 
Fjodor Dostojewskij: Verbrechen und Strafe. Fassung von Andrea Breth nach der Übersetzung von Swetlana Geier. Zürich: Ammann Verlag 2009, 173 Seiten.

Dostojewskijs Roman „Verbrechen und Strafe" hat (in der russischen AkademieAusgabe) 766 Seiten und besteht aus „sechs Teilen und einem Epilog.“ Andrea Breths Theaterfassung des Romans hat 173 Seiten und besteht aus 57 „Bildern.“ Sagen wir also: Andrea Breth hat dem Roman Dostojewskijs eine andere Form gegeben. Sie hat ihn umgegossen. Was wir im Roman „lesen“, hat sie auf die Bühne gebracht, so dass wir es nun "sehen“ sollen. Aufgeführt, erzwingt die Theaterfassung durch Regie, Schauspieler und Bühnenbild eine ganz bestimmte Visualisierung. Ihre festen Prämissen hat diese Visualisierung im nun gedruckt vorliegenden Text der Theaterfassung, die aus dem Sprechtext plus Nebentext besteht.

Fast jedes der Bilder endet mit der szenischen Anmerkung "Schnitt.“ Aber auch innerhalb eines einzigen Bildes kommen manchmal Schnitte vor. So finden sich im 11. Bild fünf Schnitte. Oft sind es weniger. - Das heißt: Andrea Breth denkt „filmisch." Sie will, dass wir als Zuschauer verschiedene Einheiten zusammensetzen, um das Ganze zu sehen. Wie im Film. Aus den separaten Einzelheiten ergibt sich das Ganze. Statt zusammenhängender großer Szenen, wie sie der Roman präsentiert, werden wir von Andrea Breth mit kurzen Wirklichkeitsausschnitten konfrontiert, die, realistisch aufgefasst, wie Fetzen von Erinnerungsbildern wirken. Oft entsteht der Eindruck, als befänden wir uns im Kopf Raskolnikows, wo Erinnerungsbilder einander ablösen, Erinnerungsbilder erlebter Wirklichkeit, die alptraumartig auftauchen: als Heimsuchung. Der Roman, den wir von unserer Lektüre her kennen, scheint hier als nacherlebtes Innenleben seiner Hauptgestalt wiederzukehren. Wir erleben den „größten Kriminal-Roman aller Zeiten“ (Thomas Mann) in seiner Hauptsache als Ereignis im Kopf der Hauptgestalt: als Ereignis im Kopf des Mörders Raskolnikow.

Liegt damit der Theaterfassung eine grundsätzlich andere Darstellungstechnik zugrunde als dem Roman? Dieser Eindruck ist tatsächlich auch unter Kritikern der Aufführung dieser Dramatisierung aufgekommen. In Wahrheit aber hat Andrea Breth nur etwas nach vorn gerückt, was im Roman nicht derart auffällig ist, dass es jeder Leser sofort bemerkt. Das Faktum nämlich, dass die Erlebnisse Raskolnikows, wie wir sie in den sechs Teilen des Romans präsentiert bekommen, als Erinnerungen Raskolnikows im Sibirischen Zuchthaus aufzufassen sind. Mehrfach begegnen uns Sätze der Art: „Wenn sich Raskolnikow später an diese Szene erinnerte, dann stellte sich ihm alles folgendermaßen dar." Das heißt: Raskolnikow lässt seine entscheidenden Erlebnisse in der Erinnerung Revue passieren: im Sibirischen Zuchthaus, anderthalb Jahre nach der Einlieferung. Solcher Hinweis im Text des Romans impliziert, dass sich Raskolnikow im Sibirischen Zuchthaus immer wieder in seine Situation vor anderthalb Jahren in Petersburg zurückversetzt, so dass uns der Roman nur eine Auswahl seiner Erinnerungsbilder vor Augen führt. 
Ihrer Aufgabe, Dostojewskijs Roman notgedrungen radikal auf das Wesentliche zu verkürzen, hat Andrea Breth mit solch gezielter Einrichtung des Ganzen als Serie von Erinnerungsbildern das einleuchtende und gleichzeitig effekvollste Fundament verschafft. Zwei „Pausen“ teilen die insgesamt 57 Bilder (d.h. Szenen) in drei „Akte“ (die aber nicht eigens so gekennzeichnet wurden). Erster Akt: Bild 1 bis 36 (Raskolnikow erhält eine Vorladung von der Polizei). Zweiter Akt: Bild 37 bis 46 (Raskolnikow kündigt Sonja sein Geständnis an). Dritter Akt: Bild 47 bis 57 (Raskolnikow bekennt, an die Auferweckung des Lazarus zu glauben). Die Frage ist: Bleibt durch die Reduktion des Romans auf das Wesentliche diese Theaterfassung auch für einen Zuschauer (oder einen Leser), der den Roman nicht kennt, verständlich? Da ich den Roman gut kenne, lese ich die Theaterfassung mit einem besonderen Vergnügen, weil ich die Geschicklichkeit und künstlerische Sensibilität bewundere, mit der Andrea Breth Dostojewskijs so umfangreichen und komplexen Text in 57 Bilder übersetzt, die durch "Schnitte“ untereinander und auch intern einen dezidiert „filmischen" Ausdruck bekommen. Eine Verfilmung dieser Theaterfassung mit Großaufnahmen der Sprechenden und Ausschnittvergrößerungen leitender Details bietet sich geradezu an.

Die Tat selber wird nicht komplett auf die Bühne gebracht. Sie findet im 11. Bild statt (S. 31-34). Das Bild hat fünf Schnitte, bevor es zu Ende ist. Zunächst erzählt Porfirij (sic!), wie Raskolnikow mit dem Beil die Treppe hinaufsteigt - in den vierten Stock zur Wohnung der „Alten“ (d. h. der Wucherin). Raskolnikow schildert „dann“ im inneren Monolog seinen (gleichzeitigen) Zustand während dieses Augenblicks. Darauf folgt der Dialog zwischen Raskolnikow und der „Pfandleiherin“, die sein vermeintliches Pfand aufschnüren will. Sofort danach sagt Raskolnikow: „Ich habe doch nur eine Laus umgebracht, eine unnütze, widerwärtige, bösartige Laus.“ Der Nebentext vermerkt: „Atmen, Lisaweta starrt auf die tote Schwester. Mord Lisaweta.“ Aus dem Roman wissen wir, dass Raskolnikow die Wucherin mit der stumpfen Seite seines Beils erschlägt (auf den Hinterkopf), Lisaweta aber mit der Schneide des Beils (direkt auf Stirn und Schläfe). Und Lisaweta hebt nicht einmal die Hand, um sich zu schützen - die linke Hand, denn mit der rechten hält sie ein Bündel Wäsche fest. Auf diese Details lässt sich die Theaterfassung nicht ein. Nach dem Schnitt lautet hier der Nebentext: „Raskolnikow wäscht das Beil und die Hände. Dialog im Off.“ Dieser „Dialog im Off“ (alles noch im 11. Bild) läuft ab zwischen Mann 1 und Mann 2, die zur Wucherin wollten, nachdem Raskolnikow gemordet hat und sich noch hinter der (erst nach dem ersten Mord von ihm verschlossenen) Wohnungstür aufhielt. Raskolnikow (vorne) sagt nur: „Wie laut sie alle sind.“ Dann „Schnitt“, und wir sehen Mikolka und Mitjka, von denen es im Nebentext heißt: „Einer malt dem anderen rote Farbe ins Gesicht.“ (Das wird im Roman erst sehr viel später referiert: Teil II, Kap. IV. Die Theaterfassung nimmt das Blut vorweg, das Raskolnikow später in der leeren Wohnung der Wucherin sucht.) Wie in einem Traum ist direkt anschließend der Ruf „Mitjka! Mitjka! Mitjka!“ zu hören. Der Nebentext schreibt vor: „im Black“ - das heißt: im Dunkel des Bühnenhintergrunds. Wiederum „Schnitt“, 
und „Raskolnikow tritt in einen Türausschnitt.“ Damit ist Bild 11 zu Ende. Der Ruf „Mitjka!“ ist, allerdings fünfmal hintereinander, genauso erratisch auch im Roman zu hören - aus der leeren Wohnung unterm Tatort, wo soeben Anstreicher tätig waren und sich lärmend entfernen.

Wir sehen: Raskolnikows Doppelmord als mehrfaches Zuschlagen mit dem Beil angesichts zweier wehrloser Frauen wird mit seinem unmittelbaren Vorher und Nachher als Erinnerungsbild im Bewusstsein des Mörders evoziert. An der Szene am Tatort während des Doppelmords (Bild 11) lässt sich das Vorgehen Andrea Breths exemplarisch ablesen. Sie nimmt das Angebot des Romans ernst, das Ganze als Welt im Kopf Raskolnikows aufzufassen, also als seine Erinnerung. Sie kann deshalb Porfirij, den Untersuchungsrichter, bereits als Erzähler ins Spiel bringen, als er (im Roman) noch gar nicht mit dabei ist. Und die rote Farbe der Anstreicher, die der eine dem anderen ins Gesicht malt, ist bereits das „Blut“, das nun als Leitmotiv Raskolnikow verfolgen wird. Das ist keine Willkür gegenüber der zu gestaltenden Sache, denn die Welt im Kopf des Raskolnikow hat ihre eigene Gleichzeitigkeit des Erlebten.

Bild 9 gibt die so wichtige, weil für das Geschehen programmatische Unterhaltung zwischen „zwei Offizieren“ wieder. Sie sprechen über die Wucherin, die reich sei „wie ein Jude“. Bei ihr bekomme man immer Geld. Und der Gesprächspartner sagt: „Bring sie um und nimm ihr Geld, um dich mit seiner Hilfe dem Dienst an der Menschheit zu widmen. (...) Ein Tod gegen hundert Leben." Im Roman (Teil I, Kap. 6) wird diese Szene kurz vor dem Mord eingeschoben. Sie passiert aber nicht zu diesem Zeitpunkt, sondern anderthalb Monate vor Einsetzen der Gegenwartshandlung. Raskolnikow war damals zum ersten Mal bei der Wucherin und machte danach in einem „ziemlich verkommenen“ Wirtshaus Halt, wo er dieses Gespräch zwischen einem Studenten und einem Offizier (nicht „2 Offizieren“ wie bei Andrea Breth) mithört. Bei oberflächlicher Lektüre des Romans wird der Eindruck entstehen, diese Szene geschehe kurz vor Raskolnikows Mord. In Wahrheit aber kommt sie Raskolnikow erst wieder in den Sinn, als er sich später (und das heißt, im Sibirischen Zuchthaus) seine Erlebnisse wieder vergegenwärtigt. Episoden assoziativ zu verbinden und nicht in chronologischer Reihenfolge zu bringen, findet sich also bereits im Roman. Dieses Prinzip wird von Andrea Breth in schöpferischer Einfühlung, wo nötig, weiter ausgedehnt.

Bild 54 zum Beispiel zeigt uns Swidrigajlow, wie er sich in Gegenwart Raskolnikows erschießt. Das entspricht nicht dem Text des Romans, denn dort erschießt sich Swidrigajlow in Gegenwart eines jüdischen Wachtpostens vor einem Feuerwehrhaus auf einem menschenleeren Platz. Der Wachtposten ruft Swidrgajlow zu, für solche Scherze sei hier nicht der Ort, und Dostojewskijs Beschreibung dieses zufälligen Augenzeugen ist explizit antisemitisch. Hat Andrea Breth die Szene verändert, indem bei ihr Raskolnikow der Zeuge dieses Selbstmords ist, um Dostojewskijs Antisemitismus nicht prominent werden zu lassen? Das mag mitgespielt haben, ist aber gewiss nicht der Hauptgrund. Im Roman erfährt Raskolnikow erst 
ganz zum Schluss, als er die Polizei aufsucht, um sein Geständnis abzulegen, dass sich Swidrigajlow soeben erschossen habe. Wenn Andrea Breth Raskolnikow zum Zeugen des Selbstmords Swidrigajlows macht, so wird damit besonders einsichtig, dass Raskolnikow sich nicht umgebracht hat, weil er, im Unterschied zu Swidrigajlow, der unter unbeweisbaren Umständen seine Frau getötet hat, fähig ist, sein Verbrechen zu gestehen und die gesetzlich vorgesehene Strafe dafür anzunehmen. (Swidrigajlow ist dazu nicht in der Lage.) Außerdem aber vereinheitlicht Andrea Breth durch Raskolnikows Zeugenschaft Dostojewskijs leitendes Verfahren. Denn jene Szenen des Romans, in denen Swidrigajlow ohne Raskolnikow auftritt, durchbrechen ja Dostojewskijs Schema, den gesamten Roman in der Hauptsache als Erinnerungsbilder Raskolnikows im Sibirischen Zuchthaus anzulegen. Die Veränderung der Zeugenschaft in Bild 54 lässt sich also sachlich rechtfertigen und ist zudem mit Rücksicht auf die vorzunehmende Verständnislenkung des Zuschauers ein glänzender Einfall.

Die allerletzte Szene der Theaterfassung schließlich (Bild 57) kommt so im Roman überhaupt nicht vor. Gedanklich aber haben wir hier die beste Zusammenfassung des Epilogs, die sich denken lässt: „(Raskolnikow, Sonja): Sonja: Glaubst du an das neue Jerusalem? Raskolnikow: Ich glaube. Sonja: Glaubst du auch an Gott? Raskolnikow: Ich glaube. Sonja: Glaubst du auch an die Auferweckung des Lazarus? Raskolnikow: Ich glaube. Sonja: Glaubst du buchstäblich daran? Raskolnikow: Buchstäblich. (Ende).“ Mit dem gleichen Fragespiel lässt Andrea Breth ihre Theaterfassung beginnen, nur dass im 1. Bild Sonjas Fragen von einer anonymen Männerstimme „im Off“ gesprochen werden, nachdem die gleiche Männerstimme zunächst Raskolnikow im Zuchthaus nach Namen, Vornamen, Vatersnamen und Haftdauer befragt hat. Raskolnikow antwortet: „Lebenslänglich.“ (Im Roman sind es acht Jahre.) Und Sonja singt dazu „Und selig ist, der weilt auf dieser Welt in ihren Schicksalsaugenblicken." Er und sie, der Mörder und die Prostituierte, eröffnen also das Stück vom Schluss her: eine lyrische Zusammenfassung vorweg all dessen, was folgt.

Und wenn ich sagte, Bild 57 sei die beste Zusammenfassung des Epilogs von „Verbrechen und Strafe“, die sich denken lässt, dann bedeutet das auch, dass wir hier, wie im Roman, in die für Dostojewskij typische humanitäre Langeweile entlassen werden: Endstation Sehnsucht im Stile seines russischen Christentums, das nicht nur den Spott Vladimir Nabokovs hervorgerufen hat. Welch ein Kontrast zu jener Szene der Theaterfassung (Bild 35), wo der Untersuchungsrichter Porfirij Petrowitsch mit Raskolnikow dessen Theorie des Übermenschen diskutiert: Raskolnikows Unterscheidung zwischen gewöhnlichen und außergewöhnlichen Menschen, aus der sein Entschluss erwachsen ist, einen Raubmord zu begehen. Diese Szene ist, wie ich sagen möchte, der gedankliche Höhepunkt der Theaterfassung und bleibt mit Wortlaut und Kohärenz der Argumentation ganz nahe am Text des Romans. (S. 81-88) Nicht eingebracht wird von Andrea Breth, dass Raskolnikow ein Jahr vor Einsetzen der Gegenwartshandlung des Romans sein Studium der Rechtswissenschaften ab- 
gebrochen hat und sich angesichts der ringsum anzutreffenden Ungerechtigkeiten seine Theorie des Übermenschen in einer Abhandlung „Über das Verbrechen“ zurechtgelegt hat, um sich für ein gesetzloses Handeln aus altruistischen Motiven eine abstrakte Rechtfertigung zu schaffen - eine aus der Not geborene Theorie also, an die er selber nicht so recht glauben kann. Unterschwellig ist solche Genese in Bild 35 allerdings spürbar.

Es fehlt auch nicht die (ausführlich inszenierte) Blamage Luschins (Bild 44 und 45), der Sonja einen 100-Rubel-Schein zusteckt, um sie dann als Diebin an den Pranger zu stellen. Die Infamie wird mit Lebesjatnikow als Zeugen und Raskolnikow als Anwalt aufgedeckt und Luschin damit aus der sittlichen Gemeinschaft ausgegliedert. Das ist in nuce Dostojewskijs Veranschaulichung einer wünschenswerten Gesellschaft der Zukunft.

Zusammenfassend bleibt festzustellen: Andrea Breths Theaterfassung beruht auf einer geradezu idealen Verständnisleistung gegenüber der Romanvorlage. Nichts Wesentliches wird ausgelassen. Die böse Wucherin und ihre fromme Stiefschwester; Swidrigajlow, der Gutsbesitzer mit liederlichem Lebenswandel auf seiner Reise in den Selbstmord; Dunja, die unbeirrt anständige Schwester Raskolnikows; seine Mutter, die über dem Schicksal ihres Sohnes die Welt nicht mehr versteht und ständig wiederholt, er werde ein „großer Staatsmann" werden (Bild 53); Rasumichin, der Freund und vernünftige Flachkopf; Luschin, der korrupte Rechtsanwalt; und, natürlich zentral, die zwei Motoren der äußeren und inneren Spannung: Porfirij Petrowitsch, das unbestechliche Auge des Gesetzes, und Sonja Marmeladowa, die blutjunge Prostituierte und ebenso unbestechliche Stimme des Gewissens; aber auch Randgestalten wie der Mann, der Raskolnikow „Mörder“ nennt, und jener andere, der sich zur Tat bekennt, ohne sie begangen zu haben - alle treten sie auf in Andrea Breths Theaterfassung: als Folie zur Profilierung der Hauptgestalt, des Mörders aus sittlicher Empörung.

Zweifellos ist der Autorin ein Meisterwerk der Dramatisierung eines Romans gelungen, deren Prinzipien die Aufmerksamkeit der Literaturtheorie verdienen. Die Verständnislenkung ist es, deren Forderungen hier in einem anderen Medium adäquat befolgt wurden. Mit sicherem Blick sind die nötigen Gewichtungen vollzogen worden.

Rezensiert von Horst-Jürgen Gerigk in: Dostoevsky Studies. The Journal of the International Dostoevsky Society. New Series. Managing Editor: Horst-Jürgen Gerigk. Vol. 14, 2010. S. 323-337. 
Premiere für „Schuld und Sühne“ im Schauspielhaus Magdeburg Ambitionierte Absicht zur zeitgenössischen Aussage

Die großen Romane des 19. und 20. Jahrhunderts im heimischen Sessel zu lesen, gehört eher der Vergangenheit an. In der Gegenwart bemächtigen sich landesweit Theater dieser Texte und setzen sie in Szene, so auch das Schauspielhaus Magdeburg mit „Schuld und Sühne" von Fjodor M. Dostojewskij in der Regie von Jan Jochymski.

Magdeburg. Die neue Crew folgt auch an diesem Abend, wie zum Exempel bei „Zusammen!“ oder bei „Michael Kohlhaas“, ihrem Programm, der Gegenwart mit existenziellen Fragen an die Gurgel zu greifen.

Jochymski und sein Team nutzen den Plot des Romans in totaler Freiheit als Material, um das Publikum mit provokanten Fragen zum heutigen Lebenssinn zu konfrontieren. Sie bieten eine sowohl interpretatorisch wie theatralisch heikle Inszenierung, die zugunsten eigener inhaltlicher Aussagen viel wagt.

Durchweg überzeugen die Darsteller. Jonas Hien als Raskolnikow eröffnet den Abend mit virtuoser Lockerheit. Im weiteren Verlauf gelingen ihm Verzweiflung und Höhenrausch, Aggressivität und Sentiment gleichermaßen.

Katharina Brankatschk zeichnet eine Sonja im Wechsel von behutsamen Emotionen sowie leidenschaftlichen Ausbrüchen. Axel Strothmann verkörpert überzeugend einen Staatsanwalt, den Schlitzohrigkeit und Erdverbundenheit charakterisieren. Silvio Hildebrandt beweist als Marmeladow wiederholt, wie sehr er seine sprachliche Ausdruckskraft mit einem körperbetonten Spiel zu einem Ereignis verweben kann. Michaela Winterstein meistert mehrere Rollen, besonders überzeugt sie als Marmeladowa. Bastian Reiber als Rasumichin erscheint nur als Stichwortgeber und erhält wenig Möglichkeiten der Profilierung.

Thilo Reuter (Bühne/Kostüme) baute eine Szenerie, die eine moderne Großstadttristesse zitiert, und das russische Milieu verfremdet, indem seitens rechts und links Holzwände aufragen, die die einstmaligen Birken der russischen Seelenlandschaft (Tschechow/Gorki) in bloße Bretter zwingen. Mit diesen Hölzern erspielen sich die Akteure faszinierende Bilder, welche sich jedoch im Verlauf der Aufführung abnutzen. Nicht nur das: Auf den ersten Blick frappante Einfälle, verunklaren mitunter die Handlung, verwischen Vorgänge oder verselbständigen sich gar, lösen sich beinahe in zirzensische, durchaus dennoch beeindruckende Darbietungen auf.

Ein strittiger Deutungshorizont

Mitunter erleiden ernsthafte Situationen auch eine unglückliche szenische Bagatellisierung und profane Erdung, so dass sie Heiterkeit erregen statt zum geistigen Disput aufschrecken.

Strittig aber macht den Abend der Deutungshorizont des Regieteams.

Sonja beispielsweise, in der Dostojewskij-Rezeption häufig als "heilige Hure“ benannt, eine mit christlicher Gläubigkeit beseelte Prostituierte, wendet brachiale Foltermethoden wie Waterboarding an. 
Am Schluss befindet sich Raskolnikow statt in der Verbannung in idyllischer Flusslandschaft. Mit Sonja an seiner Seite hat er „das Material“ im Dreck hinter sich gelassen und bekennt sich zur „Auserwähltheit“. Eine gewagte Quintessenz des Stücks, die dem russischen Romancier schon ziemlich unausgegoren in dessen ideologisches Credo schlägt. Diese Provokation erreicht nur jene, die sie erspüren, den anderen Teil des Publikums bestätigt sie aber in Fragwürdigem.

Deutlich erschließt sich die ambitionierte Absicht, eine direkte zeitgenössische Aussage zu erzielen und die Vorgänge nicht nur ins Zeitnahe zu holen, sondern sie auch einem Zuschauerkreis zu präsentieren, welcher fernab von einem Dostojewskij die Welt neu ordnen will. Dieses Anliegen ist legitim, doch es macht eine Schere auf zum schier missionarischen Denken des einzig erwähnten Autors des Abends: Dostojewskij.

Es fehlt jeder Hinweis, wer denn die Schöpfer der neuen Texte sind. Sind Autoren so unerheblich, dass man sie nicht angeben muss, auch wenn es das eigene Team betrifft, oder wähnt das Theater sich so stark und autark, dass es einen Schöpfer nach seinem Befindlichkeitsgestus ungeniert uminterpretieren darf? Frei nach Schiller: Wir, wir leben und der Lebende hat Recht!

Der Vorhang zu und viele Fragen offen.

Rezensiert von Gisela Begrich in: Magdeburger Volksstimme vom 19. Oktober 2009. 


\section{Autorenverzeichnis}

Gisela Begrich

Über Kulturredaktion der

Magdeburger Volksstimme

Bahnhofstraße 17

39104 Magdeburg

Thomas Blume

Steige 9

38102 Braunschweig

Dr. Dunja Brötz

Institut für Sprachen und Literaturen

Abt. für Vergleichende Literaturwissenschaft

Leopold-Franzens-Universität Innsbruck

Innrain 52/IV

A-6020 Innsbruck

Prof. Dr. Horst-Jürgen Gerigk

Moltkestr. 1

69120 Heidelberg

37079 Göttingen

Privat: Frieseweg 12, 37085 Göttingen

Prof. Dr. Gudrun Goes

Erlenweg 6

39291 Hohenwarthe

Dipl.-Bibl. Clemens Heithus

Flerrenwiete 81

22559 Hamburg
Lutz Keßler

Theaterplatz 11

37073 Göttingen

Isabelle Kock

Immermannstr. 24

39108 Magdeburg

Peter Krüger-Lenz

Göttinger Tageblatt

Dransfelder Straße 1

Philip Maroldt

\% Lettrétage

Methfesselstr. 23-25

10965 Berlin

Josefine Preiss

Immermannstr. 14

39108 Magdeburg

Anja Sackarendt

Theater Osnabrück

Domhof 10

49074 Osnabrück

Prof. Dr. Dr. h. c. Wolf Schmid

Universität Hamburg

Institut für Slavistik

Von Melle Park 6

20146 Hamburg 


\section{Das Jahrbuch der Deutschen Dostojewskij-Gesellschaft}

Die Deutsche Dostojewskij-Gesellschaft e. V. (DDG), am 13. Mai 1990 gegründet und Mitglied der Arbeitsgemeinschaft Literarischer Gesellschaften und Gedenkstätten e. V. (ALG), ist einem russischen Schriftsteller gewidmet, der durch sein Werk und seine Person das deutsche Kultur- und Geistesleben in besonderer Weise geprägt hat. Ihr Ziel ist es, die Kenntnis Dostojewskijs zu verbreiten, das Studium seiner Werke zu vertiefen und zur eigenständigen Auseinandersetzung mit seiner Roman- und Ideenwelt anzuregen. Die Gesellschaft vermittelt Ergebnisse gegenwärtiger Dostojewskij-Forschung und steht allen offen, die sich für Autor und Werk interessieren.

Ihr Jahrbuch dokumentiert Vorträge, die über das Jahr auf Fachtagungen gehalten wurden, und damit einen grundlegenden Aspekt der Bildungsarbeit der Gesellschaft. Der erste Band erschien 1992. Das Jahrbuch wird von der Vorsitzenden der Gesellschaft herausgegeben, die sich dabei mit den Mitgliedern des Wissenschaftlichen Beirats berät, und bietet auch angehenden Dostojewskij-Forschern die Möglichkeit, ihre Arbeitsergebnisse einer breiteren Öffentlichkeit vorzustellen. Vortragsmanuskripte, Aufsätze und Rezensionen können der Vorsitzenden oder den Mitgliedern des Wissenschaftlichen Beirats zugesandt werden. Über die Veröffentlichung entscheidet die Herausgeberin. Den Inhalt der Beiträge verantworten die Autoren.

Deutsche Dostojewskij-Gesellschaft e.V. (DDG) www.dostojewskij-gesellschaft.de

Vorsitzende: Prof. Dr. Gudrun Goes IFPH Otto-von-Guericke Universität Zschokkestraße 32 39104 Magdeburg

Volksbank Lüneburger Heide eG BLZ: 25891636 · Konto-Nr.: 522049100

Amtsgericht Flensburg VR 1325 
Worldwide Distributor:

\section{KUBON \& SAGNER}

\section{Servicing libraries since 1947}

ISBN: 978-3-86688-193-8

ISBN: (eBook) 978-3-86688-194-5

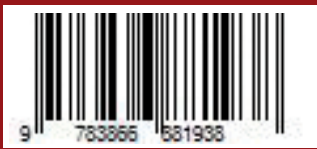

